\title{
SIEGFRIED STRAKOSCH
}

\section{ERWACHENDE \\ AGRARLANDER}




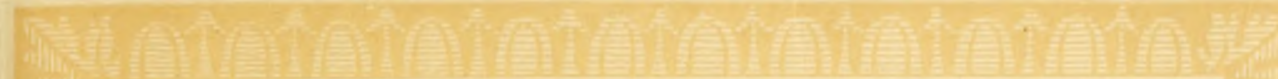
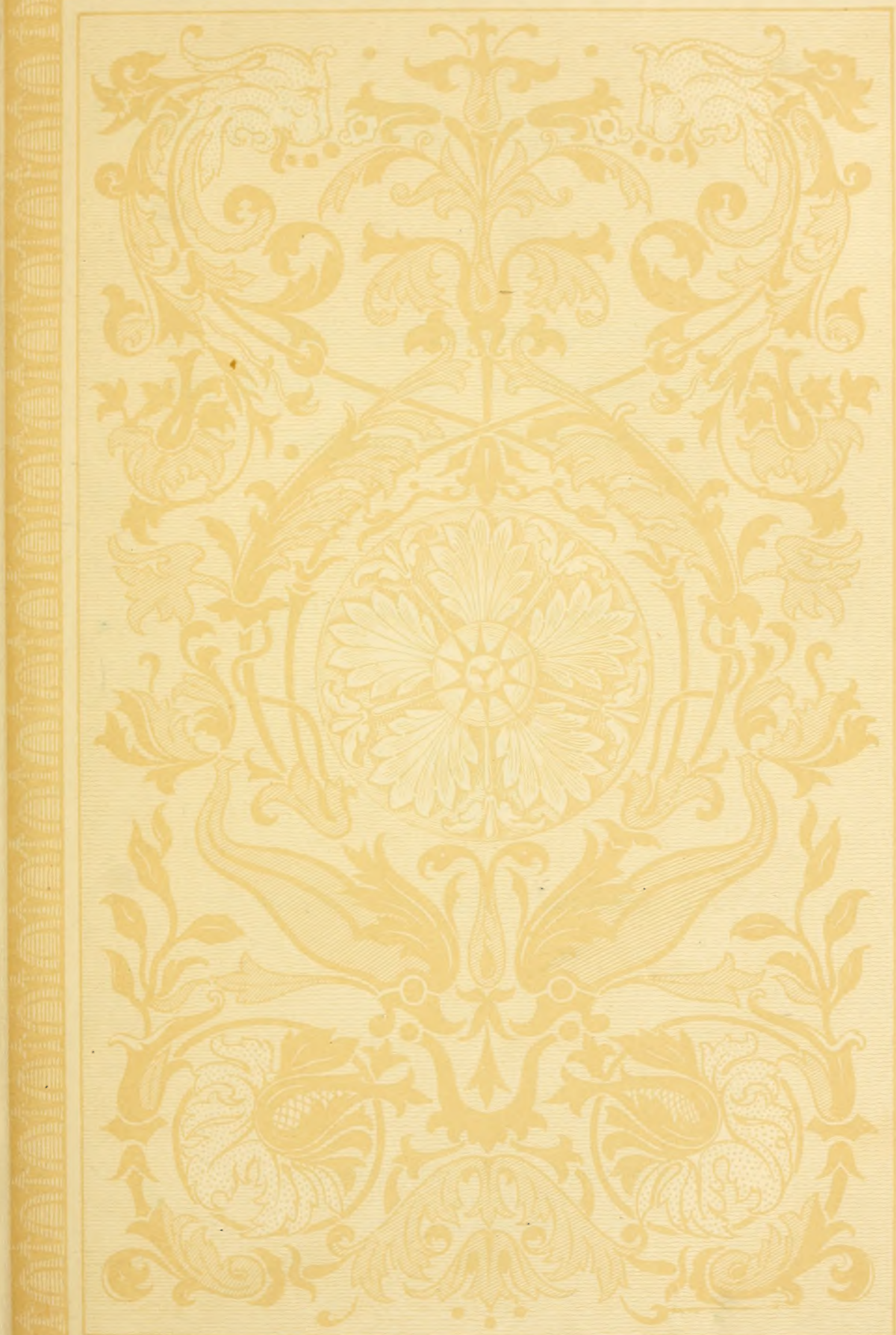



\title{
Erwachende AgI w
}

\author{
Nationallandwirtschaft \\ in Ägypten und im Sudan unter \\ englischem Einflusse.
}

Siegfried Strakosch,

Wien-Hohenau.

Mit einer Karte des englisch-ägyptischen Sudan.

BERLIN.

VerlagsbuchHandlung Paul Parey.

Veliag fir Landwirtschast, Gerteaban uad Forstwesan.

SW., Hedemannstrasse 10.

1910. 


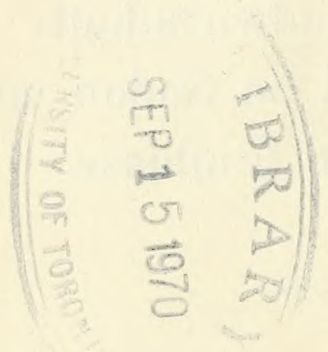

Alle Rechte - auch das der Übersetzung - vorbehalten.

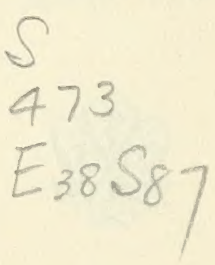

Stephan Geibel \& Co. 
Meiner Frau. 



\section{Vorwort.}

Vorübergehender Aufenthalt in einem fremden Lande genügt nicht, um dessen Wirtschaftsleben und dessen Eigenart aus eigener Anschauung kennen zu lernen. Wenn die eigene Beobachtung jedoch die Unterstützung jener findet, die im Lande leben und über die Quellen und Dokumente der tatsächlichen Verhältnisse verfügen, dann kann sie manches Urteil und Vorurteil auf seine Berechtigung prüfen.

Die guten Empfehlungen des k. k. Ackerbauministeriums und der k. k. Landwirtschaftsgesellschaft in Wien haben meinen landwirtschaftlichen Studien in Ägypten und im Sudan solche Förderung im weitesten Maße verschafft. Für diese gebührt vor allem mein ehrfurchtsvollster Dank

$$
\text { Sr. Hoheit dem Khédive Abbas II. Hilmi. }
$$

Besondere Dankespflicht verbindet mich ferner Sr. Ex z ell enz dem k. und k. Gesandten und bevollmächtigten Minister Grafen Thaddeus Bolesta-Koziebrodzky, Sr. Hoheit dem Prinzen Hussein Paseha Kamil, Präsidenten der Khedivial-Agrikultur-Gesellschaft, Sr. Ex z ell e n z Ismail Pascha Abaza, den Herren G. P. Foaden, Generalsekretär, und Abd-El-Hamid Bey Abaza, Inspektor der Khedivial-Agrikultur-Gesellschaft, Fletscher, Direktor der Landwirtschaftsschule in Giseh, unserem Landsmanne Konsul Leon Heller und dessen Söhnen, Dr. Lewi vom statistischen Departement des Ministeriums des Innern, Dr. Al fre d Eid, dem Sekretär der internationalen Handelskammer in Kairo, $\mathrm{W}$ adih Aboucassem und vielen anderen.

Im Sudan war mir die freundliche Aufnahme durch unseren berühmten Landsmann Se. Exzellenz Sir Rudolf Freiherrn von Slatin Pascha von großem Werte. Seiner Güte verdanke ich die bedeutsame Unterstützung des Herrn E. Bonns, 
Direktors des Agrikultur- und Ländereiendepartements der sudanesischen Regierung und seines Stabes. Ich hatte den besonderen Vorteil, auf meinen Reisen im Sudan und in Agypten weite Strecken in Gesellschaft des sudanesischen Landwirtschaftsinspektors, Herrn Davie, zurückzulegen und mit Herrn Poth acker, einem Großkaufmann aus Alexandrien, durch dessen Hände ein großer Teil des heutigen Sudanhandels geht. Beide haben mir interessante Beiträge zur Kenntnis des Landes und seiner Bewohner vermittelt, wofür ich ihnen ebenso wie allen Vorerwähnten an dieser Stelle verbindlichst danken möchte.

Wien-Hohenau, Januar 1910.

Der Verfasser. 


\section{In halt.}

Vorkommende Münzen, Maße und Gewichte............. XII

Erstes Kapitel.

Nationallandwirtschaft

Gesteigerte Wechselbeziehung ferner Gebiete zu den europäischen Kulturländern. - Die uralte Kultur $\ddot{A} g y p t e n s$ und die eigentümlichen Bedingungen seiner Landwirtsehaft. - Merkwürdige Folgen davon. - Agypten als Kornkammer Roms und der Verfall der Bodenproduktion. - Scheinbare Stagnation in der Gegenwart. - Der Begriff der Nationallandwirtschaft als kritische Voraussetzung. - Beispiel des ägyptischen Pfluges. - Die Entwicklung des Wasserwesens der Kernpuukt der ägyptischeu Landwirtschaft. - Typus der sudanesischen Landwirtschaft. - Der englisch-ägyptische Kulturfaktor im Sudan.

\section{Zweites Kapitel.}

\section{Die natürlichen Voraussetzungen der ägyptischen Landwirtschaft.}

1. Das Klima. Wind und Lufteuchtigkeit. - Drei klimatologische Re gionen und ihr. Witterungsverlauf. - Meine Untersuchungen über das Lichtklima. - Es ergibt sich anscheinend daraus, daß die atmosphärische Hülle unseres Planeten diesen nicht in der Form der Erde umgibt.

2. Der Boden. . . . . . . . . . . . . . . .

Wie in Ägypten der Ackerboden entstanden ist. - Seine besonderen Eigenschaften. - Analysen verschiedener Böden aus dem Niltale. - Wüstensand und Nilschlamm.

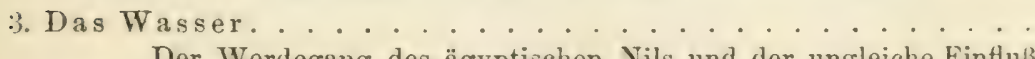

Der Werdegang des ägyptischen Nils und der ungleiche Einfluß seiner Zuflüsse auf die Landwirtschaft. - Zusammensetzung des Nilwassers zu verschiedenen Zeiten und im Vergleich mit anderen Flüssen. - Bew ässerungssysteme: Das Bassinsystem. Überragende Bedeutung der Kanalbewässerung für die Zukunft Ägsptens.

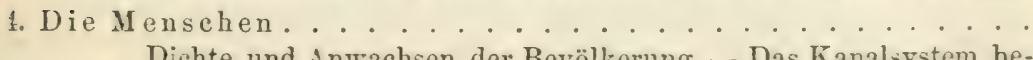

Dichte und Anwachsen der Bevölkerung. - Das Kanalsystem beeinflußt deren Verteilung. - Der Fellah als Typus des ägyptischen Ackerbauers. - Sein Leben und seine Nahrung. - Beduinen und ihr Verhältnis zum Fellah. - Eine vermögensrechtlich interessante 
Entwicklungsiorm patriarchalischer Gemeinschaft. - Der Beduinenschêch als Großgrundbesitzer. - Andere ägyptische Landwirte und ihr Einfluß auf die Bodenproduktion.

\section{Drittes Kapitel.}

\section{Die politischen Voraussetzungen der ägyptischen Landwirtschaft.}

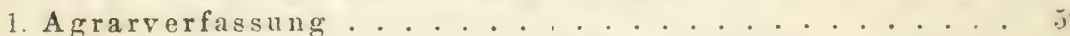

Agrarverfassung zu Anfang des XIX. Jahrbunderts. - Onchouriund Kharadji-Lünder. - Die Reformen Míhémed Alis. - Ismail Paschas Geldknappheit bringt die Freiheit des Bodens nnd eine glücklichere Verteilung des Grundbesitzes. - Die Grundstenerregelung des Jahres 1899 leitet die Wiedergeburt der ägyptischen Landwirtschaft ein. - Abschaffung des Froudienstes. - Vermehrung der produktiven Fläche. - Verwaltung und Liquidation der Domänen. - Der Boden kehrt in die Hände der Fellahs zurück. Eiufluß des mohammedanischen Erbgesetzes auf dic Landwirtschaft.

2. Kredit, Bodenpreise, Pacht- und Arbeiterverhältnisse.

Übergroße Verschuldung der ägyptischen Landwirtschaft. 一 Die Ausbentung der Fellahs. - Eingreifen der Regierung. - Gründung der Agrikulturbank im Jahre 1902. — Bodenwert und Bodenbelastung.

- Rasches Steigen der Bodenpreise. - Die Krise vom Jahre 1906.

- Preistreikerei oder Werterhühung? - Das Herrichten des Bodens.

- Pachtschilling und Bodenertrag. -- Es gibt keine selbstbewirtschafteten grofen Güter in Ägrpten. - Der große Pächter als Mittelglied zwischen Grundbesitzer und Bodenbebauer, - Weitere Zwischenglieder schieben sich ein. - Abhängigkeit der ägyptischen Landwirtschaft vom Kleinbetriebe. - Arbeits-Angebot und -Nachfrage. - Lohnhöhe. - Merkwürdige Arbeitsverträge.

3. Absatz, Preisbildung und andere Einflüsse auf die Produktion.

Kousum im Lande. - Geldknappheit und Landhunger der Fellahs drücken die Getreidepreise. - Mangelhafte Verkaufsorganisation und das Sprunghafte in Produktion und Preisbildung. - Zölle, Börze und Terminhandel. - Das Verkehrswesen. - Landwirtschaftliche Industrie.

\section{Viertes Kapitel.}

\section{Der Betrieb.}

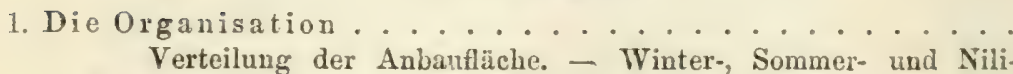
kulturen. - Fruchtwechsel und assimilatorischer Effekt.

2. Di e Düngung ... . . . . . . . . . . . . . . .

Die Stallmistbehaudlung des Fellahs. - Zusammensetzung des ägyptischen Stalldüngers. - Taubenmist. - Andere natürliche Düngerquellen Ägyptens: Coufri, Marog und 'Tafla. 


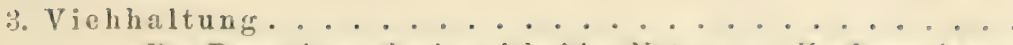

D)as Dromedar und seine vielseitige Nutzung. - Kraft verschwen. dung bei den Zugtieren. -.. Schlachtvieh. - Igypten der ungeeignetste Ort der Welt, um Viehzucht zu treiben. - Einheimische Rinderrassen. - Futtermittel. - Schaf- und Ziegenzucht. - Schweinrhaltung. - Pferdezucht. - Federvieh.

4. Landwirtschaftliche Maschinen und Geräte.......

Der Häufelpflug. - Die Zahafia. - Die Battana. - Die Kassabia.

Der Lowatah. - Drescharbeit mit dem "Norag". - Bewäisserungsbehelfe: Badala oder Wabur, Natalla, Schadûf, Sâkîje und Tabût. - Die Schneeke des Archimedes.

5. Pflanzenbau .

Baumwolle. - Zuckerrohr. - Zuckerrübe. - Berseem. - Weizen und Gerste. - Bohnen. - Mais, Durra und Hirse. - Reis. - Gemüse. - Erbsen., Linsen und Hornklee. - Die Erdnuß. - Obst. Die Dattelpalme.

\section{Fünftes Kapitel.}

\section{Die Weiterentwicklung.}

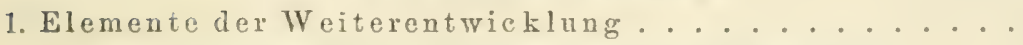

2. Die Weiterentwicklung des Bewässerungswesens ....

Der Mehrwert des kanalbewässerten Ägyptens. - 4 Milliarden Kubikmeter Stauwasser. - Der Nildamm von Assuan und seine Erhöhung. - Ein mollerner Mörissee. - Das Programm Sir Willian Garstins. - Wassernot in Ägypten. - sicherung gegen zu niedrig." Flut. - Die Umwandlung der Bassinländer und die Erhöhnung des Grundsteuerertrags.

3. Andere MaBnahmen zur Förderung der Landwirtschaft. .

Der Schulıneister leitet die Wiedererweckung ler ägyptischen Landwirtschaft ein. - Kuttabs. - Die Regierung und die alte Form moslemitischen Erziehungswesens. - Iuspeltion der Dorfschulen. Regierungskuttabs. - Handwerkerschulen. - Frauenstudium. - Die Ackerbauschule vou Gîseh. - Die Khédivial-Igrikultur-Gesellschaft. - Das künftige Regierungsdepartement für Landwirtschaft. - Hortikultur. - Andere administrative Maßnahmen. - Kom-Ombo und die Bodenaufschliefungsgesellschaften.

\section{Sechstes Kapitel.}

\section{Land, Leute und Bodenproduktion im Sudan.}

1. Einige Voraussetzungen der Bodenproduktion ......

Slat in $\mathrm{Pas}$ c ha giaubt an die Zukunft der sudanesischeu Bodenproduktion. - Möglichkeiten und Hindernisse ibrer Entwicklung. Läßt sich der ganze Sudan in eine grüne Flur verwandeln? - D as Klima: Regen, Temperatur, Winde, Luftfeuchtigkeit, Regenstürme. - Zeitweise Unerträglichkeit des Aufenthaltes. - Die tropischen 
Feinde des Menschen. - Transport- und Absatzschwierigkeiten. Wechselwirkung zwischen Mensch und Land und Betrieb.

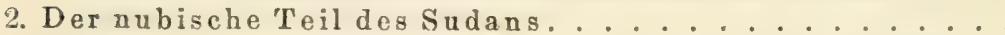

Ackerbau in Dongola. - Nomadenleben und ${ }_{5}$ Wadi ${ }^{6}-B a u$ in der B ajudasteppe. - Die sogenannte "Nubische Wüste" und ihre Kulturstätten. - Anpflanzungen in Berber. - Im Distrikt von Suakin. - Die Provinz Kassala und die Landwirtschaft am Gashilusse.

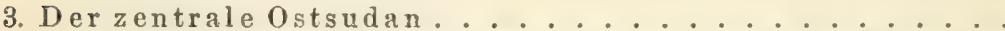

Dic Landscliaft Sennar und ihre Kulturadern, der Weiße und der Blaue Nil. - Bei den Dinkas. - Baumwollbau am Dinder. Flüchtiges Leben in der Ebene von „El Butana". - Die Gärten von Gedaref. - Merkwürdiger Ackerbau bei den TakruriNegern.

4. Ii ordofan und Darfur.

Das Erbe des Mahdi. - K ord of an und seine Landwirtschaft. - Sesamöl- und Gummigewinunng. - Eigentümlicher Wasserhaushalt. - Ackerbau mit Hindernissen bei den N ubas. - Die Shilluks. - Das Sultanat yon Darfur.

.). $\mathrm{D}$ er $\mathrm{S} u ̈ \mathrm{~d}$ sudan

Die bewegten Schicksale des Südsudans. - Die Provinzen des Bahr el Ghazal und des oberen Nils. - Das Gebiet der Wälder und des Eilfenbeins. - Die Fleischfrage bei den Nyam-Nyam. - Die Anuaks als Ackerbauer. - Das Schwergewicht der Bodeuproduktion liegt in der Bevölkerung. - Einige Beispiele dafür.

\section{Siebentes Kapitel.}

\section{Kultureinflüsse im Sudan.}

1. Diekulturelle Vorarbeit.

Art der Vorarbeit. - Straßen, Brunnen, Binnenschiffahrt und Schienenstraug. - Suakin und Port Sudan. - Post und Telegraph. - Öffentliche Sicherheit und Sklavenhandel. - Die englische Hilitärverwaltung und ihre Organe. - Opfer der sudanforschung. - Dic wissenschaftliche Hilfsarbeit. - Vermessungs- und Forschuugsarbeiten.

2. Weiterc Maßnahmen und Pläne............. 123

Rechtsprobleme und Rechtsplege im Sudan. - Ein neuartiges Steuersystem. - Bodenbesiedlung und andere Bodenfragen. - Schulwesen und Missionswerk. - Landwirtschaftliche Wanderinspektoren und die Arbeit der Versuchsfarmen. - Zuckerrohr im Sudan. Die Lösung der Bewässerungsfrage.

3. Das bisherige Ergebuis

Eine Durra-Offerte aus Omdurman. - Die bebaute und bewässertc Fläche. - Die Dichte der Bevïlkerung. - Grundsteuerertrag und andere Aktivposten. - Das Arbeitexmaterial. - Landkonzessionäre. Eine Farm am Blauen Nil. 


\section{Achtes Kapitel.}

Das kulturelle Räderwerk. ....... 220

Nationallandwirtschaft und Kultur. - Was die Untersuchung bezüglich Agyptens lehrt. - Das Sudan-Problem. - Noch einmal das englisch-ägyptische Kompagniegeschäft und die leitenden Gesichtspunkte der englischen Kolonialpolitik. - Die Zukunft des Sudans und das europäische Wirtschaftsleben. - Der ökonomische Kreislauf.

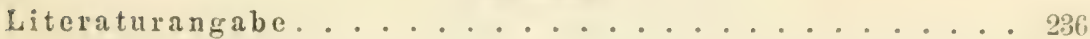




\section{Vorkommende Münzen, Maße und Gewichte.}

1 Ägyptisches Pfund (L.F.) = 100 Piaster 'Tarif (P.T.) = $20 \mathrm{Mk}$. $80 \mathrm{Pf}$.

1 Feddán $=0,42$ ha.

1 Kantar $=100$ Rotl $=44,928 \mathrm{~kg}$.

2 Kantar von Alexandrien $=112$ Oka $=139,779 \mathrm{~kg}$.

1 Ardeb $=1.98 \mathrm{hl}$.

An der Alexandriner Börse wird berechnet:

1 Ardeb Baumwollsamen zu $121,3056 \mathrm{~kg}$ netto,

1 : Bohuen

$1 "$ Weizen

1 , Gerste

1, Mais

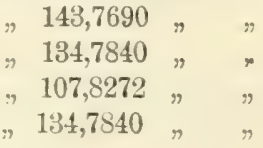

1 Acre englisch $=0,96331$ Feddán $=0,40467$ ha.

1 Pfund englisch $=0,454 \mathrm{~kg}$.

1 Englische Meile $=1760$ Yard $=1,609 \mathrm{~km}$.

1 Yard englisch $=3$ Fussa 12 Inches.

1 Inch $=2^{1 / 3} \mathrm{~cm}$.

1. Bushel englisch $=35,241$. 


\section{Erstes Kapitel.}

\section{Nationallandwirtschaft.}

Gesteigerte Wechselbezichung ferner Gebiete zu den europäischen Kulturländern.

- Die uralte Kultur Ägyptens und die eigentümlichen Bedingungen seiner Landwirtschaft. - Merkwürdige Folgen daron. - Ägypten als Kornkammer Roms und der Verfall der Bodenproduktion. - Scheinbare Stagnation in der Gegenwart. - Der Begriff der Nationallandwirtschaft als kritische Voraussetzungr. - Beispiel des ägyptischen Pfluges. - Die Entwicklung des Wasserwesens der Kernpunkt der ägyptisehen Landwirtschaft. - Typus der sudanesischen Landwirtschaft. - Der englisch-ägyptische Kulturfaktor im Sudan.

Eine Reise nach Afrika gehört heutzutage nicht mehr zu den Dingen, die man nur unter Einsatz seines Lebens unternimmt. Mühelos gelangt man durch Ägypten bis an die Grenze des Sudans, erreicht ron dort auf einer schmalspurigen Eisenbahn Chartum. und selbst hier, im Herzen Afrikas, gibt es noch Dampfschiffe. die den weißen und den blauen Nil befahren.

Wo die Kultur mit Dampfmaschine und Schienenstrang rordringt, ist der Lorbeer des Entdeckungsreisenden kaum mehr zu holen. An die Stelle abenteuerlicher Expeditionen tritt die ruhigere Arbeit systematisch-wissenschaftlicher Forschung, die, wie es in den letzten Jahrzehnten gerade in Afrika der Fall war, mehr und mehr materiellen und politischen Zwecken dient. Das Expansionsbedürfnis der Kulturvölker unterwirft schließlich die fernen Länder, welche uns die Ausgestaltung des Wegenetzes nähergebracht hat, ganz ihrem Einflusse. Und nun treten die neu angegliederten Gebiete in gesteigerte Wechselbeziehung zu den wirtschaftlichen Kräften der alten Kulturländer und werden ein wachsender Faktor des internationalen Wirtschaftslebens. Was gestern noch in unsäglicher Ferne lag, kann heute oder morgen unser Interesse empfindlichst tangieren. Denn alle Verschiebungen. 
die sich in irgendeinem abgelegenen Winkel der Erde vollziehen, pflanzen sich nach allen Richtungen, weit über die Grenzen ihrer Entstehung fort. Die Macht des modernen Verkehrswesens ist stärker als alle Zollschranken, die man fester und fester fügt. Kein staat kann sich den Änderungen im Organismus der Weltwirtschaft verschließen, keiner das eigene Land ganz unabhängig von ihnen machen.

Deshalb gewinnt die genaueste Kenntnis aller Vorgänge in den Produktionsverhältnissen fremder Länder kaum zu überschätzende Wichtigkeit, und die Beobachtung darf sich nicht auf solche Länder beschränken, die heute im Mittelpunkte des Weltmarktes stehen. Im Gegenteil, gerade jene, von denen man weniger hört, die vielleicht erst am Anfange ihrer Entwicklung stehen, können am ehesten unerwartete Überraschungen, gewaltige wirtschaftliche Evolutionen bringen.

Ägypten wird man sicherlich nicht den Gebieten zuzählen dürfen, die erst am Anfange ihrer Entwicklung stehen. An zwei Meeren gelegen und von dem ewige Fruchtbarkeit spendenden Nil durchzogen, ist es vielleicht die älteste aller menschlichen Kulturstätten. Ägypten tritt bereits in die Geschichte als hochorganisiertes Gemeinwesen ein, mit einer fertigen Kultur, welche die Vorarbeit von Jahrtausenden erkennen läßt.

Herodot nennt Ägypten "ein Geschenk des Flusses". Das ist sicherlich nicht zu viel gesagt, denn der geringe Regenfall bringt es mit sich, daß in Ägypten ohne Bewässerung keinerlei Pflanzenbau möglich ist. Wro das Überschwemmungswasser nicht hingelangt, gedeiht kein Grashalm, kein Unkraut, geschweige denn eine Kulturpflanze. Man will die erste Grundbedingung der Kultur in der Befreiung des Menschen aus der Abhängigkeit von dein erkennen, was die Natur freiwillig bietet. In Ägypten bietet die Natur ohne Nil gar nichts, der Ackerbau mit Hilfe des Nilwassers bedeutet hiel nicht "das Unabhängigmachen von dem, was die Natur freiwillig bietet", sondern die Erweckung der Natur selber. Ohne Nil gäbe es deshalb in Ägypten keine seßhaften Völker, auch nicht die Anfänge einer Kultur, nur Wüste, endlose Wüste, die in ihrer Trostlosigkeit die Schrecken der arabischen, lybischen und nubischen Wüsten noch weit hinter sich lassen müfte. Denn auch das spärliche Leben dieser afrikanischen Wüsten steht in mancher Bezichung zum Nil, der ihre Grenzen bildet.

Es konnte nicht ausbleiben, daß ein Kulturfaktor von 
so überragender Bedeutung der Entwicklung des ganzen Landes sein typisches Gepräge aufgedrückt hat. Unmittelhar zunächst der Landwirtschaft, die hier in noch höherem Maß̉e als anderswo Grundlage und Mittlerin aller Kultur werden mußite. Denn in anderen Ländern hat man den Ackerboden crst unter unsäglichen Mühen dem Urwald abgerungen, oder einer Jahrhunderte alten Grassteppe, deren undurchdringliche Narbe dem beginnenden Ackerbau keine geringere Arbeit auferlegte. Der Besiedler des Niltales fand weder Wälder noch üppigen Graswuchs vor, nur den fruchtbaren Nilschlamm, der den Boden überdeckte und die erforderlichen Nährstoffe in Hülle und Fülle besab. Der unaufgeschlossene Boden mag sonst noch so viel Reichtümer enthalten, er gibt sie nur widerwillig zu spärlicher Ernte her. Deshalb muften anderswo Jahrhunderte vergehen und reiche Erfahrung mühsame Methoden ersinnen, um das Land auf eine höhere Ertragsstufe zu bringen. In Ägypten ließ das zurücktretende Überschwemmungswasser den Boden gleich in einem Zustande zurück, der für die Aufnahme des Saatgutes mit geringer Nachhilfe geeignet war, und der feinkörnige Nilschlamm enthielt die pflanzlichen Nahrungsmittel in leicht aufnehmbarer Form. Überall hat sonst der Landwirt mit Naturphänomenen zu rechnen, die sich nicht vorher bestimmen und durch keinerlei Maßnahmen beeinflussen lassen. Die Menge und die zeitliche Verteilung des Regens, Dürre und Wolkenbruch, Hagel und Schnce bilden die wechselvollen Schicksale des Landmannes. Ägypten kennt so unerwartete Extreme nicht. Unter dem gleichmäßig heitern, meist wolkenlosen Himmel, dessen spärliche Regenspenden ziemlich gleichmäßig fallen, bringt der Nil wohl auch nicht alljährlich genau dieselben Wassermengen aus seinen südlichen Stromgebieten mit. Die Stärke der tropischen Regen in den Quellgebieten des Nils, die Menge des schmelzenden Schnees, den die abyssinischen Flüsse aus dem Hochgebirge herunterschwemmten, konnten auch in Ägypten Überfluß oder Mangel, Üppigkeit oder Hungersnot verursachen. Aber man stand hier, im Gegensatze zu anderen Ländern, doch Ereignissen gegenüber, denen man entgegenarbeiten, die man beherrschen lernen konnte. Und in der Tat, Jahrtausende vor der christlichen Zeitrechnung gab es in Ägypten schon großartige Strombauten, Reservoirs und Kanäle, welche die Wassermassen nach Bedarf aufspeicherten und verteilten, die Überstauung regelten und ableiteten. Herodot (II, 99) berichtet, daß schon König 
Menes, der nach Brugsch 4455 Jahre v. Chr. zur Regierung gelangte, den Nil 100 Stadien oberhalb Memphis durch einen Damm abgesperrt und in sein jetziges Bett geleitet hätte. In historischer Zeit, unter der zwölften Dynastie, deren Regierungsperiode (19:5 bis 1792 v. Chr.) sich einigermaßen zuverlässig bestimmen läßit, wurde dann der gewaltige Mörissee zu dem gleichen Zwecke angelegt. Dieses berühmte Wunder der Wasserbaukunst diente ebenso der Sicherung und besseren Ausnützung der Nilwässer, wie alle die unzähligen großen und kleinen Kanäle, Eindämmungen und Schleusen, die ihre Entstehung späteren Perioden dankten. Alles Zeugen dafür, daß die ägyptische Landwirtschaft von altersher mit außerordentlich gleichmäßigen Bedingungen rechmen durfte. Thre typischen Merkmale waren: verhältnismäßige Mühelosigkeit der Bodenbearbeitung, stete Sicherung des Vegetationsverlaufes, andauernd hohe Fruchtbarkeit.

Montesquie u sagt: „Die Unfruchtbarkeit des Bodens macht seine Bewohner erfindungsreich, arbeitsgewohnt, mutig, kriegstüchtig; sie müssen sich eben schaffen, was der Boden nicht von selbst gibt. Die Fruchtbarkeit eines Landes gibt mit der Wohlhabenheit die Weichlichkeit und eine gewisse Liebe zur Erhaltung des Lebens um jeden Preis." Die Lehren der Geschichte lassen an dem Einflusse der Fruchtbarkeit des Bodens auf die Entwicklung der Völker keinen Zweifel mehr aufkommen und auch daran nicht, daßs sich dieser Einfluß im allgemeinen in der von Montesquieu behaupteten Richtung äußert. Die besonderen Verhältnisse der ägyptischen Bodenproduktion mubten es aber mit sich bringen, daß die gleichen Ursachen hier ganz andere Ergebnisse ausgelöst haben. Der Boden versprach wohl die üppigste Fruchtbarkeit, diese war aber, wie erwähnt, nur dann gesichert, wenn die Überschwemmung durch den Nil richtig eingeleitet, in ihrer Stärke und Verteilung, in ihrem Verlaufe genau geregelt war. Darauf konnte der einzelne Landbauer keinerlei Einfluß nehmen, dazu besaß er weder das Verständnis, noch die Mittel, noch die Macht. Das Riesenwerk der hydrotechnischen Anlagen konnte nur mit gewaltigen geistigen und materiellen Hilfsquellen ins Leben gerufen werden und setzte eine hohe Stufe der Hoch- und Tiefbaukunst voraus. Die einheitliche Durchführung der Wasserwirtschaft erforderte exakte Kenntnisse in der Geometrie, in der Mathematik und in der Feldmeßkunst, selbst in der Astronomie, denn das 
-chwellen des Nils ist ron dem tropischen Somnenjahre ahhängig. Dann mulite der Betrieb durch entsprechende Mabnahmen uml Agrargesetze ermöglicht, nötigenfalls auch erzwungen werden, und in einer Weise, die die Gesamtinteressen des Landes ron den Sonderinteressen des einzelnen Landwirtes mahhängig nuachte. Das alles konnte nur eine, über der Berölkerung stehende Gewalt durchführen, eine starke Regierung, die über Grund und Boden und über den Nil schrankenlos gebot. Nur sie war instande, die Gewißheit des Bodenertrages und damit die Grundlage des Staates zu gewährleisten.

Die eigentümlichen Betriehsverhältnisse der ägyptischen Land. wirtschaft haben so die Kluft zwischen den Herrschenden und den Beherrschten immer mehr vertieft. Die Fruchtbarkeit des Bodens kam nicht dem Ackerbauer zugute, der sie unmittelhar hervorrief, sondern den Herren des Bodens, den regierenden Klassen. Dem Bauer, dem Fellah wurde an Pachtzins, an Steuern und Lasten so riel auferlegt, daß er sein Leben gerade mühselig fristen konnte, er blieb aber Jahrtausende hindurch in Armut und Unwissenheit. Die Eigner des Bodens hingegen, der König, die Priester und die Krieger, denen reiche Einkünfte zu Gebote standen, knnnten ihre Macht nur um den Preis der geistigen Regsamkeit behaupten, welche die Beherrschung der natürlichen Quellen des Wohlstandes roraussetzte.

Die große Fruchtbarkeit des ägyptischen Bodens hat also dessen Bebauern weder Wohlhabenheit noch Weichlichkeit gebracht und gerade jenem Teil der Ägypter, der durch die Üppiglieit des Wachstums zu Reichtum kam, der herrschenden Klasse. Erfindungsreichtum, Wissen und Tüchtigkeit.

Dennoch hat Ägypten schließlich seine Lehenskraft eingebüßt. Durch seine dem Boden entstammende alte Kultur, durch das daraus hervorgegangene strenge Kastenwesen von den übrigen Tölkern des Mittelmeeres geschieden, ist es allmählich in sich erstarrt und um seine staatliche Selbständigkeit gekommen. Die Äthiopier, Assyrier, Perser haben es der Reihe nach unterjocht. bis es dann ein Teil ron Alexander des Großen Weltreich wurde. Die spätere Herrschaft der Römer und Byzantiner, der Araber, Mameluken und Türken bedeutet eine weitere ununterbrochene Kette kulturellen Verfalles.

Aber dessenungeachtet blieb Ägypten immer ein Land, das 
nach den verschiedensten Richtungen die lebhafteste Aufmerksamkeit beanspruchen muite. Neben seinen Naturwundern, neben seiner Bedeutung als Einfallstor von Afrika, als Schlüsselpunkt des nächsten Seeweges nach Indien, ist es immer die ehrwürdige Stätte uralter Kultur geblieben. Mag diese wirklich älter sein als die indische und die chinesische Kultur, wie man behauptet, oder nicht, so hat die ägyptische Kultur doch jedenfalls die Zeugen einstiger Größe, unter dem Einflusse des trockenen Klimas, besser erhalten als jedes andere Land der Welt. Und neuerdings wird uns das ägyptische Reich interessant, indem es seit dem Beginn des XIX. Jahrhunderts als erster aller muselmannischen Staaten orientalische Sitten und Gebräuche mit westlicher Kultur in Einklang zu bringen sucht. Mohammed Ali, der gewaltige Stifter der herrschenden Dynastie, hat den gefährlichen Weg zuerst betreten, und seine Nachfolger haben ihn, mit Aus. nahme eines einzigen, Abbas, der kurze Zeit regierte, mit viel Glück weiter verfolgt. Die Besetzung Ägyptens durch England nach der Niederwerfung des Militäraufstandes im Jahre 1882 und die Einflußnahme der Engländer auf die Verwaltung des Landes konnten den reformfreundlichen Bestrebungen der Khediven nur förderlich sein.

Es ist darnach nicht zu verwundern, daß Land und Volk, die alte und die neue Kultur, so wie die wirtschaftlichen Zustände in zahlreichen Werken behandelt wurden. Und weil in Ägypten alles mit der Landwirtschaft zusammenhängt und alles aus ihr heraus sich organisch entwickelt hat, so konnte keines der vielen Bücher achtlos an der Landwirtschaft vorübergehen. Aber merkwürdigerweise, keine lebende Kultursprache hat dieser ägyptischen Landwirtschaft ein eigenes Buch gewidmet, höchstens einmal eine Abhandlung, wie der jüngere Thaer, der vor drei Jahrzehnten die altägyptische Landwirtschaft beschrieb. Vielleicht erklärt sich die Unterlassung damit, daß man auf allen Gebieten des modernen Ägyptens den Fortschritt lebhafter zu empfinden meint als auf dem Gebiete des Ackerbaues, daß man diesen auch heute noch als das Sinnbild der Stagnation oder gar des Rückschrittes ansieht. Es läßt sich nicht leugnen, die ägyptische Bodenproduktion nimmt gegenwärtig nicht mehr die hervorragende Stellung unter den Nahrung erzeugenden Ländern ein wie einstens. Als Ägypten nach der Schlacht bei Actium, 30 v. Chr., dem römischen Reiche einverleibt ward, erlieb Augustus ein Gesetz, nach dem 
kein Römer vom Range eines Konsuls oder selbst cines Ritter's die neue, so hoch bewertete Provinz ohne besondere Erlaubnis des Kaisers betreten durfte. Er glaubte, daßs die Verführung zu groß wäre, sich dieser Kornkammer zu bemächtigen, ohne die Italien Hunger hätte leiden müssen. Damals kam ein Drittel des in Rom konsumierten Getreides aus Ägypten, von wo man es auf eigenen Getreideschiffen verfrachtete, die 420) Fub lang und 57 Fuß breit waren (Athenäus, Deipnosophisten S. 37). Wir besitzen freilich keine Erntestatistik der damaligen Zeit und können vermuten, daß manche Fläche, die jetzt der Baumwolle vorbehalten wird, damals dem Getreidebau gedient hat. Aber immerhin, das Ägypten der Römer wurde von Josephus auf etwa 8 Millionen Einwohner geschätzt, hatte demnach nicht viel weniger Bewohner als heute zu ernähren und konnte doch gewaltige Mengen von Getreide exportieren. Gegenwärtig kommt es hingegen als Exportland gar nicht mehr in Frage. Dabei ist zu bedenken, daß der Lebensstandard des größten Teils der Bevölkerung, vor allem der Fellahs, kaum ein anderer geworden ist als zur Zeit der Römerherrschaft, und dak auch die Verwendung des Getreides zu industriellen Zwecken nicht annähernd denselben Umfang angenommen hat wie etwa in unseren europäischen Ländern. Der Stillstand der ägyptischen Landwirtschaft scheint auch durch andere Tatsachen bewiesen zu werden: sie benützt noch dieselben Ackergeräte, wie vor Jahrtausenden, denselben hölzermen Pflug, denselben einfachen Balken zum Glätten des Bodens, dieselbe Form der Sichel. Man kennt das Stürzen der Stoppel noch immer so wenig wie eine Bodenbearbeitung, welche auf die Förderung der Ackergare hinzielt, kennt die Sämaschine nicht und nicht den Getreidemäher. Statt der Dreschmaschine arbeitet noch immer der altehrwürdige Dreschschlitten, man zerbricht sich über Unkrautvertilgung so wenig den Kopf wie über eine rationelle Stalldüngerwirtschaft.

Mit der Viehwirtschaft steht es auch nicht besser und nicht anders als damals, zur Zeit der Pharaonen. Das Rind unterscheidet sich in den äußeren Formen kaum ron jenem, das die Wandgemälde in den alten Tempeln und Gräberstätten darstellen. Die alten Agypter besaßen anscheinend dreierlei rerschiedene Rassetypen von Rindern: ein Langhornrind, ein Rind, das ein Fettpolster auf der Schulter hatte, und eine kurzhörnige Rasse. Davon ist wohl das langhörnige Rind verschwuuden, aber an die 
zweite Gattung erinnert das Zebu, das man in Oberägypten und Nubien trifft. Auch das kurzhörnige, hochbeinige Rind, das num in Ägypten gezogen wird, kann seine Abstammung kaum verleugnen, und besser, leistungsfähiger dürfte es auch nicht geworden sein. Die Einfühung der Büffel, die angeblich cimmal ans Siebenbürgen importiert worden sind, als die heimischen Viehbestände durch die Boubonempest stark gelitten hatten, ist allerdings eine Errungenschaft der neuen Zeit; wir werden aber später sehen, daß auch sie keinen hesonderen Gewimn bedeutet. Alles in allem läbt. sich nicht leugnen, daß die neuzeitigen Methoden, die unserer Landwirtschait so großen Fortschritt gebracht haben, an der ägyrtischen Bodenkultur spurlos vorübergegangen sind, Es ist demnach nicht zu wundern, wenn man achselzuckend äber die ägyptische Landwirtschaft zur Tagesordnung übergehen zu können glaubt, sie ist ja in der Tat - ron unserem Standpunkte aus betrachtet - rührend altmodisch.

Und dennoch wage ich zu behaupten, daß die ägyptische Landwirtschaft nicht so zur ückgeblieben, nicht so veraltet und unzweckmäßig ist, wie man allgemein annimmt. Man begeht einen großen Febler, wenn man die Bodenwirtschaft eines fremden Landes einfach mit dem Maßsstab messen zu können glaubt, den man sich in der Heimat, an den eigenen Verhältnissen zurecht gezimmert hat. Thünen hat in dem bekannten Gleichnis rom isolierten Staate gezeigt, wie schon die Änderung eines einzigen Faktors, der Entfernung rom Marktorte, den Wert eines Wirtschaftssystems gänzlich verschiebt. Um wie viel mehr ist die weitgehendste Individualisierung der Landwirtschaft angesichts der unzähligen natürlichen und ölionomischen Ahstufungen notwendig, unter denen produziert wird. Die Landwirtschaft ist. ïberall die Grundlage der Kultur gewesen; aber Klima und Boden, das Tolk und seine Schicksale, Industrie und Transportmittel, der gesamte kulturelle Zuschnitt eines Landes diktieren die Gesetze seines landwirtschaftlichen Produktionswesens. Aus einer Summe von naturwissenschaftlichen und volkswirtschaftlichen Erkenntnissen setzt sich das jeweilige Erfordernis einer zweckmäßigen Bodenproduktion zusammen. Die Landwirtschaft darf sich nicht bescheiden, im Sime einer geistrollen Definition Kühns, angewandte "Physiologie und Biologie der Kulturorganismen" zu sein, sie hat ror allem stets den praktischen Zweck im Auge zu behalten und diese Kulturorganismen in einer, den Rentabilitits- 
verhältnissen des Landes dauernd entsprechenden TTeise anszunüizzen.

Österreich wird immer anders produzieren müssen als England, und Rußland anders als Indien oder Japan. Unter den jeweiligen Toraussetzungen sind höhere und niedrigere Entwichlungsstadien denkbar, aber die Formen und Typen, die sich im Laufe der Zeiten herausbilden, entstehen in umunterbrochener Wechselwirkung mit dem ganzen Wirtschaftsorganismus, in dem sie viclfach ihre innere Begründung finden. Deshalb darf man die Landwirtschaft eines Gebietes nicht losgelöst von den Verhältnissen betrachten, in denen sie wurzelt, man sollte vielmehr einen Begriff konstruieren, den ich den Begriff der Nationalland wir ts chaft nemmen müchte; die Nªt io nallandwirts chaft. die sich überall auf den vorhandenen Bedingungen und Voraussetzungen aufbaut und nur aus diesen heraus zu beurteilen ist.

Und wenn wir uns nun den ägrptischen Landwirtschaftsbetricb von diesem Standpunkte aus ansehen, so wird vieles ganz zweckmäßig und entsprechend crscheinen, ̈̈ber das wir früher überlegen gelächelt haben. Diese Erkenntnis liegt auch dem Plane des Buches zugrunde: Zunäehst die Toraussetzungen der ägyptischen Landwirtschaft kurzuskizzieren, dann die Art des Betriebes zu zeigen und zu den Toraussetzungen in Beziehung zu bringen und sehlieblich die Aussichten künftiger Entwicklung unter den ror. handenen Bedingungen zu prüfen.

Nehmen wir num als Beispiel solcher Betrachtumgsweise den viel verlästerten, altehrwürdigen Pflug der Ägypter her. Die Bezeichnung "Pflug" ist rielleicht gar nicht richtig gewählt für dieses unendlich einfache räderlose Gerät, das den Boden mit seiner hölzernen Schar nur auflockert und nicht stürzt, das kaum eine Furche linterläßt und einem einzinkigen Kultivator reit mehr ähnelt als dem, was wir sonst unter "Pflug" rerstehen. Einige Vorteile springen gleichwohl ins Auge: Dieses hauptsächlichste Werkzeug der dortigen Bodenkultur kostet liaum 20 Piaster (beiläufig $3 \mathrm{Mk}$.) ; es erfordert, da es nur aus ein par Holzstücken besteht, weder Reparatur noch Erhaltungsmaßnahmen. kein Schmieröl, kein Schleifen der Schar und kcin Einstellen seiner Teile. Das sind rom Standpunkte der ägrptischen Terhältnisse bemerkenswerte Vorzüge. Wo sollte der Fellah, der über die dürftigste Lage nie hinaus kam, das Geld für eine teuere 
Maschine hernehmen? Er steht auch nicht auf dem Bildungsniveau, das das Verständnis und die richtige Anwendung komplizierter Maschinen voraussetzen ließe. Und vollends die Erhaltung solcher? Der Fellah gilt als guter Fanilienvater, soll seine Kinder zärtlich lieben. Man kann oft sehen, wie er sie aufs Feld mitnimmt, sich mit ihnen heschäftigt, sich über sie freut. Aber es fällt ihm nicht ein, wie Kenner des Landes versichern, auch nur eine Hand zu rühren, wenn ein Kind krank wird. In Oberägypten und in Nubien sind die Kinder, wie jeder Tourist beobachtet haben wird, oft mit eiternden Wunden, namentlich in der Nähe der Augen, bedeckt, und die Fliegen sitzen zu Dutzenden darinnen und tragen den Eiter und die Ansteckung weiter. Niemals sieht man aber, daß der Vater oder die Mutter sich im mindesten darum kümmern, daß sie auch nur den Versuch machen, das lästige, schädliche Geschmeiß fortzuscheuchen. Wenn dem Fellah selber ein Unfall zustößt, etwa ein Finger abgerissen wird, so wartet er sicher ruhig ab, bis auch die andern Finger brandig werden, - der Fatalismus des Mohammedaners ins Ungemessene gesteigert durch Jahrtausende lange Entbehrung und Unterdrückung. Kann man danach erwarten, daß der Fellah der Eihaltung seiner Maschinen mehr Aufmerksamkeit und Fürsorge zuwrenden wird? Der ägyptische Pflug stellt in seiner Anspruchslosigkeit tatsächlich das angemessenste Werkzeug für den Fellah dar!

Aber auch sonst crfüllt das Gerät seine Aufgabe ganz trefflich. denn diese ist wesentlich abweichend von der Aufgabe, die unsere Pflüge zu erfüllen haben. Die ganze Bodenbearbeitung nimmt in Ägypten einen anderen Verlauf als bei uns, $m u f$ einen anderen Verlauf nehmen.

Wir beginnen im Herbste den Boden zur Aufnahme für die künftige Saat dadurch vorzubereiten, daß wir zunächst die Stoppel der Vorfrucht schälen. Jede Feldfrucht hinterläßt den Acker in mehr oder weniger lockerem Zustande. Dieser Zustand, die sogenannte Schattengare, entsteht bekanntlich dadurch, daß der Pflanzenbestand Sonne und Wind vom Boden abhält. Nach der Aberntung der Frucht verschwindet die Schattengare rasch; deshalb schälen wir so schnell als möglich, zerstören die Kapillarität der obersten Bodenschicht und bringen in der noch feuchten Erde Stoppel- und WTurzelreste zur schnelleren Verwesung. Dadurch wird der Humusgehalt vermehrt, den unterirdischen Organismen 
neue Nahrung zugeführt, und die physikalischen Eigenschaften des Bodens werden verbessert.

Die Schattengare läßt sich in Ägypten kaum ausnützen. Die Frucht, die noch kurz vor der Ernte unwahrscheinlich üppig steht, macht zur Zeit der Ernte einen notreifen Eindruck und hinterläßt die Ernterückstände und den Boden so ausgetrocknet, daß das Stürzen der Stoppel zu keiner eigentlichen Verwesung führt. Ungestürzt verstaubt die ausgedörrte Stoppel an der Luft. Das Stürzen würde diesen Prozeß nur hemmen und durch die in der Erde inmerhin besser konservierten Ernteabfälle dem Gerleihen der nachfolgenden Frucht hinderlich sein. Damit das Stoppelstürzen in Ägypten einen Wert hätte, mülite man erst besondere Methoden ausfindig machen, es etwa dort, wo genug Wasser zur Verfügung steht, mit nachfolgender leichter Bewässerung versuchen.

Nach dem Schälen lassen wir in unseren Gegenden das Unkraut auflaufen, zerstören es auf diese Weise und gewinnen ein neues Quantum organischer Substanz für die angestrebte Frühjahrsgare, jenen merkwürdigen Zustand des Bodens, welcher der Hervorbringung der Kulturpflanzen besonders günstig ist, und deshalb das Hauptziel unserer ganzen Bodenbearbeitung bildet. Der durchgeeggten Schälfurche folgt entweder die Furche vor der Wintersaat, oder die tiefe Sturzfurche. Diese bleibt den Winter über rauh, ohne Glättung offen liegen, damit die Atmosphärilien und der Frost tief eindringen und ihre günstige Wirkung ungehindert ausüben können.

Auch das kann in Ägypten nicht nachgeahmt werden. Unkraut läuft bei der großen Trockenheit überhaupt keines auf, und wollte man den Boden so viel bearbeiten und offen liegen lassen wie bei uns, so brächte das regenlose, heiße Klima bald jeden Lebensvorgang im Boden zum Stillstand. Bewässern nach einer Sturzfurche wäre erst recht verfehlt, weil das Wasser sich darin ansammeln würde, statt sich gleichmäßig über die ganze Fläche zu verteilen. Die größte Ebenheit des Bodens ist eine wichtige Vorbedingung jeder künstlichen Bewässerung.

Aus allen diesen Gründen kann man in Ägypten lieinen Pflug brauchen, der den Boden wendet oder auch nur zu sehr durchwühlt. Der heimische Pflug entspricht auch dann besser, wenn man nach dem Bewässern pflügt. $\mathrm{Er}$ ist leichter als jeder andere und drückt den Boden nicht viel zusammen. Das ist wieder 
sehr wichtig, weil die Ackergare bei den dortigen klimatischen Verhältnissen nicht die gleiche wie im gemäßigten Klima sein kann, und weil die Elastizität des Bodens immer zu wünschen übrig lassen wird.

Noch ein gewichtiges Moment scheint für die Zweckmäßigkeit des primitiven Pfluges zu sprechen: der geringe Humusgehalt des ägyptischen Kulturbodens. Die zersetzten, fein rerteilten organischen Reste, die den Humus des Bodens bilden, sind bekanntlich für das Gedeihen der Kulturpflanzen von hoher Bedeutung. Der Humusgchalt emöglicht eine feste Einwurzelung der Gewächse, befördert die Bildung der Pflanzennährsalze im Boden, bedingt die hohe wasserhaltende Krraft und das Absorptionsvermögen des Bodens. Die Menge der sich im Boden und an dessen Oberfïiche ansammelnden Humussubstanz hängt ron der Masse der Pflanzenreste ab, die zur Zersetzung gelangen, und ron der Schnelligkeit, mit der diese sich auflösen. Bei niedriger Temperatur und mäßiger Feuchtigkeit geht der Zersetzungsprozeß der Pflanzenteile langsam for sich. Diese rerwesen unter dem Einfluß der Mikroorganismen zu Humuskörpern und bilden den sogenannten gutartigen, milden Humus. Anders bei hoher Temperatur und großer Trockenheit. Da werden alle Kohlenstoffrerbindungen so rasch in Gase übergeführt, daß die Pflanzenfasern verstauben, wie wir das früher bei den Stoppelrückständen in Ägypten gesehen haben. Deshalb kann sichdort eigentlicher Humusboden oder auch nur ein nennenswerter Humusgehalt des Bodens nicht bilden. Nirgends bedeckt eine Humusschicht den Boden, die zu einer dichten Rasendecke führen könnte, nirgends findet sich eine mit Dauergräsem bedeckte Fläche, die unseren Wiesen zu vergleichen wäre. Selbst dort, wo genügender Wasservorrat eine natürliche Vegetation ohne Kultur eimöglicht, trifft man nur Kräuter, Steppenpflanzen, und dazwischen leuchtet der nackte Boden hervor. Auf dem Ackerboden läßst sich dieser Mangel an Humus durch geeignete Kulturmaßregeln einigermaßen verringern. Das wirksamste Mittel besteht unter den klimatischen Verhältnissen Ägyptens darin, daß man den Boden nicht zu viel durcharbeitet und die an Humussubstanzen stets reichere oberste Ackerschicht erhält, - also vor allem den Boden nicht stürzt.

Man sieht also, daß keiner unserer modernen europäischen Pflüge den besonderen Verhältnissen der ägyptischen Landwirtschaft so sehr angepaßt ist als der scheinbar so veraltete hölzerne, landesübliche Pflug, und daß nur er allein den immer geschäftigen 
Fellah davor bewahrt, im C̈hereifer seinen Boden zuschancien zu pflügen. Und wie an diesen Beispiele, so wird sich noch an manchem anderen zeigen lassen, dab die Maknahmen und Methoden rom Standpunkte der ägy t is chen Nationalland wirtschaft aus betrachtet gar nicht so antiquiert und unzweclimäbig sind, ja dab der Fellah, ungcachtet der nicht hohen Kulturstule, auf der er sich immer noch befindet, kaum ein schlechterer Ackerbauer ist als etwa der Durchschnittsbauer der weniger fortgeschrittenen österreichischen Provinzen. Jahrtausende hindurch gesammelte und überlicferte Erfahrung, uralte Gewöhnung hat den Fellah manches gelehrt, das seine Begründung und Erklärung erst in der neuzeitlichen Wissenschaft findet.

Ein Unterschied in der relativen Höhe des Landwirtschaftsbetriebes hat eher darin seine Ursache, daf die gebildeteren Klassen der grofen Grundbesitzer wenig Einfluf auf die Bewirtschaftung ihrer Güter nehmen und diese gerne an den Fellah weiter verpachten. Daraus haben sich eigentümliche Pachtverhältnisse, die noch geschildert werden sollen, entwickelt, und der Fellah, dem selbst nur wenig Boden gehört, bearbeitet einen weit größeren Teil der gesamten Kulturfläche ziemlich selbständig. Bestrehuugen, die vorhandenen landwirtschaftlichen Methoden auf wissenschaftlicher Grundlage auszubauen, müssen deshalh naturgemäß beim Fellah ansetzen. Es ist nicht leicht, mit diesem. größtenteils aus Analphabeten bestehenden Material Erfolge zu erzielen, aber neben bemerkenswerten Ansätzen hierzu kommt es der ägyptischen Landwirtschaft wieder zustatten, daß ihr eigentlicher Hauptfortschritt doch stets in einer anderen Richtung zu suchen sein wird: in der Ausdehnung und Verbesserung des Bewässerungswesens. An dieser Tatsache hat sich seit dem Altertume in Ägypten gleichfalls nichts geändert. Die Fortschritte, die hierin in den letzten Jahrzehnten zum Teil vollbracht, zum weit größeren Teile erst projektiert wurden, mögen in der technischen Durchführung von den Bauten der altägyptischen Könige wesentlich verschieden sein, im Prinzipe stellen sie nur das Hervorholen einer alten Erkenntnis dar, die in den letzten Jahrhunderten verloren gegangen war. Obwohl der statistische Nachweis dafür kaum zu erbringen ist, läßt sich annehmen, daßs die Fläche der gegenwärtig bewässerten Ländereien die frühere Ausdehnung zur Zeit der Pharaonen noch lange nicht wieder erreicht hat. Dafür spricht die Erwägung, daß sich die Talsohle durch Ablagerung 
fortgesetzt erhöht, daß die Verschlammung und Versandung des Nilbettes fortschreitet. Dafür spricht ferner die gigantische Ausdehnung der alten Wasserbauten, z. B. des Mörissees, den Amenemha III. angelegt hat. Aber wir werden anderseits an der Hand der vorliegenden Projekte sehen, welche Aussichten die moderne Technik des Wasserbaues dem künftigen Ägypten eröfnet. Ihre ganze Tragweite wird erst klar, wenn man sich vergegenwärtigt, daß Nichtbewässern = Wüste bedeutet, durch Überschwemmung Bewässern $=$ eine Ernte im Jahr, und Bcwässern mittels Kanälen $=2-3$ Ernten im selben Jahre, auf demselben Boden, auf derselben Fläche. Hier ist der Kernpunkt der ägyptischen Landwirtschaft zu suchen, hier liegt ihre Stärke und ihre Zukunft.

Der Vorgang, der für die Darstellung der ägyptischen landwirtschaftlichen Verhältnisse gewählt wurde, eignet sich nicht in gleicher Weise für die Darstellung der sudanesischen Verhältnisse. Auch im Sudan lassen sich geneinsame Voraussetzungen und Bedingungen für die Bodenwirtschaft auffinden, aber ihre Merkmale gehören einem zu tiefen Kulturkreise an, als daß der Zusammenhang von Ursache und Wirkung uns vom praktischen, wirtschaftlichen Standpunkte aus interessieren könnte. Wir werden uns hier weniger mit den Voraussetzungen des gegenwärtigen Landwirtschaftsbetriebes zu befassen haben als mit den Voraussetzungen seiner künftigen Entwicklung.

Der ägyptische Sudan oder, richtiger gesagt, der englisch-ägyptische Sudan, denn laut einer am 19. Januai 1899 abgeschlossenen Konvention zwischen der englischen und ägyptischen Regierung weht im Sudan die englische Flagge neben der ägyptischen, beginnt einige Kilometer unterhalb der zweiten Nilkatarakte und reicht von dort in seiner weitesten Ausdehnung 1250 Meilen südlich, bis an die Grenze des Kongostaates, der sich mit der Enclave Lado tief in die Südspitze des Sudans hineingräbt. Offizielle Schätzungen, welche einstweilen die erst teilweise erfolgten genaueren Vermessungen ersetzen müssen, berechnen den Flächeninhalt mit annähernd 1 Million englischer Quadratmeilen. Das entspricht fast dem vierfachen Umfange des Deutschen Reiches.

Eine so gewaltige Ländermasse hat naturgemäß keine gleichen Schicksale, keinen einheitlichen Werdegang durchgemacht. Nubien, die nördlichste Landschaft des heutigen englisch-ägyptischen 
Sudans, trat z. B. schon zur Zeit der 6. ägyptischen Dynastie in Berührung mit ägyptischer Kultur. Später, unter der 12. Dynastie, wurde Nubien dem ägyptischen Reiche ganz einverleibt, und Ramses II., der seine Städte- und Tempelluauten bis dahin ausdehnte, siedelte vielfach ägyptische Ackerbauer im nubischen Niltale an. Nachdem die 21. Dynastie (1085-950 v. Chr.) die AmonPriesterkünige verbannt hatte, begründeten diese im heutigen Dongola das Künigreich Napata, das später nach seiner Hauptstadt Meroe benannt und der Sitz hoher Kultur wurde. In unserer Zeitrechnung, zwischen dem VII. und XIV. Jahrhunderte, wurde Nubien nach der Unterwerfung Ägyptens durch den Islam der Zufluchtsort vieler Christen. In Dongola entstanden zahlreiche Kirchen und Klöster und damit ebenso viele Kulturzentren. Die anderen Gebiete haben keine so glänzende Vergangenheit, aber auch ihre bunte Geschichte, die überall in dem Zusammenstoße der beiden größten afrikanischen Völkergruppen, der hamitischsemitischen und der negroiden Rasse kulminiert. Der ganze Sudan ist schließlich arabisiert worden, durchsetzt mit arabischen Stämmen, arabischen Gewohnheiten, arabischem Einflusse.

Nur nach einer Richtung hat der arabische Einschlag keine eingreifenden Spuren hinterlassen, ebensowenig wie die altägyptischen Kulturerinnerungen und die christliche Gesittung: im Ackerba $u$. Der Landwirtschaltsbetrieb des Sudans hat noch heute vollkommen negerhaften Charakter bewahrt. Nicht daß die Neger schlechte Ackerbauer wären! Im Gegenteil, sie gelten für die fleißigsten und besten Ackerleute unter allen Naturvölkern, und es ist erstaunlich, wie vielerlei Nutzgewächse sie zu ziehen verstehen. Aber der Typus ihres Ackerbaues behält auch bei Überfluß an Boden stets etwas Kleines, Gartenartiges. Er schmingt sich niemals zum ausgedehnten Betriebe auf, kennt weder die Ver. wendung von Maschinen noch die Terwendung des Zugrichs zur Mithilfe bei der Felderbestellung. Man kennt also im Sudan auch den Pflug so gut wie gar nicht. Nach der Kulturkarte in Ratzels Völkerkunde soll im Sudan der Pflug bis nahe an den 10. Grad nördlicher Breite, daher noch unterhalb Chartums in Gebrauch stehen. Mr. Bonus, der Direktor des Landwirtschafts-Departements der sudanesischen Regierung, versicherte mir im Gegensatze hierzu, daß es im Norden, von Berber bis Chartum, keine 20 Pflüge gäbe, südlich von Chartum aber nur zehn. Das sind jene zehm hölzernen Pflüge, relche die sudanesische Regierung für ihre Versuchsfarm 
in Kamlin am blauen Nil angeschafft hat. Die Eingeborenen behelfen sich weiter wie bisher mit einer Art von Spaten oder Hacke, die den Boden wenn nötig von Gestrüpp oder Tiefwurzlern reinigt. Größere Sträucher werden verbrannt, Bäume durch Entrinden getötet. Vor der Aussaat wird der Boden an manchen Orten mit eirem flachen Holze geglättet. Dann schreitet der Landmann das Feld ab und scharrt bei jedem Schritte mit dem Fuße ein Loch, in das die Hand ein paar Körner wirft. Das Unkraut, das sich später zeigt, wird oft ganz sorgfältig gejätet, sonst aber bis zur Ernte keine weitere Bodenarbeit versucht. Zur Ernte verwendet man, wenn nicht einfach mit der Hand gepflückt wird, ein geschärftes, gezähntes Stück Blech, wohl auch ein primitives Werkzeug, das sich daraus entwickelt hat. In der Gegend von Chartum ist das z. B. eine sägeartige Sichel, die gerade verläuft und nur an der Spitze leicht eingebogen ist. Gedroschen wird mit einfachen Holzstecken, das Mahlen besorgen die Weiber nit ausgehöhlten Steinen. Typisch für die sudanesische Landwirtschaft ist auch die geringe Sefhaftigkeit ihrer Ackerbauer, der leichte Übergang rom seßhaften Landmanne zum Nomaden und umgekehrt, wie denn überhaupt die Grenzen zwischen beiden nicht immer scharf zu ziehen sind. So gibt es in Kordofan Gegenden, wo sich der Regen nicht in jedem Jahre genug stark einstellt, um eine Ernte zu ermöglichen. Da wandert der Ackerbaner mit TVeib und Kind weiter und baut seine Durrha und seinen Sesam dort an, wo es gerade mehr geregnet hat. Die Baggara, das sind die Rinderzucht treibenden Nomaden derselben Provinz, sïen in jedem Jahre einmal Hirse und im Westen, wo diese nicht gut gedeiht, Melonen, um das Vieh über die trockene, weidelose Zeit hinüber zu bringen. Die keine Rinder besitzenden Siat El Ilbil, die mit ihren Kamelherden nördlich von El Obeid nomadisieren, haben in den letzten Jahren eine so große Anzahl Tiere durch Seuchen verloren, daf sie notgedrungen vielfach sekhaft werden mußten. Im Süden von Talodi hat wieder eine andere Ursache zu einer gewissen Seßhaftigkeit der bergbewohnenden Hirtenvölker geführt. Die einzelnen Stämme leben nämlich in ununterbrochener Fehde miteinander, und die Notwendigkeit, sich ein Gebiet zu sichern, zwingt jeden Stamm auf seinem Berge zu bleiben.

Man sieht, daß Klima und Kulturzustand der Bevölkerung zusammen die bewegende Ursache der labilen Lebensverhältnisse sind. 
In Sudan ist nicht wic in Ägypten jede Lebenstatigheit an den Nil gebunden; denn, von anderen Wasserläufen und Quellen abgesehen, die jährlichen Regenmengen nehmen gegen Süden und gegen die Meeresküste zu. Das Klima gibt zwar nicht immer und überall genug Nahrung her, aber an vielen Orten ist Ackerbau olne künstliche Bewässerung möglich, und solange die Berölkerung Raum zur Ausbreitung hat und die Nahrung dort aufsuchen kann, wo sie gerade gedeiht, ist für die Menschen kein Anlaß gegeben, dic Lebensgewohnheiten zu ändern und die Natur beherrschen zu lernen.

Der Sudan könnte nun, auch bei der bisherigen primitiven Arbeitsweise, viel mehr Menschen ernähren, als er besitzt. Er gehört zu den wenigstbesiedelten Gebieten der Welt und beherbergt auf einer ungeheueren Fläche kaum so viel Einwohner als die Stadt Wien allein. Das ist nicht unbegreiflich, denn seit den Zeiten der alten ägyptischen Dynastien, die ihre Eroberungszüge bis nach dem Sudan ausdehnten, seit der Gründung Karthagos, das seine Blüte zum Teil dem Sudanhandel dankte, hat man in Sudan nie etwas anderes als eine Quelle des Sklaven- und Elfenbeinhandels erblickt. Das blieb so bis in die letzten Zeiten, und noch im XIX. Jahrhundert waren die Sklarenjäger im Sudan daheim, allen voran der grausame Araber Sobehr, der sich später zum Herrscher des südöstlich von Darfur gelegenen Dar Fertit aufschwang. Vizekönig Said Pascha erschien 1855 persönlich in Chartum, um dem Slilavenhandel Einhalt zu tun, aber das gelang weder ihm noch einem, im Jahre 1869 zur Bekämpfung des Sklavenhandels unter Baker Pascha ausgesandten ägyptischen Heere vollkommen. Und was der Sklarenhandel übrig lief, dezimierten die Seuchen, die in den Sümpfen der Überschwemmungsperioden üppige Nahrung fanden, und die ewigen Kriege der im Sudan zusammenprallenden Völkergruppen. Man behauptet, daß allein die Kämpfe des Mahdi und seines Nachfolger's, des Khalifa, welche vor 10 Jahren ihr Ende fanden, sowie die, zu jener Zeit dort grassierenden Seuchen $75 \%$ der Bevölkerung vernichtet haben.

Übervölkerung kann also keineswegs die Nahrungsfrage aufrollen, und deshalb ist die Landwirtschaft auf ihrer tiefen Stufe stehen geblieben und hat die Organisation des Bewässerungswesens nicht gelernt, ohne die auch im Sudan weder eine höhere landwirtschaftliche Entwicklung noch ein höherer allgemeiner kultureller Aufschwung überhaupt möglich ist. Das Problem, das 
im Sudan zunächst Lösung heischt, ist also ein zweifaches: es betrifft nicht nur die Bewässerungsfrage, wie in Ägypten, sondern vor allem die Berölkerungszahl. Die geringe Dichte der Bevölkerung ist die Klippe, die jeder Kulturbestrebung im Sudan droht, das grölite Hindernis, das sich der englisch-ägyptischen Verwaltung dort entgegenstellt.

Der Grundzug dieser englisch-ägyptischen Gemeinsamkeit im Sudan scheint mir vielfach verkannt zu werden. Die oberste militärische und zivile Gewalt liegुt in den Händen eines Generalgouverneurs, der allein über die Gültigkeit von Gesetzen und Verfügungen im Sudan entscheidêt und rom Khedive ohne Zustimmung der englischen Regierung weder ernannt noch abgesetzt werden kann. Daraus hat man auf eine englische Schutzherrschaft unter völliger Beiseiteschiebung Ägyptens schließen wollen. Alle wichtigen Posten sind heute in der Tat mit englischen Offizieren besetzt. Die gemischten Gerichte, die für Ägypten zuständig sind, haben für den Sudan, mit Ausnahme ron Suakim, keine Geltung und werden vorläufig noch durch das Kriegsgericht ersetzt; die diplomatischen Vertreter fremder Mächte dürfen ihren Wohnsitz im Sudan nicht ohne Zustimmung Englands nehmen. An der Vorherrschaft Englands und an dessen Absicht, die in Ägypten so unangenehm empfundene inteìnationale Kontrolle alozuschütteln, kann darnach nicht gezweifelt werden; aber es wäre verfehlt, den Anteil, den England Ägypten an dem Besitze des Sudans einräumt, so gering einzuschätzen. Die Biologie kennt den Ausdruck „Symbiose" und versteht darunter das Zusanmenleben von Organismen, die sich dadurch gegenseitig fördern. England hat den Gedanken der Symbiose in seine Kolonialpolitik eingeführt und dankt diesem zu großen Teile die unglaubliche Fähiglieit, mit einer Handvoll Soldaten das gewaltigste Kolonialreich der Welt zusammenzuhalten. Die Heranziehung der Boers zur selbständigen Verwaltung ihres Landes ist für dieses Prinzip ebenso typisch, wie die wirtschaftliche Eroberung des Sudans unter der Mitwirkung Ägyptens. England setzt im Sudan seine ägyptische Politik fort, und befestigt sie, denn der Sudan beherrscht die Nilquellen und darum das Wohl und Wehe $\ddot{A g y p t e n s . ~ D e r ~ B e s i t z ~ d e s ~ S u d a n s ~ b e d e u t e t ~ f u ̈ r ~ E n g l a n d ~ f e r n e r ~}$ die Möglichkeit einer direkten Bahnverbindung von Kairo nach Kapstadt, durch die Abzweigung von Berber nach Suakim eine Abkürzung des Weges nach Indien und Ostasien; nebenbei ein 
neues agrarisches Produktionsland und ein vielversprechendes Absatzgeljet für die englischen Industriecrzengnisse. Aber nur eine kurzsichtige Politik könnte üher diesen Vorteilen die Gefahr übersehen, die eine selbständige sudanesische Erobermgsialitik Englands für dieses mit sich bringen mülite. Tausende lieilen von der Heimat entfernt. ohne Müglichkeit Truppen, Material. Proviant leicht nachzuschieben, immitten einer fremdrassigen feindlichen Bevölkerung: künnte es seine Herrschaft nur unter unendlichen und immerwährenden Opfern aufrechterhalten. Das Zusammengehen mit Ägypten verändert die Sachlage mit einem Schlage. Das Hinterland ist nah, die Ägrpter sind gute Soldaten. Der Khedive kann auf die Araber, die ihm treu ergeben sind, unbedingt zählen. und selbst im Sudan steht er dem grüliten Teile der Bevölkerung schon durch den Glauhen nah. Und schlieflich: dic Übervölkerung Ägyptens stellt die Hoffnung des menschenleeren Sudans dar. Das sind dic Vorteile, die Ägypten zu bieten hat. Ind deshialh glaulie ich nicht an das gänzliche Beiseiteschieben Ägyptens, das aus der Symbiose mit England keine kleineren Torteile zichen wirl, als dieses selbst. Das englische Organisationstalent und die englischen Iolnnialerfahrungen sind ron keiner zweiten Tation erreicit worden und kommen dem ägyptischen Anteile am Sudan ebenso zustatten, wie sie dem Fortschritte Ägyptens gedient haben. Die Wechselbeziehung zwischen England und $\ddot{A g}$ gpten ist eine der wichtigsten Yoraussetzungen für die künftige Entwicklung des Sudans. 


\section{Zweites Kapitel.}

\section{Die natürlichen Voraussetzungen der ägyptischen Landwirtschaft.}

\section{Das Klima.}

Regen, Wind und Luftfeuchtigkeit. - Drei klimatologische Regionen und ihr Witterungsverlauf. - Meine Untersuchungen über das Lichtklima. Es ergibt sich anscheinend daraus, daß die atmosphärische Hülle unseres Planeten diesen nicht in der Form der Erde umgibt.

Die Voraussetzungen der Landwirtschaft lassen sich unschwer in natürliche und in politische teilen. Klima und Boden, die WVasserverhältnisse gehören zu jenen und die Menschen, die das Land bevölkern und den Boden bebauen. Freilich ganz streng läßt sich die Teilung nicht durchführen; denn Art und Entwicklungsstufe der Menschen, welche für die Gestaltung der Nationallandwirtschaft so wichtig sind, bilden sich wieder unter dem gemeinsamen Einflusse der anderen natürlichen und der politischen Voraussetzungen. Die Mcnschen sind ebenso das Produkt beider, als die Hauptursache der politischen Voraussetzungen. Das kunstrolle System, durch welches das rorhandene Wasser mehr und mehr nutzlar gemacht wird, stellt auch Errorbenes neben Ursprüngliches.

Der Falitor Klima und sein Einflufs auf den Landbau wird in Ägypten rorzüglich durch drei Merkmale gekennzeichnet: die geringe Menge der Niederschläge, die Höhe der Temperatur und die relative Gleichmäkigkeit des Witterungsganges und dessen alljährlichen Verlaufes.

An der Küste ist der Regen im Winter noch häufig, in Kairo schon viel seltener und in Oberägypten fast unbekannt. Für die rapide Abnahme gegen Süden ist es bezeichnend, daß beispielsweise im Jahre 1904 Alexandrien $196,9 \mathrm{~mm}$ Regen. Heluan bei 
Kairo 21,4 mm und Assiût (27 $11,0^{\prime \prime}$ nürdlicher Breite) gar keinen Regenfall mehr hatte. Der Regen an der Küste ist meist von West- oder Nordweststürmen begleitet, und nur deren vorübergehender südlicher Ausbreitung sind die spärlichen Regen in Unterägypten zu danken.

Um einen Begriff der Regenverteilung auf die eimzelnen Monate zu geben, führe ich das Beispiel des Jahres 1904 hier an ${ }^{1}$ ):

\section{mm Regen.}

Alexandrien:

Jan. Febr. März April Mai Juni Juli Ang. Sept. Okt. Nov. Dez. Total

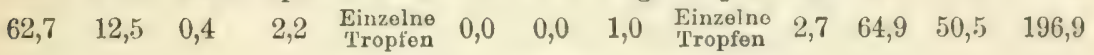
Hel u an $29^{\circ} 51^{\prime} 34^{\prime \prime} \mathrm{N}$.

$\begin{array}{lllllllllllll}14,2 & 2,5 & 0,0 & 4,0 & \prime & 0,0 & 0,0 & 0,0 & 0,0 & 0,0 & 0,4 & 0,5 & 21,4\end{array}$

Im Durchschnitte dreier Jahre hatte Alexandrien $247 \mathrm{~mm}$ Regen, Heluan bei Kairo nur noch $35,66 \mathrm{~mm}$. Sowohl die Quantität als das Verhältnis zwischen der Regenmenge der Küste und der nur wenig südlicher gelegenen Teile Ägyptens ist daher ziemlich konstant. Zu gering, um Ackerbau ohne künstliche Bewässerung zu gestatten, sind die Regenmengen aber überall, selbst an der niederschlagreicheren Meeresküste. Es lälit sich im allgemeinen annehmen, daß die Kulturpflanzen in unseren gemäßigten Gegenden je nach Art und Dichte während der Vegetationszeit, auf den Tag berechnet, $2-5 \mathrm{~mm}$ Regenhöhe benötigen. In wärmeren, trockenen Ländern brauchen die Pflanzen aber weit mehr, da vor allem ihre Transpiration beschleunigt wird. Haberland $t^{2}$ ) gibt folgende interessante Daten an:

Es verdunsteten aus einem mit Wasser stets vollgehaltenen Gefäße:

$\begin{array}{cc}\text { Mittlere Jahrestemperatur } & \begin{array}{c}\text { Mittlere jährliche } \\ \text { in Graden Celsius }\end{array} \\ \begin{array}{c}\text { Verdunstung in mm } \\ 10,4\end{array} & 6 \diamond 6 \\ 15,9 & 1976 \\ ? & 9450\end{array}$

in Tübingen . . . . .

in Rom ........

in der afrikanischen Steppe
Mittlere Jahrestemperatur den Celsius 10,4 ?

Dieser Versuch zeigt wohl die Verdunstung unter verschiedenen Wärmeverhältnissen, er gibt aber noch kein getreues

1) Der zurzeit letzterschienene "Meteorological Rapport" des Survey Department von Ägypten hat das Jahr 1904 zum Gegenstande.

2) Friedrich Haberlandt, Der allgemeine landw. Pflanzenbau. Wien 1897. S. 333. 
Bild von dem Wasserbedarfe im Tropenklima. Denn die Transpiration lebender Organismen ist kein bloßes Verdunsten, sondern steht in engem Kontakte mit allen Lebensprozessen, die wieder von der Wärmemenge beeinfiußt werden. Wasser wird überdies auch zum Aufbau der organischen Substanz verbraucht.

Die Transpiration und folglich der Wasserbedarf wird durch den Wind und den relativen Feuchtigkeitsgehalt der Luft mitbestimmt. Winde befördern die Transpiration, führen den Pflanzen steis eine neue Menge der Kohlensäure zu, die ihr hauptsächlichstes Nahrungsmittel bildet, lösen wohl auch einen Wachstum fördernden Reiz aus - lauter Y'orgänge, mit denen direkt oder indirekt eine Steigerung des Wasserbedarfes verknüpft ist. Die Luftleuchte aufzunehmen sind die Pflanzen wohl nicht imstande, und weder das Wasserquantum, das der Boden anzuziehen und zu verdichten vermag, kann Regen ersetzen, noch der Nicderschlag, der als Tau bezeichnet wird. Nur sehr starker Tau, der die oberste Bodenschicht durchfeuchtet, wird vielleicht von den feinsten Wurzelverzweigungen, die sich dort befinden, verwertet werden. Aber sowohl Luftfeuchte, wie die oberflächliche Benetzung der Pflanzen und des Bodens, üben einen Einflut auf das erforderliche Wasserquantum aus, indem sie die Verdunstung herabsetzen.

An Wind fehlt es in Ägypten nicht. Der Passatwind bläst fast das ganze Jahr hindurch, und besonders gegen das Mittelländische Mieer zu sind Zylklone, außer im Sommer, ziemlich häufig. Im Frühjahr steigern diese sich zu den glühendheißen Chamsins (Samum), die wohl aus dem Süden kommen, aber ihre Wirkung doch mehr in Mittel- und Unterägypten äußern.

Die relative Feuchtigkeit der Luft ist nur an der Küste beträchtlich, wo sie, wie in Alexandrien, im Jahresdurchschnitte $76 \%$ erreicht. Für einen Ort an der See ist das auch nicht hoch; denn das kontinental gelegene Wien hat z. B. keine viel trockenere Luft (Jahresmittel $72 \%$ ), während der durchschnittliche relative Feuchtigkeitsgehalt im Seeklima zwischen 88 und $90 \%$ betragen kann.

Gegen das Innere und den Süden zu fällt die Größe dieser Werte rasch. Heluan bringt es nur auf ein Jahresmittel ron $53 \%$ Lufteuchtigkeit, Assuan gar nur auf $35 \%$. Das sind Zahlen, welche die Steigcrung des Wasserbedarfes schon erkennen lassen. Tau gibt es dagegen in Agypten fast das ganze Jahr hindurch, 
namentlich im Herbst und in Winter, wenn die Lufteuchtigkeit zur Zeit der Nilüberschwenmung zunimut und die Temperatur plötzlich sinkt. Dann kann sich auch Reif bilden, in besonkers strengen Wintern und bei starkem Nordwinde sogar dünnes Eis.

Wir sind gewolnt, bei dem Worte Eis an Kältegrade der Luft zu denken. In Ägypten sinkt aber das Thermoneter gewöhnlich nur in den Wüsten und nur in den Näichten der Monate Dezember bis Februar unter den Gefrierpunkt. Der herühnte Afrikaforscher Rohlfs hat z. B. im Februar des Jahres 1874 in der Lybischen Wüste $-5^{\circ} \mathrm{C}$ erlebt. Das entspricht dem Klina des kultivierbaren Ägypten ganz und gar nicht. Dieses gehört sciner geographischen Lage nach allerdings zum größten Teile der gemäßigten Klimazone an, denn der Wendekreis des Krobses schneidet es unweit Assuan. Aber Afrika ist heißer, als seiner Lage entspräche. Nimmt man die heife Zone nicht als astronomischen, sondern als klimatologischen Begriff, so liegt es fast zur Gänze in dex heißsen Zone, die nach dem Vorschlage Supans durch die Jahresisotherme von $20^{\circ}$ bestimmt wird.

Ägypten läßt sich klimatologisch in drei charakteristische Regionen teilen: die Nordküstc und das Delta, Mittelägrpten bis zum 27. ${ }^{\circ}$ nördlicher Breite und Oberägypten. Wie nicht anders zu erwarien, wächst der jährliche Temperaturdurchschnitt gegen Süden ebenso, wie wir den Feuchtigkeitsgehalt der Luft in gleicher Richtung abnehmen sahen. Nur die nördlichen Ufergebiete reguliert das Nittelmeer, und die Temperatur ist dann im Winter dort höher als in Mittelägypten, fällt noch seltener als in Mittelïgypten unter den Gefrierpunkt. Was die Wärme anbelangt, so üherschreitet das Thelmometer an der Küste selten $35^{\circ} \mathrm{C}$; in Kairo beobachtet man Temperaturen von $42^{\circ} \mathrm{C}$, die in Assuan auf $45^{\circ} \mathrm{C}$ und in Wadi Halfa noch weiter steigen können. Die drückendste Schwüle und die höchsten Temperaturen bringt stets der Chamsin mit; wenn dieser weht, kann das Thermometer selbst in Kairo 46 Hitzegrade erreichen.

Um eine Übersicht über die Verteilung der Wärme auf die einzelnen Monate des Jahres in den drei erwähnten klimatologischen Zonen zu geben, lasse ich die betreffenden Zahlen aus dem Jahre 1904 folgen, das in keiner Weise abnornal war. Als Bestimmungsort für das Delta wurde Alexandrien gewählt, für Unterägypten Heluan und für Oberägypten, die dritte Zone, Assuan. 
Alexandrien.

Heluan.

A s sua $n$.

(Grade Celsius.)

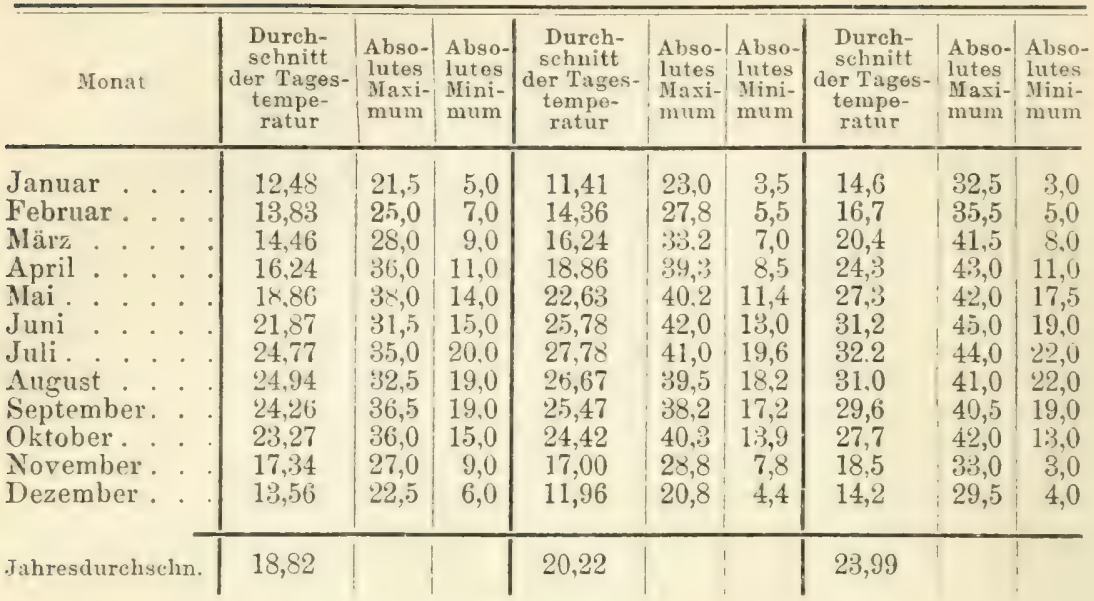

Die Tabelle zeigt die relative Gleichmäßigkeit der Temperaturverhältnisse. Die Jahreszeiten unterscheiden sich nicht so ausgesprochen roneinander als bei uns; der Temperaturdurchschnitt der einzelnen Monate variiert nicht viel rom Gesamtdurchschnitte; die absoluten Maximal- und Minimaltemperaturen liegen näher beisammen. Und wie das eine Jahr in bezug auf die Temperatur gleichmäßiger verläuft, so älneln sich im Laufe der Zeiten die Jahre in klimatologischer Beziehung. Nach jeder Richtung sind die Gegensätze geringer, die unerwarteten Extreme seltener.

In den Zonen, wo Regen vorkommt, verteilt er sich in annähernd gleicher Weise Jahr für Jahr, die Regenmengen bleiben relativ ziemlich gleich. Die Winde stellen sich meist zur erwarteten Zeit ein, kommen von der erwarteten Seite. Man weißs im voraus, dafi der winterliche Passatwind im Delta von Nordwest, in Unterägypten rom Norden und in Oberägypten von Nordosten wehen wird, weiß, daß die Zeit des Chamsin das Frühjahr ist, und daßs er seinen Weg rom Süden nimmt. Die Schwankungen des Luftrlruckes sind geringfügig. Im Jahre 1904 hielten sich Maximum und Minimum des Barometerstandes in den engen Grenzen von 752,4 und 763,4 in Alexandrien, von 756,3 und $745,8 \mathrm{~mm}$ in Heluan und von 755 und $745,6 \mathrm{~mm}$ in Assuan. Gleichmäßig steigt und fällt die Luftfeuchtigkeit, zeigt niemals 
grobe Abweichungen von der Regel. Den Verlaul kemmeichnet. folgende Tabelle:

Durchschnitt der relativen Feuchtigkeit in Prozenten:

\begin{tabular}{|c|c|c|c|c|}
\hline 1904 & & Alexandrien & Heluan & Assuan \\
\hline Januar & $\cdots$ & 75,6 & 67,2 & 48,0 \\
\hline Februar. . & $\ldots$ & 79,0 & 59,4 & 42,9 \\
\hline März . . . . & $\cdots$ & 77,1 & 51,8 & 31,2 \\
\hline April .... & ... & 82,0 & 50,9 & 27,7 \\
\hline Mai. . . . & $\cdots$ & 85,3 & 46,3 & 25,5 \\
\hline Juni $\ldots \ldots$ & $\cdots$ & 83,2 & 43,1 & 22,8 \\
\hline Juli . . . . & ... & 74,2 & 43,7 & 23,8 \\
\hline August . . . & $\ldots$ & 74,2 & 50,6 & 30,8 \\
\hline September . & ... & 72,2 & 54,0 & 29,8 \\
\hline Oktober. . . & ... & 74,3 & 53,2 & 35,8 \\
\hline November. . & . . . & 71,8 & 60,3 & 57,4 \\
\hline Dezember . . & ... & 73,4 & 63,3 & 53,8 \\
\hline Durchschnitt & $\ldots$ & 76,9 & 53,6 & 35,77 \\
\hline
\end{tabular}

Man sieht daraus, wie gleichmäßig wieder der Verlauf selbst in seiner Ungleichmäßigkeit ist. Alexandrien, vom nahen Meere beeinflubt, macht nur geringe Schwankungen in Feuchtigkeitsgehalte der Luft mit, während Heluan und Assuan innerhalb ihrer verschiedenen Feuchtigkeitslagen regelmäßig der Nilschwelle folgen.

Zur Gleichmäßigkeit des Klimas gehört es auch, daß Ägypten keine verheerenden Gewitter kennt, keinen Hagelschlag und keine Schneeschäden. In Unterägypten kann wohl zur Zeit der Äquinoktien einmal ein Gewitter vorkommen, aber in Oberägypten gehört es, ebenso wie der Schnee, zu den seltensten Naturphänomenen. Häufiger dagegen ist der Nebel, der in Herbst. Winter und Frühjahr auftritt. Alles in allem läßt sich kaum bestreiten, daß das ägyptische Klima dem Nachteil ungenügender Niederschläge gewichtige Vorteile entgegenzusetzen hat und wohl keinen von wesentlicherer Bedeutung, als die relative Gleichförmigkeit seiner Witterung.

Die Ursachen dieser Erscheinung sind zu komplizierter Natur: als daf sie hier eingehend erörtert werden könnten. Ihre verbreitetste Deutung ist ja bekannt: große Stabilität der Druck- und Windverhältnisse, die durch das ungeheuere Gebiet der Wüsten reguliert und ausgeglichen werden.

Das Wüstengebiet in Vereine mit dem Regenmangel sind vielleicht teilweise noch für eine andere Naturerscheinung ver- 
antwortlich zu machen - die Gestaltung des Lichtklimas in Ägypten.

Um das Lichtklima scheren sich die Klimatologen im allgemeinen noch recht wenig, und die, welche es am meisten angeht, die Landwirte - wissen zumeist gar nicht, was Lichtklima eigentlich ist. Doch liegt der Gedanke nahe, die Intensität des Lichtes gerade so zu messen, wie man die Wärme, die Luftfeuchtigheit mibt. Ist es doch das Licht, sind es doch die Sonnenstrahlen, welche die Kulturpflanzen zum Leben erwecken und zur schaffung der organischen Substanz befähigen. Die Wirkung steht auch hier innerhalb gewisser Grenzen in Beziehung zur Stärke der Ursache. Die Intensität des Lichtes ist abcr nicht überall gleich, nimmt rom Äquator gegen die Pole bedeutend ab. Von 1000 Somnenstrahlen werden am Äquator 378 bis an die Obertiäche der Erde gelangen, um den $45 .{ }^{\circ}$ nördlicher Breite nur 228 , in der Polargegend nur 110.

Wiesner hat die Abhängigkeit der Pflanzenproduktion vom Lichtlima zuerst eingehend studiert und eine Methode ausgearbeitet, die das Messen der Lichtintensität leicht gestattet. Seine Aufnahmen des Lichthlimas reichen bis Kairo, ich selbst habe sie in Lnter- und Oberägypten und im Sudan weiter fortgresetzt. Schon in Kairo hatte sich ergeben, dak die Intensität auch bei gleicher Somenhöhe und gleicher Sonnenbedeckung niederer als in Wien ist.

Wiesner hielt es für möglich, daß diese Erscheinung durch die geringe Regenhäufigkeit und Regenstärke verursacht werde. Je öfter" und reichlicher der Regen niederfällt, desto mehr wird die Luft ron festen, in ihr suspendierten Teilen befreit werden. In Ägypten vermehrt die nahe Wüste die Menge der Staubteile und den Salzgehalt der Luft, und der reinigende Regen fehlt. Meine Lichtmessungen bis Khartum fortgesetzt, haben nun ein überraschendes Resultat ergeben: Die relative Lichtintensitüt, d. h. die Lichtintensitït im Terhältnis zur Sonnenhöhe, nimmt mit der Annäherung an den Äquator in fast gesetzmäßiger Weise immer nehr ab und das unter Umständen, die sich durch den zweifellos mitbeteiligten Faltor: „suspendierte feste Teile in der Luft" allein nicht erklären lassen, vielmehr einen andern Erklärungsgrund wahrscheinlich machen. Dieser Erklärungsgrund ist der, daßs die Lufthülle unseres Planeten diesen nicht in der Form der Erde umgibt, soudern ron den Polen gegen den Äquator 
zu immer mehr an Ausdelnung gewinnt und dadurch die Intensität des Sonnenlichtes im selhen Malie herabsetzt ${ }^{1}$ ).

\section{Der Boden.}

Wie in Ägypten der Ackerboden entstanden ist. - Seine besonderen Eigenschaften. - Analysen verschiedener Böden aus dem Niltale. - Wüsterısand und Nilschlamm.

Die Gesamtheit der klimatischen Erscheinungen mulite nachdrücklich auf die Gestaltung des ägyptischen Ackerbodens einwirken; denn Boden in landwirtschaftlichem Sinne ist nur der, welcher einen hohen Grad von Verwitterung erreicht hat und zersetzte organische Substanzen beigenischt enthält. Nur ein solcher bietet in seiner chemischen und mechanischen Struktur dem Pflanzenwachstum die nötigen Bedingungen. In Ägypten ist die Verwitterung und die Zertrümmerung des Gesteines überall weit fortgeschritten, in der Wüste wie im Kulturland. Aber dieses konnte sich nur dort bilden, wo Wasser hinkam, unter dessen Mitwirkung organische Substanz geschaffen und zu Humus zersetzt wurde. Die Regenmengen genügen dazu nicht, und sonst hat es seit der Diluvialzeit, wo die Gewässer des Meeres Ägypten bedeckten, kein Wasser mehr gegeben, als den Nil und die verschiedenen Salz- und Bitterseen in der Nähe von Alexandrien, am Westrande des Fayûm und auf der Landenge von Suez. Nennenswerter Salzgehalt des Wassers schlicht dessen Verwendung zur Bodenbewässerung aus, und so hätte in Ägypten niemals anderswo Boden in landwirtschaftlichem Sinne entstehen können als an den Ufern des Nils.

Die Breite des Niltales einschließlich der schon wüstenhaften Strecken an den Rändcrn wechselt in Nubien von 7-15, in Ägypten von 20-50 Kilometern. Von Nubien an bis tiei hinein nach Oberägypten bildet Sandstein aus der mittleren Kreidezeit. das Urgestein; bei Assuan schiebt sich ein Qucrriegel von schwarzem, glänzendem Granit vor. Weiter nördlich setzt Tertiärkalk ein, der bei Kene und Siut durch vorgelagerten Ton unter. brochen wird. Diese Formationen haken aber weder den Ackerboden noch seinen Untergrund geliefert. Der Ackerboden besteht ausschließlich aus dem Schlamm, den der Nil in Laufe der Jahrtausende angeschwemmt hat. Darunter befindet sich in ganz

${ }^{1}$ In den Sitzungsberichten der Kais. Akad. d. Wissenseh, in Wien veröffentlicht. 
Ägypten ein Lager von Meeressand. Fraas erklärt das damit, daß das ganze Land zwischen den Katarakten und dem Mittelmeer ehedem ein negatires Delta, eine enge Mecresbucht gewesen ist, die allmählich durch den Lagunenschlick ausgefüllt wurde. Später, nach der Erhebung Ägyptens aus dem Meere, grub der Strom sein Bett in den Schlick, auf dessen Unterlage der Nil dann seine Schlammassen absetzte. Man kann beobachten, wie der Sand am Grunde eines Brunnens oder im Bette des Flusses in Bewegung gerät, sobald er mit dem Wasser in Berührung kommt und alshald das Nachstürzen der darüberliegenden Tonschichten hervorruft.

Tie ein unendlicher schmaler, blühender Garten inmitten der großen Wüste liegt das kulturfähige Schwemmland da. Nur im Delta verbreitert es sich ansehnlicher und in der Oase Fayûm, in die der Nil seinen Ausläufer, den $33 t \mathrm{~km}$ langen Bahr Jûsuf entsendet. Die beispiellose, anhaltende Fruchtbarkeit des ägyptischen Kulturlandes setzt das glücklichste Zusammenwirken ron Klima und Boden roraus. Dieser besitzt tatsächlich hervorragende Eigenschaften, darunter solche, die kein anderer Boden aufzuweisen hat. Tor allem die Mächtigkeit seiner Ackerkiume. Thaer nahm an, daß der Wert seines Bodens für jeden Zoll Zunahme der Ackerkiume über 6 Zoll um $8^{\circ} .0$ steige. Die Erdschichte, die der Nil geschaffen hat, reicht $10 \mathrm{~m}$ tief hinab. Tielleicht ist es zu weit gegriffen, wenn man die ganzen $10 \mathrm{~m}$ als Ackerkrume auffaßt. In jenem engsten Sinne, der darunter nur die oberste Bodenschichte rersteht, die durch den Pflug gewendet oder durch tiefer gehende Bodenbearbeitung gelockert und durchgewühlt wurde, ist das gewiß der Fall. Aber anderseits trïgt die ganze Erdschichte doch alle Merkmale an sich, die man sonst dem Obergrund zuschreibt. Die gesamte Bodenmasse ist ziemlich einheitlicher Natur, Ober- und Unterschichte in den Mischungsverhältnissen, im Grade der chemischen Auflösung, in physikalischer Beziehung, in bezug auf den Humusgehalt nicht sehr abweichend voneinander. Die Erklärung ergibt sich unschwer aus der Entstehungsart des Bodens. Jahr für Jahr hat der Nil seinen Schlamm an den Ufern abgesetzt. Die letzte Anschwemmung war stets die, welche die momentane Ackerkrume in engsten Sinne darbot oder verstärkte. Die neuen Schlammassen wurden bearbeitet, waren die Träger der Vegetation, die Ablagerungsstätten der allerdings spärlichen organischen Pflanzenreste. Das nächste 
D e natürlichen Voraussetzungen der ägyptischen Landwirtschaft.

Jahr brachte wieder eine neue Schlammschicht, die nun die oberste war, und so ging es stets weiter und weiter. Was früher eigentliche Ackerkrume war, kam mit der Zeit immer tiefer hinab. Schlieblich, nach Jahrtausenden, waren die $10 \mathrm{~m}$ beisammen, und die ganze Bodenmasse, aus ehemaligen Ackerkrumen gebildet, verleugnet noch heute den Gegensatz zwischen Ober- und Untergrund.

Eine andere Eigenschalt ist die Gleichförmigkeit des Ackerbodens an topographisch verschiedenen Stellen. Anderswo wird die Beurteilung von Böden dadurch sehr erschwert, daß die Faktoren für ihre Bewertung, die Zusammensetzung, die physikalischen Eigenschaften selbst innerhalb eines verhältnismäßig engen Raumes nicht die gleichen sind. Es gibt Böden, bei denen jeder Quadratmeter anders ist. Das kommt bei den ägyptischen Kulturböden nicht vor, und selhst weit entfernte Stellen weichen wenig voneinander ab. Burns, der Chemiker der landwirtschaftlichen Schule in Ghizeh bei Kairo, hat eine Reihe von Böden, die den verschiedensten Teilen des Niltales entstammen, untersucht und folgendes gefunden:

(Alles auf Trockensubstanz umgerechnet.)

Oberägypten

Tantah (Delta) Fayoum Matai Heweslich

\begin{tabular}{|c|c|c|c|c|c|c|c|}
\hline Pottasche. . . . . & . & . & . . & 0,55 & 0,63 & 0,76 & 0,53 \\
\hline Soda . . . . . . & . . & . . & . . & 0,58 & 0,72 & 0,74 & 0,65 \\
\hline Kalk. . . . . . . & . . & . & . . & 3,38 & 5,53 & 4,47 & 3,26 \\
\hline Magnesia . . . . . & . . & . & . . & 2,88 & 2,75 & 2,89 & 2,63 \\
\hline Eisenoxyd und Alumin & nium & m. & . . & 23,36 & 20,23 & 24,39 & 21,89 \\
\hline Manganoxyd .... & . . & . & . & 0,22 & 0,24 & 0,26 & 0,23 \\
\hline $\mathrm{CO}_{2}$....... & . & . & . . & 0,67 & 3,03 & 1,10 & 0,91 \\
\hline Phosphorsäure $\left(\mathrm{P}_{2} \mathrm{O}_{5}\right)$ & . . & . & . . & 0,20 & 0,22 & 0,28 & 0,26 \\
\hline Chlor. . . . . : & . . & . & . . & 0,09 & 0,11 & 0,10 & 0,06 \\
\hline Organische Substanz & . . & . & . & 7,79 & 7,38 & 7,78 & 6,16 \\
\hline Unlösliche Substanzen & & ilik: & ate & 60,28 & 59,16 & 57,23 & 63,42 \\
\hline $\begin{array}{l}\text { Stickstoff . - . - } \\
\text { Salpetersäure }\left(\mathrm{N}_{0} \mathrm{O}_{5}\right.\end{array}$ & & & & $\begin{array}{l}0,07 \\
0,0038\end{array}$ & $\begin{array}{l}0,05 \\
0,0016\end{array}$ & $\begin{array}{l}0,095 \\
0,0278\end{array}$ & $\begin{array}{l}0,0 \\
0,0\end{array}$ \\
\hline
\end{tabular}

Die chemischen Unterschiede sind jedenfalls in Anbetracht. der Ausdehnung des Untersuchungsgebietes gering, was wieder mit der Entstehungsart zusammenhängt, - überall hat ja der selbe Nilschlamm den Boden gebildet. Daß dieser dennoch nicht an allen Orten ganz gleich ist, erklärt sich außer durch die verschiedene Bodenkultur hauptsächlich durch zwei Ursachen: 
die ungleiche mechanische Trennung der Schlammteile durch das absetzende Nilwasser und die Beimischung von Wüstensand durch den Wind. Im ersten Falle sind, soweit die Mineralbestandteile in Betracht kommen, die physikalischen Unterschiede nicht von chemischen begleitet. Hughes von der Khédivialgesellschaft hat das durch Analysen ron Bodenproben aus der Provinz K eneh, wo es keinen Wüstensand gibt, gezeigt. Er teilte sechs Bodenproben nach der mechanischen Analyse in zwei Gruppen ein. Gruppe I stellt leichteren Boden, Gruppe II schwereren Boden dar. Die Durchschnittsanalysen von je drei Proben, die zu einer Gruppe vereint waren, ergaben:

$\begin{array}{lcc} & \text { Gruppe I } & \text { Gruppe II } \\ \text { Grober und feiner Sand . . } & 79,9 & 29,9 \\ \text { Feiner Schlamm und Ton . } & 18,0 & 64,0 \\ \text { Gesant-Pottasche . . . . . } & 0,70 & 0,94 \\ \text { Lösliche Pottasche. . . - . } & 0,032 & 0,027 \\ \text { Gesamt-Phosphorsäure'. - . } & 0,25 & 0,34 \\ \text { Lösliche Phosphorsäure . . } & 0,056 & 0,064\end{array}$

(der Boden auf $100^{\circ} \mathrm{C}$ getrocknet.)

Die Beimischung ron Wüstcnsand reründert das Bild rasch. Hughes hat Durchschnittsproben aus Gegenden, wo die Beimischung aus Wüstensand zu erwarten war, nach der Korngröße in Serien geteilt und untersucht und nunmehr ganz andere Resultate erhalten:

$\begin{array}{ccccc} & 1 & \text { II } & \text { III } & \text { IV } \\ \text { Grober Sand. * . . } & 29,6 & 54,8 & 74,5 & 84,5 \\ \text { Total-Pottasche . * . } & 0,58 & 0,29 & 0,34 & 0,09 \\ \text { Total-Phosphorsäure . } & 0,40 & 0,30 & 0,19 & 0,10\end{array}$

Die Quantität der Pflanzenuährstoffe fällt hier in dem Maße, als Sand beigemischt ist.

Die merkwürdigste Eigenschaft der ägyptischen Büden, selbst solcher, die selbst aus feinsten Partikeln bestehen, wie die Lehmböden, ist ein ganz unverhältnismäßig hoher Grad ron Durchlässigkeit. F. H. Mi e ans ${ }^{1}$ ) erzählt von einem Boden zu Kassassin, der nicht weniger als $75 \%$ Lehm und Ton enthielt und dorh genügend durchlässig war, um mit Erfolg bebaut zu werden. Mieans glaubt, daß diese Erscheinung auf den hohen Gehalt von Kalk- und Magnesiumsalzen zurückzuführen sei, wogegen ich bemerken müchte, daf bei unscren europäischen Böden

1) Reclamation of alkali lands in Ägypt. U. S. Dep. Ag. 
der gleiche oder sogar hölere Gehalt an diesen Pestandteilen nicht die gleiche Wirkung hervorruft. Man wird aber auch hier auf die Entstehungsart zurückgehen, sich erinnern müssen, dal; schon der Nilschlamm in seinen Eigenschaften ganz cinzig auf der Erde dastcht. Fraas ${ }^{1}$ ) hat das mechanische Verhalten des Nilschlammes mit dem curopäischer Böden verglichen. Er wog je $10 \mathrm{~g} \mathrm{ab}$ und schüttelte sie in einem halb mit Wasser gefüllten Titrierglase so lange, bis sich der Boden gelöst hatte. Nach zehn Minuten Ruhe wurden die Niederschläge im Glase gemessen und ergalıen: Lehm von Hochdorf $11,5 \mathrm{ccm}$ (4 Sand 8 Ton),

. Zagen ha usen (kalter Boden) $10 \mathrm{ccm}$ ( 4 Sand, 6 Ton), (heifer Boden) $13 \mathrm{ccm}$ ( $4^{1} / 2$ Sand, 81/2Ton). Lehm ron Wissbach $11 \mathrm{ccm}$ (8 feinster Sand, 3 Ton).

Nilboden ron Schubra (Baumwollenfelder) 22 cen, und die ganze Masse so gleichmäßig verteilt, daf zwischen Sand und Ton kein Unterschied gemacht werden konnte. Nigerschlamm, auf der Westliüste von Afrika geholt, glich in seinem mechanischen Verhalten dem europäischen Lehm und Löß.

Der Nilschlamm zeigt also schon die Besonderheiten, die den fertigen Boden auszeichnen. Diese Erkenntnis läßst den Kreis der Wechselwirkung in der ägrptischen Landwirtschaft immer weiter eischeinen. Der Ackerbau wird rom Boden beeinflußt und beeinfluft wieder den Boden in physikalischer Beziehung und in Beziehung auf die Zusammensetzung, namentlich was den Stickstoffgehalt betrifft. Dieser ist ron Natur aus gering und mehr von der Art der Bodenbearbeitung und der Fruchtfolge abhängig, als von der natürlichøn Beschaffenheit des Bodens. Aber beide. sowohl Ackerbau wie Boden, hängen wieder mit dem Nil zusammen und mit den Bedingungen, unter denen er seinen Weg aufnimmt und zurücklegt. die Schlammassen in fernen Ländern an sich reißt und später an seinen Ufern ablagert.

\section{Das Wasser.}

Der Werdegang des ägyptischen Nils und der ungleiche Einfluß seiner Zuflüsse auf die Landwirtschaft. - Zusammensetzung des Nilwassers zu rerschiedenen Zeiten und im Vergleich mit anderen Flüssen. - Bewässerungusysteme. - Das Bassinsystem. - Überragende Bedeutung der Kianalbewässerung für die Zukunft Ägsptens.

Der ägyptische Nil entsteht bekanntlich bei Khartum aus dem Weißen und aus dem Blauen Nil. Der Ursprung jenes führt

1) Dr. Oskar Fraas, Geol. Beobachtungen aus dem Orient, Stuttgart 1867. 
nach der Feststellung Speckes ${ }^{1}$ ) auf das Quellgebiet des Kagera zurück; der Blaue Nil entspringt den Hochländern Abessyniens.

Der vereinigte Nil nimmt auf einer Strecke ron $3000 \mathrm{~km}$, zwischen Khartum und dem Mittelmeer, nur einen Nebenfluß auf, den A tbara. Dieser kommt auch ron den Abessynischen Bergen her und bildet während der Hochflut eine mächtige Wasserquelle Ägyptens, ähnelt aber sonst in der trockenen Jahreszeit mehr einem unbedeutenden Bach, als einem Flusse.

Das scheinbar so einfach gegliederte Flufsystem wird zum Anlaßs sehr komplizierter Vorgänge. Der Bla u Nil und der Atbara wälzen zur Zeit der Hochflut, von August his Norember, gewaltige Wassermassen von ihren hochgelegenen $\mathrm{Ur}$ sprungsorten hinab. Der W eiß e Nil hat kein so großes Gefälle, fliebt langsamer dahin und kann gegen das stürmische Vordrängen der beiden anderen nicht aufkommen. Er ist deshalb zunächst nur schwach an den Wassermengen beteiligt, die der Nil nach Ägypten hineinführt. Wenn die Hochflut zu Ende geht und der Blaue Nil und der Atbara sich zu erschöpfen scheinen, damn tritt der Weibe Nil in seine Rechte ein, und nun rührt fast alles Wasser im ägyptischen Nil von ihm her.

Das ist für die ägyptische Landwirtschaft gar nicht so gleichgültig, als man bei obertlächlicher Betrachtung glauben könnte; dem die chemischen Eigenschaften des Nilwassers und die Zusammensetzung und die Mienge des Nilschlammes stehen in engstem Zusammenhange mit dem Gebiete, aus dem die Zuflüsse kommen, und mit den Terhältnissen, unter denen die Zuflüsse sich bilden und weiterbewegen. Der Weibe $\mathrm{Nil}$ hat einen ganz anderen Werdegang durchzumachen als die beiden anderen Quellflüsse

1 Das Verdienst, den Ursprung des Nils bis zum Kagara zurück verfolgt zu haben, gebührt zweifellos Speke, der in den Jahren 1862-64 den Ukerewesee entdeckte und die Frage, ob dieser See die eigentliche Quelle oder nur ein Durchgangsgewässer des Nils bilde, durch Entdeckung des $K$ aga ra an der Westseite des sees entschied. Ba umann, der nach den meisten Handbüchern die Quelle des Kagara als Nilquelle festgestellt haben soll, hat dann im Jahre 1892 einen Zufuß des Kagara, den $R u w u w u$, entdeckt und fast bis zu seinem Crsprunge verfolgt. Neuerdings haben die Beobachtungen Goetzens, dann Kandts Zweifel darüber erweckt, daß mit der Entdeckung des $R u w u w u$ wirklich, die letzten Schleier des Nilproblems gelüftet sind", wie Ba u mann in seinem Reisewerke schrieb. Man glaubt vielmehr, daß die Quelle des R ukarara die Quelle des Kagara und folglich die des Weilen Nils ist. 
des ägyptischen Nils, und deshalb verhält er sich auch ganz anders als sie.

Der Blaue Nil und der Atbara treten in ihre bedeutungsvolle Pcriode gegenüber Ägypten, wenn im Abessynischen Hochlande die Zeit der anhaltenden starken Regengüsse eingetreten ist. Als reines, fast chemisch reines Wasser, dem nur Spuren von Ammoniak und Salpetersäure beigemengt sind, fällt der Regen zur Erde. Seine Heftigkeic läßst dem IVasser gar nicht Zeit, in Mengen in den Boden einzudringen. Ein grober Teil stürzt auf der Oberfläche zur nächsten Wasscrfurche, überall im Laufe die Erde lostrennend, mit sich reißend. Die Quellen vereinen sich zu Bächen, und auf dem steilen Wege zum Tal wächst die Geschwindigkeit, mehren sich die Schlammassen. Endlich läßt der Regen nach. Der aufgerissene Boden nimmt jetzt mehr Wasser in sich auf. Dieses strebt seinem Bestimmungsort nicht wie früher hauptsächlich an der Oberffläche zu, sondern als Wasserader, die in der Erde weitersickert, dabei den Boden auslaugt und seine Mineralbestandteile in sich aufnimmt. Ein Teil entweicht vielleicht als Wasserdampf und deponiert die gelösten Bestandteile wieder im Boden, ein anderer findet den Weg zu einer ticferen Stelle des Nils, und das in dem Maße mehr, als der Flußs fällt.

Den Weißen Nil brauchen wir nicht in sein letztes, noch immer umstrittenes Quellgebiet zu verfolgen, um uns seine Zusammensetzung und seine Eigenschaften zu erklären. Wohl ist auch er zunächst ein Bergstrom, der in ungezählten Stromschnellen, Kaskaden, Wasserfällen hinabeilt und auf seinem abenteuerlichen Laufe den Victoria Njansa und ein halbes Dutzend anderer Seen durchfließt. Aber bei Lado, der Hauptstadt der ehemaligen Äquatorialprovinz, tritt or noch unter dem Namen Kivira, Somerset-oder Victoria- $\mathrm{Nil}$ in das ostsudanesische Flachland ein und nimmit dort nach und nach den Charakter an, der ihn später so sehr von dem Blauen Nil und dem Atbara unterscheiden wird. Müde und träge fließt der Strom num zwischen den flachen Ufern nordwärts, bildet Inseln, zersplittert sich in Nebenarmen und Kanälen, bereitet das Sumplgebiet des oberen Nilsystems vor. Die Regenzeit tut das Weitere. Der Strom erfüllt jetzt die breite Niederung mit seinen Wässern, und wenn diese versickert sind, haben sich die berüchtigten Pflanzenbarren neuerdings verdichtet, in ihren Wurzeln noch undurchStrakosch, Erwachende Agrarlander. 
dringlicher verzweigt ${ }^{1}$ ). Der abgeschwellte Fluf muß sich seitlich seinen Abfluß suchen, während sein altes Bett das fiebergeschwängerte Sumpfgebiet wieder vergrößert hat.

Der Weiße Nil, wie er nach der Einmündung des Sobat genannt wird, liann seine Herkunft aus den südlichen Gegenden der Sümpfe und der überreichen Tropenvegetation dann nicht rerleugnen. Die Pflanzenbarren, die seinen Lauf hemmen, halten den Schlamm zurück, den er mit sich geführt hat, und bereichern ihn dafür an organischer Substanz. So durchgesiebt und nur wenig feste Teile enthaltend, kann er um so leichter die Salze in sich lösen, die seine Nebenflüsse, namentlich der Sobat, reichlich mit sich bringen.

Wir begreifen nun die ungleiche Bedeutung der Nilzuflüsse für die ägyptische Landwirtschaft. Der Schlamm des Blauen Nils und des Atbara ist der Schöpfer des Kulturlandes; der Weiße Nil ermöglicht den Bau von Sommerfrüchten. Zur Zeit des niederen Wasserstandes, im Juni oder Juli, wenn das meiste Wasser rom Weißen Nil herstammt, enthält es wohl nur wenig Schlammteile, aber $15-20 \%$ organische Substanz und 0,80\% Stickstoff. Im September, wo der Blaue Nil und der Atbara am Werke sind, findet sich nur $7,9 \%$ organische Substanz und $0,10-0,15^{\circ}$ o Stickstoff ror, und ebenso nimmt jetzt der Gehalt an Phosphorsäure, an Kalk und Kohlensäure ab.

Mackenzie ${ }^{2}$ ) führt folgende Untersuchungsergebnisse über die Menge der festen Bestandteile im Wasser des ägyptischen Nils zu verschiedenen Zeitpunkten an:

In 100000 Gewichtsteilen Wasser waren enthalten feste Bestandteile:

$\begin{array}{lrrrr} & 1896: & 1897: & 1898: & 1899: \\ \text { 15. Juli . . . } & 9,6 & 9,8 & 20,1 & 13,1 \\ \text { 15. August. . } & 96,0 & 163,7 & 186,2 & 112,2 \\ \text { 15. September } & 156,2 & 155,2 & 128,8 & 120,2 \\ \text { 15. Oktober . } & 128,3 & 96,6 & 90,8 & 63,4 \\ \text { 15. November } & 85,9 & 57,5 & 58,0 & 32,8 \\ \text { 15. Dezember } & 58,2 & 32,7 & 42,9 & 13,8\end{array}$

1) Die Pflanzenbarren bestehen bekanntlich aus verflochtenen Wurzeln größerer Wasserpflanzen, wie Papyrus und Ambatsch, die mit kleineren Pflanzen und abgeschwemmter Erde ein undurchuringliches Gewirr bilden und die Schiftahrt im oberen Teile des Nils oft monatelang gänzlich unterbinden.

2) IV. C. Mackenzie, The Nile in Relation to Egyptian Agriculture, Yearbook of the Khedivial Agricultural-Society, Cairo 1905. 
Es ist klar, daß die Wassermenge die Geschwindigkeit des Stromes und diese wieder die Feinheit der Schlammteile und ilure Quantität heeinflubt. Derselben Arbeit Mackenzies entnehme ich die Zusammensetzung des Schlammes während der Hochflut nach einer Analyse von Burns:

In 100000 Gewichtsteilen Nilwasser $1898 \quad 1899$

waren enthalten Gewichtsteile Aug.: Sept.: Okt.: Aug.: Sept.: Okt.:

Schlamm . . . . . . . $186,2 \quad 128,8 \quad 90,8 \quad 112,2 \quad 130,2 \quad 63,4$

Pottasche . . . . . .

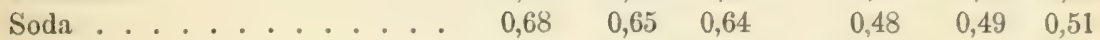

Kalk . . . . . . . . $\quad 3,71 \quad 2,49 \quad 3,64 \quad 3,07 \quad 3,02 \quad 2,68$

Magnesia . . . . . . . 2 2,53 $\quad 2,66 \quad 2,52 \quad 2,76 \quad 2,79 \quad 2,56$

Eisenoxyd und Aluminium. . . $25,69 \quad 24,90 \quad 26,91 \quad 25,44 \quad 26,22 \quad 26,39$

Manganoxyd. . . . . . . . $0,24 \quad 0,28 \quad 0,23 \quad 0,19 \quad 0,28 \quad 0,39$

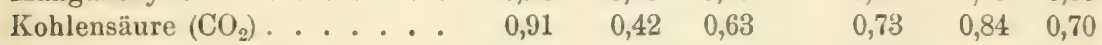

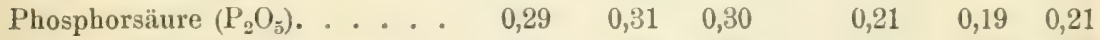

$\begin{array}{rrrrrrr}\text { Organische Substanz. } \cdots \cdots & 8,23 & 8,38 & 8,63 & 9,13 & 9,53 & 9.93\end{array}$

Unlösliche Bestandteile u. Silikate $\quad 57,20 \quad 59,38 \quad 55,92 \quad 57.49 \quad 56,08 \quad 56,14$

Stickstoffgehalt der organisehen

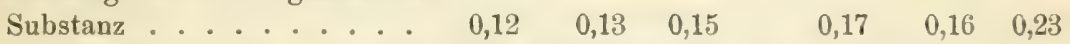

Gelöste Teile enthielt das Nilwasser nach Dr. Letheby ${ }^{2}$ ) in 100000 Gewichtsteilen:

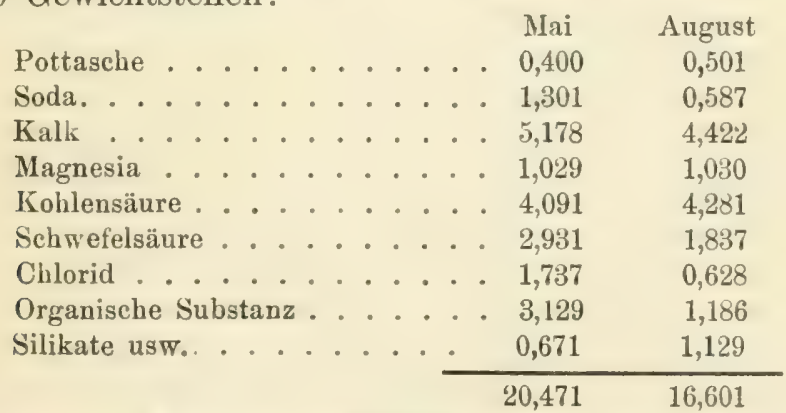

Im Dezember wies das Nilwasser nur 15,26 Teile gelöste Substanzen in 100000 auf, im Juni hingegen, zur Zeit des niedrigsten Wasserstandes, 24,77 Teile und davon 5,61 Chlorsalz. Mit Ausnahme des Maximums im Juni enthält der Nil danach kaum mehr Salze in sich gelöst als andere Flüsse. Man fand z. B. in 100000 Teilen gelöst:

$$
\begin{aligned}
& \text { im Ganges . . 21,66, davon Chlorsalze 0,71, } \\
& \text { im Rhein .... 19,14, " " } 1,42 \text {, } \\
& \text { in der Themse . 28,87, }
\end{aligned}
$$

1) Auch in Mackenzie angeführt. 
Aber diese Flüsse haben nicht dieselbe Aufgabe wie der Nil zu erfüllen. Bei der Bewässerung summieren sich die jährlichen Mengen von Salz ebenso wie der Schlamm und die anderen Bestandteile, die der Nil absetzt, und schließlich könnte das mit der Zeit mehr werden, als die Pflanzen vertiagen. Eine weitsichtige Bewässerungspolitik muß das um so mehr berücksichtigen, als das System der Bewässerung auf die Beschaffenheit der abgesetzten Bestandteile von Einfluß ist. Man weiß ja, daß das ehemalige, willkürliche Überfluten des Landes gelegentlich des Nilaustrittes längst durch wohlorganisierte Wasserausnutzung abgelëst wurde. Dabei kommen zwei Systeme in Betracht: das Bassinsystem und das Kanalsystem, auch "perennierendes", „immerwährendes" genamnt. Jenes ist das ältere, jetzt noch in Oberägypten geübte, dieses das System der Zukunft, das, vom Delta ausgehend, nach und nach in ganz Ägypten Anwendung finden soll.

Das Bassinsystem teilt das ganze Land mittels Dämmen in Bassins, die von Süden nach Norden terrassenförmig abfallen und von 2000 bis 4000 Feddáns umfassen. Jedes Bassin besitzt einen Zufluß- und einen Abzugskanal. Wenn die Hochflut da ist, wird das mit Schlamm gesättigte Nilwasser hineingeleitet. Das Füllen beginnt je nach der Stärke der Flut zwischen dem 10. und 15. August und dauert bis zum 20. oder 25. September. Dann bleibt das Wasser darinnen stehen, bis die festen Teile zu sinken beginnen und das geklärte Wasser so um den Anfang des Oktober in den Strom zurückgeleitet werden kann. Zuerst haben sich die gröberen Teile abgesetzt, später, während die Wassermengen langsam das Becken verlassen, die feineren und feinsten Teile. Nach etwa 29 Tagen ist das Werk vollendet, und jeder Feddán hat, wenn das Bassin ganz gefüllt war, gegen 5000 cbm Wasser erhalten. Beim Einlassen enthielt dieses vielleicht 160 feste Teile in 100000 , jetzt nur noch 49 Teile, oder mit anderen Worten gesagt, jedem Feddán kam eine Schlammdüngung von 10 tons zugute, eine neue $1 \mathrm{~mm}$ starke fruchtbare Schicht überhöht den alten Ackerboden. Dort, wo das Wasser eingetreten ist, hat sich verhältnismäßig leichter, lockerer Boden gebildet, weiter entfernt, an den Sinkstellen der feinen Teile, schwererer, festerer Boden. Und nun überblicken wir unter Vergleichung der früher gegebenen Zusammensetzung des Nilwassers und des Nilschlammes zur Zeit der Hochflut die Bedeutung der Bassinirrigation und finden dabei die Gefahr der Versalzung nicht so groß. Die Über- 
schwemmung durch namhafte und anhaltend wirkende Wassermassen wäscht den Boden auch ein wenig durch, und der Salzgehalt des Nilwassers war überdies zur Zeit der Hochflut am geringsten. Aber anderseits darf nicht übersehen werden, daß die Überflutung nur im Spätherbste tunlich war, und daß eine zweite im Verlaufe desselben Jahres vor der nächsten Nilschwelle nicht mehr denkbar ist. Der Boden hat genug Feuchtigkeit erhalten, um eine Winterernte hervorzubringen; aber die wertvollsten Pflanzen, die Sommergewächse, wie Baumwolle, Zuckerrohr, bleiben ihm ebenso rersagt wie die Möglichkeit, noch ein zweites Mal im Jahre Früchte zu tragen.

Ganz anders liegen die Verhältnisse bei der Kanalbewässerung. Dieses System rerdankt seine Anfänge den Plänen der Ingenieure. die mit Napoleon I. nach Ägypten gekommen waren, und das Delta besitzt schon ron dem Vizekönig Mohamed Ali her ein wohlgeordnetes Netz von Kanälen. Da gibt es stets mit Wasser gefültte Hauptkanäle. Zweigkanäle, die nicht immer Wasser führen, aber jederzeit damit gespeist werden können, und Entleerungskanäle, die in den Salzseen unweit der Küste münden. Sehr weit kam man damals allerdings nicht damit, denn der Sperrdamm bei Kairo, die Barrage du Nil, der das Nilwasser dazu dem Plane gemäß um 3 m über die gewöhnliche Höhe des Wasserspiegels zur Sommerszeit heben sollte, war das nicht imstande. Erst die letzten Jahre, die die Erbauung des Nillreservoirs bei Assuan und der Barrage von Assiut brachten, haben das Kanal. system über ganz Unterägypten ausgebreitet und die Umwandlung der Bassins von Oberägypten in Kanalland in das Bereich der Möglichkeit gerückt. Dabei wird viel Wasser gespart. Beim Bassinsystem braucht man $1 \mathrm{cbm}$ Wasser per Sekunde für 700 Feddán; das Kanalsystem bewässert mit 1 cbm Wasser per Sekunde 8500 Feddán. Sommerfrüchte, die viel Wasser brauchen, z. B. Reis, konnte man früher gar nicht bauen, sie benötigen auch jetzt naturgemäßs ein größeres Wasserquantum. Bei Reisland rechnet man 1 cbm Wasser per Sekunde auf 2000 Feddán. Wo das Kanalsystem schon eingeführt ist, kann man nun das ganze Jahr hindurch nach Belieben bewässern. Die Praxis macht daron etwa zehnmal im Jahre Gebrauch, mit beiläufig 3-40u cbm Wasser per Feddán bei jeder Überstauung. Davon kommen hüchstens viermal auf die Zeit der Hochflut, wo das Nilwasser viel Schlamm mit sich führt, und auch da gelangt nicht viel Schlamm auf das Kulturland, 
weil das Wasser vorher langsam durch neilenlange Kanäle geflossen ist und ihn unterwegs überall abgelagert hat. Die alljährliche Neubelebung des Bodens durch die Nährstoffe des Nilschlammes füllt also fast gänzlich aus, und die Verwendung von Dünger wird unbedingt erforderlich. Aber das ist nicht der einzige Nachteil des Kanalsystems. Seine größte Gefahr bildet vielmehr das Versalzen der Felder. Wir haben oben gesehen, daß der Nil zur Zeit des Tiefstandes sehr viel Chlorsalze enthält. Diese gelangen nun auch auf den Ackerboden. Mackenzie herechnet die Menge gewöhnlichen Salzes, die alljährlich den mit. Kanälen bewässerten Böden zugeführt wird, mit $96 \mathrm{~kg}$ per Feddán. Wenn man bedenkt, daß nur wenige Kulturpflanzen nennenswerte Quantitäten von Salz im Boden ohne Schädigung vertragen, so wird man leicht ermessen, was die jahrelange Ansammlung für Folgen haben muß. Die einzige Hilfe dagegen besteht in der Durchführung einer entsprechenden Durchwaschung und Drainierung, die allerdings Kosten, Aufmerksamkeit und Zeit erfordern. Die Drainröhren werden $1 / 3$ so stark wie die Bewässerungskanäle gewählt; man rechnet auf 10000 Feddán 1 cbm Wasser in der Sekunde, bei Reisland auf 6000 Feddán 1 cbm IVasser. Zu den Vorteilen des Systems darf man es rechnen, daß der Boden mehr Stickstoff als früher erhält, was sich wieder aus dem höheren Gehalt an Stickstoff und organischer stickstoffhaltiger Substanz zur Zeit des niederen Wasserstandes ergibt. Die rorstehenden Analysen lassen den Stickstoffgewinn bei Annahme einer jährlichen Bewässerungsmenge von $4000 \mathrm{cbm}$ mit $3-4$ Pfund pro Feddán berechnen.

Dieser kleine Vorteil wiegt nur leicht neben dem anderen, größeren, der Kontinuität der Bodenkultur. Ein System, das dem Boden unter der verschwenderischen Mithilfe des Klimas ununterbrochene Fruchtbarkeit rerleiht, mubte alle seine Nachteile überwinden lassen und seinem Prinzip die unbedingte Vorherrschaft sichern. Im Jahre 1904 waren denn auch von den $6^{1} \cdot 4$ Millionen Feddán bewässerbaren Bodens bereits 4 Millionen mit Kanalirrigation versehen worden. Von dem Rest entbehrte mehr als der vierte Teil noch jeder Bewässerungsanlage, das übrige wurde mittels Bassins überschwemmt. Nun grünt und blüht der überwiegende Teil des ägyptischen Bodens das ganze Jahr hindurch, trägt im Winter die Früchte des gemäßigten Klimas und im Sommer die Kulturen der Tropen. Dazwischen 
noch Mais und Reis. Das ist das Ereignis der letzten Jalırzehnte, und weil es im weitesten Ausmake erst unlïngst eingetreten ist, so hat es seinen Stempel dem ägyptischen Ackerbau bisher kaum noch aufprägen können. Der Stand der Landwirte ist überall konservativ und wäre in jedem anderen Lande gleichfalls aufierstande gewesen, so gewaltigen Unwälzungen des Betriebes, wie sie der Übergang von der Bassinbewässerung zur Kanalbewässerung mit sich bringt, mit sofortiger, vollkonmener Anpassung zu begegnen. So steckt noch vieles im Übergangsstadium, es fehlt an der Sicherheit, die die langjährige Erfahrung gibt, und an wohlerprobten Methoden.

\section{Die Menschen.}

Dichte und Anwachsen der Bevölkerung. - Das Kanalsystem beeinflußt deren Verteilung. - - Der Fellah als Typus des ägyptischen Ackerbauers. — Sein Leben und seine Nahrung. - Beduinen und ihr Verbältnis zum Fellah. - Eine vermögensrechtlich interessante Entwicklungsform patriarchalischer Gemeinschaft. - Der Beduinensehêch als Großgrundbesitzer. - Andere ägyptische Landwirte und ihr Einfluß auf die Bodenproduktion.

Nach einer Richtung scheint der Fortschritt in Bewässerungswesen indessen seine Wirkung schon geäufert zu haben: Die Bevölkerungszahl wächst rapid. Ägypten ist immer eines der reichbevölkertsten Länder gewesen. Im dichtest bevölkerten Lande Europas, in Belgien, kommen 571 Menschen auf die Quadratmeile, in Ägypten zählte man schon 1897750 Menschen auf derselben Fläche. Die letzten zehn Jahre haben noch ein wesentliches Anwachsen gebracht. Im Jahre 1897 waren es 9,7 Millionen, 1907 11,2 Millionen, ohne Beduinen und Nomaden. Diese außerordentliche Dichte und das rasche Wachstum hängen nicht wie in unseren Ländern mit der Entstehung der Großstädte, mit der Bildung von neuen Arbeitszentren zusammen. Die einzigen Großstädte Ägyptens, Alexandrien und Kairo, haben ihre Bevölkerung in den zehn Jahren um 14,6\% vermehrt; der gesamte Bevölkerungszuwachs Ägyptens macht $15,5 \%$ aus.

Ich stelle den Bevölkerungszahlen der verschiedenen Gourernements, die Firck für das Jahr 1894 brachte, jene vom Jahre 1907 gegenüber $\left.{ }^{1}\right)$.

1) Nach den mir vom ägyptischen Ministerium des Innern zur Verfügung gestellten Daten. 


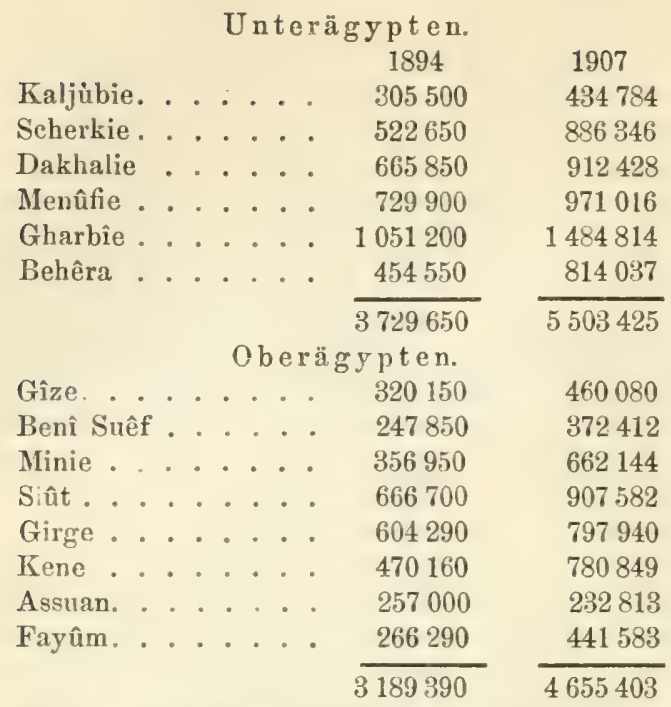

Nach diesen Zahlen hätte sich die Provinzhevölkerung Unterägyptens seit dem Jahre $1894 \mathrm{um} \mathrm{47 \%}$ vermehrt und in Oberägypten um $46 \%$. Das klingt wohl ein wenig unwahrscheinlich, läßt fast an der Richtigkeit der damaligen oder der heutigen Daten zweifeln. Vielleicht sind beide nicht ganz richtig. In einem Lande, das so viel Analphabeten, so viel Nomaden und so viel Menschen besitzt, die ihre einfache Schlammhütte jeden Tag ohne materielle Einbuße abbrechen und an anderer Stelle wieder aufbauen können, sind Volkszählungen nicht leicht durchzuführen. Zudem dehnt sich rechts und links das ungeheuere Wüstengebiet aus, und die Beamten besitzen in Ägypten noch nicht die gleiche Vertrautheit mit statistischen Erhebungen wie bei uns. Ailes will gelernt werden, und die Art der Volkszählung vom Jahre 1907 wurde ron den ägyptischen Zeitungen genug belirittelt. Früher wird es wohl noch schlimmer gewesen sein. Aber eines läßt sich doch mit Sicherheit erkennen: daß eine solche Verdichtung der Provinzberölkerung in diesem Lande ohne nennenswerte Industrie und ohne wesentliche Handels- und Gewerbetätigkeit außerhalb der Städte nur mit der immerwährenden Bewässerung denkbar ist. Nur der Boden, dem mehrere Ernten im Jahre abgerungen werden, kann aus eigener Kraft auch die mehrfache Anzahl von Menschen ernähren. Und so sind die Menschen dem Kanalsystem nachgefolgt wic die Schwärmsporen der Algen 
und Pilze den Lichte. Wo cine Provinz ihre Berölkerung verhältnismäßig weniger rasch vermehrt hat, ist das uniehlbar irgendwie mit der geringeren Ausbreitung der Kanalbewässerung in Zusammenhang zu bringen. Dichte Berölkerung hat von jeher als Zeichen hohei Kultur gegolten; die nene Hochkultur Ägyptens hängt mit der Entwicklung des Kanalsystems eng zusammen.

Es wäre indessen verfehlt, aus der starken Vermehrung der Bevölkerung in den Kanalprovinzen auf eine hesondere Beweglichkeit der Bodenbebauer zu schlieben. Im Gegenteil! Der Fellah hängt nicht an seinem Haus und nicht an seinem geringen Hausrate, er hängt aber an dem Boden, den er bebaut hat. Sachsengängerei, Wanderarbeiter, die wir in Österreich und Deutschland zur Sommerszeit so viel verbreitet finden, gibt es unter den ägyptischen Bauern nicht. Der Ausgleich zwischen Übervölkerung und Arbeitermangel vollzicht sich langsam und schwerfällig. Im Delta, wo die Kanalbewässerung lange besteht, gibt es Überfluß an Leuten, und im Fayûm, wo sie erst jetzt ihre volle Blüte erreicht, fehlen die Arbeiter so sehr, daß der Mangel vielleicht bald zur Kalamität werden wird. Die speziellen Verhältnisse Ägyptens verlangen ja direkt ein überreiches Menschenmaterial und schließen jede weitergehende Anwendung von Maschinen aus.

Es wurde früher das Wort Fellah gebraucht. Wenn man vom ägyptischen Ackerbauer spricht, denkt man unwillkürlich nur an den Fellah. Der Name bedeutet auch so viel wie Pflüger, Ackerbauer. In Ägypten soll es nach der Volkszählung des Jahres 1897 ungefähr 2 Millionen Fellachen geben; aber diese Zahl wurde nicht etwa nach der Abstammung, sondern nach dem Berufe gezählt. Den Ursprung des eigentlichen Fellahs führt man auf die alten Ägypter zurück, speziell auf die ackerbautreibende Kaste der alten Ägypter. Die Reinheit des Volksstammes wird wohl durch die Sklavenwirtschaft des alten Reiches und die zahllosen Einwanderungen längst gelitten haben. Araber, Perser, Griechen, Römer, Türken und andere Völker kamen nacheinander zu Einflu:, und ihr Blut mag sich mit dem der Fellahs gemischt haben, auch das der dunkelfarbigen Vülker Afrikas, vor allem der Nubier und Äthiopier. Aber im Kulturleben der Länder kommt es nicht auf rein anthropologische Begriffe an, sondern auf die Eignung der Menschen, sich den vorhandenen Bedingungen gut anzupassen, sie auszunützen und weiterzubilden. Diese Eignung 
wird nicht nur durch angeborene Fähigkeiten hervorgebracht, sondern ebenso durch den Zwang der Notwendigkeit, die Gewohnheit, das Beispiel. Gleiche Schicksale und gleiche Umgebung haben darum eine merkwürdig ausgleichende Kraft. In Ägypten haben sie den Typus des Fellahs geschaffen, der zumindest heute kaum als anthropologischer Begriff, sondern als Repräsentant einer Berufsklasse - des ägyptischen Ackerbauer's - aufzufassen ist. Das entschuldigt das summarische Vorgehen der Behörden bei der Volkszählung. Neben dem Fellah im eigentlichen Sinne, dessen mehr oder weniger große Stammesreinheit wir hier nicht weiter zu prüfen haben, enthält die Berufsklasse der ägyptischen Ackerbauer noch Kopten, seßhaft gewordene Beduinen und Nubier.

Von diesen sind die eigentlichen Fellahs zweifelsohne das wertvollste Element. Es hat niemals einen leidenschaftlicheren Ackerbauer gegeben als den Fellah. Alle Unterdrückung rergangener Jahrhunderte, der hohe Pachtzins, die schweren, früher ungerecht verteilten Steuern haben ihm die Freude an seinem Berufe nicht vergällen können. Die Arbeit ist bei der großen Hitze doppelt hart, die Sonne brennt, aber unermüdlich ist der Fellah am Felde tätig, schöpft dort, wo die Bewässerung nicht ausreicht, in wahrer Sisyphusarbeit mittels der Schadufs, der uralten Ziehbrumnen Wasser auf seine Saaten oder dreht mit seinen Zugtieren den Sâkîje, das ebenso ehrwürdige, knarrende Wasserhubrad im Kreise herum. Dabei ist der Fellah noch heiter und lustig, namentlich in der jüngeren Generation manchmal ron beneidenswerter, ausgelassener Lustigkeit. Seine Art zu arbeiten ist ja nicht gerade sehr ökonomisch zu nennen. Es ist das Schicksal aller südlichen Tölker, ihre Arbeitsökonomie nicht recht ausbilden zu können. Die Unkenntnis des Zeitrertes ist auch dem grebildeten Orientalen eigentümlich und führt im weiteren zu eincr Verschwendung der Kräfte. Stöße, die rasch nacheinander wiederholt werden, summieren sich, einzeln, in langen Pausen ausgeführt geht die Gesamtwirkung nicht über die Wirkung des einzelnen Stoßes hinaus. Das ist auf rein geistigem Gebiete ebenso der Fall wie auf körperlichem. Ins Leben der Völker übertragen bedeutet die Ausbildung der Arbeitsökonomie deshalh einen gewaltigen Vorsprung, ein gewichtiges Machtmittel. Das Beispiel hoher Arbeitsökonomie zeigt uns England; das Gegenteil solcher setzt den Orientalen im Kampf ums Dasein gegen alle nördlichen Völker in Nachteil. Der Fellah hat auch seinen Teil von dieser 
Eigenschaft abbekommen. Er rennt und läuft, schreit und gestikuliert von früh his spät herum. Aher die geleistete Arbeit steht in keinem rechten Verhältnis zu den Aufwande, den sie beansprucht. Um eine notwendige Verrichtung zu machen, hat er viele unnötige vollfülırt, alle Muskeln spielen lassen, wo ein richtiger Griff genügt hätte. Vielleicht ist's nicht überall gerade so, aber ähnlich sicherlich. Deshalh braucht die ägyptische Landwirtschaft viel Arbeitermaterial, und der WVert des Arbeitstages bleibt gering. Er wird noch geringer, wenn der Fellah nicht für sich, sondern für seinen Herrn arheitet. "Die Welt ist noch kalt, Herr," sagt er in der Früh und fängt deshalb spät mit der Arbeit an, und um 3 oder 4 Uhr nachmittags bereitet er sich wieder in astronomisch sehr unrichtiger Weise auf den bevorstehenden Sonnenuntergang vor, der dem Muselmann das Ende des Arbeitstages bedeutet. Der Fellah hat aber auch noch weitere gute Eigenschaften: freundliches IVesen, Verläßlichkeit, unbedingte Ehrlichkeit. Diebstahl kommt äuferst selten vor. Von Natur aus friedfertig und harmlos, ist der Fellah seinen Vorgesetzten gegenüber folgsam, beinahe unterwürfig. Früher galt er für besonders konservativ. Firck sagt in seinem bereits zitierten Werke: „Überhaupt enthält er sich jedes Nachdenkens über Verbesserungen in der Art seiner Arbeit und arbeitet nur gerade so viel, wie unumgänglich notwendig ist, da er aus Erfahrung weil, daß er wegen der hohen Besteuerung und Grundpacht keine Ersparnisse zurücklegen kann." Und an anderer Stelle: „Die Fellahs sind in jüngeren Jahren munter und anstellig, verlieren jedoch infolge ihrer eintönigen Lebensweise und schweren Arbeit sowie der unter ihnen herrschenden Not in höherem Alter ihre geistige Frische und werden dann gleichgültig gegen alle äußeren Vorkommnisse... Die Überlieferung von Jahrtausenden hat die Fellachen jeder Hoffnung beraubt, dak ihr Los ein besseres, ihr Iceben ein minder mühseliges, ihr geringes Besitztum ein auskömmlicheres werden könne, und die fatalistische Lehre des Islam, nach welcher, was geschieht, unabänderlich vorher bestimmt ist, hat sie darin bestärkt, alles, auch die härteste Bedrückung, die ungerechteste Behandlung widerstandslos über sich ergehen zu lassen." Es scheint, daß dies heute nicht mehr ganz stimmt, daß die letzten Jahre auch darin Wandel geschaffen haben. Wie wir später sehen werden, liann gegenwärtig von einer Unterdrückung durch ungerechte Steuerverteilung nicht mehr die Rede sein, und die wirt- 
schaftliche Lage des Fellahs ist ebenfalls nicht mehr so trostlos, da mit der Ursache auch die Folgen geschwunden sind. Die Alten sind natürlich auch bei den Fellahs weniger übermütig, weniger unternehmend und regsam als die Jungen. Das ist bei unseren Bauern nicht anders und bei den übrigen Ständen auch nicht. Aber gar so apathisch ist der alte Fellah nicht und kaum gleichgültiger gegen den Fortschritt als der europäische Bauer. In manchem Kopfe mag es auch dort zu dämmern beginnen. Prinz Hussein, der nicht nur ein Sohn des großen Khédive Ismael ist, sondern auch selbst eine bedeutende Persönlichkeit und einer der größten und tätigsten Landwirte Ägyptens, weiß mir davon zu erzählen, wie der Fellah den Belehrungen nicht mehr so fremd gegenübersteht, aber auch nicht mehr so blind unterwürfig und gehorsam ist als früher. Leider, leider, fügt der hohe Herr hinzu und spricht vom abendländischen Sozialismus, der nun seine Schatten auch hier vorauswerfe. Und Mister Fohden, der Engländer, der Generalsekretär der Khédivialgesellschaft, äußert sich wieder von einem anderen Standpunkte darüber: "Der Kunstdüngerbedarf steigt, die Äcker werden ertragreicher. Der Fellah hat sein Mißtrauen gegen die Exposituren der Khédivialgesellschaft aufgegeben, erkennt ihren wohltätigen Einfluß auf die Wertsteigerung seiner Arbeit. Er erkennt dic Bedeutung der Schulen, ist froh, seine Kinder etwas lernen lassen zu können."

So haben der Fortschritt und die Aufklärung zu allen Zeiten und allerorter begonnen. Man steht noch mit beiden Füßen in der Vergangenheit, aber die Gegenwart lugt bereits zu jeder Spalte herein.

Nur in bezug auf die Bedürfnisse zeigen sich noch nicht die kleinsten Anzeichen einer Änderung. Der Fellah ist unglaublich bedürfnislos geblieben. Nach wie vor baut er sein Haus aus getrocknetem Nilschlanm auf, deckt es notdürftig mit ein paar Matten aus Maisstroh, mit Schilf oder Baumwollstroh. Der Luxus der Fensterscheiben ist wenig rerbreitet. Möbcl gibt es keine, höchstens ein selbstgefertigtes Bettgestell aus Palmenrippen oder eine solche Matte. Mist, in flache Kuchen geformt und an den Außenwänden der Hütten getrocknet, dient als Feuerungsmaterial. Für die Bekleidung gibt man auch wenig aus. Bei der Arbeit geht der Fellah fast nackt und trägt selten mehr als ein um die Hüften geschlungenes Tuch. Kupfer-, Silber-, Goldringe, Goldmünzen, mit denen er seine Weiber zu schmücken liebt, bilden 
vielleicht die einzige größere Ausgabepost in Budget. Ein wahrer Künstler ist der Fellah in der Ökonomic der Nahrung. Zu jeder Jahreszeit weif er stets die Nahrungsmittel ausfindig zu machen, die seinen Magen am billigsten füllen. Ein Kaufmann in Alexandrien sicherte seinem Tabak dadurch Ahsatz, daß er behauptete, das Rauchen davon stille den Hunger. Der Fellah kennt ausser Kaffee kein anderes Getränk als Wasser, und da zieht er das dicke, schlammige Nilwasser der Hochflut jedem anderen vor, weil es nahrhafter wäre. Herr Rothacker, der die Nahrungsmittel des Fcllah durch seine berufliche Tätigkeit wohl kennen gelernt hat, gibt als hauptsächlichste an:

1. Datteln. Man unterscheidet gegen 100 verschiedene Arten daron. Unter dicsen solche, die frisch genossen werden, andere, die vorher getrocknet werden müssen. Der Fellah iBt selbstgezogene Datteln, Datteln aus den Oasen und DatteIn aus dem Persischen Golf, die zusammengestampft in Mlatten versandt werden;

2. Früchte, vor allem Kürbisse, die überall gezogen werden, und Wassermelonen, die zur Zeit des niederen Wasserstandes in dem Teil des Nilbettes selbst gebaut werden; wo das Wasser gerade zurückgetreten ist. In guten Obstjahren, wenn Äpfel und Birnen in Europa billig sind, werden selbst diese importiert. Aus Singapore kommen Ananasschnitzel in Büchsen zu 1 Piaster?

3. alle möglichen selbstgebauten Gemüse, die mit Fladen aus Mais oder Durramehl verzehrt werden. Im Sommer namentlich viel Gurken. Dem Brot wird oftmals Bohnenmehl beigemischt. Weizenbrot genießen nur die wohlhabenderen Fellahs;

4. B o hn en gekocht und mit Lein- oder Sesamöl angemacht;

๖. Reis und zwar meist hinterindischer und solcher aus Birma, da der feinere, ägyptische Reis seines höheren Preises halber exportiert wird;

6. Fische, frisch und getrocknet aus den ägyptischen Salzseen. Dann: geräucherte Heringe und Stockfische, ordinäre Ölsardinen aus Spanien.

7. Eine große Rolle spielt der Milchgenuß, namentlich ron Büffelkühen, von Ziegen und Schafen. Der Fellah bereitet aucn eine Art Käse daraus.

8. Zuckerrohr. Dieses wird roh genossen, dann auch der eingedickte Saft davon. Die Araber gewinnen den Saft zwischen Mühlsteinen, kochen ihn in offenen Kesseln ein und verkaufen 
das Produkt als Honig ( $\ddot{A} s z a l$ ) in Tontöpfen. Trotz der primitiven Arbeitsweise, die 4-5\% Zucker in den Rückständen läßt, be. deutet diese Hausindustrie eine gefährliche Konkurrenz für die ägyptischen Zuckerfabriken, weil sie ohne jede Regie arbeitet und die eigene Arbeit äußerst gering bewertet.

9. Fleisch wurde früher nur am Beiramfest und im Monate Pamadân genossen; jetzt soll der Fleischgenuß auch unter den Fellahs zunehmen.

Das Menü des Fellah ist, wie man sieht, ebenso anspruchslos geblieben wie alle übrigen Lebensgewohnheiten. Die Bedürfnisse steigen nicht wie anderswo, und das Tempo des allgemeinen, kulturellen Aufschwunges wird dadurch zurückgehalten; fehlt doch eine wichtige Triebfeder zu erhöhter Tätigkeit: der Anreiz zu intensiverer Ausnützung von Boden und Arbeitskraft.

Die Ersparnisse, welche die Gunst der Verhältnisse den Fellah in den letzten Jahren machen ließ, kommen nicht im Wege der Konsumtion der ägyptischen Volkswirtschaft und damit wieder dem Fellah selbst zugute. Sie werden auch nicht zu Meliorationen benützt oder in die Kanäle des Verkehrs geleitet, indem man sie etwa Zinsen tragend anlegt. Geld gegen Zinsen verleihen ist nach den Anschauungen des Mohammedanismus verächtlich. Der Viehstand kann bei dem Mangel an natürlichen Weiden auch nur in beschränktem Maße rermehrt werden, obwohl ein jeder seine Büffelkuh oder wenigstens seine Ziege sein Eigen nennen will, der besser Situierte wohl auch ein Kamel, ein oder zwei Esel. Vielleicht legt man sich noch einige ron den Dünger gebenden Tauben zu, oder von den Hühnern, die dort so unwahrscheinlich kleine Eier legen. Aher sonst gibt es nur eine Art, zu Ansehen und Würde zu gelangen: die Tergrößerung des Bodenbesitzes. Und so erklärt es sich, daß der Anteil der kleinen und kleinsten Bodenbesitzer in den letzten Jahren so rasch gestiegen ist - der überzeugendste Beweis, daß die Not und sprichwörtlich gewordene Bedrängnis des Fellahs ihr Ende erreicht hat.

Er ist reicher geworden, aber die Art, wie das Erworbene angelegt wird, bringt es mit sich, daß hieraus keine größere Intensität des landwirtschaftlichen Betriebes entstehen konnte.

Ein rechtes Kreuz erwächst dem armen Fellah aus der Nachbarschaft der Beduinen. Die Bücher über Ägypten sind meist voll des Lobes über dieses ritterliche Volk, dessen stolzer Sinn dem armseligen Wesen des Ackerbauers gegenübergestellt wird. 
Die Erfahrungen der Herren Heller im Fayûn stehen dazu im rechten Widerspruch. Sie hatten sich an einem Orte angckauft, der damals noch keine Bahnverbindung besaß und mühselig auf Wüstenwegen zu erreichen war. Gleich die erste Nacht nach der Besiedlung war einer der mitgehrachten Esel gestohlen worden. Den nïchsten Tag kam ein Beduine und versprach gegen Zahlung. von 2 Pfund, das Versteck des Esels zu verraten. Die Energie der Hellers brachte den Esel auch ohne Lösegeld zur Stelle und wußte weiteren Versuchen, auf ähnliche Weise eine Art Steuer zu erpressen, ein Ende zu machen. Aber der Fellah ist solchen Schlichen nicht gewachsen. Gewöhnlich treibt ihn schon die Angst vor dem Militärdienst in ein gewisses Ablängigkeitsverhältnis $\mathrm{zu}$ den Beduinen. Die genießen das Vorrecht, im Frieden vom Militärdienst befreit zu sein, und stellen dem Khédive nur im Kriegsfalle Reiter bei. Der Fellah, der nicht zum Militär will, läßt sich also unter die Verwandtschaft der Beduinen zählen und muß dafür mit diesen seine Ernte teilen. Aber auch sonst weif der Beduine sich rechtzeitig einzufinden, wenn der Fellah die mühselig eingeheimste Ernte zu Markte bringt. Gibt er dann nicht gutwillig davon her, so kann er sicher sein, daß ihm demnächst eine Kuh aus dem Stall gestohlen oder sonst etwas angetan werden wird. Und das nächste Gericht ist weit, und wenn der Geschädigte auch schwören wollte, wie er es selbst gesehen, daf der und der Beduine seine Kuh aus dem Stall gezogen hat, so finden sich immer Gegenzeugen, natürlich auch Beduinen, die das Gegenteil beschwören werden. Zwei ägyptische Sprichwörter kennzeichnen trefflich die dortige Meinung über die Beduinen. Das eine lautet: „Besser die Tyrannei des Türken als die Gerechtigkeit des Beduinen." Das andere: „Bewirte den Beduinen, er wird dir deine Kleider stehlen."

Die seßhaft gewordenen, ackerbautreibenden Beduinen, die in geschlossenen Dörfern beisammen wohnen, stehen gerade so wie die nomadisierenden unter ihren erblichen Schêchs. Die groß̧e Autorität, welche diese besitzen, und das patriarchalische Verhältnis unter den Stammesgenossen, läßt alle Macht und allen Besitz in die Hände des Schêchs übergehen. Der verfügt über das oft reiche Eigentum des Stammes und kauft Grund und Boden, den er von den übrigen bebauen läßt. Über die Art und Weise, in der der Ertrag geteilt wird, gibt keine der mir zugängigen Schriften Auskunft. Herr Heller versichert mir, daß der Schêch 
die Leute zumeist mit Naturalien, Kleidern und den anderen Dingen beteile, die sie zu ihrer bescheidenen Lebensführung benötigen, mit Geld nur in geringem Ausmaße. An eine Aufteilung des Gewinnes oder an ein Rechnunglegen werde nicht im entferntesten gedacht. Im Falle der Minderjährigkeit des Nachfolgers geht das absolute Regiment einstweilen auf zwei angesehene Beduinen über.

Die ackerbautreibenden Beduinen bilden so eine vermögensrechtlich interessante Entwicklungsform patriarchalischer Gemeinschaft. Ihr durch den Schêch repräsenticrter Besitz ist eigentlich dem Großgrundbesitz zuzuzählen. Der Schêch Hamed Bey Bassal, der im Fayûm 56000 Beduinen unter sich hat, besa schon im Jahre 1907 nicht weniger als 5000 Feddán Ackerland, als er von den Heller's noch deren anstoßendes Gut im Ausmaße von 2150 Feddán dazu erwarb. Die hatten sich nach und nach bei ihren Nachbarn, den Beduinen, so weit in Respekt zu setzen gewußt, daß das Zusammenleben ein recht leidliches genannt werden konnte. Man tauschte regelmäbig Höflichkeitsbesuche mit dem Schêch aus, und dieser wurde europäischer Kultur bald so zugänglich, dak er in Begleitung seines Dieners eine Reise nach Paris unternahm, die recht vergnüglich verlaufen sein soll. Die Hellers zogen es aber schließlich doch vor, ihr Getreide anderswo zu bauen. Zuletzt hatte ein Beduinenarbeiter mit der Hälfte des anvertrauten Saatgutes das Weite gesucht, und der Aufseher hatte ihn kurzerhand erschossen. Das hatte das Maßs voll gemacht.

Später lernte ich den Schêch Hamed Bey Bassal, einen Mann von einigen 40 Jahren im Bureau des Konsul Heller persönlich kennen, als er nach Kairo kam, um eine Änderung dex Iaufbedingungen zu erwirken. Laut Vereinbarung waren von dem $3 \frac{1}{2}$ Millionen Franken betragenden Kaufpreise 1,9 Millionen bar erlegt worden, der Rest sollte in fünf Jahresraten beglichen und mit $5 \%$ pro Jahr verzinst werden. Konsul Heller verblieb dagegen das sogenannte "Privilége du vendeur", d. h. ein Pfandrecht auf das ganze Gut bis zur Begleichung der letzten Rate. Laut Kontrakt wurde bei Nichtzahlung einer Rate der ganze Rest mit $6^{0} 0$ Zinsen drei Monate nach Fälligkeit dieser nichtbezahlten Rate fällig, während ein gleichzeitig einzuholender Gerichtsbeschluf die sofortige Sequestrierung zur Folge gehabt hätte.

Unterdessen war die große Krisis in Ägypten ausgebrochen. Der Schêch konnte das nötige bare Geld nicht auftreiben und war 
froh, einer Zwangsversteigerung durch folgenden Vergleich entgehen zu können: Er erlegte toun ägyptische Pfund sofort und verpflichtete sich, den Rest des Kaufschillings in zehn Jahresraten unter Berechnung ron ; $^{0}$ o Zinsen zu zahlen. Bis zur vollständigen Tilgung hatte die Schuld anf dem gesamten Bodenbesitz des Stammes hypotheciert zu bleiben.

Wo Beduinen nicht unter ihresgleichen wohnen, für eigene Rechnung Ackerbau treiben oder bei Grundbesitzern Arbeit nehmen, sind sie gewöhnlich nicht ganz rassenrein und mit dem Fellah irgendwie blutsverwandt oder verschwägert. Dann haben sich auch die ursprünglichen Eigenschaften abgeschliffen; der Charakter hat mehr den Fellahtypus angenommen, mit dessen Tugenden und Lastern. Aber der Gutshesitzer oder der Aufseher wird in der Behandlung immer einen gewissen Unterschied machen; denn er weiß genau, daß das größere Selbstgefühl bei aller zur Schau getragenen Unterwürfigkeit doch gelegentlich zum Ausdruck kommen wird. Der Kampfesmut, der auch bei den echten Beduinen meist nur Schwächern gegenüber zutage tritt und unter lem sicheren Gefühl, mit anderen in größerer Zahl geeint zu sein, setzt sich hier in eine gewisse Frechheit um. Die drückt ja oft auch anderswo den Mut des Feigen aus.

Die Kopten, bekanntlich die christlichen Nachliommen dev alten Ägypter, sollen die gleiche Abstammung reiner wie die Fellachen hewahrt haben. Das gilt wohl mehr für die Bewohner der Städte als für die dunkelfarbigeren koptischen Ackerbauer in Oherägypten. Dort sind sie von den Fellahs kaum zu unterscheiden, höchstens durch die Unmäßigkeit im Trinken, das ihr Glaube nicht verbietet. Eine angebliche Begabung für das Rechenwesen weist den Kopten in den größeren Landwirtschaftsbetrieben vielfach Verwaltungsstellen zu.

Von den übrigen Bodenbebauern kommen ihrer grölßeren Zahl halber noch die Nubier oder Berberiner in Betracht. Nan lemt dieses schwarze Mischvolk von Negern und Semiten üherall in Ägypten als Diener und Kellner, als Natrosen auf den Nildampfern und in ähnlichen bescheidenen Stellungen kennen und jch möchte beinahe sagen lieben. Es sind bescheidene, anstellige und ehrliche Leute, vor denen man Kasten und Koffer nicht ¿ u versperren braucht. In ihrer eigentlichen Heimat, im Niltale südlich von Assuan, sind sie Ackerbauer, die es aber, nach dem was man hier von Bodenbestellung sieht, nicht in entferntesten 
mit der Geschicklichkeit der Fellahs aufnehmen können. Freilich, der Boden ist recht armselig und das Fruchtland oft nur meterbreit. Dahinter dehnt sich das felsige Gestein und tritt mitunter dicht an den Nil heran. Mein Freund, der Nubier Kalil, besitzt dort, nicht weit ron Abu Simbel, ein paar Quadratmeter Ackerland mit einigen Dattelpalmen und eine Lehmhütte am Rande der Wüste, worin seine zwei Weiber und seine Kinder hausen. Die armselige Erde trägt zu wenig, um davon leben zu können, und da geht er, wie so viele seiner Landsleute, auf den Nildampfer und kehrt erst im Frühjahr mit seinen Ersparnissen und cinem Sack Getroide zurück. Davon wird er friedlich mit den Seinen den Sommer über zehren und Fische im Nil fangen und warten, bis die Nilflut die eine Ernte im Jahr gewährt. Sie wird auch künftighin nur mager ausfallen, aber Kalil geht ja wieder auf das Schift. Und wenn der Fremdenverkehr rege ist und Kalil viel Backschisch bekommt, damn will er sich einen schönen arabischen Burnus kaufen, den blauen Turban des Mekkapilgers und eine dritte Frau. Aus diesen lindlichen Menschen werden wohl niemals tüchtige Ackerbauer werden, wie diese Gegend für die Bodenproduktion Ägyptens niemals Bedeutung erlangen kann.

Unter den Eigentümern ausgedehnter Ländereien gibt es Türken, Araber und Europäer. Die Türken und Araber nehmen keinen nennenswerten Einfluß auf die Gestaltung des landwirtschaftlichen Betriebes. Oder besser gesagt, sie nehmen einen Einfluß, allerdings einen negativen Einfluf darauf, indem sie alles den eingeborenen Verwaltern überlassen und ihre höhere Intelligenz nur selten in den Dienst der Sache stellen ${ }^{1}$ ). Die wenigen,

1) Nach Vollendung des Kapitels kommt mir das eben erschienene interessante Werk Lord Cromers: "Das heutige Ägypten" zu. Lebhaft bedauernd, daß die räumlichen Grenzen, welche dieser Studie gezogen sind, eine eingehende Benützung der Cromerschen Ausführungen über die Bevölkerung nicht gestatten, kann ich mir doch nicht versagen, an dieser Stelle einige charakteristische Bemerkungen zu zitieren. Über das Wesen der Orientalen im allgemeinen heißt es da: "Der Geist des Orientalen entbehrt wie seine malerisehen Straßen des Ebenmaßes. Seine Gedankenfolgen sind unordentlicher Art. Obwohl die alten Araber sich bis zu einem ziemlich hohen Grade die Wissenschaft der Dialektik aneigneten, sind ihre Nachkommen auffallend mangelhaft in bezug auf Logik begabt." Dann: „Man vergleiche diese Eigenschaften des Eurcpäers (Organisationstalent, Willensstärke, Neigung, Handlungen seiner Vorgesetzten zu kritisieren) mit den schwachen organisatorischen Fähigkeiten des Orientalen, mit seinem, das Unvermeidliche ruhig hinnehmenden Fatalismus und 
die es anders halten, wird man, einerlei ob Araber, Türken oder andere Nationen, wohl der europäischen Kultursphäre zuzählen müssen. Thr Einfluß und ihr Beispiel haben bisher den Charakter der ägyptischen Landwirtschaft nicht grundlegend geäindert, nur die Aussichten für die künftige Entwicklung vermelıt.

mit seiner Unterwürfigkeit gegen jede eingesetzte Obrigkeit." Hingegren rühmt er: „Wenn man einem Ägypter einmal klargemacht hat, was er tun soll, wird er sich den Gedanken schnell zu eigen machen. Er ist cin guter Nachahmer und wird eine treue, manchmal sogar eine zu sklavische Kopie der Arbeit seines europäischen Lehrers liefern." Auf' den 'Turko-Ägypter ist Cromer nicht gut zu sprechen. Immerhin läßt er auch einige gute Eigenschaften gelten: „Der Zauber einer Herrscherrasse umschwebt noch sein Haupt, wenn auch ein sehr matter. Er ist sicherlich nicht mehr verderbt als der Ägypter; er ist männlicher, und je größer der Zusatz türkischen Blutes ist, der in seinen Adern fließt, desto männlicher sind seine Eigenschaften. Er ist manchmal in seiner Art wahrhaftig und offenherzig. Er hat einen rauhen Ehrenkodex. Man kann in Ägypten hingehen, wohin man will, aber wenn irgendein Stück Verwaltungsarbeit, das eine gewisse Energie erforderte, von einem eingeborenen Beamten gut ausgeführt worden ist, so wird man meist finden, daß der betreffende Beamte ein Tscherkesse oder ein Turko- $\ddot{A}$ gypter ist, der wahrscheinlich mehr Türke als Ägypter ist." 


\section{Drittes Kapitel.}

\section{Die politischen Voraussetzungen der ägyptisehen Landwirtschaft.}

\section{Agrarverfassung.}

Agrarverfassung zu Anfang des XIX. Jahrhunderts. - Ouchouri- und KharadjiLänder. - Die Reformen Méhémed Alis. - Ismail Paschas Geldknappheit bringt die Freiheit des Bodens und eine glücklichere Veıteilung des Grundbesitzes. Die Grundsteuerregelung des Jahres 1899 leitet die Wielergeburt der ägyptischen Landwirtschaft ein. - Abschaffung des Frondienstes. - Vermehrung der produktiven Fläche. - Verwaltung und Liquidation der Domänen. Der Boden kehrt in die Hände der Fellahs zurück. - Einfluß des mohammedanischen Erb. gesetzes auf die Landwirtschaft.

Zu Anfang des XIX. Jahrhunderts lag die Landwirtschaft in Ägypten arg darnieder. Aller Bodenbesitz war damals wie seit alters her noch Eigentum des Landesherrn und scine Nutzung an die Zahlung des Zehnt oder eines Tributs gebunden. Zu den Zehntländereien (Ouchouri), die geringfügige Abgaben zu leisten hatten, gehörten einige Güter besonders bevorzugter Günstlinge, der überwiegende Teil alles Bodens hingegen wurde den tributpflichtigen Ländereien (Kharadji) zugezählt. Die hatten die Herrscher seit Generationen immer als unerschöpfliche Melkkuh betrachtet und möglichst gründlich auszunützen gesucht. Erbliche Generalpächter waren mit dem Eintreiben von Grundrente und Steuern betraut und gaben ihren berüchtigten französischen Kollegen des XVIII. Jahrhunderts in der Kunst der Volksaussaugung nichts nach. Der Bauer aber, das Opfer des Raubsystems, übertrug dieses wieder auf den Boden, der ihm ohnedies nicht gehörte, vielleicht morgen schon genommen werden konnte. So hatte man's im Laufe der Zeiten glücklich dahin gebracht, daß die Bewässerungsanlagen und Kanäle verfielen und weite Strecken einst fruchtbaren Landes zur Wüste wurden. 
Méhẻmed Ali, dem Gründer der Dynastie, gebührt das Verdienst, die Unhaltbarkeit solcher Zustände erkannt und die wirtschaftliche und soziale Wiedergeburt der ägyptischen Landwirtschaft durch eine Reihe von Reformen eingeleitet zu haben. Bis dahin hatten die Gemeinden den Boden gemeinsam bebaut, nun sollte an die Stelle der Gemeinsamkeit das persönliche Interesse des einzelnen treten. Das ganze Land wurde neu vermessen (1813), und jedem grofjjährigen Bauern wurden 3-4 Feddán Bodens zugeteilt, nicht als Eigentum, aber doch als grundbücherlich gesichertes Pachtgut auf Lebenszeit, das mehr als bisher der Willkür ungerechter Steuerverteilung durch Einreihung in eine von drei Bodenklassen entrückt war. Die ganze Ernte wurde dem Fellah um einen, von der Regierung festgesetzten Preis abgekauft, dem Bauer genau vorgeschrieben, wieviel Getreide, Baumwolle usw. er zu bauen hatte. $\mathrm{Zu}$ gleicher Zeit vermehrten umfangreiche Damm- und Kanalanlagen wieder den kulturfähigen Boden.

Viele dieser Maßnahmen, besonders die Nötigung an den Staat zu verkaufen, und die grundsätzlich beibehaltene Vereinigung des Grundeigentums in der Hand des Herrschers, haben in der Geschichte eine abfällige Beurteilung gefunden, während sie doch von hoher staatsmännischer Klugheit zeugen. Es wäre damals ganz aussichtslos gewesen, die herabgekommene Landwirtschaft durch den Fleißs und die Initiative der Bauern allein emporheben $\mathrm{zu}$ wollen. Das wiedererweckte persönliche Interesse des Fellah war eine schätzenswerte Mithilfe; die besonderen Verhältnisse Ägyptens erforderten aber das Vorgehen nach einem einheitlichen Plane, erforderten weitsichtigere, umfassendere Ideen, als man vom Fellah erwarten durfte. Wer die Landwirtschaft Ägyptens wiedererwecken wollte, mußte zunächst politisch und ökonomisch Herr des Landes bleiben.

Seit dem Jahre 1833 konnte der Fellah sein Getreide wieder frei verkaufen und mußte nur die Steuern in Gestalt dieses abstatten. 1854 verordnete ein Gesetz dann die Erblichkeit des Nutznießungsrechtes am Boden, und ein paar Jahre später durfte dieses auch verkauft und verpachtet, sogar hypothekarisch belastet werden. Damit war das Privateigentum an Grund und Boden wohl nicht dem Wortlaute, aber dem Sinne nach proklamiert.

Wirtschaftlicher Vorteil erwuchs dem Lande vorerst keiner daraus, eher das Gegenteil. Das Abgehen von der ursprünglichen Idee des unbedingten Thronrechtes auf den Boden führte dazu, 
ausgedehnte Länderstrecken in Ouchouri zu verwandeln und einzelnen Günstlingen zu überlassen, während die ganze Steuerlast nun auf einem immer kleiner werdenden Kreise von KharadjiLändereien ruhte. Das eine wie das andere, die Bildung von großen Domänen wie die Überlastung des kleinen Landbesitzes, stand der Entwicklung der Landwirtschaft entgegen. Die primitive Kunst des Ackerbaues reichte gerade zur Not für das Bewirtschaften eines kleinen Bauerngutes aus, der größeren Aufgabe gegenüber, große Domänen zu leiten, mußte sie vollkommen versagen. Der Fellah wieder sah sich unter dem Drucke der Steuern und der Fronarbeiten genötigt, von dem Danaergeschenk der erlaubten hypothekarischen Belastung Gebrauch zu machen. Dort Riesenbesitztümer, die fast wertlos waren, weil sie niemand ausnützen konnte, hier unter der Last der Hypothekenzinsen zusammenbrechende Kleinwirtschaft, das war das Bild der ägyptischen Landwirtschaft zu Beginn der zweiten Hülfte des XIX. Jahrhunderts.

Von 1861 an durften Europäer in Ägypten Kharadji-Länder erwerben. Das Gesetz über die Mokabala, das der Geldknappheit des Khédive Ismail Pascha seinen Ursprung dankte, brachte dann vollkommene Freiheit des Bodens. Jetzt konnte jeder, der seine Steuern auf sechs Jahre vorausbezahlte, das unumschränkte Eigentum seines Bodens erwerben.

Ismail Pascha hat der Landwirtschaft Ägyptens durch dieses Gesetz vielleicht einen Dienst erwiesen. Mehr genützt hat er ihr aber zweifelsohne durch die großartigen Entsumpfungsarbeiten, durch die Kanal- und Eisenbahnbaten und am meisten durch etwas, was er gar nicht beabsichtigte: durch eine glücklichere Verteilung des Grundbesitzes. Zu Ende der Regierung Ismael Paschas zwang die wachsende Finanznot diesen, einen Teil der Domänen zu konfiszieren, um eine Unterlage für aufzunehmende Anleihen zu gewinnen. Auch der Khédive trat seinen Grundbesitz an den überschuldeten Staat $a b$, wie alle Prinzen und Prinzessinnen des vizeköniglichen Hauses. An Stelle der Latifundienwirtschaft traten die Liquidatoren der Anleihen, die den Boden an jene verkauften, die am meisten dafür zahlen konnten. - Das waren aber, aus den früher angeführten Gründen nicht die großen Landbesitzer, sondern die kleinen Bauern, die ihr Land selbst bewirtschafteten. Von den Grundstücken, die im Besitze des Staates gellieben waren, ging ein Teil gleichfalls aus denselben Ursachen denselben Weg. 
So waren die Voraussetzungen der ägyptischen Landwirt-chaft. zu Ende des XIX. Jahrhunderts entschieden günstiger geworden. Es waren aber doch nur Ansätze zu einer Besserung. Der entscheidende Schritt nach vorwärts konnte nur von der gründlichen Revision der ganzen Agrarverfassung erwartet werden. Eine solche datiert erst wenige Jahre zurück. Im Winter 189.5/916 begamn eine Kommission unter dem Generaldirektor M. Wilcox die Vorarheiten dazu. Es galt vor allem mit dem Unterschiede zwischen Ouchouri- und Kharadj-Ländern auízuräumen, eine gleichmäfisige und gerechte Verteilung der Lasten vorzubereiten. Die Kommission, die aus Vertretern der Regierung und der Bodenbesitzor zusammengesetzt war, sollte den Mietwert der Grundstücke erheben und damn auf dieser Grundlage Vorschläge über die Höhe und die Verteilung der künftigen Grundsteuern erstatten. Dic Direktiven der Regierung lauteten:

1. Der Melnwert von Obstgärten und Palmenanlagen hat nicht berücksichtigt zu werden; solche Anlagen sind den in voller Kultur stehenden Böden derselben Güte gleichzuschätzen.

2. Der bisherige Gesamtertrag der Grundsteuer, in runder Summe 4780000 ägyptische Pfund, muß gewährleistet werden; die Maxinalsteuer darf 164 Piaster per Feddán nicht übersteigen.

Am 14. Mai 1899 erschien dann das für die Zukunft des Landes so bedentungsvolle Gesetz: Der Unterschied zwischen Ouchouri und Kharadji-Ländereien ist aufgehoben, ron jedem Feddán Kulturland sind künftighin $28,64^{\circ} 0$ des Mietwertes als Grundsteuer zu zahlen. Diese soll weiter, wie seit dem Jahre 1881), in monatlichen gleichen Raten eingehoben werden.

Die Dattelstener wurde vorläufig in der bisherigen Höhe von 2,20 Piaster per Jahr und Baum belassen. In Jahre 1:10 1 hat die gesetzgebende V'ersammlung der Regierung die Abschaffung der Dattelsteuer nahegelegt. Die Steuer brachte in diesem Jahrc 130000 L.E. ein. Um den Nietwert möglichst gerecht zu ermitteln, wird das Kulturland jedes Dorfes nach der Qualität in verschiedene Klassen geteilt und für jede Klasse der Bodenwert. gesondert bestimmt. $5 \%$ des Bodenwertes haben dann als Wietwert zu gelten.

Die Regierung verpflichtete sich zugleich, vor Ablauf von 30 Jahren keine Änderung des Steuersatzes eintreten zu lassen, behielt sich aber das Recht vor, die Grundstücke, die jetzt Bassinbewässerung besitzen, in eine höhere Steuerklasse einzu- 
reihen, wenn ihre Umänderung in Kanalland durchgeführt sein wird. Ebenso sollten die gegenwärtig unproduktiven Böden nach deren Nutzbarmachung einbezogen werden.

Da die Steuer 28,64\% des Mietwertes beträgt und dieser $5 \%$ des Bodenwertes, so ergibt sich, daß die Grundsteuer 1,43\% des Bodenwertes ausmacht. Was die neue Aufteilung der Grundsteuer für die ägyptische Landwirtschaft bedeutet, werden einige Zahlen illustrieren:

Im Jahre 1881 gab es Kharadji-Länder im Ausmaße von 3406480 Feddán, Die Kharadji-Länder "zahlten insgesamt an Steuern 4394359 L. E., durchschnittlich per Feddán 1,290 L. E..

Die Ouchouri-Länder zahlten insgesamt an Steuern 686761 L.E., durchschnittlich per Feddán 0,525. L. E.

1895 betrug die steuerpflichtige Gesamtfläche 5237000 Feddán, mit einer Gesamtsteuerleistung von L.E. 4780000 Durchschnitt per Feddán L.E. 0,913.

Seither ist der Steuerertrag alljährlich gestiegen:

1904 auf 4683692 L.E.,
$1904 " 4 \times 25462 "$
$1905 " 4902608$ "

und der Voranschlag für 1907 konnte schon mit einer Steuerleistung von 5060000 L.E. rechnen. Neben der Regelung der Grundsteuer muß auch der Aufhebung der anderen drückenden Steuer gedacht werden, die den Bauern in der Form von Fronarbeit auferlegt war. Noch im Jahre 1885 wurden 106000 Fellahs für 100 Tage zur Fronarbeit einberufen, die hauptsächlich in der Reinigung von Kanälen und im Bau und der Ausbesserung von Dämmen bestand. Wochenlang mußten die armen Fellahs ihren Familien und ihren Feldern fern bleiben, ohne jede Gegenleistung. Erst seit $18: 10$ besteht eine solche in geringfügiger Bezahlung. Nun sind die von Unternehmern betriebenen Baggermaschinen an die Stelle der Fronarbeiter getreten, und manche andere Arbeit, die früher diesen zufiel, gehört heute in das Gebiet des wohlorganisierten Bewässerungsdienstes, der nur Angestellte und keine Fronarbeiter kennt. Nur während der Nilflut müssen die Anrainer ihre Dämme an den Ufern des Nils in Ordnung halten und im Notfalle zur Hilfsarbeit herbeieilen.

Die Wirkung der geänderten Steuergesetze und der übrigen Maßnahmen tritt nun immer klarer und nachdrücklicher in die 
Erscheinung und äußert sich auch in der konstanten Vermehrung der produktiven Fläche. Nach den mir vom statistischen Departement des ägyptischen Ministeriums des Innern zur Verfügung gestellten Daten betrug die steuerpflichtige Fläche im Jahre 100). schon 5266584 Feddán, während die wirklich bebaute Fläche von Anfang September 1903 bis Ende August 1904 nach demselben Anite 5376781 Feddán umfaßt hat. Beide Zahlen stimmen wieder nicht ganz mit jenen überein, die der Minister der üffentlichen Arbeiten in seinem Rapport für das Jahr 1904 veröffentlichte, und Lord $\mathrm{Cromer}$ gibt in seinen Berichten abermals andere Daten. Es ist eben ungeheuer schwer, in Ägypten eine verläßliche Statistik ins Leben zu rufen, der in diesem Falle noch dadurch eine weitere Schwierigkeit erwächst, dab das Registrieren der Grundübertragungen nicht obligatorisch ist und da: die Gebühren hoch sind. In der letzten Zeit hat man sie zwar von $5^{\%} \%$ auf $2^{\circ}$ o herabgesetzt, aber dennoch wird nicht jeder Besitzwechsel sofort eingetragen. Das statistische Departement gibt folgende Besitzverteilung an:

Es gehörten Feddán 1904:

$\begin{array}{ccc}\text { in den Steuerkataster } & \text { kultvierbarer } & \text { das ganze Jahr } \\ \text { einbezogener Fläche } & \text { Fldiche } & \text { hindurchkultivier }\end{array}$ einbezogener Fläche Fläche hindurchkultivie

Privatpersonen (Einheimische oder Fremde)......

Der Wakufsadministration . Elementarschulen ..... Der Khedivialbibliothek (arab.) Dem Staat .

\begin{tabular}{ccc}
5305509.17 & 4871990,00 & 2013591,00 \\
68228,12 & 66312,4 & 25557,3 \\
21098,23 & 16073,23 & 11668,22 \\
1966,1 & 1997,96 & 1363,11 \\
625670,2 & 90415,2 & 16187,13 \\
160039,00 & 108789.00 & 52522,00 \\
277409.00 & 221243.00 & $8596: 3,00$ \\
\hline 6459921,00 & 5376780,61 & 2206853,00
\end{tabular}

Der Domänenverwaltung . .

Der Daira Saniéh.....

6459921,00

5376780,61

2206853,00

Da die Ackerfläche, die zufolge der Kanalbewässerung das ganze Jahr hindurch bebaut werden kann, mindestens zwei Ernten im Jahre trägt, so muß sie auch doppelt gerechnet werden, wenn es sich darum handelt, ein Bild der produktiven Fläche zu gewinnen. Wir bekommen dann statt 5376780,61 Feddán die Zahl von 7583633 Feddán, von denen Ägypten im Jahre 1904 seine Ernte zu erwarten hatte. Der Fortschritt der Landwirtschaft wird erst dadurch richtig charakterisiert; denn zu Beginn der Neuregelung der Agrargesetzgebung im Jahre 1895 war der Bau des Staudammes bei Assuan noch nicht begonnen und die immerwährende Kanalbewässerung größtenteils auf das Delta beschränkt. 
1904 standen selbst in Oberägypten $632 £ 50$ Feddán unter ganzjähriger Kultur.

Von der kultivierbaren Fläche befanden sich, wie aus rorstehender Tabelle ersichtlich ist, mehr als $90 \%$ im Besitze von Privatpersonen und nicht einmal $10^{\circ} 0$ in der Verwaltung des Staates und der öffentlichen Administrationen.

Von diesen ist die Wakufadministration die Terwaltung der Kirchengüter, der frommen Stiftungen. Die Domänenverwaltung und die Daira Saniéh führen ihren Ursprung auf die früher erwähnten Anleihen zur Deckung der Schulden Ismael Paschas zurück. Die Administration der Domaines de l'Etat Égyptien unfaßte ursprünglich ein Areal ron 426000 Feddán, das einer Anleihe im Hause Rothschild rom Jahre 1877 als Unterlage diente. Der Verwaltungskommission gehört ein ägyptischer, ein französischer und ein englischer Administrator an. Am 30. Dezember 1907 unterstanden der Domänenadministration nur noch 145948 Feddán, während der Verkauf des übrigen die Rücklösung ron Schuldscheinen im Werte ron 6965300 Sterling ermöglicht hatte. Nach der günzlichen Liquidation wird den Staate eine Fläche von 117000 Feddán im Terte von mindestens L.E. 5000000 als freier, unbelasteter Besitz übrigbleiben.

Die Daîra Saniéh, ebenfalls unter gemischter Kontrolle stehend, nmfaßte die Domänen, die der Khédive Ismael Pascha und die Angehörigen der vizeköniglichen Familie als Unterlage der Daîra-Anleihe zur Verfügung gestellt hatten. Zu Ende des Jahres $1900^{\circ}$ war die Liquidation gänzlich durchgeführt und die Schuld von 95120100 L.E. (240 419961 Franks) durch Verkauf der Grundstücke zur Gänze getilgt worden. Auch dabei wurde ein Mehrerlös erzielt, der nicht weniger als $3200000 \mathrm{~L}$. E. beträgt.

TWurde früher die Bildung der Domänenverwaltung als das Ende der zahlreichen Latifundien und als Vorteil für die ägyptische Landwirtschaft bezeichnet, so hat diese Ursache die Finalisierung der Domänenliquidation noch freudiger zu begrüßen. Der kleinere, leistungsfähigere Besitz ist wohl langsam an die Stelle der Latifundien getreten; aber in den langen Jahren des Überganges hatte die Domänenverwaltung bezüglich des unverkauften Teiles eine zweifache Rolle zu spielen: die des Liquidators und die des Landwirtes. Die beiden Aufgaben lassen sich kaum vereinen, ohne daß die eine die andere beeinträchtigen würde. In unserem Falle mußte begreiflicherweise der Landwirt hinter dem Liquidator 
Die politischen Voraussetzungen der ägyptischen Landwirtschaft.

zurücktreten, dem der Weg noch enger begrenzt war als dem Besitzer der früheren Latifundien.

Von 1896-19106 haben sich die Besitzverhältnisse folgendermaßen verschoben ${ }^{1}$ ):

\begin{tabular}{|c|c|c|c|c|c|}
\hline \multirow{2}{*}{\multicolumn{2}{|c|}{ Bodenbesitz }} & \multicolumn{2}{|c|}{1896} & \multicolumn{2}{|c|}{1906} \\
\hline & & $\begin{array}{l}\text { Zahl der } \\
\text { Besitzer }\end{array}$ & $\begin{array}{l}\text { Gesantfläche } \\
\text { Feddán }\end{array}$ & $\begin{array}{l}\text { Zahl der } \\
\text { Besitzer }\end{array}$ & $\begin{array}{c}\text { Gesamtfläche } \\
\text { Feddán }\end{array}$ \\
\hline Unter 5 Feddán & . & 611674 & 993843 & 1005705 & 1264084 \\
\hline 5-10 Feddán. . & . & 80810 & 565810 & 77663 & 544264 \\
\hline 10-20 Feddán. & . & 41276 & 574084 & 37817 & 523528 \\
\hline 20-30 Feddán. & . & 12928 & 317341 & 11488 & 278793 \\
\hline 30-50 Feddán. & . & 9297 & 358298 & 8601 & 321561 \\
\hline Über 50 Feddán & . . & 11875 & 2191625 & 12475 & 2356602 \\
\hline 'T'otal & $\cdot$ & 767260 & 5001001 & 1153749 & 5298772 \\
\hline
\end{tabular}

Man sieht, wie der Besitz des Bodens langsam in die Hände der Fellahs zurückgekehrt ist, denen er einst durch den Staat und die Mächtigen des Reiches entrissen wurde. 18! t; besaßen die allerkleinsten Bauern weniger als 20\% der gesamten Bodenfläche, 1906 schon 24\%. Der perzentuale Anteil des Großbesitzes über 50 Feddán - ist nahezu der gleiche geblieben, der mittlere Besitz von 5-51) Feddán hat sogar zugunsten der kleinsten Grundbesitzer etwas hergeben müssen. Das erklärt sich zum groben Teil durch das mohammedanische Erlogesetz. Dieses kennt keinerlei Begrenzung, der Grundbesitz wird durch Erbteilung immer mehr zerstückelt, selbst die weiblichen Fanilienmitglieder erben ihren Teil mit.

Das Forterben des Besitzes immerhalb der Familie ist für die Landwirtschaft ungeheuer wichtig. Der Landwirt, der seinen Boden in der Hoffnung bewirtschaftet, daß die aufgewendete Mühe einmal seinen Erben zugute kommen wird, geht gewiß ganz anders vor. Diesen Erbgang sichert die Vielweiberei des Mohammedaners, indem sie ihn auf mehr Augen stellt; aber die Gefahr übergroßer Zersplitterung wächst dabei bedeutend. Sie wird durch die Anspruchslosigkeit des Fellahs gemildert, wie denn auch Klina und Boden und die übrigen Verhältnisse den Kleinbetrieb begünstigen. Deshalb ist die Zunahme des Parzellenbesitzes in Ägypten, zumindest unter den heutigen Bedingungen, als Vorteil anzusehen, während sie sonst in einer reinen Agrar-

1) Lord Cromer, Rapport sur l'Égypte et le Soudan pour l'année 1890 (p. 63), zitiert in Eid, La Fortune immobilière de l'Égypte, Paris 1907. 
gegend bedenklich erscheinen müßte. Der Erbe weniger Quadratmeter gewinnt seinem Boden nicht mehr die Mittel für die Befriedigung der notwendigsten Bedürfnisse ab; durch seinen kleinen Besitz aber an die Scholle gebunden und mit ihr vertraut, gibt er jenen treueren, brauchbareren Arbeiter der großen Güter ab, den diese benötigen, um sich entwickeln zu können. Die bodenständigen Parzellenmänner sind auch die Träger der merkwürdigen Pacht- und Arbeitsverhältnisse, die wir später kennen lernen werden, und ohne die der Betrieb größerer Güter in Ägypten vorläufig noch schwer denkbar wäre.

\section{Kredit, Bodenpreise und Arbeiterverhältnisse.}

Übergroße Verschuldung der ägyptischen Landwirtschaft - Die Ausbeutung des Fellahs. - Eingreifen der Regierung. - Grüıdung der Agrikuiturbank im Jahre 1902. - Borlenwert und Bodenbelastung. - Rasches Steigen der Bodenpreise. Die Krise vom Jahre 1906. - Preistreiberei oder Werterhöhung? - Das Herrichten des Bodens. - Pachtschilling und Bodenertrag. - Es gibt keine selbstbewirtschafteten großen Güter in Ägypten. - Der große Püchter als Mittelglied zwischen Grundbesitzer und Bodenbebauer. - Weitere $\mathrm{Z} w$ ischenglieder schieben sich ein. - Abhängigkeit der ägyptischen Landwirtschaft vom Kleinletriebe. Arbeitsangebot und -nachfrage. - Lohnhöhe. - Merkwürdige Arbeitsverträge.

Die übergroße Verschuldung des Grundbesitzes, die auch in anderen Lündern schon manche Agrarkrisis hervorgerufen hat, ist in Ägypten das chronische Leiden der Landwirtschaft geblieben. Der Fellah benötigt zum Betrieb, für seine Baulichkeiten und zu seiner Lebensführung weniger Kapital als irgendwer, aber der Steuerdruck und die Auswucherung, denen er bis vor kurzem ausgeliefert war, haben ihm arg zugesetzt. Dazu kommt noch die stete Leidenschaft, Land zuzukaufen. Man kann sich vorstellen, was für Folgen so ein Landkauf mit teilweise geborgtem Gelde haben mußte, wenn man hört, daß $4-5^{0} 0$ pro Monat bei den meist griechischen Geldleihern, die sich in jedem Dorfe vorfinden, der übliche Zinsfuß war. Die großen Kreditbanken, wie der Crédit Foncier Egyptien, die angloägyptische Bank usw., bestehen seit Jahren und haben manches Unheil abgewendet, aber mit ihren Mindestleihbeträgen von $100 \mathrm{~L}$.E. und dem ziemlich schwerfälligen Apparat konnten sie gerade das Elend der kleinsten, der Ausbeutung am meisten ausgesetzten Fellahs nicht beseitigen. Billig sind übrigens diese Banken gerade auch nicht gewesen. Die Nationalbank von Ägypten, die bis Ende 1!01 400000 L.E. 
in kleineren Summen an Fellahs verlieh, hat sich diesen Liebesdienst mit $10 \%$ pro Jahr bezahlen lassen.

Im deutschen Mittelalter war ein Zinsfula von $12 \%$ für Grundkredite nichts Seltenes, und es ist noch nicht lange her, dab bei uns für Hypothekardarlehen $5-6 \%$ gezahlt werden mubten; aber dic Besserung in den Verhältnissen der deutschen Landwirtschaft ist mit der Herabsetzung des Zinsfußes und der Regelung des hreditwesens eng verbunden gewesen, und die ägyptische Landwirtschaft hat das Gegenteil nicht überwinden kömmen. Der Fellah, der $10 \%$ zahlen mubte. belastete sein Land mit. einer Hypothek ron 100 Mark ebenso schwer, wie der deutsche Landwirt, der 250 Mark zu 4\% ausleiht.

Endlich erregt die Schuldnot die Aufmerksamkeit des gesetzgebenden Rates. Man berät das Budget des Jahres 1894 und stößt auf eine Vermehrung der bäuerlichen Schuldenlast, die von 12 Millionen L.E. im Jahre 1881 auf 20 Millionen im Jahre 1891 gestiegen ist. "La commission nommée par le Conseil Législatif trouve que les Égyptiens sont dans und état de pauvreté et de gêne qui tend à augmenter de jour en jour", heißt es in dem Bericht darüber. Sir E. Palmer weist Irrtümer in der Aufstellung der Zahlen nach, die die Schuldsumme geringer erscheinen lassen, aber die Notwendigkeit, ron Staats wegen einzugreifen, wird dadurch nicht beseitigt. 1902 läßt die Regierung durch die ägyptische Nationalbank. mit der sie enge Bezielıungen unterhält, die Agrikulturbank ron Ägrpten ins Leben rufen, und Sir E. Palmer selbst organisiert sie in einer Weise, durch die dem kleinsten Grundbesitzer und dem ganzen Lande ein großer Dienst geleistet wird. Die übrigen Hypothekenbanken können die grundbücherliche Eintragung nur bei den drei gemischten Gerichtshöfen in Kairo, Alexandrien und Mansourah rornehmen lassen - der Agrikulturbank wurde das Recht eingeräunt. gültige Eintragungen an Ort und Stelle durch delegierte Beamte der Notariatskanzleien vornehmen zu lassen. Mit dem Einheben der Zinsen und der Annuitäten belassen sich die staatlichen Steuereinheber und die Schuld geniebt selbst der Steuer gegenüber die Priorität.

Die kostspieligen Schätzungen, die die anderen Banken rornehmen lassen, werden durch den Grundsatz der Agrikulturbank unnötig, stets. nur ein bestimmtes Mehrfaches der Grundsteuer zu verleihen. Ursprünglich bildete die 25 fache Steuer die Grundlage, 
jetzt ist man auf das 30 fache hinaufgegangen. Die Zinsen, anfänglich mit $9^{\circ} \cup$ festgesetzt, wurden seit dem 31. Dezember 1906 auf $8 \%$ ermäßigt. Die Bank gibt Darlehen in zweifacher Form:

1. als Hypothek in Beträgen von 10 L.E. bis zu 500 L.E.,

2. als Torschuß auf die Einte in Beträgen zwischen $1 / 2$ L.E. und 20 L.E.

Die Hypothekendarlehen waren ursprünglich in zehn Jahresraten zu tilgen; jetzt hat man die Frist im Interesse der Schuldner auf 20 Jahre verlängert.

Die Regierung garantiert dem Aktienkapital eine Verzinsung: von $3^{\circ} 0$. Dieses wurde 1905 auf 37400100 L.E. erhöht. Im Jahre 1906 hat die ägrptische Regierung überdies eine $3{ }^{1} \%$ ige Garantie für 6570000 L.E. neve Obligationen übernommen. Daron wurden $2500000 \mathrm{~L}$.E. den Besitzern von Obligationen in der gleichen Höhe, die der Staat früher nicht garantiert hatte, gegen Aufzahlung ron $6^{0}$ o zum Umtausch angeboten. Es scheint, dab man diese Garantie für ziemlich überflüssig hielt, denn nur die Besitzer ron 150000 L.E. haben ron dem Rechte Gebrauch gemacht und dem Reservefond der Bank dadurch 9000 L.E. zugeführt. Ton den übrigen neuen Obligationen sind im April 1906 1570000 L.E. al pari begeben worden.

Die Konkurrenz der Agrikulturbank hat die übrigen Banken gezwungen, sogar unter den Zinsfuß jener zu gehen. Sie berechnen nach der Höhe der Belelınung und der Dauer 6-8\%. Noch hilliger stellen sich die Darlehen der englischen Assekuranzgesellschaften, die in den letzten Jahren einen Teil ihres Reservefonds $\mathrm{zu} 5^{1} / 2-6 \%$ aui diese Theise festgelegt haben. Bei Landverkäufen auf längere Termine hinaus werden durch die Verkäufer gewöhnlich 4.5-5,5\% berechnet, das letzte Fünftel, das oft stehen bleibt, trägt $6-7 \%$.

Das staatliche statistische Amt, erst vor drei Jahren ins Leben gerufen, ist noch zu jung, um genaue Daten über den Stand der Verschuldung liefern zu können. Ich verdanke indessen dem gewiegten Kenner des ägyptischen Kreditwesens, Alfred Eid, folgende Übersicht: 


\section{6 :}

1. Eigentliche IIypothekenschulden, aufgenommen von privaten Hypothekenbanken:

Crédit foncier égyptien

Land \& Mortgage Compagny

Caisse hypothécaire d'Egypte Land Bank .

Agrikulturbank von Ägypten

Englische Assekuranzgesellschaften

Private

$$
\begin{aligned}
& \begin{array}{ccc}
\cdot & \cdot & \cdot \\
\cdot & \cdot & \cdot \\
\cdot & \cdot &
\end{array} \mid 15026986 \text { L.E. } \\
& \begin{array}{l}
\cdot 5571000 \text { " } \\
\cdot \quad 22000000 \\
. \quad 5445000 \text {.. } \\
\hline 28145000 \text { L.E. }
\end{array}
\end{aligned}
$$

2. Schulden aus Landverkäufen aut Termin .

Summe 38897700 L.E.

Die gesamte Verschuldung hat danach zuerst 39 Millionen L. E. oder 1 Milliarde Franken betragen und sich seither wieder stark rermehrt. Am 1. Januar $190 \%$ belief sich das Guthaben der fünf Banken schon auf 25815215 L. E., wovon 7714000 L. E. auf die Agrikulturbank entfielen. Die Bodenverschuldung macht gewaltige Fortschritte.

1891 hat eine angebliche Verschuldung ron 20 Millionen, die dann durch cine Enquete Sir E. Palmers auf 7323000 \& richtiggestellt worden ist, das Entsetzen und die schwärzesten Befürchtungen des gesetzgebenden Rates hervorgerufen; 1906 beträgt die hypothekarische Belastung $5^{1 / 2}$ mal so viel. Die Situation erschiene trostlos, wenn sich ihr keine mildernden Umstände zubilligen lieben.

Als solche müssen wir zunächst die Tatsache ansehen, daß̧ die ägyptische Landwirtschaft, wie sich aus dem bisher Gesagten ergibt, erst in den allerletzten Jahren bessere Voraussetzungen für ihr Gedeihen fand. Noch in voller Umwandlung begriffen, hat sie nicht Zeit gehabt, die Voraussetzungen auszunützen, in klingende Münze umzusetzen und dabei der großen Aufgabe, gewaltige neue Länderstrecken urbar zu machen, gerecht zu werden. Die kultivierte Fläche hat in zehn Jahren, wie bereits konstatiert, um 1 Million Feddán zugenommen, und die Zahl der Ernten entspricht, zufolge der ganzjälırigen Bewässerung, noch größerem Wachstum; aber eine so beispiellos rasche Ausdehnung erfordert vor allem Geld, viel Geld. Das kann durch die Ersparnisse der armen, so 
lange rückständig gebliebenen Fellahs nicht beschafft werden. Unter den speziellen Verhältnissen der ägyptischen Nationallandwirtschaft ist die Möglichkeit, im Wege der Hypothekarbelastung Kapital zu beschaffen, das einzige Mittel zum Fortschritt gewesen. Die schwindelnde Termehrung der Grundverschuldung stellt hier kein Memento des Niederganges, sondern ein Zeichen beginnenden Aufschwunges dar. Indem die Regierung dem kleinen Grundbesitzer die Mittel zum Bodenkaufe und zum Wirtschaften an die Hand gab, hat sie dem Lande einen großen Dienst erwiesen. Selbst die Kehrseite der Terschuldung birgt nicht dieselben Gefahren in sich wie anderswo, weil Mißernten wegen der Konstanz der natürlichen Bedingungen ausgeschlossen, die jährlichen Erträge viel gesicherter sind. Auch der hohe Zinsfuß darf in einem Lande nicht mit unserem Maßstabe gemessen werden, das einen Pachtzins von $6^{1} 2-7 \%$ erreicht und verträgt. Der Fellah, dessen Boden mit dem lü̈chst zulässigen Maße von $60 \%$ belehnt ist, steht sich noch immer nicht schlechter wie ein anderer, der den Boden gepachtet hat. Treten keine ganz unerwarteten Ereignisse cin, so kann er ruhig seine Zinsen und seine Annuitäten zahlen und mit den Jahren das schuldenfreic Eigentum seines Gutes erlangen. Dabei hat das Bewufitsein des Besitzes dem Boden und dem landwirtschaftlichen Fortschritte nur genützt.

Eid berechnet den gegenwärtigen Bodenwert Ägyptens mit 360000000 L.E. Die Belastung von 31200000 L.E. beträgt $8,6^{\circ}$ o davon. $\mathrm{Ob}$ das gerade das wünschenswerte Maß für die ägyptische Landwirtschaft ist, läßt sich kaum entscheiden. Aber konstatieren wir: Die Zwangsversteigerungen sind ungeachtet der Vermehrung der Bevölkerung und des kultivierten Terrains zurückgegangen. Bei den Gerichtshöfen in Kairo und Alexandrien gab es 1894 190, 1897 266, 1904 151, 1905110 Zwangsversteigerungen von Gütern. Und die Agrikulturbank erhält im Jahre 1907 von ihren kleinen Schuldnern 1760892 L.E. zurückgezahlt, und von den restlichen Außenständen von 113127 L.E. gehen im Januar 1907 noch 34000 L.E. ein. Von den Hypothekardarlehen werden ihr 178112 L.E. vor Verfall zurückerstattet. Vielleicht hat man anderswo billigeres Geld gefunden; auch das ist ja schon ein günstiges Zeichen. Und ein weiteres: Im Jahre 1905 blieben bei einer Grundsteuersumme ron mehr als 5000000 L.E. nur 18000 L. E. unbeglichen.

Eine der wichtigsten Voraussetzungen jeder Landwirtschaft. 
ist die Höhe der Bodenpreise, aber auch eine, die am schwerster: $z u$ erfassen und wiederzugeben ist. Zwischen den besten und den schlechtesten Böden, der Beschaffenheit und der Lage nach, gilst es unzählige Abstufungen, und das Aufzählen der gezahlten Maximal- und Minimalpreise verrät dem Fernestehenden weder die Art der Böden noch das Verhältnis zwischen Wert und Preis. Vielleicht trägt es zur Klärung der Frage bei, wenn man die Fluktuationen der Preise betrachtet und die Gründe, die sie verursacht haben; beides wirkt ja auf die Landwirtschaft ein. Ist der Bodenpreis gestiegen, weil erhöhte Nachfrage eingetreten war, dann kann der Besitzer, der seinen Boden verkauft, einen Gewinn dabei erzielen. Aber schon der nächste Besitzer und der Pächter des teuerer gewordenen Bodens haben nun ein höheres Grundkapital zu verzinsen und sind schlechter daran als früher, denn der Boden ist nicht fruchtbarer geworden und gibt nicht mehr Ertrag als vorher. Liegt die Ursache der Preissteigerung in einer Werterhöhung, dann hängt es von der Dauer der Werterhöhung und von dem Maße, in dem sie eingetreten ist, ab, ob dic Preissteigerung einen Gewinn für das Land bedeutet, oder das Gegenteil. Vorübergehende Wertsteigerung, etwa eine Ertragserhöhung, die nicht andauert, im Bodenpreise zum Ausdruck gebracht, wird ein Unglück für die ganze Landwirtschaft. Wieder kann der momentane Besitzer oder der Pächter einen Nutzen daraus ziehen, der zufälligerweise vor Eintritt der Konjunktur und für deren Dauer gepachtet hat; aber was nachher kommt, ist ein rechter Jammer; der dann, bei fallenden Bodenpreisen in umgekehrter Reihenfolge in dem Verluste des momentan letzten Besitzers des Bodens stabilisiert wird.

Daf die Bodenpreise in Ägypten gestiegen sind, ist erklärlich, finden wir doch dieselbe Erscheinung, wie die Geschichte lehrt. im Laufe der Zeiten überall. Überall finden sich ja dieselben Ursachen dafür, die Tendenz, vorübergehende Konjunkturen als dauernd anzusehen, einzelne Betriebserfolge zu verallgemeinem; der Boden ist überall unvermehrbar, und überall wächst die Bcvölkerung und die Nachfrage nach dem Boden. Aber in Ägypten ist der Bodenpreis in den letzten Jahren rascher als anderswo gestiegen, sprunghaft, unaufhaltsam gestiegen, bis zum Eintritt der groben Krise des Jahres 1906, die das gesamte Wirtschaftsleben des Landes noch immer in Atem hält. Alle Welt sprach von der 
tollen Frundspekulation und ron den Gefahren, in die sie das Land stürzen würde, und alle Trelt trug selber dazu bei und beeilte sich das eigene Schäfchen ins Trockene zu bringen. Wie die Pilze nach dem Piegen sind die neuen Grundverwertungsgesellschaften emporgeschossen, und die Liquidatoren der alten Sünden, der Domänen- und der Dairanleihen, konnten das verpfändete Land spielend zu Preisen losschlagen, die man früher nie geahnt hätte. Im Jahre 1898 schätzte man den Wert der Güter, die die Administration der Domänen im Fayûm besak, auf L. E. 402000 , ein Jahr später auf L.E. 625000. Im Bericht Lord Cromers rom Jahre 1905 wird der Wert derselben Güter mit L.E. 1300000 angegeben. In den Dörfern Rodah, Ronbyat und Tamyeh springt der Bodenwert von L.E. 10-15 per Feddán im Jahre 1898 auf L.E. 30-40 in 1905, bei Tutun, Kalamcha und Ezbet im Distrikt Bahr Nazleh von L.E. $\check{-}-15$ auf L.E. $25-30$ per Feddán. Und ähnlich geht's fast überall. Gute Baumwollbüden in Unterägypten, die früher L.E. 80 kosteten, werden nur mit L.E. 150-180 bezahlt; in der besten Lage des Delta sind sie wohl auch noch teuerer. In Oberägypten, wo das Terrain immer weniger wert ist, erreicht der Feddán jetzt L.E. 80-85, während früher kaum L.E. 50 dafür erzielbar waren.

Die Spekulation mag neben allen anderen Ursachen viel zu der Preistreiberei beigetragen haben. Wer könnte den Anteil, der jedem Faktor dabei zukam, richtig begrenzen? Aber die Preissteigung des ägrptischen Bodens hat zweifellos ihre besondere, innere Begründung, die in einer dauernden Ertragserhöhung besteht. Außer den vielen Maßnahmen, die schon erwähnt wurden, dem Ausbau des Bewässerungswesens, der Neuordnung der Agrargesetze und der Steuern, der Regelung des Kreditwesens, sind noch andere daran beteiligt gewesen. Die Regierung hat seit den achtziger Jahren in Unterägypten und im Fayûm versumpfte Gebiete, aus denen das Überflutungswasser keinen Ausweg fand, durch Dränierung in der Länge von $4,185 \mathrm{~km}$ fruchtbar gemacht und ihr Beispiel den Weg zu systematischer Bodenverbesserung gewiesen. Das Herrichten ron Böden wurde nachgerade ein besonderer Erwerbszweig, der seinem Mann oft Reichtümer und nebenbei dem Lande wirklichen Nutzen brachte. Leute, die einen weiteren Blick und das richtige Verständnis besaßen, kauften von den Paschas, von den Mitgliedern der prinzlichen Familie große, meist recht vernachlässigte Domänen zu- 
sammen, hoben deren Wert durch entsprechende Arleciten unk verkauften sie dann wieder in kleinen Losen, unter günstigen Zahluugsbedingungen an die Fellahs. Die gestiegene Ertragsfühigkeit rechtfertigte den gelorderten Preis, der diesmal beiden, dem Kïufer und dem Verkäufer, zum Vorteil gereichte.

Ich will als Beispiel, wie das vor sich ging, von Gütern erzählen, die im südlichsten Teile der Oase Fayûm, dort wo sie an die Wüste grenzt, bei den Dörfern Calámsha, Foutoun und Abouhamed gelegen sind. Vor zehn Jahren hatten die Besitzer die 1400 Feddáns Regierungsland um den durchschnittlichen Preis von L.E. 5 erworben, bisher an Fellahs verpachtetes, elend bewirtschaftetes Land. Das salzhaltige Untergrundwasser, das keinen Abfluß besak, hatte längst einen großen Teil der Fläche mit einer weißen Salzschicht bedeckt und jeder anderen Vegetation, außer den wildwachsenden, wirtschaftlich wertlosen Salzpflanzen, ein Ende bereitet. Nur 500 Feddáns, die erst drei Jahre später um L.E. 18 dazu gekauft wurden, hatten nicht unter der Salzplage und der Versumpfung zu leiden, weil sie $1 \mathrm{~m}$ höher gelegen waren.

Nun begann die Urbarmachung. Mit der Hacke wurden die dichten, tiefwurzelnden Pflanzen entfernt. Der Pflug ging dem Nivellieren voraus, ohne das keine entsprechende Bewässerung oder Entwässerung möglich ist. Man baute Wege und Straßen, scheute den langwierigen Instanzenweg nicht, um den Anschluf an den $2 \mathrm{~km}$ entfernten Bahr Gharak-Kanal bewilligt zu erhalten. Dieser Kanal empfängt sein Wasser von dem altehrwürdigen Hauptkanal Bahr Jusuf, dessen Anlage angeblich dem Josef der Bibel zu danken sein soll.

Bevor noch ein Samenkorn zur Aussat gelangte, hatte der Boden bereits 11 L.E. Spesen pro Feddán verschlungen, von der Energie und Arbeit abgesehen, die die neuen Besitzer im Kampfe gegen die Ungunst der Verhältnisse aufwenden mußten. Ägypten ist ein Land, das doch noch keine so geordneten Verhältnisse wie unsere Heimat hat und manchen unerwarteten Zwischenfällen unterworfen ist. Krankheiten sind unter dem Vieh nur zu häufig, und bis in die letzte Zeit wütete die Beulenpest unter den Rindern. So hatten auch unsere Kolonisten den Verlust ihrer Arbeitstiere zu beklagen, und die Arbeit ging erst ordentlich rorwärts, als ein Fowlerscher Dampfpfiug von 20 Pferdekräften angeschafft worden war. 
Der Boden wurde nach dem Salzgehalt und der Lage in drei Teile geteilt. Der schlechteste salzhaltigste Boden mufte unter Wasser gesetzt werden. Je mehr Wasser zur Verfügung steht, desto rascher geht die Auslaugung vonstatten. In manchen ähnlichen Fällen konnte man bis zu $1 \mathrm{~m}$ hoch überstauen, bei unserer Wirtschaft reichte der Wasserzufluk oft nur auf $6 \mathrm{~cm}$, höchstens auf $10 \mathrm{~cm}$ aus. Alle $4-5$ Tage wurde das Wasser abgelassen, um frischem Wasser, das noch kein Salz in sich gelöst hatte, Platz zu machen. Im Winter, wenn das Nilwasser weniger Schlamm enthielt, ging die Entsalzung rascher vor sich; aber die schlechtesten Böden brauchten, namentlich wegen des geringen Wasserquantums, bis zu fünf Jahren zur Nutzbarmachung.

Auf den Böden der ersten besten Kategorie begann man mit dem Reisbau. Der Reis verträgt Böden mit einem Gehalt an Salz bis zu 10:0 und soll viel davon in sich aufnehmen können, wird überdies als Sumpfpflanze durch das stark nasse Terrain nicht geschädigt. Den Sabaini, wie die Reissorte genannt wird 17) weil man den 70fachen Ertrag davon erhofft), hatte man schon Mitte Juli gepflanzt und nach 70 Tagen geerntet. War der Boden dadurch genügend entsalzt, folgte Bersim (eine Kleeart), Baumwolle und wieder Reis, bei mindern. noch nicht ganz entsalzten Böden wohl auch zweimal hintereinander Reisbau. Die Böden der mittleren Kategorie, die nicht ganz unbrauchbar, aber doch für den Reisbau noch nicht genug salzfrei waren, wurden zuerst mit „Deneba" bepflanzt. Diese Grasart verträgt riel Salz, wird im August gebaut und nach zirka 60 Tagen abgeweidet. Sie soll namentlich für Schafe ein gutes Futter abgeben. Nach der einmaligen Weide läßt man den Boden abtrocknen, wobei das Gras abstirbt, da es viel Feuchtigkeit benötigt.

Ist der Boden noch zu salzhaltig für andere Kulturpflanzen, wird wieder Deneba gebaut, bis endlich Reisbau in den normalen Fruchtwechsel überleitet.

Nachdem man noch Wirtschaftsgebäude erbaut hatte, konnte der Boden beim Wiederverkaufe schließlich im Durchschnitt L. E. 50, also das Sechsfache des Einkaufspreises erzielen. Ohne Kenntnis der näheren Details wäre der enorme Unterschied zwischen Einkaufs- und Verkaufspreis ohne weiteres einer wahnsinnigen Grundspekulation zugeschrieben worden; wir werden nach dem Gesagten doch noch anderes darinnen sehen. Menschlicher Scharfsinn hat hier wirkliche Werte geschaffen, und in ähnlicher Weise 
haben die vielen Grundverwertungsgesellschaften nicht blok ihren eigenen spekulativen Zwecken gedient, sondern auch den Weri des Landes durch zielbewulites Vorgehen wirklich gehoben. Dic Spekulation trug zu der allgemeinen Preissteigerung bei, allein verursacht hat sie sie nicht. Deshalb konnte die Krise wohl zu einer Abflauung, aber zu keinem katastrophalen Sturze der Bodenpreise führen. Ob der Tiefstand schon erreicht ist, wird jetzt wohl zunächst von der Gestaltung der Produktenpreise, namentlich der Preise der Baumwolle abhängen. Die Nachfrage nach Boden hat sich indessen nicht vermindert, und als die Domänenadministration neulich 131 Lose zu 12 Feddán ausbot, gab es nicht weniger als 573 Bewerber darum. Das sieht nicht nach einem bevorstehenden Zusammenbruche der Bodenwerte aus, und nach ruinösen Bodenpreisen auch nicht.

Die Entwicklung der Bodenpreise ist naturgemäß von hohem Einfluß auf die Höhe des Pachtschillings geworden. Die Gleichmäßigkeit der natürlichen Bedingungen bringt es mit sich, dab auch auf die Gleichmäßigkeit der jährlichen Erträge mit größerer Sicherheit als irgendwo anders gerechnet werden darf. Gut bewirtschafteter Boden trägt jetzt bei den höheren Bodenpreisen im Durchschnitt immer noch $6-7 \%$ pro anno. $6-7 \%$ des Bodenpreises bilden demnach den Betrag, der zwischen Pächter und Verpächter aufzuteilen ist, die Grenzen, innerhalb deren sich dic Bildung des Pachtpreises vollziehen kann. Der Verpächter wird schon im eigenen Interesse, um sich die Möglichkeit der Verpachtung dauernd $\mathrm{zu}$ sichern, diese Teilung nicht allzusehr zu seinen eigenen Gunsten verschieben dürfen und dem Pächter einen entsprechenden Anteil an dem Bodenertrag lassen. Besitzer, die es wie jener sehr reiche ägyptische Prinz halten, von dem ich erzählen will, wird es freilich nicht allzuviele geben. Der Prinz, der in Paris lebt, gab sich mit einem Pachtschilling von $6 \mathscr{L}$ pro Feddán zufrieden, während das Land in gleicher Lage sonsi mindestens $9 \mathscr{L}$ wertet. Auf die Frage, warum er sich so übers Ohr hauen ließe, erwiderte er: "Ich könnte auch in der 3. Klasse nach Paris fahren und fahre in der 1. Klasse, was mich Geld kostet, und ebenso halte ich es mit meiner Vermögensverwaltung." Bei oberflächlicher Kenntnis der orientalischen Gebräuche wird man sich nicht wundern, daß die $3 \mathscr{L}$, auf die der Prinz verzichtete, nicht einfach dem Bodenbebauer zugute kamen, sondern zwischen dem Sekretär des Prinzen und dem Pächter geteilt 
wurden. Der Pächter wieder war wahrscheinlich noch lange nicht mit dem schlieblichen Bebauer des Bodens identisch. Der große Pächter ist nämlich eine eigentümliche Spezialität der ägyptischen Landwirtschaft. Alle Welt will in Ägypten verpachten: "Sie werden wenig selbstbewirtschaftete große Güter hei uns finden," sagte mir der Khédive bei der gewährten Audienz; .wir verpachten alles, das trägt mehr als das Selbstbewirtschalten, und der Fellah schlägt dabei für sich auch noch genug heraus."

Aber wenn auch alle Welt verpachten will, so will doch keiner ohne eine gewisse Sicherstellung des Pachtzinses verpachten. Die kann der kleine Bodenbebauer nicht geben, und da schiebt sich zwischen ihn und den Besitzer ein Zwischenglied ein ıer große Pächter, mit eigenem Grundbesitz, der in der Lage ist, Garantien in Form von Hypotheken oder dergleichen beizustellen. Gewöhnlich ist er ein $\mathrm{Omdeh}$ oder $\mathrm{Schech}$, einer der Pfeiler (ler administrativen Einheit, die das Dorf bildet. Diese Würdenträger nehmen eine bevorzugte und gewichtige Stellung ein und sind wohl in der Lage, für den richtigen Eingang ihres Aftermietzinses zu sorgen. In früheren Jahren sollen sie den Fellah oft recht geschunden haben, nun ist auch dem durch die Reformen ein Riegel vorgeschoben worden.

Der Schêch pachtet also ein paar tausend Feddán, so viel als er auf Grund seines eigenen Besitzes sicherstellen kann, und gibt sie in kleinen Losen von 15-100 Feddán weiter. Er hat für gutes Land vielleicht 5 oder $6 \mathscr{L}$ gezahlt und erhält nun i-8 $\mathscr{L}$ per Feddán dafür. Dabei sucht er sich seine Leute noch sut aus. Ein Familienoberhaupt, ein wohlhabenderer Fellah mit l.leinem Grundbesitz ist der nächste Garant des Pachtgrundes. Und auch dieser gibt den Boden in noch kleineren Parzellen wieder weiter, und wieder muß der Übernehmer, ein Familienmitglied oder ein kleinerer Fellah, für die Gutstehung Opfer bringen. Diesmal sind sie nicht zu groß, die Aufteilung unter die letzte Hand, die eigentlichen Bodenbebauer, soll recht patriarchalisch vor sich gehen. Das Familienoberhaupt gibt sich vielleicht mit 1/12 der Ernte zufrieden, worin sein Ansehen und seine Kreditfähigkeit honoriert und eine Art Ausgeding mit enthalten sein mag.

Ägypten ist übrigens das historische Land der Pachtwirtschaft. Was bedeutete das Eigentumsrecht des Staates an allem Grund 
und Boden anderes, denn die gesetzliche Festlegung der Pachtwirtschaft als einzige Form des Betriches? Und hente, wo das Privateigentum am Boren längst zur Wirklichkeit geworlen ist. weisen die Verhältnisse immer noch auf die Vorteile des Verpachtens hin. Die ganze Art der Landwirtschaft ist ja dort writ entfernt, sich die Vorteile des Großhetrifbes nutzhar machen zu können, und das Verpachten des Grofgrundhesitzes in kleineren Losen ist die Folge derselben Ursachen, die in Igypten die fortschreitende Vermehrung des kleinsten Grundbesitzes herbeiführen und wünschenswert erscheinen lassen. Zu diesen Ursachen wird! man vielleicht auch das geringe Organisationstalent des Orientalen zählen dürfen, von dem Lord Cromer spricht; denn eine gute Organisation ist bekanntlich für das erfolgreiche Bewirtschaften großer Güter unerläßlich.

Die Abhängigkeit der ägyptischen Landwirtschaft vom Kleinbetriehe kommt auch in der vielgestaltigen Art zum Ausdruck, in der die Arbeiter entlohnt werden. Selten arbeiten sie gegen bloßen Tagelohn, meistens nach mannigfachen Abmachungen, die oft die Grenze zwischen Arbeiter und Pächter verwischen. Neben der Arbeit gegen Anteil treten alle möglichen Zwischenstufen auf.

Die Entwicklung Ägyptens und die zahlreichen, auch gewerblichen Arbeitsgelegenheiten, die sie mit sich bringt. haben das Angebot ron landwirtschaftlichen Arbeitskräften selbst in den dichtest bevölkerten Teilen des Landes verringert, und die bessere Ausnützung des Bodens hat die Nachfrage erhöht. Deshall, ict der Lohn in jeder Form stark gestiegen, obwohl er gegen die europäischen und mehr noch die amerikanischen Verhältnisse zurücksteht. Vor 3 oder 4 Jahren erhielt ein Tagelölner nicht mehr als $2 \frac{1}{2}$ Piaster per Tag, jetzt sellst in Oberägypten $3^{1 ; 2}$ Piaster und zur Zeit größeren Arbeitsbedarfes, z. B. einige Wochen nach dem Anban, wenn das Jäten beginnt, 4 Piaster. Bei Kairo zahlt man his zu 5 Piaster, besonders wenn der Mann sich verpflichtet, das ganze Jahr über nach Bedarf zu erscheinen. Andere, man nennt sie "Tamalieh", erhalten weniger Lohn, aber gegen die gleiche Verpflichtung, jederzeit zur Verfügung zu stehen, das unentgeltliche Benützungsrecht ron Land. Und je wichtiger die Dienste des Fellah erscheinen, desto mehr tritt die Geldlöhnung zurück und die Beteiligung mit Land in den Vordergrund. In einem Falle wurden beispielsweise einem Arbeiter $11 / 2$ Feddán 
zugeteilt. Für 1/2 Feddán zahlte er den vollen Pachtzins von 335 Piastern, für das übrige nur 170 Piaster. Nebst dem Monatslohn von 25 Piastern lag darin die Entschädigung für seine Dienste. Ein kleiner Grundbesitzer ist auf dem Gute eines großen Landwirtes als Aufseher angestellt und erhält dafür $3^{1 / 2}$ Feddán zu 200 Piastern und 81; Feddán zu 375 Piastern verpachtet. Dort, wo Mangel an Arbeitern herrscht, wie z. B. in gewissen Teilen des Fayûm, sucht man die Sache noch anders anzupacken. Da gibt es solche Vereinbarungen:

Der Grundbesitzer stellt den Boden, das Zugvieh, die Maschinen, den Dünger, den Samen bei, zahlt die Steuern und gibt dem Fellah einen Torschuß in Form von Lebensmitteln. Eine Büffelkuh, eine Ziege, Schafe, die ihm Milch geben, hat der Fellah gewöhnlich selbst. Der Besitzer schreibt vor, was zu bauen ist, und beaufsichtigt die erforderliche Arbeit, die der Fellah ganz zu über. nehmen hat. Am Schluß werden die Kosten berechnet, der Pachtzins, die Miete des Zugriehes, der Samen und alles übrige, das der Gutshesitzer beigestellt hat, und rom Werte der Ernte abgezogen. Der Rest wird zwischen dem Besitzer und dem Fellah geteilt, wobei es diesem freisteht, das Getreide in Natura zu übernehmen oder in Geldwert. Sein Konto regelt der Fellah gewöhnlich so, daß er $2 / 3$ aus dem Gewinn der Baumwoll- oder Sommerernte und $1 / 3$ aus dem der Winterernte zurückzahlt. Streitigkeiten bei der Abrechnung sollen fast nie vorkommen.

Beispiel einer Abrechnung: Der Fellah hat ron seiner Erntehälfte zu zahlen:

4 Feddán

Pachtzins ì 400 Piaster $=1600$ Piaster, davon die Hälfte . . . Miete für Zugvieh und Maschinen zur Baumwollackerung 75 Piaster per Feddán $=300$ Piaster, davon die Hälfte Getreidesamen 25 Piaster per Feddán $=100$ Piaster, davon die Hälfte Reis, Bersim, Bohnensamen $=250$ Piaster, davon die Hälfte . . Bewachung 5 Piaster per Feddán $=20$ Piaster, davon die Hälf $\mathrm{e}$ Vorschuß an Naturalien (gewöhnlich 4 Kehle Mais per Monat à 6 Piaster, bei Verheirateten $6-8$ Kehle) . . . . . . Kanalisations- und Drainagearbeiteu 10 Piaster per Feddán $=$ 40 Piaster, davon die Hälfte . . . . . . . . .

800 Piaster

\section{0}

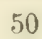

75

10

300

20

1405 Piaster.

Man macht natürlich Abstufungen nach der Bonität des Bodens. Bei schlechtem, stark salzhaltigem Boden, bekommt der Fellah wohl auch die halbe Ernte, ohne daß ihm ein Pachtzins oder 
die Ausgaben belastet werden. Oder er hat bei etwas besseren Boden nichts zu zahlen und bekommt ein Drittel der Ernte. Der Betrag, mit dem der Pachtzins eingestellt wird, unterliegt ebenfalls der Vereinbarung und kann von 50 Piastern bis zu 850 Piastern per Feddán variieren.

\section{Absatz, Preisbildung und andere Einflüsse auf die Produktion.}

Konsum im Lande. - Geldknappheit und Landhunger der Fellahs drücken die Getreidepreise. - Mangelhafte Verkaufsorganisation und das Sprunghafte in Produktion und Preisbildung. - Zülle, Börse und Terminhandel. - Das Verkehrswesen. - Landwirtschaftliche Industrie.

Ein Versuch, die Faktoren eingehend $\mathrm{zu}$ untersuchen, von denen die Preisbildung der Agrarprodukte in Ägypten abhängt, würde den Rahmen dieser Studie sicherlich überschreiten. Aber eine Besprechung der Voraussetzungen der ägyptischen Nationallandwirtschaft kann doch nicht achtlos an der Frage vorübergehen, wie die Absatzverhältnisse und Preise ihrer Produkte beschaffen sind.

Von der Baumwolle abgesehen ist das Land in der Lage, seine ganzen Agrarprodukte selbst zu konsumieren. Einem geringen Export in tierischen und pflanzlichen Nahrungsmitteln steht ein größerer Import gegenüber. Im Jahre 1906/07 ergab sich das Verhältnis:

Export Import

L.E. L.E. L.E.

Tierische Nahrungsmittel . . $131007 \quad 1280039$ (davon Butter 130000 )

(davon Eier 99499 L. E.) Käse 159000 )

Pflanzliche Nahrungsmittel mit

Ausschluß von Baumwollsamen ${ }^{1}$ ) $796397 \quad 2963954$ (davon Mehl 1227 086)

(davon Reis 135430 L. E.)

Fleisch 97000$)$

Erdäpfel 70719 )

Gerste 100354 )

Reis 385569 )

Weizen 112838 )

Tabak 666663$)$

zusammen $\overline{927404} \overline{4243993}$

Vor den importierten Nahrungsmitteln wird der größte Teil gleich in den Ankunftshäfen selbst konsumiert. So ist Alexandrien der

1) Baumwollsamen wurde im Werte von 2393095 L.E. exportiert. 
Hauptkonsument für das Mehl, das aus Marseille kommt, und für den syrischen Weizen ${ }^{1}$ ). Bedenkt man überdies, daß Ägypten nicht das Land grofer zentralisierter Industrieorte ist, die die Produkte etwa aus weiter Ferne an sich reißen, daß seine größten Bevölkerungsdichten vielmehr fast ausschließlich mit den Orten höherer Fruchtbarkeit des Bodens, intensiverer Bodenkultur zusammenfallen, so kann man annehmen, dak der Konsumtionsort im allgemeinen, natürlich wieder mit Ausnahme der Baumwolle, nicht allzuweit rom Produktionsorte zu suchen sein wird. Zudem gibt es überall im ganzen Lande kleinere und mittlere Getreide: mühlen in großer Zahl, in Oberägypten selbst Rohrzuckerquetschen zur Erzeugung primitiven Zuckers, die das gewonnene Material gleich an Ort und Stelle verarbeiten.

Mit dem Näherrücken des Konsums an die Produktion ist aber ein Vorteil für die Landwirtschaft verbunden: Das Wegfallen kostspieliger Transportspesen, die Möglichkeit, das Produkt um den ersparten Frachtlohn teuerer rerkaufen zu können. Dieser Vorteil geht freilich wieder zufolge anderer Umstände verloren. Der Fellah hat selten bares Geld. So wie er eines hat, kauft er sofort Land dafür, oft das gerade verkäufliche Grundstück des Nachbarn, ohne auch nur die Anzahlung aus Eigenem leisten zu können. Die Hypothekenbanken sind ja dazu da, um das Geld zu liefern. Nun hat er Annuitäten über Annuitäten zu zahlen und muk seine Ernte schon am Halm verkaufen oder belehnen lassen. Den Käufer findet er meist in dem Griechen, den jedes Dorf aufzuweisen hat; aber man kann sich leicht denken, daf solche Mukverkäufe nicht gerade geeignet sind, dem Fellah gute Preise zu bringen. Und je geringer die Geldflüssigkeit des Landes ist, desto inehr wird der Preis gedrückt. Der Händler, der so manche Ernte beangabt hat, braucht zu ihrer Übernahme und Auszahlung die Unterstützung der Banken. Die speichern in normalen Jahren das Getreide auf und zahlen den Wert heraus. Sind die Barmittel der Banken knapper, so fehlt die Geneigtheit zu solchen Geschäften. Im Jahre 1907 z. B., während der großen ägyptischen Krise, mußten die Banken mit den Vorschüssen auf Getreide sehr zurückhalten. Das wirkt dann hemmend auf die Kaufkraft und Kauflust der Händler, und da der Fellah zum Verkaufen gezwungen

1) Bulletin mensuel de la Chambre de Commeree internationale de Cairo 30 Sept. 1907 Nr. 9. 
ist, weil er sonst scinen Verpflichtungen nicht nachkommen liann. so wird das Angehot dringender, und die Preise fallen. Die Wechselwirkung bleibt nicht aus. Die Banken werden noch zurückhaltender, der Händler bekommt das Geld noch schwerer vorgestreckt, und der Fellah unterbietet seinen Nachbar noch verzweifelter.

Zarte Rücksichten für das Wohl des Fellahs, Erwägungen allgemein rolkswirtschaftlicher Natur scheinen die Staatsverwaltung nicht bewegt zu haben, als sie im Jahre 1!107 ihren ansehnlichen Jahresbedarf an Getreide in Australien deckte. Das .. War Cffice" allein bezog von dort 38 (nu Ardebs zu Preisen, die sich höher als die ägyptischen Getreidepreise stellten. Dieser bedeutende Abschlußs schlug dem Faßs vollends den Boden aus. Der Fellah verkaufte jetzt um jeden Preis, und der Weizen fiel trotz der Unzulïnglichkeit der Ernte im August auf L.E. 90 das Ardeb.

Als dann größere Quantitäten in die Hände der Händler und Müller übergegangen waren, die mehr Toraussicht und mehr Fühlung mit der Welt haben, begann der Markt sich zu crholen. Man erinnerte sich mit einem Male, daß der Ausfall der Ernte und die Lage des Weltmarktes endlich auch in Ägypten in der Preisbildung zum Ausdruck kommen müsse.

Für den Fellah, der schon den größten Teil seincr Fechsung verkauft hatte, kam die Steigerung freilich zu spät. Der Mangel an Verkaufsorganisationen, das Fehlen landwirtschaftlicher Genossenschaften macht sich in solchen Fällen stark fühlbar. Die Produktion bleibt immer sprunghaft, und die Vertrautheit mit den eigenen Bedarfsverhältnissen, mit den Vorgängen auf dem Weltmarkte ist gering. Ein Beispiel:

Die Gerste dient nur in einigen, sehr armen Dörfern als menschliches Nahrungsmittel, im übrigen ausschließlich als Viehfutter. Wie zu Beginn des landwirtschaftlichen Aufschwunges der Viehstand stark vermehrt wurde, dachte niemand daran, dem steigenden Bedarf an Gerste durch erhöhte Produktion Rechnung zu tragen, und Viehfutter wurde ein rarer Artikel. Nun kam die Zeit der weiteren ausgedehnten Bodenerschliefungen. Jungfräuliche Böden müssen mindestens zwei Jahre andere Früchte tragen, bevor sie der kostbaren Baumwollstaude als Standort dienen können. Diese zwei Jahre bauten jetzt alle Gerste. Auf einmal war sie massenhaft da, besonders in der Gegend ron Guergueh, und im F a y ûm produzierte man enorme Quantitäten davon. Eine einzige 
Domäne lieferte oft 15-20000 Ardeb, und der Preis fiel auf 40-45 Piaster per Ardeb. Nach zwei Jahren waren die Böden für die Baumwolle vorbereitet, und die Maßnahmen der Regierung, vor allem der Ausbau der Bewässerungsanlagen, führten weitere große Länderstrecken, die bisher nur Getreide hervorgebracht hatten, der Baumwollkultur zu. Mit deren Rentabilität kann sich die Rentabilität des Getreidebaues nicht im entferntesten vergleichen. Der Fellah baut also so viel Baumwolle, als irgend möglich, baut sie nicht bloß jedes dritte oder vierte Jahr, wie es die starken Ansprüche der Pflanze an die Bodennährstoffe und die übrigen physiologischen Eigenschaften erfordern würden, sondern oft schon jedes zweite Jahr. Die mit Baumwolle bebaute Fläche steigt zufolge aller dieser Umstände von 1121261 Feddáns im Jahre 1898 auf 1603224 Feddáns in 1907.

Die Folgen bleiben nicht aus: quantitativ und qualitativ gehen die Erträge der Baumwolle zurück, und die ungenügende Produktion von Zerealien macht das Land mehr und mehr von den fremden Märkten abhängig. 1:104 importiert man, um auf unser Beispiel zurückzukommen, 250000 Mc Gerste, 1906 schon $310000 \mathrm{Mc}$; der Export beträgt in dicsem Jahr nur noch 140 Ardeb. Als schlechte Ernten in Cypern und Syrien im Jahre 1907 die Leichtigkeit der Zufuhr verringern, steigt der Preis der Futtergerste von L.E. 70 per Ardeb auf L.E. 105.

Das Beispiel dürfte zeigen, dafí das Auf- und Niederschwanken der Preise unter dem Einflusse lokaler Verhältnisse in Ägypten stärker als bei uns vor sich geht. Diese Erscheinung wird auch durch den Umstand nicht beseitigt, daß Ägypten zufolge seiner niederen Getreidezölle dem ausgleichenden Einflusse der Weltmarktpreise mehr als unsere Länder unterworlen sein sollte. Für Bodenprodukte ist bei der Einfuhr bloß ein $8^{\circ}$ o iger Wertzoll zu entrichten. Die Herabsetzung der früheren Vertragszölle auf dieses Maß ist eine Folge der Konvention zwischen Ägypten und Frankreich vom Jahre 1902. Dem Khedive steht das Recht zu, solche Konventionen, die auf Zoll- und Handelswesen Bezug haben, mit fremden Mächten selbständig abzuschließen, sie müssen aber vor der Promulgation durch den Khedive der Hohen Pforte mitgeteilt werden. Ägypten hat solche Verträge mit den Vereinigten Staaten von Amerika und einigen anderen Staaten auf Grund des Zollreglements vom Jahre 1884 abgeschlossen. Später kam dann 1889 ein Vertrag mit England, 1890 mit Österreich-Ungarn und 
Portugal, 1891 mit Belgien, 1892 mit Deutschland und Italien usw. zustande, und alle diese Verträge helegten die Bodenprodukte mit cinem Einfuhrzoll von $10 \%$. Zufolge der Meisthegünstigungsklausel fielen die Errungenschaften des französischen Vertrages dann allen andern Vertragsstaaten zu. Die Tabakeinfuhr wurde durch separate Abmachungen geregelt, in denen sich die ägyptische Regierung das Recht vorbehielt, die Einfuhr autonom zu beschränken oder ganz zu verbieten.

So wenig die Geringfügigkeit der Zölle imstande war, die unaufhörlichen Fluktuationen der Preise einigermaßen zu mildern, so wenig hat sich ein solcher Einfluli der Börse im Interesse des Fellahs bemerkbar machen können. Es wäre das von den Preisnotierungen der Börsen von Alexandrien und Kairo zu erwarten gewesen, die den Fellah über den Preis, den er beanspruchen darf, unterrichten sollten. Die Organisation der Bürse scheint indessen bisher viel zu wünschen übrig zu lassen und recht empfindliche Nachteile mit sich zu bringen. Das Effektivgeschäft in den wichtigsten Ausfuhrartikeln, in Baumwolle usw., geht an der Warenbörse Minet el Bassal in Alexandrien vor sich. Nach mitgebrachten Proben werden dort die auf der Bahn oder auf dem Nilboot zugeführten Waren verkauft. Alle großen Exporthäuser Alexandriens sind dort ständig vertreten; die Kurse werden da aber ebensowenig festgesetzt, wie nach den effektiven Geschäften in den Importartikeln. Es gibt überhaupt keine amtliche Feststellung der Kurse, sondern nur eine solche durch das Ǩomitee der "Association des Courtiers en Marchandises". Und diese Feststellung erfolgt nach den riesigen Umsätzen der Termingeschäfte, die nur durch Differenzzahlung geregelt werden und in keinem Verhältnisse zu den effektiven Geschäften stehen. Grunzel, der die Zustände an der Alexandriner Börse eingehend studiert hat, sagt in seinem Berichte darüber: „Die Börse umgibt ein ungeheuerer Troß von Outsiders, welcher durch maßlose Engagements alle Preisfluktuationen verschärft, indem alles kauft, wenn die Preise steigen, und alles verkauft, wenn die Preise fallen. Die heftigsten Preisschwankungen sind die Folge, ohne dab sich das Verhältnis zwischen Angebot und Nachfrage in effektiver Ware wesentlich geändert hätte. Die Spekulationswut des Publikums wird wesentlich unterstützt durch die Organisation der Alexandriner Börse, welche die denkbar größte Freiheit genießt. Das Gewerbe der Mäkler, Courtiers, ist frei zugänglich und unterliegt nur jenen 
Normen, welche sich diese selbst gegeben haben. Wir finden als Courtiers auch Aktiengesellschaften und Banken. Der Courtier macht Geschäfte für eigene Rechnung und bildet die Gegenpartei seines Klienten. Jede behördliche Aufsicht fehlt. Der Courtier beschäftigt wieder eine Anzahl ron Agenten, die sogenannten Remisiers, welche ihm gegen eine bestimmte Provision die Klientel aus dem ganzen Lande zutreiben. Den zweifelhaftesten Elementen ist hiermit ein freier Spielraum gegeben, die Börse selbst gleicht tatsächlich weniger einem Markte als einer Spielhölle."

Um diesen Übelständen, die noch durch ungleiche Entscheidungen der internationalen gemischten Gerichtshöfe in Angelegenheiten des Differenzeinwandes bei Termingeschäften verschärfft wurden, abzuhelfen, hat sich die ägyptische Regierung in leizter Zeit veranlaßt gesehen, der Konferenz der diplomatischen Vertreter der Signatarmächte einen Gesetzentwurf über die Reorganisation der Börse rorzulegen. Der Entwurf anerkennt den Terminhandel, will ihn aber durch Beseitigung des Einwandes von Spiel und Wette auf eine solidere Basis stellen.

Wenn an früherer Stelle der Vermutung Raum gegeben wurde, daß Produktions- und Konsumtionsorte in Ägypten nicht allzuweit auseinander liegen dürften, so ist dabei selbstverständlich nur an die gebräuchlichen landwirtschaftlichen Nahrungsprodukte gedacht worden. Der Hauptartikel der dortigen Bodenerzeugung, die Baumwolle, der nicht weniger als $95^{\circ}$ o des gesamten Exportes ausmacht, hat im Gegensatz hierzu weite Strecken zu durchlaufen. Von den Bohnen werden auch noch immer ansehnliche Mengen ausgeführt, von den Zerealien gewisse vorzügliche Qualitäten, um in Ägynten durch ausländische billigere Sorten ersetzt zu werden. Das ist z. B. beim Reis der Fall, während die Einfuhr anderer Produkte, wie die der Futtergerste, des Weizens, mehr oder weniger große Verschiebungen der Konsumtionsgebiete hervorruft. Hier rerringern sich die Vorteile der Konsumtionsnähe für den Produzenten im selben Maße, wie die Entfernung zunimmt, und können nur durch die Entwicklung des Verkehrswesens eingeholt werden. Deren Grad ist deshalb für die Beurteilung der Absatzverhältnisse von Wichtigkeit und das um so mehr, als der Leichtigkeit des Verkehrs die Tendenz innewohnt, die Preise auszugleichen und beständiger zu gestalten.

Die äußere Gestaltung des Verkehrs, die sich aus der Lage des Landes zwischen zwei Meeren und aus dem Bestehen des Suez- 
kanales ergibt, ist hinlänglich bekannt. Schon die grofore Zahl drer Ïgypten den Weltverkehr vermittelnden auslündischen Sehiffahrts. gesellschaften verbürgt relativ günstige Terkehrsverhältnissor. und bringt es mit sich, dalis die Errungenschaften des modernen seewesens auch diesem State zugute kummen müssen. Unab. hängiger rom Fortschritt des Weltverkehrs entwickelt sich das innere Transportwesen eines Landes. In Ägypten ist das Verkehrsnetz recht dicht gespannt, und Transportlinien, die sich ergänzen oder gelegentlich den Vorrang streitig machen künnten, gibt es genug. Da sind die altehrwürdigen Karawanenwege, die festen Landstraßen, zum Fortschaffen der landwirtschaftlichen Produkte eigens gebaut, da ist der Nil mit seinen Kanälen und die wachsende Menge der Schienenstränge. Wie in so vielen

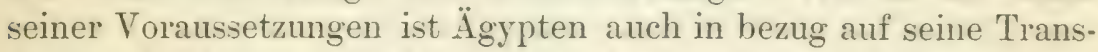
portmöglichkeiten glücklich reranlagt. Keine nennenswerten Terrainschwierigkeiten stellen sich dem Bau seiner Straben und Eisenbahmen entgegen; der wichtigste Teil seines Terkehrs vollzieht sich längst des Nils oder seiner Kanäle, in dem ebenen Fruchtland, das sich an den Ufern der Wasseradern hinzicht. Fast das ganze Transportbedürfnis konzentriert sich dort. Die Wege werden weder durch Regengüsse durchweicht noch durch Lawinen verschüttet, und die Ausdauer und Anspruchslosigkeit des Dromedars erhöhen den Wert der Landstraßen, wie sie die Trüste passierbar machen. Selbst Kanäle, in unseren Ländern der Zukunftstraum der Transportpolitik, stehen in Ägypten ron der Bewässerung her zur Verfügung. Da haben sich nun diese Transporteinrichtungen entwickelt:

Karawane nwege. Den Wüstenstraßen zu den Oasen und zum Meeresstrand kommt heute lange nicht mehr die Bedeutung zu wie ehemals. Sie stellen eine aussterbende Form ron Verkehrsweg dar, die wohl über kurz oder lang der Konkurrenz des modernen Transportwesens erliegen wird. Gegenwärtig sind ron wichtigeren Karawanenwegen noch der von $\mathrm{Keneh}$ nach $\mathrm{K}$ osseir am Roten Meer, rom Niltal nach den Oasen Kargeh und Siwah und weiter nach Benghasi und von Kantara an Suezkanal nach el Arisch im Osten im Gebrauch.

Im Nubischen Teile von Oberägypten wäre vielleicht noch die Wüstenstraße von Korosko zu erwähnen, die ron dort in neun bis zehn Tagen nach Abu Hamed am Nil führt. Der Verbindungsweg nach dem Sudan, von W adi Halfa nach D ongola 
und von dort durch die Bajûdha-Steppe nach Khartum war stets sehr beschwerlich, da die Bajûdha-Steppe, wie ich aus eigener Erfahrung weiß, wenig Brunnen und entsetzlich viel Sandstürme aufzuweisen hat. Seit der Eröffnung der Bahn von W â di $\mathrm{Halfa}$ nach Khartum hat er seine Bedeutung ganz verloren.

Landstraßen, mit festem Unterbau, kannte man noch vor wenigen Jahren nur in der nächsten Umgebung von Kairo und Alexandrien. Neuerdings wird solchen Kommunikationen auch im Interesse der Bewegung landwirtschaftlicher Erzeugnisse mehr Beachtung geschenkt. Der Bericht Lord Cromers vom Jahre 1905 stellt fest, daß Ägypten $2552 \mathrm{~km}$ Landstraßen, „Agricultural Roads" besitzt. In der Berichtperiode waren L.E. 11600 für deren Instalthaltung aufgewendet und $87 \mathrm{~km}$ neue Straßen um den Betrag von L.E. 22000 angelegt worden.

Auch die Entwicklung der Eisen bahnen gehört der letzten Zeit an. 1890 standen erst $1547 \mathrm{~km}$ im Betrieb, 1905 schon $5204 \mathrm{~km}$. Der Umfang hat sich demnach mehr als verdreifacht. Dennoch kommen auch gegenwärtig nur $0,5 \mathrm{~km}$ Bahnlänge auf $100 \mathrm{qkm}$. Wie wenig das verglichen mit unseren Ländern ist, zeigen deren Zahlen. Deutschland besitzt $10,4 \mathrm{~km}$ auf $100 \mathrm{qkm}$, Österreich-Ungarn inklusive Bosnien $5,9 \mathrm{~km}$ auf $100 \mathrm{qkm}$. Ägypten besitzt aber verhältnismäßig mehr Eisenbahnen, als die bloße Zahl verrät, weil das fruchtbare Land eng zusammengerückt ist und nur einen kleinen Teil der Gesamtfläche des Landes ausmacht. Die Hauptlinien sind zumeist Statsbahnen. Die sogenannten "Light Railways" stehen durchwegs unter privater Ägide von drei Gesellschaften. Diese schmalspurigen Feldbahnen, zum Transporte der Agrikulturprodukte erbaut, tragen viel zur Förderung der Landwirtschaft bei. Der offizielle englische Rapport vom Jahre 1906 führt $1145 \mathrm{~km}$ solcher landwirtschaftlicher Bahnen im Betriebe an, auf denen 929000 tons Güter befördert wurden. Der Gesamttransport des Jahres betrug auf allen Bahnen zusammen 6712019 tons, davon 2795346 tons für eigene Zwecke der Bahnadministration.

Es wäre ein leichtes, hier ein vollständiges Verzeichnis der Bahngesellschaften, ihrer Kapitalien und Erträge und ihrer Linien anzuführen, wje das bei ähnlichen Berichten meist üblich ist. Dergleichen Daten würden indessen dem Fernerstehenden kaum ein Bild von der Bedeutung des ägyptischen Bahnwesens für die dortige Landwirtschaft geben. Nicht einmal die Länge der Linien 
und die Menge der beförderten Güter werden uns viel sagen. denn sie stellen ein Endergebnis vor, ohne Einblick in die Gruppierung der Einzelposten zu gestatten, aus denen sich jenes aufbaut. Die Richtung, in der die Transporte erfolgen, ist daraus ebensowenig zu ersehen als die Länge des Weges, den die einzelnen Warenmengen zurückgelegt haben, und die Höhe der Belastung, die der Tarif den landwirtschaftlichen Erzeugnissen auferlegt. Ein tieferes Eindringen in den subtilen Organismus der ägyptischen Verkehrspolitik würde andererseits ausgedehnte Spezialstudien erfordern und überdies diesen Bericht weiter als beab. sichtigt ausdehnen. Deshalb bleibt nur der Versuch übrig, Wahrscheinlichkeitsschlüsse aus einzelnen Tatsachen zu ziehen. Eine solche Tatsache kann man vielleicht in der Leidensgeschichte der ägyptischen Staatsbahnen erblicken. 1880 kamen sie durch das Liquidationsgesetz unter internationale Verwaltung, in der je ein englischer, französischer und ägyptischer Delegierter saß. Der Reingewinn sollte in die "Caisse de la dette publique fließen. Um ihn recht zu sichern, wurde die Höhe der zulässigen Betriebsausgahen im Verhältnis $\mathrm{zu}$ den Bruttoeinnahmen im rorhinein festgelegt und jede neue Investition zur Verbesserung des Betriebes an die vorherige Genehmigung der Staatsschuldenverwaltung: gebunden. Die Betriebsausgaben waren indessen mit den bedungenen $45 \%$ unzureichend dotiert, und auch die später zugebilligte Erhöhung auf $55 \%$ reichte nicht hin, um die teuer gewordenen Kohlen und Materialpreise und die gestiegenen Arbeits. löhne zu decken. Es fehlte an Lokomotiven, fehlte an den nötigsten Betriebsmitteln, die der wachsende Verkehr erforderte. Indem man vor jeder Investition zurückschreckte, mußte die Verwaltung der Bahnen nachgerade einer Gutsverwaltung ähneln, die den Boden nicht bepflanzt, damit der Vorrat an Bodennährstoffen erhalten bleibe.

Der offizielle Bericht des englischen Generalagenten rom Jahre 1906 sagt es geradeheraus: "Die Administration der Staatsbahnen stand dank diesem System, das die politische Notwenaigkeit diktiert hatte, ror dem gänzlichen Zusammenbruch."

Das englisch-französische Abkommen des Jahres 1904, die Folge der Marokkopolitik Frankreichs, hat den administratiren Bestrebungen Englands mehr Bewegungsfreiheit geschaffen und auch den unhaltbaren Zustünden in der Eisenbahnverwaltung eir: Ende bereitet. Nun erst schreitet die Neuorganisation des ägyr. 
tischen Staatsbahnbetriebes unter Major J o h n s t o n es energischer, zielbewußter Leitung tüchtig vorwärts. Man hat der Verbesserung d(r Betriehsmittel L.E. 3000000 aus dem Reservefonds gewidmet und trägt sich mit dem Plane, eine weitcre Million diesem Zwecke zuzuwenden. Nun sieht der Bericht den Himmel der ägyptischen Staatseisenbahnen wieder voller Geigen.

An eine Tarifpolitik in volkswirtschaftlichem Sinne kamn wohl nicht gedacht werden, bevor die Grundlagen eines geregelten Betriebes gegeben sind. Das war, wic wir gesehen haben, his zum Jahre 19014 nicht der Fall, und deshalb wird die Bodemproduktion bis dahin wenig Unterstützung durch die Staatshahnen gefunden haben. Eine andere Tatsuche scheint das zu hestätigen. In den Jahren 1902 und 190:; wurden die Gütertarife auf kuze Distanzen unter dem Konkurenzurucke der Binnenschiffahrt herabgesetzt, auf größere Entfernungen hingegen noch crhöht. Die schwere Schädigung des agrarischen Exportes veranlatite damals die Alexandriner Kaufleute zu einer Denkschrift, die ausführte, dabs die ägyptischen Eisenbahnfrachttarife kaum niedriger wären als die früheren Kamelfachtsütze. Nach diesen stellte sich der Transport per Tonne und Kilometer ciurchschnittlich auf 0,47 Franks, während lie Eisenbahnfrachtsätze bis zu 0,40 Franks per Tonnenkilometer gingen. Das sind allerdings enorme Transportpreise, die sich nach der Reorganisation der Bahnrerwaltung gewiß nicht mehr wiederholen werden. Aber wenn man auch eine Terbilligung des Terkehrs erwarten darf. so wirl diese doch kaum der Ausflug piner Transportpolitik in agrarischen Sime sein. Die Herabsetzung der Tarife wird voraussichtlich dem Konsumenten ebenso zugute kommen als dem Produzenten, ein Cnterschied zwischen den Import- und Exportfrachtsätzen eher zugunsten jener als zugunsten dieser gemacht werden. Ein anderes Vorgehen würde der sonstigen Handelspolitik des englischen Weltreiches, das in İgpten in so gewichtiges Wort zu reden hat, nicht entsprechen. Eine Förderung in der Richtung hat der ägyptische Landwirt noch nicht $\mathrm{zu}$ erwarten.

Bei den lcichten landwirtschaftlichen Eisenbahnen der Privatgevellschaften gibt es keine andere Politik als die des Reingewinnes. Sie entwickeln ihren Verkehr ganz gut und rentieren wich dabei. scheinen also im wohlverstandenen 'Eigeninteresse iiuch dem Interesse ihrer landwirtschaftlichen Kunden Rechnung zu tragen. Klagen hört man nichtsdestoweniger auch über ihre 
Verwaltung: Die Stationen enthiciten nicht genug Lagerräume, was sich besonders beim Baumwolltransport unangenehm fühlbar mache.

Die Binnenschiffahrt $\ddot{A}$ gyptens steht, so überraschend das hei dem Lande mit der ältesten Wasserwirtschaft klingen mag. gleichfalls erst in ihren Anfängen. Erklärungsgründe gibt es genue dafür. Das Flußbett des Nils ist seicht und der viele Schlanm dè Schiffahrt gerade so hinderlich, als dem Boden nützlich. Ohwoh! alle Nilfahrzenge ungemein flach gebant sind, ist ihr fortwährender Auffahren unvermeidlich und bringt zumindest Zeitverlust mit sich. Die Vorrichtungen zum Aufstauen des: Wassers hilden gleichfalls Verkehrshindernisse, die selbst die Sehleusenanlagen! nicht ganz beseitigen. Wer eimmal sein Boot durch die Anlagen von Assuan durchschleusen liek, weif, wie endlos lang das dauert. Die Kanäle sind zwar vorhanden, aber sie lassen sich nicht olne weiteres für die Schiffahrt rerwenden. Un sie dazu geeignet zu machen. braucht es wieder Geld, viel Geld. Man war frril, die Mittel für die Kanäle als Bewässermgsanlagen aufzuhringen. für ihren anderen Zweck blieb nichts übrig.

Dabei ruhten bis vor kurzem allerlei Lasten und öffentliche Ahgaben auf den schiffbaren Strecken. Tonnengebühren, Schleusenund Brückenmauten, Überfuhrsabgaben, Erlaubnisscheine wett. eiferten, diese Verkehrsader'n zu unterbinden. Von 191)-191.:) räumten verschiedene Dekrete ein solches Erschwernis nach dem anderen fort; alle Schiffsgebühren auf dem Nil und seineu Kanälen sind jetzt aufgehoben. Und nun mehren sich die Schiffahrtsgesellschaiten und bemühen sich einander und den primitiven arabischen Segelbooten den Rang abzulaufen. Von Jalu zu Jahr vächst der Frachtenverkehr auf dem Nil und seinen Kan̈̈len, am stärksten zwischen Alexandrien und Kairo. An dem Kasr-el. Nil bei Kairo wimmelt es ron Schiffen, und der Alf Lock. die Verbindung des Mahmoudieh-Kanals mit dem ivil, wurle im! Jahre 1905 bereits ron 2206$)$ Schiffen befahren; gegen $45 t i 1$ im Jahre 190\%. Die Bimnenschiffahrt zeigt also. zweilellos Ansätze einer Entwicklung, die un so wertvoller wäre, als sich der Wassertransport in $\ddot{A g y p t e n}$ schon heute zirka $25 \%$ billiger als die Eisenbahnfrachten stellt und übertriebenen Erhöhungen dieser wirksam entgegentritt. Von der vollen Ausnutzung der gï̈nzenden natürlichen Bedingungen ist die Binnenschiffahrt aber womöglich noch weiter entfernt als die Eisenbahnen und dio übrigen Transportmittel. 
Der Wunsch nicht allzu weitschweifig zu werden, läßst mich an der Entwicklung des Post- und Telegraphenwesens und an manchen anderen Dingen vorübereilen, die alle von Einfluf auf die landwirtschaftlichen Absatzverhältnisse sind. Nur eines soll der wesentlichen Bedeutung für die Landwirtschaft halber noch besprochen werden: die landwirtschaftliche Industrie. Das heißst, ron wesentlicher Bedeutung für die Landwirtschaft der meisten Länder, jedoch kaum für die Landwirtschaft Ägrptens. Nur wenig von dem, was das Interesse unserer Bodenkultur für die landwirtschaftliche Industrie begründet, findet sich in Ägypten wieder. Ubberhaupt in Frage kommen nur die Zuckerund die Spiritusindustrie, die Mühlerei, die Ölfabrikation. In gewissem Sinne vielleicht noch die Baumwollindustrie, insofern auch diese in Ägypten den Rohstoff zu sofortiger Verarbeitung an Ort und Stelle vorfinden könnte.

Die Zuckerfabrikation nimmt bei uns die erste Stelle in der landwirtschaftlichen Industrie ein. Sie liefert außer Zucker und Melasse Quantitäten wertvollen Viehfutters, die kostbaren Mineralbestandteile kehren größtenteils in diesen wieder in den Boden zurück; die höheren Ackererträge der Nachfrüchte ersetzen die Unkosten, welche dic intensivere Bodenarbeit verursacht hat. Nebenbei schaffen der Rübenbau und die Zuckerfabrikation fast das ganze Jahr dauernde Arbeitsgelegenheiten für die landwirtschaftlichen Arbeiter und bewahren dadurch den Getreidebau, die Wiesennutzung vor noch größerer Landflucht, noch empfindlicherem Arbeitermangel.

Nichts von alledem trifft bei der Rohrzucherproduktion zu. In Ägypten, wo man das ganze Jahr über bauen und erntei kann, gibt es jederzeit genug Arbeit; das Rohr erhöht den Ertrag der Nachfucht nicht, läßt im Gegenteil den Boden in ausgesogenem Zustande zurück, und auch die Rohrrückstände, die zur Feuerung dienen müssen, liefern kein Vichfutter. Dabei sieht dei ägyptische Landwirt nicht mit Unrecht einen großen Nachteil des Zuckerrohres in dessen langer Vegetationszeit. An zweimaliges Ernten, was zweijährigen Stand voraussetzt, Genkt man ohnedies in Ägypten nicht, und das oftmalige Bewässern treibt die Pflanze zu rascherem Wachstum. Sie wird im Februar und März, zum Teil noch im April gepflanzt und im Dezember-Januar geerntet. Aber dann erreicht das Rohr nur in besonders günstigen Jahren einen Durchschnittsgehalt ron $14 \%$ Zucker, weil es nicht Zeit hatte, wirklich auszureifen. 
Die Krisen der ägyptischen Zuckerindustrie sind bekannt. Man weil von den schlechten Geschäften, welche die Daira Sanieh damit gemacht, und von der gegenwärtig fast ausschlieflichen Konzentration der gesamten Zuekerindustrie in den Händen der Société Générale des Sucreries. Diese arbeitet jetzt mit cinem Aktienkapital von $91 / 4$ Millionen Franks und einem Obligationsanlehen von 3 Millionen. Aber wenn jetzt auch vorübergehende Erfolge erzielt werden, wenn das Auberbetriebsetzen veralteter Fabriken, die Vereinigung der Produktion in wenigen, modern eingerichteten Etablissements die Lage der Gesellschaft auch verbessert hat, die ägyptische Zuckerindustrie wird doch stets eine Treibhauspflanze ohne rechte Lebensfähigkeit bleiben, weil sie keinem Bedürfnisse der Landwirtschaft entspringt, keinem dient. Der Fellah wird stets mit mehr Vorteil seine Baumwolle bauen und der Fabrikant stets über ungenügende Mengen und ungenügende Qualität von Rohr zu klagen haben. Und darüber kann die Rohrzuckerindustrie nicht hinauskommen. Selbst der Weg, eigene Ländereien in ausreichender Menge anzukaufen, wäre ungangbar, weil die Bodenpreise, welche die Baumwolle in die Höhe getrieben hat, für die Zuckerindustrie ruinös wrären. Es ist deshalb nicht erstaunlich, daß die Rohverarbeitung stark zurückgeht. 1906 betrug die Zuckerrohrernte 700000 Tonnen, $1907=500000$ Tonnen, während 1908 nur 400000 erwartet werden.

Es ist vielleicht der Erwähnung wert, daß die Rohrzuckerfakrikation in Ägypten bei den Arabern Gegenstand einer Art Hausindustrie ist. In kleinen primitiven, durch einen Büffel bewegten Mühlen wird das Rohr meist mittels Holzzylinder ausgeprefic und in offenen Verdampfpfannen eingekocht. Das Produkt bringt man in geschlossenen Tontöpfen als Honig (Aszal) in den Handel. Trotz der primitiven Arbeitsweise - die Rückstände, die sogenannte Bagasse, die zum Heizen verwendet werden, sollen immer noch 4-5\% Zucker enthalten - bilden die Mühlen eine nicht unbedentende Konkurrenz für die ägyptische Zuckerfabrikation, weil ihre Spesen äußerst gering sind, weil die eigene Arbeit kaum bewertet wird, und weil die Eingeborenen diesen Honig jedem anderen Zucker vorziehen.

Die Spiritusindustrie hat für die ägyptische Landwirtschaft gleichfalls nicht die Bedeutung wie für die unsere, weil sie ausschließlich die Melasse der Zuckerfabriken aufarbeitet. Die Landwirtschaft hat ihr nichts $z u$ liefern und gewinnt nichts 
durch sic. Die Bierbrauerei bezieht Malz und Hopfen ausschlieflich aus dem Auslande, größtenteils aus Österreich.

Die Mühlenindustrie kommt der Landwirtschaft am meisten durch die kleinen Mühlen zugute, die man in allen Dürfern im Inneru des Landes findet. Fast überall sind es noch primitive Handmühlen; nur an der Meeresküste, bei Ramleh. Abukir, gibt es einige Windmüllen. Wassermühlen sind zufolge des geringen Nilgefälles ausgeschlossen. Diese kleinen Mühlen verarbeiten das Getreide ihrer Gegend und setzen das Mehl dort wieder ab. Die Frachtersparnis und die geringen Betriebskosten erhalten sie lebensfähign, wälırend die Dampfmühlen der Société Anonyne des Moulins d'Egypte in Alexandrien, Kairo, Tanta, Tahta und Akmin schwer gegen die übermächtige Auslandskonkurenz anzukämpfen haben und ihre Zufucht vielfach zu billigerem ausländischem Getreide nehmen:

Sonst gibt es in Ägypten nur noch eine, ihrem Charakter nach landwirtschaftliche Industrie. die den unmittelbaren Interessen der Landwirtschaft entspricht, die Erzeugung von Ba umwollsamenöl. Sie besitzt vor allem den Vorteil, daß ihr Rohunaterial. der unvermeidliche Begleiter der Baumwolle, in ungeheuerer Menge gewonnen wird. Das Gewicht der Samenhaumwolle besteht in Durchschnitt zu zwei Dritteln aus Samen und zu einem Drittel aus Baumwolle. Selbst bei den hochgezüchtetsten Sorten hat sich dieses Verhältnis nicht günstiger gestalten lassen, als $60 \%$ Samen zu $40 \%$ Baumwolle. Man kann danach leicht berechnen, wie enorm viel Samen die jährliche Bammwollernte Ägyptens von nahezu 7 Mill. Kantars (à 44,928 kg) ergilut. Im Jahre 1907 wurde Baumwollsamen im Werte von nicht weniger dem L.E. 2555067 exportiert. Jede weitere Ölpresse bedeutet da un so mehr eimen Vorteil für die Landwirtschaft, als sie dieser nicht nur das Rohprodukt abnimmt, sondern auch wertvolles Futter in den Rückständen liefert. Die Landwirtschaft macht vorläufig davon allerdings geringen Gebrauch und verfüttert zumeist nur die Abfälle der Ölkuchen, während diese selbst ausgeführt werden. 1907 gingen Kuchen für L.E. 211251 ins Ausland, obwohl der Preis von zirka 81/2 Mk. per 100 Kilo im Verhältnis zum Futterwert gering ist und das Verfüttern im Lande wohl lolinen würde. Der Ölexport von L.E. 10692 läßst aagegen auf namhaften Eigenkonsum schließen; denn es sollen gegenwärtig gegen 150 Pressen in Betrieb stehen, darunter nicht 
Jie politischen Vorausetzungen der ägyptischen Lavdwirt-chaft. Di

allein die kleinen Pressen der heimischen Erzeuger in Al:xandrien und im Innern des Landes, sondern auch die der mondexnern Industrieunternehmungen der Kafr-el-Zayat Cotton Co.. den. Socièté des Huileries et des Savonneries d'Egypte und der Salt and Soda Co. Die erste Gesellschaft allein hesitzt th grolir. Pressen.

Die sonstige fabrikmäfige Terarbeitung der Hauptkulturptianz: Ägyptens hat dagegen für die dortige Landwirtschaft keine unmittelbare Bedeutung. Es gil,t wohl Baunwollspinnereien uni Webereicn, aber sie erzeugen ihre billigen Mussenartikel nicht aus der feinen ägyptischen Baumwolle, sondern aus der nur halh, so teneren minderen amerikanischen Bamwolle. 


\section{Viertes Kapitel. \\ Der Betrieb.}

\section{Die Organisation.}

Verteiluns der Anbaufläche. - Winter-, Sommer- und Nilkulturen. - Fruchtwechsel und assimilatorischer Effekt.

Verteilung

$\left.1904^{1}\right)$.

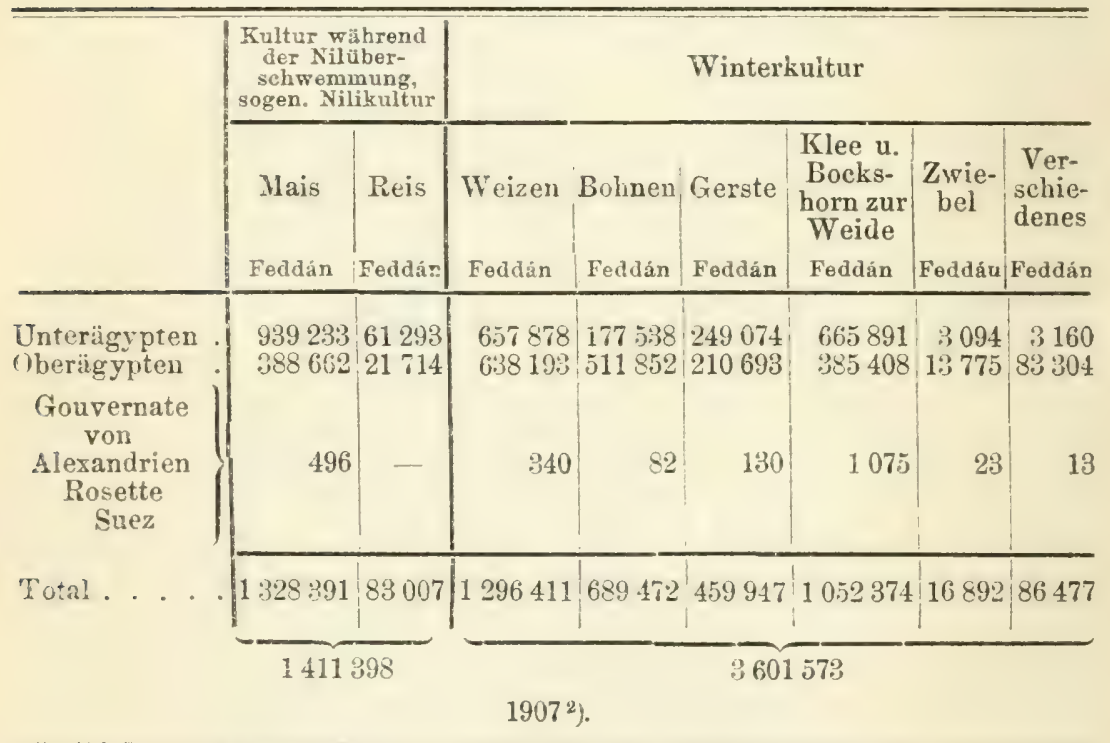

\begin{tabular}{|c|c|c|c|c|c|c|}
\hline & \multicolumn{2}{|c|}{ Nilikultur } & \multicolumn{4}{|c|}{ Winterkultux } \\
\hline & $\begin{array}{l}\text { Mais } \\
\text { Fecỏán }\end{array}$ & $\mid \begin{array}{c}\text { Reis } \\
\text { Foddán }\end{array}$ & $\begin{array}{l}\text { W eizen } \\
\text { Fodđán }\end{array}$ & $\left\{\begin{array}{l}\text { Bohnen } \\
\text { Fedidán }\end{array}\right.$ & $\begin{array}{l}\text { Gerste } \\
\text { Fedian }\end{array}$ & $\left|\begin{array}{c}\text { Zwie- } \\
\text { bel } \\
\text { Foddản }\end{array}\right|$ \\
\hline $\begin{array}{l}\text { Unterïgypten } \\
\text { Oberägypten }\end{array}$ & $\begin{array}{r}1128278 \\
494710\end{array}$ & $\begin{array}{l}65088 \\
19001\end{array}$ & $\begin{array}{l}6 \frac{1}{2} 4305 \\
572955\end{array}$ & $\begin{array}{l}124408 \\
471035\end{array}$ & $\begin{array}{ll}256 & 114 \\
201 & 503\end{array}$ & \begin{tabular}{|r|}
8647 \\
19844 \\
\end{tabular} \\
\hline Total . . . & 1622988 & $8+0 \triangleleft 9$ & 1217260 & 595443 & 457617 & 28491 \\
\hline
\end{tabular}

1) Nach den mir vom ägyptischen Ministerium zur Verfü gung gestellten Daten.

2) Nach Daten der Khedivial-Agrikultur-Gesellschaft. 
Aus den Voraussetzungen, die in den beiden letzten Kapitcln behandelt wurden, ergibt sich die ganz besondere Art des ägyptischen Landwirtschaftsbetriehes mit zwingender Selbstverständlichkeit. Fin diesen ist gleich die Verteilung der Anbaufläche ungemein charakteristisch. Da findet sich die seltsam anmutende Gliederung in Winter-, Sommer- und Nilikulturen. Die Frage drängt sich aui: Kann man in Ägypten tatsächlich dreimal in einem Jahre säen und ernten? Und man fragt sich weiter, welche Umstände das ägyptische Ackerjahr in diese Kulturperioden zerlegt haben.

der Anbaufläche.

1904. $\left.{ }^{1}\right)$.

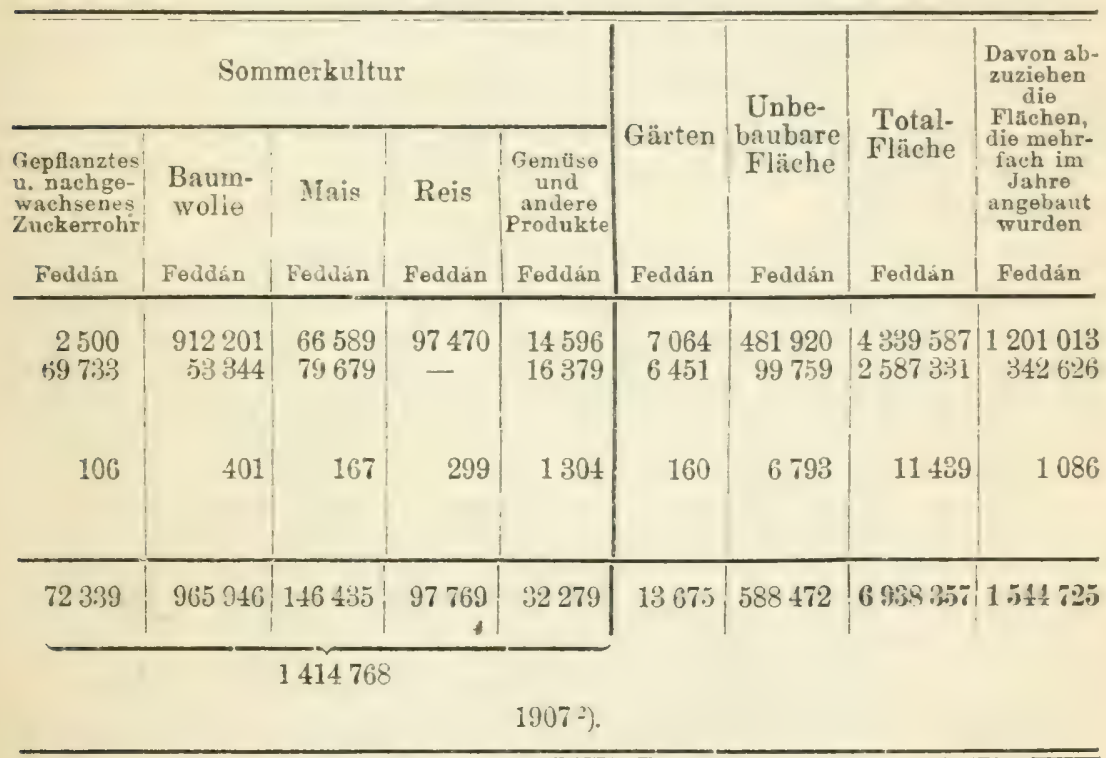

\begin{tabular}{|c|c|c|}
\hline \multicolumn{3}{|c|}{ Sommerkultur } \\
\hline $\begin{array}{l}\text { Baum- } \\
\text { wolle } \\
\text { Feddán }\end{array}$ & $\begin{array}{l}\text { Mais } \\
\text { Feddán }\end{array}$ & $\begin{array}{c}\text { Reis } \\
\text { Feddån }\end{array}$ \\
\hline $\begin{array}{r}1289233 \\
313956\end{array}$ & $\begin{array}{r}37527 \\
137482\end{array}$ & $\begin{array}{r}155762 \\
172\end{array}$ \\
\hline 1603189 & 175009 & 155934 \\
\hline
\end{tabular}


Der ägyptische Boden kann, theoretisch gesprochen, das ganze Jahr über bebaut werden. Wie viel Ernten man dabei in einem Jahre erhält, hängt jedoch ron einigen Faktoren ab. Der wichtigste Faktor ist, wie wir geschen haben, die Beschaffung genügender Bewässerung. Danach kommt die Art der gebauten Früchte in Betracht, die Zeit, die diese zu ihrer Entwicklung benötigen, die Zeit, die die Herrichtung des Saatbeetes und das Abräumen der Ernte erfordert, schließlich die Möglichkeit, den Pflanzen eine genügende Menge aufnehmbarer Bodennährstoffe zu schaffen. In welchem Sinne diese Faktoren zusammenwirken, crgibt sich aus dem Endresultate: im Jahre 1904 standen blok 1 11/2 Millionen Feddán, d. i. nicht einmal der vierte Teil des gesamten Ackerlandes, unter Repetitionskultur.

Die Einteilung in Winter-, Sommer- und Nilikulturen bedeutet also zunächst nicht, daß derselbe Boden alljährlich drei Kulturen trägt; sie bedeutet vielmehr, daß dreimal im Jahre die Möglichkeit gegeben ist, mit der Aussaat ron Kulturpflanzen erneut $\mathrm{zu}$ beginnen.

Der ursprüngliche Ackerbau mit Hilfe der natürlichen Nilüberschwemmung und selbst die Ländereien mit Bassinbewässerung kennen nur eine Vegetationsperiode im Jahre, die Winterkultur. Wenn der Nil nach der Überschwemmung in Herbste in sein Bett zurücktritt, wenn die Bassins ihr Wasser wieder an den Fluß a.bgegeben haben, dann beginnt auf den Ländereien, die keine immerwährende Kanalbewässerung besitzen, die Aussaat. Man legt den Samen rasch in den nassen Boden zwischen die Wasserpfützen, die die Erde noch vielfach bedecken. um nur ja nichts von dem kostbaren Naß zu verlieren, mit dem die Wintersaaten nun bis zu ihrer Reife auskommen müssen. Nur stellenwcisc wird man vielleicht imstande sein, den Pfianzen kurz ror der Ernte durch unermüdliche Arbeit an den Ziehbrunnen etwas Wasser zuzuführen. Im November hat man den Boden bestellt und wenn die Saaten ihn im Frühjahr geräumt haben, gibt es auf den Ländern ohne Kanalirrigation keinerlei Kultur mehr. Höchstens eine Art Gartenkultur, die wieder mülsam durch die Arbeit der Sâkije und Schadûfs und der übrigen Schöpfvorrichtungen aufrecht erhalten wird. Manchmal sät man in den Schlamm des zurückgetretenen Nils im Frühjahr. Wassermelonen oder dergleichen.

Die Einführung der Kanalbewässerung ändert das Bild voll- 
kommen. Wohl beginnt man wieder im November oder anfangs Dezemher mit dem Auslegen der Samen, baut wie früh... auf den Bassinländern Unterägyptens We izen, Gerste. $\mathrm{B}$ ohnen, Klee und in Oberägypten Flachs, Linsen, Wicke. $\mathrm{Zw}$ iebel usw. Aber nun entwickeln sich die Pflanzen unter der Einwirkung wiederholter, ihren Ansprüchen besser entsprechender Bewässerung rascher und kräftiger. Die Ernte, die in Oberägypten im April, in Unterägypten im Mai oder Juni eingeholi wird, hat nicht mehr den notreifen Charakter wie bei der einmaligen Bewässerung. Die Bassinländer konnten niemal. anderes bringen als Getreide, Hülsenfrüchte, Klee und dergleichen, Pflanzen, die mit den Wintertemperaturen auskommen. ihren Wasserhaushalt der einmaligen Bewässerung anzupassen verstehen. Der Reis ist schon ausgeschlossen und vollends die wertvollsten Pflanzen, die Baumwolle und das Zuckerrohr. Der Winteranbau mit Kanalbewässerung behält zwar auch die Pflanzen der Bassinkultur bei, obwohl sie über genügend Wasser verfügt, un auch andere, in dieser Hinsicht weniger anspruchslose Pflanzen wählen zu können; aber jetzt kann man eben die Baumwolle und das Zuckerrohr in die Periode größerer Wärme, in die Sommerkultur weisen, auch dem Reis und dem Mais, dem Sorghum, einen besseren Platz unter der Sonne einräumen, indem man diese Pflanzen als Sommer- und Nilikultur baut.

Der gewaltige Vorteil der neuen Anbauperioden tritt nun klar hervor. Die wichtigste Kulturpflanze des heutigen Agyptens, Baumwolle, dann das Zuckerrohr, werden erst dadurch lebensfähig, und manche andere Pflanze hann erst jetzt zum rollen Ertrage gebracht werden. Ist es auch unmöglich, dreimal im Jahre zu säen und zu ernten; so hat die Anbaufläche doch gegen die einmalige Kultur der Bassinländer eine wesentliche Vermehrung erfahren, der Landwirt erntet auf seinem Boden öfters und gewinnt bessere und wertvollere Produkte.

Der Anbau der Sommerkultur beginnt in Oberägypten früher. in der zweiten Hälfte des Februar oder aniangs März: in Unterägypten und im Delta später, Ende März, anfangs April, wenn kein Frost mehr zu fürchten ist. Während der Sommerkultur ist der Wasserbedarf groß, denn die Baumwolle benötigt viel Wasser, Reis, Zuckerrohr auch, und der Mais und die Brachfelder, die des Anbaues harren, wollen gleichfalls bewässert werden. Dabei ist 
der Wasserstand des Nils zur Sommerszeit sehr nieảrig. Die rorhandenen Wassermengen können also nur durch die umsichtigste Leitung des Bewässerungswesens, durch strenges Einhalten einer gewissen Reihenfolge in der Kanalbenutzung mit dem Erfordernis in Einklang gebracht werden. Die Hauptfürsorge gilt stets der Baumwolle, für die zunächst genug Wasser vorhanden sein muß, und deshalb darf in Jahren mit niedrigem Nilstande kein Sommerreis gebaut werden. der riel Wasser konsumiert. Die Erlaubnis zur Bewässerung der Brachländer wird durch ein Regierungsdekret erst dann erteilt. wenn die Baumwollfelder mit dem nötigen Wasser versorgt sind. Dies ist das Zeichen für den Beginn der dritten Anbauperiode. der sogenannten Nilikultur. Die Aussat der Nilikultur kann auch in guten Wasserjahren frühestens anfangs Juli erfolgen. in Jahren mit niedrigem Nilstande erst dann, wemn der Fluf zu steigen heginnt. Deshalb nennt man diese Periode auch „Nili“kultur. Ihre hauptsächlichste Frucht ist der Mais. Im Jahre 1907 wurde Flut- oder Nilimais auf 1622988 Feddáns gebaut, Sommermais nur auf 175000 Feddán. In Oberägypten pflanzt man auch Sorghum als Nilikultur. Größere Ausdehnung kommt dem Reisbau während dieser Anbauperiode zu. 1907 wurden $8+089$ Feddán mit Flutreis bestellt, gegen 155934 Feddán Reis unter Sommerkultur.

Zusammenfassend sehen wir, dab sich die drei Anbau. perioden $\mathrm{Winter}$, Sommer und $\mathrm{Nili}$ in der Zeitfolge nicht ergänzen, sondern daß die eine Kultur zeitlich vielfach in die nächste hineinreicht. Der Winterkultur kamn gewöhnlich auf gleichem Felde nur damn eine Sornmerkultur iolgen. wenn jene Klee war, der zeitlich gestürt wurde. Der rechtzeitige Anbau Aer Winterfüchte hängt wieder in hohem Maße von dem Zeitpunkte ab, zu dem die Bewässerung der Nilikultux vorgenommen werden konnte. Die Anbautabelle vom Jahre 1904 zeigt, daß der Winterkultur auch jetzt noch die größte Bedeutung zukommt; 3001573 Feddán umfassend, überragt sie die Sommer und Nilikulturen bei weitem an Ausdehunng, während lie beiden nahezu die gleiche Fläche bcanspruchen. Die lückenhafteren Daten von 1907 lassen übrigens das besondere Anwachsen der Sommerkulturen in den letzten Jahren erkennen.

Fohden führt einen dreijährigen Fruchtwechsel an, der früher auf guten Böden mit Kanalbewässerung sehr gebräuchlich war: 


$\begin{array}{cccc}\text { I. Jahr } & \begin{array}{c}\text { Winterkultur } \\ \text { Klee }\end{array} & \begin{array}{c}\text { Sommerkultur } \\ \text { Baumwolle }\end{array} & \begin{array}{c}\text { Nilikultur } \\ \text { II. }\end{array} \\ \text { III. } & \text { Bohnen oder Klee } & - & \text { Mais } \\ \text { Weizen } & - & - & \text { Mais. }\end{array}$

Gegenwärtig ist ein zweijähriger Fruchtwechsel häufiger:

$\begin{array}{lccc} & \text { Winterkultur } & \text { Sommerkultur } & \text { Nilikultur } \\ \text { I. Jahr } & \text { Klee } & \text { Baumwolle } & - \\ \text { II. } & \text { Bohnen oder Weizen } & - & \text { Mais oder Brache. }\end{array}$

In beiden Fällen alljährlich zwei Ernten.

Auf ärmerem Boden wird öfter's Klee gebaut, und statt Mais schiebt man Reis ein oder läßt das Land brach liegen. Die Baumwolle mit ihrem großen Nährstoffbedürfnis folgt gewöhnlich auf Klee, Mais oder Brache. Nach Flutmais, der im Oktober oder November ausgebrochen wird, bleibt der Boden bis zur Baumwollaussaat im März unbebaut; mitunter verlängert man aber die Brache, indem man schon dem Wintergetreide keine weitere Frucht vor dem Baumwollenanbau im nächsten Frühjahr nachfolgen läßt. Das Brachen wird namentlich ron den größeren Grundbesitzern geübt, die wegen ihres relativ geringen Viehstandes kein Verwendung für so viel Klee haben und überdies schwer imstande sind, die heikle Arbeit der Saatbettherrichtung für die Baumwolle auf großen Flächen in der kurzen Zeit zu bewältigen, die zwischen dem letzten Kleeschnitt und dem Legen der Baumwollsamen übrigbleibt. Die kleinen Bauern nützen den Boden intensiver aus. Sie säen den Kleesamen schon zwischen die Reihen der noch stehenden Maispflanzen und erhalten so bequem zwei Schnitte Klee vor der Baumwollaussaat.

Der Übergang rom dreijälurigen auf den zweijährigen Turnı: in der Fruchtfolge ist nicht ron der fortschreitenden Erkenntinis der Ansprüche der Kulturpflanzen veranlaßt worden. Er dient auciz nicht dazu, den einzelnen Pflanzenarten in der Fruchtfolge eine Stellung zu geben, die ihren physiologischen und biologischen Ansprüchen besser zusagt, sondern einfach dem Zwecke. mehı Baumwolle zu bauen. Man sieht immer wieder, dab alle Mal: nahmen zur Förderung der Landwirtschait in Ägypten in erster Linie auf die Vermehrung der Baumwollproduktion hinauslaufen, dem Grundpfeiler der gesamten heutigen Bodenkultur des Landes. Die Baumwolle bekommt den besten Platz in der Fruchtfolge, nach Klee oder Körnerleguminosen. Ihrer Kultur wird die größte Sorgfalt zugewendet; die Düngung, die Bewässerung. 
alles wird nach den Ansprüchen der Baumwolle bemessen und eingerichtet. Obwohl nun die anspruchsvolle Pflanze einen so namhaften Teil der gesamten Ackerfläche bedeckt, läßst sich doch nicht bestreiten, daß die Bodenökonomie in Ägypten besser daran ist als in unseren europäischen Hochkulturländern. Ich habe wiederholt und nachdrücklich auf die Bedeutung hingewiesen, die der ungleichen Arbeitsteilung der Kulturpflanzen (dem assimilatorischen Effekte) für die gesamte Volkswirtschaft zukommit, und daraus die Forderung abgeleitet, "Bodenökonomie" zu treiben "). Das heißst mit anderen Worten gesagt: solchen Pflanzen einen größeren Raum auf den Ackerfächen cinzuräumen, die bei gleicher Inanspruchnahme des Bodenkapitals relativ mehr leisten als andere. Ägypten erfïllt diese Forderung zum Vorteile seiner Fruchtbarkeit und seiner Produktivität in hohem Mafe. denn es bebaut den vierten Teil seiner Kulturfläche mit Klee, Bohnen und anderen Hülsenfrüchten, durchwegs guten Verwertern der Bodennährstoffe, and nahezu ebensoviel mit Mais, dem besten Arbeiter unter den Getreidearten. Der Weizen, der in Ägypten ebenfalls stark gebaut wird, besitzt einen höheren assimilatorischen Effekt als der Roggen, die Gerste arbeitet günstiger als cer Hafer, den sie dort zu ersetzen hat. Die Ausbreitung des Mais hängt mit dessen grober Ausgiebigkeit als Nahrungsmittel der ärmeren Klassen zısammen. Gefüttert mit Maiskörnern werden meist nur Hühner und Tauben, dagegen sind Stengel und Kolben bei der großen Not an Feuerungsmaterial als solches sehr geschätzt. Die Tabelle zeigt ausgedehnten Maisbau in Unter- und Oberägypten, doch handelt es sich dabei eigentlich um eine Namensverwechslung. Unterägypten haut wirklichen Mais (Zea Mays), während der sogenannte Niais Oberägyptens zumeist Durra (Sorghum) ist. Dic Vermischung rührt daher, daß auf arabisch Mais "dura schâmî", syrische Durra, und die eigentliche Durra Oberägyptens „dura baladî", inländische Durra benannt wird. Botanisch steht die Durra dem Mais nicht näher als irgendeine andere Getreideart. Unter dem Sammelnamen Durra ist in Oberägypten auch Hirse (Panicum) mit inbegriffen, die in einigen Varietäten gebaut und gleichfalls meist vermischt mit dem Mehl des Hornkleesamen (Trigonella foenum graecum L.) zum Brotbacken verwendet wird.

1) Das Problem der ungleichen Arbeitsleistung unserer Kulturpflanzen. Berin 1907, Parey. - Bodenökonomie und Wirtschaftspolitik. Wien u. Leipzig 1908, Braumüller. 
Ohne so hochentwickelte Bodenökonomic hütte Ïgypten seine Fruchtbarkeit hei dem geringen Mafe der angewendeten Düngung sicherlich nicht erhalten können. Er dankt hierbei viel einem empfindlichen Mangel: dem vollkommenen Fehlen natürlichıı. Weiden und Wiesen. Der Fellah mufte viel Klee bauen, um sein Vieh weiden zu künnen, und Bohnen, um für die Sommermonate, wo es keine Kleeweide giht, das wichtigste Grundfutter zn schatfen.

\section{Die Düngung.}

Jie Stallmistbehandiung des Fellab. - Zusammensetzung des ägyptischen Stalldüngers. - Taubenmist. - Andere natürliche Düngerquellen Ägrptens : Coufri, Marog und Tafla.

Man kann nicht sagen. dab der Fellah der Michtigkeit der Düngming rerständnislos gegenübcrstünde. Die Düngerhaufen oder. besser gesagt, die Düngerwälle, die jedes Dorf umgeben. zeugen rom Gegenteil. Aber der Viehstand ist gering, und ein Teil des erhaltenen Düngers wird überdies in allen Dörfern getrocknet und ron der ärmsten Bevölkerung zu Heizzwecken ver. wendet. Die "gillahs", wie die trockenen Düngerscheiben genamnt werden, bilden selhst in der Nähe der grofen Städte einen ausgedehnten Handelsartikel. Was gleichfalls schwer in die Tragschalc fällt, ist die Tatsache, daßs der Fellah noch keine Ahnung von einer halbwegs rernünftigen Düngerbehandlung hat. Del siallmist hat in Agypten eine andere Beschaffenheit als bei uns. Da als Streumaterial nur selten Stroh, sondern meistens Nilschlamm dient, enthält er ron rornherein weniger organische Substanz. Nun wird der Stalldünger gerade in der heißesten. trockensten Zeit, im Sommer und im Herbst gesammelt. wenn es keine Kleeweide gibt, enthält rerhältnismäßig weniger Wasser als hei uns und trocknet bei dem geringen Fenchtigkeitsgehalte der Luft äulierst rasch aus. Die Nitrifikation geht dann natürlich schwer ror sich, und die Stickstoffrerluste werden um so bedeutender, als man die Haufen weder begielst. noch fest trit.t. noch mit Erde bedeckt. Das, was wir unter verrottetem Stallmist verstehen, gibt es daher in Ägypten überhaupt nicht. nur eine rermodernde Masse, die mehr und mehr eintrocknet und weniger Stickstoff, aber mehr Kali aufweist als der europäische Stallmist. Direktor Fletscher gibt an, daß der ägyptische Stallmist durchschnittlich nur - - 100\% organische Substanz enthalte, mitunter 
noch weniger. Wie wenig das ist, werden einige europäische Vergleichszahlen, die der Düngerlehre von Lemmermann entnommen sind, zeigen. Darnach enthält durchschnittlich:

$\begin{array}{llll}\text { Rinderkot: organische Substanz } & 14 \%, \\ \text { Pferdekot: } & n & n & 21 \%, \\ \text { Schafkot: } & & & 31 \% .\end{array}$

Wasser, Stickstoff, Phosphorsäure und Kali enthält der ägyptische Sommerdünger nach Analysen, die mir Direktor Fletsch e r ebenfalls zur Verfügung stellt:

\begin{tabular}{|c|c|c|c|c|c|c|c|}
\hline & & & & Wasser & Stickstoff & Phosphorsäure & Kali \\
\hline Kühe . & - & - & • & 80,5 & 0,17 & 0,16 & 0,14 \\
\hline Ochsen & . & - & • & 82,8 & 0,14 & 0,14 & 0,12 \\
\hline Büffel . & . & . & • & 79,3 & 0,21 & 0,21 & 0,14 \\
\hline Pferde & . . & . . & - . & 72,6 & 0,33 & 0,32 & 0,21 \\
\hline
\end{tabular}

Hingegen besitzt unser Stallmist nach E. Wolf in 100 Teileu durchschnittlich:

$\begin{array}{lrc} & \text { Frischer Rindermist } & \text { Frischer Pferdemist } \\ \text { Wasser . . . } & 87,5 \% & 71,30 \% \\ \text { Stickstoff . . } & 0,34 \% & 0,58 \% \\ \text { Phosphorsäure. } & 0,16 \% & 0,28 \% \\ \text { Kali. . . . . } & 0,40 \% & 0,53 \%\end{array}$

Die Not an tierischem Dünger veranlaßt manchen Grundbesitzer seine Grünfutterernte oder den letzten Schnitt des Klees an Besitzer von Schafherden zum Abweiden unter der Bedingung. billiger zu überlassen, daß die Herde auf dem Felde übernachte. Jeden Abend bestimmt der Besitzer einen anderen Platz des Feldes dazu. damit der dabei fallende Dünger möglichst gleichmäbig verteilt werde.

Nebst dem Stallmist wird, namentlich in Oberägypten, noch ein anderer tierischer Dünger viel verwendet - der Taubenmist. Der Fellah hält die Tauben hauptsächlich wegen der Düngergewinnung. Der teure Preis - Taubenmist wird mit 40-50 P.T. per ardeb $=$ P.T. $31^{1 / 2}$ per 100 Kilo gehandelt - macht ihn für die gewöhnlichen Feldfrüchte zu kostbar; hingegen wird er wegen seiner leichten Zersetzlichkeit bei der Gemüsezucht, zu Melonen und zu allen Früchten, die keine lange Vegetationszeit haben, besonders gern angewendet.

Ägypten besitzt noch eine Reihe anderer natürlicher Dünger, die dem Fellah kostenlos zur Verfügung stehen. Da man, wic 
ich glaube, davon auberhalh des Landes wenig weil;, will ich sie etwas eingehender besprechen. Sowohl in Unterägypten als in Oberägypten ist "Coufri" für die Landwirtschaft sehr wichtig. "Coufri" besteht aus den Resten längst vergangener menschlicher Niedcrlassungen, gemischt mit organischen Ablällen aller Art. Überall im ganzen Lande haben sich unter dem Schutze des trockenen, fast regenlosen Klimas solche Überreste erhalten; überall verstreut finden sie sich vor, noch für viele Jahrzelnnte einen ausgezeichneten Dünger gewährend. Analysen einiger Coufrimuster durch das Chemische Laboratorium der KhedivialAgrikultur-Gesellschaft haben diese Zusammensetzung ergeben:

Muster Nr. I Muster Nr. II Muster Nr. III Muster Nr. IT

$\begin{array}{lllll}\text { Gesamtstickstoff . . . } & 0,42 & 0,718 & 0,296 & 0,190 \\ \text { Nitric. nitrogen. . . } & 0,112 & 0,178 & 0,158 & 0,121 \\ \text { Natrium nitrat. . . } & 0,68 & 1,046 & 0,931 & 0,737 \\ \text { Natriumchlorid . . . } & 2,72 & 3,51 & 0,970 & 2,17\end{array}$

Die leicht lösliche Form, in der der Stickstofi hier rorkommt, läßst ihn für schnell wachsende Pflanzen, wie Mais und Sorghum, geeignet erscheinen. Auch zur Düngung von Gemüsen und in Oberägypten von Zuckerrohr wird er verwendet, seltener zur Baumwolldüngung. Außer Stickstoff enthält Coufri noch 1 bis $13 \%$ Phosphorsäure und $1-2 \%$ Kali. 100 Kilo Coufri ersetzen in der Wirkung beiläufig 1 Kilo Stickstoff in Form von salpetersaurem Natron (Chilisalpeter).

Das Material selbst ist freies, herrenloses Gut. Die Kosten, die sein Transport aufs Feld verursacht, lassen sich schwer be. rechnen, weil sie nach der Lage ungleich sind. Mit Boot und Bahn, auf Kamel und Esel schafft der Fellah den wertrollen Dünger herbei, meist nachdem Steine, Scherben und andere Beimischungen durch Sieben entfernt wurden. Der Erfolg ist nicht immer der erwünschte, weil der Salzgehalt, wie die Analysen ergeben, mitunter zu hoch ist. Man hat Coufri mit $5 \%$ und noch mehr Kochsalzgehalt gefundeñ und in der Praxis aus dem gleichen Grunde Salzausschwitzungen der mit Coufri gedüngten Böden beobachten können.

In Oberägypten, wo die perennierende Bewässerung noch nicht lange eingeführt ist und bisher keine allzu grobe Ausdehnung gewann, hat man der Düngerfrage lange nicht die gleiche Wichtigkeit beigemessen als in Unterägypten und im Delta. Dadurch 
erklärt es sich, daß einem anderen Stickstoffdünger Oberägyptens erst jetzt erhöhte Aufmerksamkeit zugewendet wird, der "T a fla Tafla ist ein schwarz-blauer Lehm, manchmal auch Mergel, der sich in den Hügeln der Wüsten südlich von $\mathrm{K}$ enneh vorfindet. Tafla enthält Stickstoff in Form ron salpetersaurem Natron. Die rerdienstvolle Khedivial-Agrikultur-Gesellschaft hat eine Anzahl Muster von Tafla untersuchen lassen und dabei gefunden:

\begin{tabular}{lccccc} 
& Muster & Muster & Muster & Muster & Muster \\
& Nr. I & Nr. II & Nr. III & Nr. IV & \multicolumn{1}{c}{ Nr. V } \\
Kochsalz . . . . . . . & 6,25 & 3,97 & 4,92 & 5,88 & 9,24 \\
Natrium Sulphat. . . . . . & 3,84 & 1,16 & 2,74 & 5,28 & 4,12 \\
Salpetersaures Natrium . . & 9,13 & 6,80 & 9,02 & 4,42 & 9,01 \\
Gesamtsalze . . . . . . & 19,22 & 11,93 & 16,68 & 15,58 & 22,37
\end{tabular}

Man scheint es hier mit einer Art Chilisalpeter zu tun zu haben, der in unreiner Form unter Beimischung von Lehm usw. vorkommt. Die Fellahs nehmen Tafla von der Oberfläche, wo der Gehalt an Stickstoff stets wesentlich größer ist. Dort kann der Stickstoffgehait bis zu $24 \%$ steigen, während er kaum $30 \mathrm{~cm}$ tiefer oft bis auf $3 \%$ fällt. Wenn die Fellahs nach einiger Zeit an dieselbe Stelle zurückkehren, hat sich dic nunmehr oberste Schicht neuerdings mit Stickstoff angereichert. Bisher wird Tafla in Unterägypten noch gar nicht angewendet und in Oberägypten nur dort, wo kein Coufri gefunden wird. Es ist aber kaum zu zweifeln, daß hier eine bedeutsame Stickstoffquelle Ägyptens ihrer Ausnützung harrt.

Ägypten besitzt noch ein anderes ganz eigentümliches Stickstoffvorkommen, den Marog. Die unkultivierten Strecken zwischen dem Nil und dem Hügelland Oberägyptens, zwischen Luxor und Assuan, bedecken sich oft mit einer Salzschicht, die ganz ansehnlichen Düngerwert besitzt. Nach den Analysen der KhedivialAgrikultur-Gesellschaft enthält Marog:

\begin{tabular}{|c|c|c|c|c|c|c|c|}
\hline & & & $\begin{array}{l}\text { Muster } \\
\text { Nr. I }\end{array}$ & $\begin{array}{l}\text { Muster } \\
\text { Nr. II }\end{array}$ & $\begin{array}{l}\text { Muster } \\
\text { Nr. III }\end{array}$ & $\begin{array}{l}\text { Muster } \\
\text { Nr. IV }\end{array}$ & $\begin{array}{l}\text { Muster } \\
\text { Nr. V }\end{array}$ \\
\hline Feuchtigkeit ... & - . & & 4,60 & 3,97 & 6,21 & 3,50 & 3,34 \\
\hline Organische Substanz & . . & & 10,41 & 14,56 & 8,52 & 9,61 & 11,30 \\
\hline Lösliche Salze . . . & . . & & 10,28 & 10,28 & 8,46 & 8,86 & 10,23 \\
\hline Chloride .... & . . & & 3,19 & 4,09 & 3,35 & 3,56 & 4,41 \\
\hline Nitrate. . . . & . . & & 5,92 & 4,88 & 3,67 & 3,52 & 4,22 \\
\hline Schädlicbe Salze . . & . . & & 4,36 & 5,40 & 4,79 & 5,34 & 6,01 \\
\hline
\end{tabular}


Danach enthält "Marog" mehr Stickstoff als gewöhnlicher Coufri. Der Vermutung nach stammt Marog aus den umliegenden Hügeln, die reich an Tafla sind. Aus diesem werden die Salze wahrscheinlich ausgewaschen und über die Ebene verteilt. Marog wird gewöhnlich zum Düngen von Getreide benutzt.

Es wurde bereits an früherer Stelle ausgeführt, wieviel größer die Anforderungen sind, die die gegenwärtige Kanalbewässerung an die Düngung des Landes stellt, als die früher allgemeine Bassinbewässerung. Der Wechsel im vieltausendjährigen System der Nilüberflutung und der einmaligen Ernte hat nur zu rasch die Mythe von der Unerschöpflichkeit des ägyptischen Bodens zerstört. Unzertrennlich vom Fortschritt des Bewässerungswesens ist der Fortschritt im Düngeraufwand. Wo jenes den Übergang zur immerwährenden Bewässerung gefunden hat, steigt auch die Nachfrage nach Dünger, und dieser Nachfrage können alle die aufgezählten Dünger nicht genügen. Es gibt keinen besseren Beweis für diese Erscheinung als die Kunstdünger-Importziffern (Chilisalpeter und Phosphate) der letzten Jahre.

\begin{tabular}{|c|c|c|c|c|c|c|}
\hline 00 & urde & Kunstdünger & eingefül & fü & L. I & \\
\hline 1901 & $"$ & $"$ & $\pi$ & $n$ & n & 6000 \\
\hline 1902 & $\Rightarrow$ & , & $"$ & , & $\Rightarrow$ & 15000 \\
\hline 1903 & $\Rightarrow$ & . & $\because$ & $\therefore$ & $\because$ & 30000 \\
\hline 904 & $\Rightarrow$ & $"$ & $\Rightarrow$ & , & $\Rightarrow$ & 66000 \\
\hline 0 & , & $\Rightarrow$ & , & $\Rightarrow$ & $"$ & 130000 \\
\hline 100 & $\because$ & $"$ & $\because$ & " & n & 160009 \\
\hline & $\Rightarrow$ & $\Rightarrow$ & , & $\Rightarrow$ & , & 250000 \\
\hline
\end{tabular}

\section{Viehhaltung.}

Das Dromedar und seine vielseitige Nutzung. - Kraftverschwendung bei den Zugtieren. - Schlachtvieh. - Ägypten der ungeeignetste Ort der Welt. um. Viehzucht zu treiben. - Einheimische Rinderrassen. - Futtermittel. - Schafund Ziegenzucht. - Schweinehaltung. - Pferdezucht. - Federrieh.

Der Viehstand des ägyptischen Landwirtes ist bunt genug zusammengewürfelt. Da sieht man im Winter auf der Bersim-(Klee-) Weide Schafe und Rinder, Ziegen und Pferde, Esel und Maultiere, Dromedare und Büffel, und das alles weidet oft einträchtig nebencinander. Dem Europäer erscheint die Mamigfaltigkeit der 
Gattungen ebenso bunt wie die Seltsamkeit mancher dieser Tierformen und Arten. Er gewöhnt sich nicht gleich an das würdige Gehaben der Dromedare, ist erstaunt, in dem fleißigen, flinken Esel unser übelbeleumundetes Grautier wiederzufinden, und steht den dürftigen kleinen Ziegen und dem merkwürdigen Habitus gewisser ägyptischer Schaỉarten anfänglich recht betreten gegenüber. Die dortigen Rinder und Büffel lassen sich auch nur schwer mit den Begriffen in Einklang bringen, die man rom Hause in hezug auf Züchtung und Pflege mitgebracht hat.

Di€ zahlreichen Bücher über ägypten wissen viel über die ägyptischen Dromedare, Maulesel und Esel zu erzählen, aher wenig ron dem Standpunkte aus; der für den Landwirtschafts. betriel) wichtig ist; fast gar nichts dagegen über die landwirtschaftlich wichtigsten Haustiere, die Büffel, Rinder, Schafe, Ziegen und ihre Leistungen. Die Tatsache, daß ein Reitkamel bis zu $160 \mathrm{~km}$ im Tag zurücklegt, ist für den Fernverkehr bemerkenswerter als für den Landwirtschaftsbetrieb, und ebenso die andere, dafs Lastkamele, die in Schritt gehen, eine Belastung von t/10 kg in der Stunde 3-4 km weit tragen können. Für größere Entfernungen nimmt man 260 Oka (zirka 250 $\mathrm{kg}$ ) als normale Kamellast an, mit der ein Tier 20-30 km täglich zurücklegt. Die große Tragkrait kann indessen im internen Wirtschaftsuetrieb selten ausgenutzt werden, weil die landwirtschaftlicheis Produkte, wie Stroh, Heu, unverarbeitete Ernteprodukte und dergleichen, spezifisch zu leicht sind, um in solchen Gewichtsmengen auf dem Rücken cines Kamels Platz zu finden. Das Kamel wird aber auch zur Feldarbeit benutzt, sein Fleisch wird verzehrt, seine Milch nicht verschmäht. Wichtig ist die Anspruchslosigkeit in bezug aui Nahrung. Das Kamel ist der sinnfälligste Beweis dafür, dafs es auch unter den Tieren gute und schlechte Nahrungsverwerter, einen verschiedenen „ascimilatorischen Effekt" gibt. Ärmliche Gräser der Wüstenränder, Bolnen- und Durrahäcksel, in Winter etwas Kleeweide, im Sommer, wenn es hoch kommt, etwas Miais- oder Bobnenschrot, das sind die Leckerbissen der Kamelnahrung. Das Kamel wird in Ägypten wegen der Milchleistung nur von den Beduinen gehalten. Über die Milchergiebigkeit konnte ich nichts erfahren. Der Fellah betrachtet das Kamel vor allem als Lastund Zugtier, obwohl die Milch der Muttertiere fallweise genosser und wegen ihres süfen, angenehmen Geschmackes gerühmt wird. 
Der Fruuenmilch gleicht sic darin, dab sie, mit Lab oder Sïuren versetzt, ein feinflockiges Gerinnsel liefert. Das Fleich kommt regelmäßig auf die Märkte. In Alt-Kairn z. B. existieren cigene Läden, in denen Kamelfleisch den ärmeren Klassen feilgehroten wird. Das Durchschnittsgewicht der dort zur Schlachtung gebrachten Tiere schätzt man auf $530 \mathrm{~kg}$.

Das gutmütige Schiff der Wüste läßt sich geduldig an den Pflug spannen oder an den Balken, der das Schöpfrad dreht. Aber ich glaube nicht, dak der Fellah, der stets über die ungenügende Kraft seiner Zugtiere klagt und darin einen Grund der geringen Maschinenverwendung sieht, die Muskelkraft dieser starken Tiere jemals richtig ausnutzt. Dem steht schon die kraftvergeudende Art des Anspannens entgegen. Ein fester Tragbalken, der auf dem Halsansatze, dort, wo der Rumpf beginnt, aufliegt, wird mittels Stricken an das Vehikel gebunden. Die Kraftversehwendung wird noch augenscheinlicher, wenn, wie man das häufig antrifft, Tiere von ganz verschiedener Gattung, von ganz verschiedenen Größen und Kräfteverhältnissen unter demselben starren Tragbalken zichen müssen. Der Fellah spannt unbedenklich einen kleinen Esel und ein haushohes Kamel zusammen, cinen großen Büffel und eine winzig kleine Kuh, oder was ihm sonst gerade zur Hand ist. Der starre Tragbalken balancicit dann auf dem Nackenansatz der beiden Gespanngenossen wie ein Schlagbaum anf seinem Untergestell; ein starres System, das keine Anhänger verdient. Bei den Rindern oder anderen Zugticren, die über größere Ohrlappen verfügen, hat der Fellah überdies eine Methoule ersonnen, das sicherlich die Zugleistung nicht erhöht und äußerst tierquälerisch ist: Er zieht das Leitseil einfach durch ein Loch, das er in das Ohr schneidet. Das Seil reißt das Loch bei der wenig zarten Handhahung bald auf, wonach der Follah wieder daneben ein frisches Loch in das Ohr macht, und das geht so fort, bis keines der Zugtiere ein halbwegs unversehrtes Ohr mehr besitzt und das Leitseil nur noch mühsam an den Resten der Ohrlappen befestigí werden kann.

Professor J. S. J. Me. Call von der Ackerbauschule in Ghizeh hat einige interessante Daten über das durchschnittliche Gewicht und den Preis zur Schlachtung gelangter Kamele sowie des übrigen Schlachtviehes gesammelt. 


\begin{tabular}{|c|c|c|c|c|c|}
\hline T'ierklasse & $\begin{array}{l}\text { Durc } \\
\text { Lebe } \\
\text { Kilo }\end{array}$ & $\begin{array}{l}\text { chschnittl. } \\
\text { ndgewicht } \\
\text { Oka } \\
\text { approximatir }\end{array}$ & $\begin{array}{l}\text { Schlachtgewicht } \\
\text { vom Lebeud- } \\
\text { gewicht } \\
\%\end{array}$ & $\begin{array}{l}\text { Preis } \\
\text { per } \\
\text { Oka } \\
\text { P.T. }\end{array}$ & $\begin{array}{l}\text { Durchschnittl. } \\
\text { Wert des } \\
\text { Schlachtriehes } \\
\text { L.E. }\end{array}$ \\
\hline Rinder über $2^{1 / 2}$ Jáhre & 480 & 384 & 54 & 7,5 & 15,52 \\
\hline Jungvieh $1^{1 / 2}-2^{1 / 2}$ Jahre & 275 & 220 & 52 & 8 & 9,12 \\
\hline Alte Kühe. . . . . . & 245 & 196 & 45 & 6,5 & 5,72 \\
\hline Büffelkühe. . . . . . & 460 & 368 & 51 & 7,5 & 14,10 \\
\hline Junge Büffel $1^{1 / 3}-2^{1 / 2} \mathrm{~J}$. & 360 & 288 & 48 & 8 & 11,04 \\
\hline $\begin{array}{l}\text { Büffelkälber } 20 \text { Tage } \\
\text { Kamele (syrische oder }\end{array}$ & 56 & 45 & 57 & 8 & 2,05 \\
\hline $\begin{array}{l}\text { Shami) } \\
\text { Kamele (ägyptische oder }\end{array}$ & 530 & 424 & 58 & 3,5 & 8,61 \\
\hline $\begin{array}{l}\text { Baladi) } \\
\text { Schafe (Baladi, Unter- }\end{array}$ & 390 & 312 & 52 & 3,5 & 5,67 \\
\hline ägypten) . . . . . & 37 & 29,5 & 62,5 & 11 & 2,035 \\
\hline Sehafe(Saidi, Oberägypt.) & 36 & 29 & 60 & 10 & 1,740 \\
\hline $\begin{array}{l}\text { Sudanesische und impor- } \\
\text { tierte syrische . }\end{array}$ & 44 & 35 & 53 & 9 & 1,665 \\
\hline
\end{tabular}

Die Zusammenstellung zeigt, daß Ägypten in dem Kamelfleisch ein ungemein billiges Volksnahrungsmittel besitzt. Bei den Rindern fällt der namhafte Verlust an Schlachtgewicht gegenüber dem Lebendgewicht auf, der wohl $4-6 \%$ mehr als bei uns beträgt. Das ägyptische Rind ist eben kein ideales Fleischvieh; es ist aber nach dem Urteile maßgebender Fachleute Ägyptens in seinem gegenwärtigen Zustande auch gleich ungeeignet für Milchzwecke wie für harte Arbeit. Kühe, die nach dem Kalben 4-6 I Milch per Tag geben, gelten, wie man versichert, schon als gut und werden mit $20-25$ L.E. bezahlt. 4-10 jährige Arbeitsochsen kosten 15-40 L.E. Der große Spielraum im Preis hängt zweifelsohne mit der Seltenheit guter Arbeitstiere zusammen. T.P. Go odschild, Inspektor der Khedivial-Agrikultur-Gesellschaft, bezeichnet die Zucht yon Zugvieh als den rernachlïssigtsten Zweig der ägyptischen Landwirtschaft und weist auf den indirekten, ungünstigen Einfluß hin, den der Mangel an gutem Zugvieh auf die Bodenbestellung und auf die Bodenerträge ausübt. Im Jahresbericht der Gesellschait vom Jahre 1906 sagt er über die ägyptische Zucht im allgemeinen: "Ägypten ist der ungeeignetste Ort der Welt, um Viehzucht zu treiben. Der hohe Bodenpreis verhindert die grolen Grundbesitzer am speziellen Futterbau, deshalb fahren sie fort, ihren Viehbestand fallweise bei den kleinsten Fellahs zu decken, die die Viehzüchter Ägyptens sind. Die Fellahs 
ziehen die Tiere in geringer Anzahl auf der spärlichen Grasweide, welche die Kanaldümme bietet, oder ernähren sie im Sommer während der Trockenheit mit den Resten ihrer Durraernte. Bei dem Mangel an Verständnis für Erzeugung, Selektion und Aufzucht, das diese kleinen Fellahgrundbesitzer aufweisen, ist es nicht zu verwundern, daß besseres Vieh von Jahr zu Jahr spärlicher wird, und daßs sich die großen Grundbesitzer bei ihren Viehkäufen mit sehr minderem Material zufrieden geben müssen." Das ägyptische Rind entspricht in seinem Habitus diesen Verhältnissen. Es ist hochbeinig, von ungenügender Brust- und Beckenbreite, hohlem Rücken und geringer Brusttiefe. Bei den Kühen sind die Milchzeichen nur schwach ausgeprägt. Beide Wege, die zu einer Verbesserung des Schlages führen könnten, die Selektion und die Kreuzung, sind schwer gangbar. Die Selektion würde bei den wenigen guten und vielen schlechten Eigenschaften der vorhandenen Elterntiere schr lange Zeit in Anspruch nehmen und nur schrittweise Resultate erbringen. Die Erfahrungen. die man beim Kreuzen mit europäischen Rassen gemacht hat, sind gleichfalls nicht sehr ermutigend gewesen, da die Kreuzungsprodukte sich für die eigentümlichen klimatischen und Ernährungsverhältnisse nicht eigneten. Importversuche haben diesen Übelstand in noch höherem Maße ergeben, zudem auch sehr unter den vielen Seuchen gelitten, die in Ägypten heimisch sind. Diese Seuchen bilden überhaupt eine furchtbare Erschwerung der Viehzucht und der ganzen ägyptischen Landwirtschaft. Eingeführtes Tieh fällt den "ägyptischen Fieber", dem Texasfieber, zum Opfer, gegen die das heimische Vieh schon in der Jugend eine gewisse Immunität gewinnt; aber gegen die Rinderpest ist auch dieses nicht gefeit. Ungeachtet aller Regierungsmaßregeln, wie Impfung, Schließung der Viehmärkte usw, ging noch im Jahre 1904 ein großer Teil der Viehbestände durch die Rinderpest zugrunde; man spricht ron 135000 Stück. Konsul Heller erzählte mir, er hätte in wenigen Tagen sein ganzes Zugvieh, 200 Stück, verloren. In welchem Verhältnis die 135000 Stück zur Gesamtheit des damaligen ägrptischen Viehstapels standen, läßjt sich nicht konstatieren, weil schon lange keine Viehzählung stattgefunden hat. Die letzte rom Jahre 1878 ergab 228316 Rinder und Büffel, darunter 147739 Kühe. Nach Mr. Fohden rechnet man gegenwärtig 8-10 Zugochsen oder Büffel auf 100 Feddán. Könnte man diese Anzahl als Regel ansehen, so ergebe das allein an Zugrieh einen Stand ron 400000 
bis 500000 Stück. Die Wirklichkeit wird hinter dieser Zahl wohl wesentlich zurückbleiben; denn der Mangel an Zugvieh ist ja bereits erwähnt worden. Aus den ebenfalls früher angegebenen Gründen geht hervor, daf die kleinen und kleinsten Fellahs relativ viel mehr Vieh halten als die Großgrundbesitzer.

Die ofimalige Verseuchung des ägyptischen Rindvielıstandes hat die ursprünglichen einheimischen Rassen sichcrlich längst zum Aussterben gebracht. Über die Abstammung des heutigen Viehstapels sind die Ansichten deshalb auch sehr geteilt. Goodschild hält an der traditionellen Herkunft vom Bos Indicus, dem Zebu oder Buckelochsen, fest und erklärt daraus den ungünstigen Aus. fall der Kreuzungsversuche mit den importierten europäischen Rassen, die bekanntlich dem Bos taurus $L$. entstammen. Wer die Schwierigkciten liennt, die sich schon der erfolgreichen Kreuzung von emropäischen Nicderungsrassen mit Gebirgsvieh entgegenstellen, wird dafür nicht erst so weitliegende Abstammungsursachen haftbar machen. Sollte das ägyptische Rind tatsächlich Blut vom Bos indicus besitzen, so müite dieses schon sehr verdünnt sein; denn von den äuferen Merkmalen zumindest, die das Zebu sonst und auch im nahen Sudan besitzt, ist bei dem ägyptischen Rind nicht viel zu merken. In Indien sind Kreuzungen zwischen dem reinen Zebu und dem gewöhnlichen Rindvieh nach Jouatt (Treatise on cattle) übrigens häufig und ganz criolgreich. Man wäre versucht, für die geringen Erîolge der ägyptischen Viehzucht in hohem Grade das Fchlen eines Sommergrünfutters mitverantwortlich zu machen. Von Dezember bis Juni weidet das Vich regelmäbig auf den Klecfeldern, meistens an Pfïcke gebunden, die man an anderer Stelle in den Boden steckt, wenn der Kreis abgefressen ist. Zeitliche Kleeaussaat kann die Kleenutzung etwas früher eintreten lassen; aber im Sommer giöt es nicmals Grünfutter, weil man das kostbare Land mit Kanalberässerung, das allein den Futterbau zur Sommerszeit ermöglichen wïrce, für wertvollere Pfanzen verwendet. So ist das Vieh gerade in den heißesten Monaten auf das trockene Futter angewiesen, das wegen Mangel an Heu und an Abfällen landwirtschaftlicher Gewerbe und Industrien noch weniger bekömmlich und reizvoll ist als unsere Winterfütterung. In Ägypten gibt es ja weder Rübenschnitte noch Kartoffelpulpe oder ähmliches Futter. Während der Weide hat man $3 / 4$ Feddán Klee per Stück gerechnet; nun erhalten die ausgewachsenen Tiere von Juni bis Dezember 
nur Bohnen und gehäckseltes Stroh, zirka is $\mathrm{kg}$ von jenen und $11 \mathrm{~kg}$ ron diesem. Es ist mir aufgefallen, dab als Futterstroh in erster Linie Weizenstroh betrachtet wird und nicht Gerstenstroh wie bei uns. Nach Untersuchungen von Dr. Nack enzie hahen diese beiden Stroharten tatsüchlich in Ïgypten eine andere Zusammensetzung, und das W Weizenstroh enthält dort mehr Nährstoffe als das Gerstenstroh.

\section{Analysen.}

\begin{tabular}{|c|c|c|c|c|}
\hline & \multicolumn{2}{|c|}{ Gerstenstroli } & \multicolumn{2}{|c|}{ Weizenstroh } \\
\hline & $\underset{\% \%}{\ddot{A g y p t e n}}$ & $\begin{array}{c}\text { Europa } \\
\text { \% }\end{array}$ & $\underset{0 / 0}{a ̈ g y p t e n}$ & $\begin{array}{c}\text { Europa } \\
\%\end{array}$ \\
\hline Wasser. . . . . . & 4,83 & 14,3 & 4,27 & 14,3 \\
\hline Eiweiß . . . & 2,48 & 3,5 & 2,98 & 3 \\
\hline Fett.. & 1,09 & 1,4 & 1,25 & 1,2 \\
\hline Stickstofffreie Extraktstofie . & 39,23 & 35,9 & 44,79 & 35,9 \\
\hline 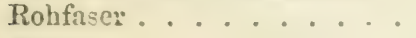 & 42,85 & 39,5 & 36,10 & 40,8 \\
\hline \multirow[t]{2}{*}{ 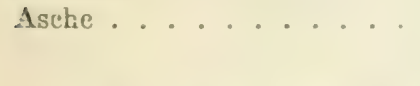 } & $9,5:$ & 5,4 & 10,70 & 4,8 \\
\hline & 100 & 100 & 100 & 100 \\
\hline
\end{tabular}

Der Miangel einer Sommerweide mag auch schuld daran sein, daß die Büffel (Bos bubalus L. $_{\text {.) }}$ in Ïgypten nicht die gleichen Eigenschaiten aufweisen wie etwa in Lngarm oder Siebenbürgen. Aus dicsem Lande sollen sie angeblich erst vor einigen Jahrzehnten nach einer Scuche, die fast den ganzen Rinderstand vernichtet hatte, wach Aggpten gebracht worden sein. Mit Sicherheit läft sicl sagen, daß die Abbildungen in den alten Tempeln wohl das Zebra und zwei andere Rinderrassen darstellen, aber nicht den Büffel. Die Büffel sind gegen Irrankheiten, insbesondere die Rinderpest, viel wider'standstähiger als die anderen Pinder, sind auch genügsamer in ihren Nahrungsansprüchen als diese. Während der Nilüberschwemmung sind sie in ihrem Elenent, da sie den Aufenthalt im Wasscr scbr lieben und sich für die Arbeiten ati den überstauten Feldein gut eignen. In der trockenen Periode läßt ihre Leistungsfähigkeit als Arbeitstiere sehr nach: die Fellahs halten die Tiere hauptsächlich wegen der Milch. Büfelkühe geben etwa ein Drittel mehr Milch als die gewöhnlichen ägyptischen Kühe, zudem wesentlich fettreichere Wilch, die aber einen Beigeschmack nach Muskatnüssen haben soll. Die Butter ist seir weiß und ölig. Dis Büffelfleisch wird geringer als das RindHeisch geschätzt, weil es hart ist und nach Moschus schmeckt. Ein Nachteil der Büffel ist ihre 
späte Reife. Die Kühe werden mit drei Jahren belegt, die Büffel sind erst mit sechs oder sieben Jahren rollständig ausgewachsen. Büffelkühe bezahlt man je nach Milchergiebigkeit mit $20-35 \mathrm{~L}$. E.

Der Schaf - und Ziegenzucht kann man nichts Günstigeres nachsagen als der Rinderzucht. Das anspruchslose Schaf findet in den Grenzgebieten zwischen fruchtbarem Lande und der Wüste immer noch ein paar ausgedorrte Steppenpfianzen oder auf den Kleefeldern die Überreste, welche die anderen Tiere übrig ließen. Aber das Fehlen von guten natürlichen Weiden stand auch der höheren Entwicklung der Schafzucht entgegen, während die dem Orientalen anerzogene Vorliebe für Hammelfleisch und die anderen Produkte, Schaffett, Schafmilch, Butter, sie förderte. Man unterscheidet folgende Rassen:

Meraise, hauptsächlich in Unterägypten gehalten:

Balladi, in Ober- und Unterägypten zu Hause;

Saidi und Berki, hauptsächlich in Oberägypten, und

Sanaboom, in Unterägypten gehalten.

Nebenbei zählt man alle möglichen Unterabteilungen ron Rassen auf, oftmals sind es dieselben, nur in anderen Orten anders benannt. Das Sudanesische Schaf zeichnet sich durch außerordentlich lange Ohren aus, sieht überhaupt einer Ziege ähnlicher als einem Schafe. Die beste ägyptische Schafrasse ist das Berberschaf mit dem stattlichen Fettschwanze. Auf 100 Schafe wird gewöhnlich ein Hammel gehalten. Die Preise und das Gewicht zeigt die Tabelle auf Seite 102. Daf dieses sehr gering ist, wird niemanden wundern, der das unscheinhare Gewürm ron Schafen beobachtet hat, das sich namentlich in Oberägypten herumtreibt. Recht kümmerlich sind auch die Ziegen, obwohl auch sie, wie die Schafe, schon seit Pharaonenzeiten in der Wirtschaft des Fellalss cine Rolle spielen. Die Ziegenmilch ist beliebt und wird manchmal, wie bei uns das Bier frisch rom Faß, rom Euter weg rerkauft. Der Besitzer treibt die Tiere von Haus zu Haus und mellst überall so viel aus, als gerade gewünscht wird. Die Milch wird auch zu Butter und Käse rerarbeitet, das Fleisch gegessen. Die so charakteristischen Wasserschläuche, die der Fellah oder der Beduine auf seinen Esel lädt oder der Wasserträger auf den Rücken, sind aus der Haut der Ziege genäht.

Der ehemaligen ausgedehnten Schwe in ehaltung des alten Ägypten hat der Mohammedanismus ein Ende bereitet. Nur die 
Kopten, denen das Schwein nicht als unrein gilt, ziehen es mitunter.

Den Pferden kommt vom landwirtschaftlichen Standpunkte aus so gut wie keine Bedeutung $\mathrm{zu}$, da sie fast niemals als Arbeitstiere benutzt werden. Der Fellah verwendet zum Zug Ochsen, Büffel, manchmal eine Kuh oder ein Kamel; er bedient sich zum Reiten und zum Transport mit Vorliebe des Esels, dessen großer Leistungsfähigkeit bereits gedacht wurde. Der kleine graue Esel, der kaum 4 L.E. kostet, gutwillig, fleifig und erstaunlich kräftig ist, trägt den Dünger aufs Feld, das Weib samt ein paar Kindern zum Einkaufen in den nächsten Ort, die Ernte nach Hause, und zur Zeit der Fremdensaison soll er womöglich noch als feuriges Reittier das Einkommen des Fellahs erhöhen. Die Universalität des Grautieres hat schließlich auch Grenzen, und deshalb darf man's diesem nicht übelnehmen, wenn die von Haus aus schwächere Vorderhand auf größeren Touren und bei schnellerem Tempo manchmal einknickt und dem stolzen Fremden zu einem unerwarteten Salto mortale verhilft, wie das zu passieren pflegt Die eigentlichen Reitesel, weike Tiere sudanesischer Abstammung, werden hoch bezahlt und sind die besten Reittiere, die man sich denken kann. Die außerordentliche Genügsamkeit und Ausdauer des Esels, seine Geschicklichkeit, auf schlechten Wegen vorwärts zu kommen, die größere Billigkeit gegenüber dem Pferde lassen es erklärlich erscheinen, wenn el diesem in der Wirtschaft des Fellahs rorgezogen wird. Auf größeren Domänen hält man, hauptsächlich zum Zug, Maulesel, die wesentlich mehr erziehen, aber viel teuerer sind und in den Nahrungsansprüchen den Pferden nicht viel nachgeben.

Die Pflege der Federriehzucht hatte in alten Ägypten eine erstaunlich hohe Stufe erreicht. Die Tempeldarstellungen zeigen Enten, Gänse, Tauben, Wachteln; nur das Huhn wurde erst später aus Indien eingeführt. Plinius (X, 54) spricht von der Kunstfertigkeit der Ägrpter im künstlichen Ausbrüten der Eier; eine hieroglyphische Inschrift bezeichnet eine Abbildung mit ..Einführen der Nahrung in eine Gans". Gegenwärtig kann ron einer hohen Stufe der Federvichzucht nicht die Rede sein. Günse, Enten, Truthühner, Hühner werden gehalten; aber es geschieht nichts zur Terbesserung ihrer Rassen. Das Geflügel ist klein und unansehnlich, und da Mästung im allgemeinen nicht üblich ist, auch wenig schmackhaft. Interessant ist, daf hingegen das Aus- 
brüten der Eicr mit den uralten Brutöfen noch immer in Übung steht, angeblich weil das heife Klima die Bruttätigkeit der Tiere einschränkt. Dic auffallend kleinen Eier werden in bedeutenden Mengen exporticrt, im Jahre 190666 Millionen Eier im Werte von 99499 L. E.

Nicht unerwähnt möge bleiben, daß sowohl der Nil als seine Kanäle und die Seen im Delta in ihrem reichen Fischbestand dem Fellah einen Nebenerwerb und ein wichtiges Nahrungsmittel bieten, das seinen Kampf ums Dasein erleichtert.

\section{Landwirtschaftliche Maschinen und Geräte.}

Der Häufelpflug, die Zalhafia, die Battana, die Kassabia, der Lowatah. - Drescharbeit mit dem,Norag“. - Bewässerungsbehelfe: Badala oder Wabur, Nattala, Schadûf, Sâkîje uud Tabût. - Die Schnecke des Archimedes.

Während Europa und Amerika unter dem Drucke steigenden Arbeitermangels und teurer Arbeitslöhne immer mehr Maschinen in Uen Dienst ihrer Landwirtschait stellen, kommt Ägypten noch immer mit seinen primitiven Geräten aus. Die Abneigung des Fellahs gegen jede Neuerung, scine geringe Eignung, mit Maschinen umzugehen, das Vorhandensein zahlreicher und billiger Arbeitskräfte erklären das ebenso wie die eigenartige Bodenbearbeitung, die durch die Bewässcrung und das Klima bedingt wird, und der Mĩngel an flüssigem Kapital. Daß der Fellah für Maschinen keine 39 Piaster per Feddán investieren muß, hat seine Mission innerhalb der ägypticchen Bodenkutur seir erieichtert. So finden wir noch heute dic altehrwürdigen Geräte des alten Ägyptens als fast auschließliches Werkzeng seiner heutigen Landwirte vor. Selbst der Dampfpflug, den Eyth, der spätere Begründer der Deutschen Landwirtschafts-Gesellschait, ror mehr als 40 Jahren in Ägypten eingefüht hat. konnte keine große Verbreitung erringen, weil der Charakter der dortigen Landwirtschaft nicht durch den Großgrundbesitz, sondem durch den Fellah hestimmt wird. Europäische Eggen sind wenig in Gebrauch; mit Mähmaschinen, gar Selbstbindern hat man auch leine günstigen Resultate erzielt. Neben den übrigen Ursachen hat sich hier noch der starke Körnerausfall beim Getreide hindernd in den Weg sestellt, der eintritt, wenn die Frucht bei exzessiver Hitze an Tage geschnitten wird. Ebenso geringen Erfolg liat ein Versuch gehabt, den "Norag" durch Einführung europäischer Dreschmaschinen zu ersetzen. Man hat diese durch Anbringung rotierender Trommeln zum Zer- 
malmen und Zerquetschen des Strohes den Landesbedürfnissen anzupassen versucht; denn das kieselige, harte Stroh, auf das der dortige Viehbesitzer zur Fütterung angewiesen ist, ließe sich sonst nicht rerwenden. Die Maschine hat den Norag indessen nur auf einigen groken Gütern rerdrängen kömmen. Ton heirischen Geräten kommen außer dem bereits in ersten Kapitel geschilderten Pfluge in Betracht:

der Häufelpillug, der sich rom gewöhnlichen Pflug nur durch ein hinzugelügtes dreieckiges Stück Holz unterscheidet und sich besscr zum Aufwerfen der Kämme für Baumwolle. Zuckerrohr, Erdäpfel usw. eignet;

die Zahaffa, eigentlich cin einfacher Holzballen, der mit Ochsen über das Feld gezogen wird. wobei der Kutschei darauí steht. Sic dient zum Glätten der Oberfläche und rertritt etwa Egge und leichte Walze;

die Battana. Schlittenartiges 90 cm langes Holzgestell in Trapezform auf Kufen, dessen gleiche Seitenteile derart zusammenlaufen, daß dis Gesteli an einem Ende $30 \mathrm{~cm}$, an anderen Ende $85 \mathrm{~cm}$ breit ist. Zieht man das Gerät mit der breiten Seite zuerst über den gelockerten Boden, so sammelt sich die Erde darin und wird durch die schief zusammenlaufenden Scitenteile in Kämme gepreßt;

die Kassabia. Gutes Gerät zum Nivellieren des Bodens, das man etwa mit einer vorn offenen Holzschachtel oder einer großen Schaufel vergleichen künnte, an der an drei Seiten $3 \mathrm{sm}$ hohe Wände und rückwärts zwei Handhaben angebracht sind. Der $90 \mathrm{~cm}$ breite Boden ist an der rorderen offenen Seite mit Eisen beschlagen und etwas konver gebaut, um die Erde leichter aufnehmen zu kümmen. Wird das Gerät durch Zugtiere über den Boden geschleift, so füllt es sich an den erhöhten Bodenstellen mit Erde, die der Arbeiter dimn an rertieiten Stellen durch Heben an den beiden Griffen wieder ablädt.

Riesenkassabias werden in Oberägypten zum Nivellieren der Bussins benutzt und durch die Lokomobile der Dampfpflüge in gleicher Weise wie diese über das Land gezogen.

Der Lowatah ist eine mit aufrechtstehender fester Handhabe versehene Holzplanke, die durch Zugtiere über überflutetes Land gezogen wird. Dabei wird der Boden einigermaßen nivelliert und das Wasser besser verteilt.

Zum Abschneiden der Frucht wird seltener die Sense, öfters 
die Sichel benutzt, die sich in mehreren Formen vorfindet. Dabei ist auch das Pflücken der Ähren mit der Hand noch vielfach üblich. Ich erinnere mich, in Oberägypten Fellahs gesehen zu haben, die wohl mit Sicheln bewaffnet waren, den Bersim damit aber mehr ausrupften als schnitten, was offenbar auf mangelhafte Übung im Schneiden oder auf ungenügende Schärfe des Instrumentes hinwies.

Ein eigentümliches, den ägyptischen Verhältnissen jedoch sehr entsprechendes Gerät ist der Dreschschlitten, der Norag. Er besteht ans einem Schlittengestell, dessen Kufen durch eiserne Achsen miteinander fest verbunden sind. An jeder dieser Achsen ist eine Anzahl ron beweglichen stählernen Scheiben angebracht. Das Getreide wird in großen flachen Hanfen aufgeschüttet und der Norag durch Zugtiere im Kreise darüber bewegt. Der Tritt der Tiere und die brechende, quetschende Tätigkeit der Stahlscheiben trennen die Körner rom Stroh und bringen dieses in den fein verfeilten, zerquetschten Zustand, der eriorderlich ist, um das Stroh trotz seiner kieseligen Härte und Sprödigkeit mit Nutzen verfüttern zu künnen. Ein solcher Norag kostet nicht mehr als $6-800$ Piaster $(120-160) \mathrm{Mk}$.), und das Dreschen per Feddán stellt sich auf etwa 90-120 Piaster (43-57 Mk. per Hektar). Darin sind die Kosten der nachfolgenden Trennung der ausgedroschenen Körner rom zerquetschten Stroh, dem Tibu, mit inbegriffen. Nachdem der Norag seine Arbeit getan, bilden beide natürlich ein Gemenge. das erst geschieden werden muß. Mit eigens dazu geformten Gabeln, deren fünf Zinken strahlenförmig auseinandergehen, wird das Gemenge so in die Luft geworfen, daßs die Körner, weil schwerer, direkt auf den Boden fallen, während der "Tibu" durch den Wind weiter getragen und abseits deponiert wird. Die Körner reinigt man dann mit Handsieben von der eventuell noch anhaftenden Spreu. Auf größeren Gütern findet sich manchmal auch eine europäische Getreideputzmaschine mit Handbetrieb.

Die an und für sich bedeutenden Kosten des ägyptischen Dreschverfahrens erscheinen geringer, wenn man die relativ unbedeutenden Investitionsbeträge für den Norag in Betracht zieht und bedenkt, daß die Arbeit des Strohhäckselns dadurch entbehrlich wird. Gegenüber unseren bäuerlichen Dreschflegeln dürfte der Norag entschieden einen Vorsprung bedeuten.

$\mathrm{Zu}$ den unumgänglich notwendigen Hilfsmitteln jedes ägyp- 
tischen Landwirtes gehören auch die verschiedenen Behelfe zur Unterstützung der Bewässerungseinrichtungen. Von jenen hat weder die Bassinbewässerung noch die Anlage der Kanäle den Landwirt unabhängig machen können. Überall gibt es Stellen, die das Wasser nicht erreicht oder wenigstens nicht immer zu der Zeit erreicht, wo man es braucht. Neben den großen modernen Pumpwerken curopäischer Konstruktion, die das offizielle Bewässerungswesen unterstützen. müssen dann bei den kleineren Landwirten die mannigfachen landesüblichen Geräte zum Wasserheben in Tätigkeit treten, die sich je nach den örtlichen Bedürfnissen herausgebildet haben. Diese werden außer durch die Unterschiede in der Bodenerhebung schon durch die zu verschiedenen Zeiten und an verschiedenen Orten ungleiche Höhe des Wasserspiegels in abweichender Weise hervorgerufen. Im nördlichen Ägypten beträgt die Differenz zwischen dem höchsten und niedrigsten Nilstande heispielsweise nur $1 \mathrm{~m}$, in Oberägypten bis zu $8 \mathrm{~m}$. Die Menge des beanspruchten Wassers bildete weitere Typen, vom primitiven Schadûf angefangen, der blok 100 cbm Wasser im Laufe eines: mühsamen Arbeitstages herbeischafft, bis zur Dampfpumpe, die 350 cbm Wasser in der Minute auf die ausgedehnten Felder der Grolgrundbesitzer wirft.

Da ist die "Badala" oder "Wabur", eine einfache hölzerne Röhre, mit der Wasser in geringer Menge aus dem Fluß, Kanal, Tümpel durch einen Mann nicht höher als $50 \mathrm{~cm}$ gehoben werden kann; der "Nattala“, der primitivste aller Wasserheber, der nur aus einem Strohkorb besteht, den zwei Mann mit Wasser füllen und an zwei Handgriffen aus Seil hinaufschwingen. Der Schaduf, eine Art Ziehbrumen, aus einem frei schwingenden Balken gebildet, an dem ein geflochtener Eimer hängt, wird durch einen Menschen bewegt. Der heht den Balken, bis das Wasser im Eimer eine Rinne erreicht, durch die es auf den Acker fliebt. Ist das Feld höher gelegen oder der Nilspiegel gefallen, so bringt man eine ganze Reihe solcher Schadûfs übereinander an. Jeder höhere, wieder von einem Manne bedient, schöpft das Wasser aus der ersten Sammelrinne in die nächst höher gelegene, bis das Wasser aus der letzten, im Niveau des Ackers gelegenen, endlich auf das Feld gelangen kann - eine unendliche Verschwendung von Arbeitskraft, die nur in diesem Lande des Überflusses an Menschenhänden möglich ist.

Etwas ökonomischer arbeitet das Schöpfrad (sâkîje), das 
man ebenso wie Schaduf und Badala schon zu Pharaonenzeiten benutzt hat. Hölzerne Räder, an der Außenseite paternosterartig mit Eimem bcsetzt, hoben das Wasser empor und entleeren es in Rinnen. In die Speichen des Rades greift cin zweites wagrechtes Rad ein, an dem ein langer Balken befestigt ist. An diesen Balken spannt man das Zugtieĩ. Das Tabût ist eine Abart von Sâkîje, die in Unterägypten henutzt wird, un Wasser 1-2 m hoch zu heben. Der holle Felgerkranz des Wasserrades ist durch eingelegte Brettchen in Fächer geteilt, die nach vorn offen sind. Bei der Drehung füllen sich die Fächer mit Wasser, das sich wie bei der Sâkîje in Rinnen entlleert. Im Fajûm, wo die Kanäle größeren Fall haben, läßt man das Schöpirad mitunter durch die Strömung antreiben.

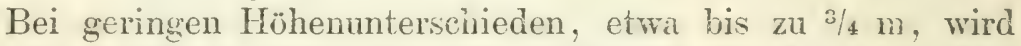
auch die berühmte Schnecke noch verwendet, die Archimedes angeblich für die Bewässeiungszwecke Ägyptens ersonnen haben soll. Sie dient oft zux Ergänzung einer Sâkije, wenn das Wasser im Nil oder im Kanal so weit gefallen ist, daß das Schöpfrad den Wasserspiegel nicht mehr erreicht. Nanchmal läßt man zwei oder drei solcher archimedischer Schnecken übereinander arbeiten. Aus Holz gebaut und innen mit einer doppelten Spirale versehen, lieferm sie unter den fleifigen Händen von zwei kräftigen Burschen nahezu die gleiche frbeit wie eine Sâkîje.

\section{Pflanzenbau.}

Baumwolle. - Zuckerrohr. -- Zuckerrübe. - Ber im. - Weizen und Gersie. Bohnen. - Mais, Durra und Hirse. - Reis. - Gemüse, - Errisen, Linseu und Hornklee. - Die Erdnus. - Obst. - Die Dattelpalme.

Die Baumolle. Ägypten erzengt haum $8 \%$ der ge. samten Baumwollwelternte und wird darin ron Amerika und Ostindien weit übertroffen. Dennoch kann keines dieser Lünder den Anspruch erheben, so sehr das Baumwolland par excellence zu sein als Ägypten. Hier sind alle Bedingingen rereint, die dem Gedeihen der Baumwollpflanze besonders zubräglich sind. Der Boden ist reich an Kieselsäure und Kochisalz und nicht zu arm an Phosphor und Kali; er besitat vor allem dic rollkommene Durchlässigkeit des echten Baumwollhodens. Ein feuchtigkeits. beladener Untergrund schadet der Pflanze nicht weniger als plötzlicher heftiger Regen, besonders den Arten amerikanischer Herkunft; denn deren Pfahlwurzel dringt bis zu $1 \mathrm{~m}$ und weiter in den Boden ein und verbindet die Pflanze so tief mit dem Unter- 
grund. Die indische Staude, der die Untergrundfeuchte wegen der kürzeren Pfahlwurzel weniger schadet, wird jetzt in Ägypten nicht mehr gebaut. Die Baumwolle, ein Kind der Sonne, findet genügenden Sonnenschein und die nötige Wärme vor, Luftwärme und Bodenwïrme. Wetterunbill und plötzliche Regengüsse, die namentlich den jungen Pflanzen verhängnisvoll werden, sind seltener als anderswo. Die Baumwollstaude verlangt nach steter, gleichmäßiger und nicht allzu großer Feuchtigkeit, und auch die wird ihr durch die künstliche Bewässerung geboten. Die Kultur der Baumwolle ist zienlich schwierig und setzt geschickte Arbeiter voraus. $̈$ gypten ist reich daran, und die geringen Löhne, die es zu zahlen hat, sichern die Konkurrenzfähigkeit auf dem Weltmarkte.

Solange die immerwährende künstliche Bewässerung des Nillandes nur auf geringen Flächen möglich war, konnte auch die Baumwollkultur keinerlei Ausdehnung erfahren. Deshalb ist es kein Zufall, daf dic ersten Bestrebungen zur Hebung dieser mit der Herstellung der ersten Kanäle in Delta durch Mehemed Ali zeitlich zusammenfallen. Damals brachte der Franzose JumeI aus Dongola in Nubien eine Varietät mit, die bald durch eine von den Antillen importierte Sea-Island-Staude (Gossypium bardadense) ersetzt wurde. $1825-1835$ war das die verbreitetste Art in Ägypten: später soll sich ihr nach Fohden eine aus Peru zugesellt haben. Von diesen beiden Arten stammt angeblich die älteste der jetzt gebauten Varietäten ab, die "A shmouni“. Nicht so glanzreich und fein als die Baumwollarten Unterägyptens, von mittlerer Stärke und kürzerer Faser, gedeiht sie in Oberägypten besser als diese, die hier leicht degenerieren und verminderte Erträge geben. Das Anbaugebiet der Ashmouni beschränkt sich gegenwärtig auf die Provinzen Beni-Suef, Fayûm und Minieh. Die Ernteresultate sind wegen der geringen Ausbeute an Fasern - 30\% von der Samenbaumwolle - unbefriedigend.

Afifi ist gegenwärtig die Hauptvarietät Agyptens; ihr Preis bildet die Basis für alle anderen. Wie fast alle ägyptischen Arten von brauner, langer, sehr glänzender, kräftiger und doch feiner Faser, wird auch ihre Abstammung auf die Sea-Island zurückgeführt. Der Ackerertrag ist durchschnittlich höher als bei allen andern Varietäten. Die Abbasi übertrifft sie wohl in manchen bevorzugten Distrikten darin, gibt jedoch nicht auf jedem guten Durchschnittsboden 500-600 Pfund per Feddán Faser wie die Af if i. Weitere Vorzüge sind: ein hoher Prozentsatz an Faser, 30-35\% Strakosch, Erwachende Agrarländer. 
der Samenbaumwolle betragend, die Leichtigkeit, mit der sich der Samen von der Fiber trennen läßt, und der geringe Unterschied in der Qualität zwischen der ersten und der zweiten Pflückung. Die Afifi gibt daher weniger Arbeit bei der Auslese und beim Egrenieren (Trennen der Baumwolle rom Samen); ihr Markt ist überdies stets gesichert. Deshalb zieht der Fellah sie jeder anderen Art vor und betrachtet andere Qualitäten als mühsamere Spezialkulturen, die nicht für jeden passen.

Die einzige weiße Baumwolle Ägyptens ist die Abbasi. Sio leidet weniger als alle anderen Sorten unter den WVitterungs. einflüssen, übersteht selbst Trockenperioden besser; aber ihre Auslese erfordert schon wegen der weißen Farbe viel Mühe. Die erste Pflückung überragt die zweite an Güte bei weitem und verkauft sich gut. Ihre Faser ist ebenso fein als die der Afifi, dabei sogar noch länger. Aber die zweite Pfiückung steht hinter der zweiten der Afif qualitativ sehr zurück und ist auch schwerer verkäuflich als diese. Die erste Qualität kostet per Kantar ron 315 Pfund sogar 1/4 L.E. mehr als die Afifi, die zweite Pflückung hingegen erzielt wesentlich geringere Preise. Einen Nachteil bildet auch die größere Schwierigkeit, die ihr Egrenieren verursacht. Die Abbasi wird seit 1891/92 gebaut und erfreute sich anfänglich rasch zunehmender Beliebtheit, die jetzt wieder abzunehmen scheint.

Die größeren Grundbesitzer in den nördlichen Teilen des Delta nahe beim Neer, wo der Salzgehait des Bodens beträchtlich ist, bauen seit 1897 eine Sorte „Jannorich", die als die seidenreichste und feinste aller ägyptischen Arten gilt. Man hält sie für eine Kreuzung ron Gallini und Afifi; ihr Preis notiert zirka ${ }^{1 / 2}$ L.E. über der Afifi, die sie auch an Längc und Stärke übertrifft. Der Ernteertrag ist kleiner als bei der Afifi, die Faserausbeute gleichfalls.

Die vielen anderen Arten, die vor Jahren in Ägypten gebaut wurden, wie Ham ouli, Gallini, Hindi, Bahmia, Ha ri ri usw., sind heute zumeist durch die oben aufgezählten ersetzt worden und können deshalb übergangen werden.

Da die Baumwolle einen fein verteilten, gut durchgemischten Boden verlangt, wird der Ackerung viel Aufmerksamkeit geschenkt. Von den großen Domänen abgesehen, die Dampfpflüge benutzen und damit während der Herbstmonate gewöhnlich $36 \mathrm{~cm}$ tief ackern, wird auch das Baumwolland mit dem inländischen Pfluge bearbeitet. Es gilt als Regel, so bald als möglich damit anzu- 
fangen, damit der Boden in den Herbstmonaten noch eine gewisse Ackergare bekommen könne. Viermal nacheinander, auch öfter. geht der Pflug über das Land; jede Furche wird senkrecht auf die vorhergehende gezogen. Das erste Umbrechen des Bodens, etwa nach Klee, geht schwer vonstatten; mit zwei Ochsen ackert man kaum 1/a Feddán um; weiterhin pflügt man leicht einen Feddán im Tage.

Nicht jeder Fellah kann sich den Luxus der hölzernen Battana zum Aufwerfen der Kämme gestatten. So umwickelt cr den Pflug mit trockenem Werg, mit alten Säcken, Fetzen oder dergleichen und improvisiert damit ein Gerät, das, durch den Boden gezogen, die Erde rechts und links aufwirft. Jeder ron einem Paar Ochsen gezogene Pflug legt auf diese Art etwa $2^{1 / 2}$ Feddán per Tag in Furchen, aber drei Mann sind nötig, un daraus auf einem Feddán die Kämme mit der Schaufel zu formen.

Bevor an die Aussaat geschritten werden kann, sind auf diese Weise schon $1^{1 / 4}-1^{1}$ 2 L. E. an Kosten aufgelaufen, wovon etwa $1 \mathscr{L}$ für das viermalige Ackern und der Rest für das Furchenziehen und Kämmemachen zu rechnen ist. Ersparen läßt sich davon nichts, denn die Bewässerung verlangt die sorgfältigste Herstellung des Saatbettes. Das ganze Land wird zur Erleichterung der Bewässerung mittels niedriger Dämme, die auf den Kämmen der Saatfurchen senkrecht stehen, in Abschnitte geteilt. Solche Dämme wiederholen sich meist nach 36 Fuf; nur bei sehr ebenem Terrain werden sie seltener aufgeworfen, während der kleine Fellah, dessen Boden meist nicht so eben ist, die $\mathrm{Ab}$. schnitte noch häufiger eintreten läßt.

Das Land wird damn so in Sektionen geteilt, daf 6-7 Furchen auf einmal bewässert werden können.

Die Kämme liegen näher zusammen, als dies in Amerika üblich ist, und sind gewöhnlich nur $75 \mathrm{~cm}$ voneinander entfernt, selten $95 \mathrm{~cm}$. In den Reihen werden die Samen durchschnittlich in einer Entfernung von $35-37 \mathrm{~cm}$ ausgelegt, auf dem besten Boden 44-46 cm entfernt. Das macht 13000 Löcher, und da man je zwei Pflanzen stehen läßt, 26000 Pflanzen per Feddán. Die Er. fahrung lehrt, daß zu weites Pflanzen eine Verminderung des Ertrages herbeiführt. Fohden meint aber, daß man in Ägypten nach der anderen Richtung sündige und gar zu nahe pflanze, was wegen der starken Beschattung der Feinheit der Faser nicht günstig sei und zugleich die tierischen Schädlinge vermchre.

Die Samen werden nicht auf den Scheitel der Kämme ge- 
pflanzt, sondern im oberen Drittel der Schräge, vom Scheitel bis zur Sohle der Furche gerechnet. In jedes Pflanzloch, das man mit einem Stecken macht, kommen $8-10$ Samen etwa $6-7 \mathrm{~cm}$ tief hinein. Nach der nun folgenden Bewässerung gehen die Samen in 10 oder 12 Tagen auf. Dort, wo die Keimung nicht erfolgt ist, legt man Samen, die vorher in Wasser geweicht wurden, nach.

Wenn die Saat ordentlich aufgegangen ist, wird durch die erste Hacke das Unkraut zerstört und die Bodenoberfläche gelockert. 3-4 Mann behacken eiren Feddán im Tage. Etwa 35 Tage nach der Aussat wird wieder bewässert, vorher werden jedoch die Pflanzen so verdünnt, daß in jedem Loch nur die zwei kräftigsten stehen bleiben. Die Baumwolle wird bis zur Ernte neun- oder zehnmal bewässert und die ersten vier- oder fünfmal nachher immer wieder behackt. Von Juli angefangen bis zum Beginn der Ernte, die im Delta in der ersten Hälfte September, in Oberägypten früher vor sich geht, erfordert die Baumwolle außer der Bewässerung keine Kulturarbeit mehr.

Den Stalldüngèr gibt man gewöhnlich zu der letzten Ackerung vor dem Anbau, 130-200 Mc pro Feddán. Die richtige Düngung ist nicht nur eine Frage des Ertrages, sondern auch der Qualität der Baumwolle. Zu frischer, nicht verrotteter Dünger soll die Reife verzögern und die Faser vergröbern. Mit Kunstdünger allein lassen sich wohl vorübergehende Erfolge erzielen, aber die nachfolgenden Früchte geben nicht mehr die gewünschten Erträge. Die besten Resultate werden nicht durch große Mengen Stalldünger erreicht, sondern durch gleichzeitige Anwendung von Stall- und Kunstdünger. Diese ägyptische Erfahrung ist um so interessanter, als sie sich mit unseren europäischen Ansichten vollkommen deckt. Vom Kunstdünger wirkt Superphosphat am vorteilhaftesten, besonders vor der Aussaat gegeben, Kali nur auf leichten Böden. Chilisalpeter als Kopfdüngung empfiehlt sich nur im frühesten Stadium, später verzögert er die Reife unter gleichzeitiger Verschlechterung 'der Qualität.

Zum Pflücken der Baumwolle verwendet man gewöhnlich Kinder. Eines pflückt 14-18 Mc Samenbaumwolle im Tage und verdient damit 30-40) Pf. Nach dem ersten Pflücken wird wieder gewässert, und im Oktober findet dann die zweite Ernte statt. Die dritte und letzte Pflückung ergibt nicht nur viel mindere Qualität, sondern auch wesentlich geringere Ausbeute. Nach der Ernte, die im Durchschnitt von ganz Ägypten 
gegenwärtig zirka $4^{1}$ 'a Kantar per Fedlín ergibt, wird die Samenbaumwolle vom Fellah oder Gutshesitzer eingelagert und in Siicke gefüllt. Die Agenten der groben Exporthäuser besuchen die Landwirte, kaufen das Produkt gewöhnlich an Ort und Stelle zusammen und führen es in ihre Egrenieranstalten, die über ganz Ïgypten verstreut sind. Bei sehr großen Partien sucht wohl auch der Produzent die Egrenieranstalten selber auf, die während der Saison, yon November bis Mai, Tag und Nacht arbeiten.

Zuckerrohr. Wie die Kultur der Baumwolle, hat sich auch die des Zuckerrohr's erst im vorigen Jahrhundert, in den siehziger Jahren, entwickelt, ohne annähernd die Bedeutung jener gewinnen zu können. Im Gegenteil. nach kurzem Aufschwung ist die Anbaufläche im Jahre 1904 anf 72339 Feddán gefallen, und das "Zuckerrohr weicht überall zurück. wo die Baumwolle gedeiht. Man hat die Ursache hiervon in der mangelnden Organisation der ägyptischen Zuckerindustrie und in allen möglichen Dingen erblicken wollen, sie liegt aber vor allem in den großen Vorteilen des Baumwollhanes und in den Übelständen, die der Rohrbau gerade unter den ägyptischen Verhältnissen mit sich bringt. In cinem Lande, in dem zwei Ernten im Jahre möglich sind, kann eine Pflanze, die im günstigsten Falle das Feld ein ganzes Jahr okkupiert, schwer ihren Platz behaupten. Man weiß ja, daß das Zuckerrola gewöhnlich zwei Jahre, ja sogar drei Jahre stehen bleibt. 8-9 Nonate nach der Pflanzung, gewöhnlich im Norember, kommt es erst zur Reife und gibt dann 200-120 Mc, im Maximum 240 Me Rohr pro Feddán. In zweiten Jahre wird von den Sprößlingen nur noch der halbe Ertrag geerntet, im dritten Jahr noch weniger. Begnügt man sich mit einer Ernte und reißt den Boden nachher um, so sind die Anhaukosten unverhältnismäßig groß; benötigt man dazu doch an Stecklingen allein etwa 4.5 Mc pro Feddán. Läßt man das Rohr zwei oder gar drei Jahre, so lohnt die Ernte kaum den Entgang so vieler Ernten anderer Früchte.

Solange die Daira Sanieh ihre Zuckerfabriken und Zuckerplantagen noch besaf, rerpachtete sie die Felder unter der Bedingung einer bestimmten Fruchtfolge und der Lieferung des Rohres an die Administration zu einem festen Proise (gewöhnlich 11/a Mk. für $100 \mathrm{~kg})$. Das erste Jahr mußte Brache gehalten werden, während der die Administration das Pflügen veranlaßte. Das zweite und dritte Jahr waren für das Zuckerrohr bestimmt. Die darauffolgenden drei Jahre wurden anderen 
Pflanzen eingeräumt, mit Ausschluß von Sommergetreide. Roggen sollte während der Flutsaison kultiviert und fest gedüngt werden. Den letzten Winter baute man Klee als Vorfrucht für den nun von neuem wieder beginnenden sechsjährigen Turnus.

Fellahs, die ergenen Boden besitzen, wollen diesen intensiver ausnutzen. Sie düngen das Rohr, was die Daira ihıen Pächtern wegen der Herabsetzung des Zuckergehaltes verboten hatte, mit Stallmist oder Coufri und erreichen dadurch viel höhere Erträge. Nach einer Rohrernte folgen zwei Jahre Getreide und Klee und dann wieder Zuckerrohr.

Jetzt, nachdem die Daira Sanieh ihre Güter verkauft hat, gelangt fast alles Rohr in die Hände der Société générale des Sucreries et de la Raffinerie d'Egypte; nur ein kleiner Teil wird in den kleinen Zuckermühlen der Eingeborenen rerarbeitet oder direkt verzehrt. Und nun hat sich auch ein anderer vorteil. hafterer Frichtwechsel eingebürgert: zwei Jahre Rohr, das dritte Jilur eine Flut und eine Wintersaat und das vierte Jahr Brache. Manchmal schiebt man vor dem Brachjahr noch ein Jahr mit gewöhnlichen Früchten ein und macht so den Fruchtwechsel fünfjälurig.

Die Saat wird, ähnlich wie bei der Baumwolle, durch vier- und noch mehrmaliges Pflügen mit den einheimischen Pfluge vorbereitet oder, in selteneren Fällen, von den großen Gesellschaften mit dem Dampfpfluge. Die Saatfurchen laufen ron Norden nach Süden und werden $70-90 \mathrm{~cm}$ breit und $35 \mathrm{~cm}$ tief gemacht. Größere Landwirte eggen die Basis der Furchen mit einer Art Rechen auf, der hinter dem Pfluge geht. Dadurch soll, ähnlich wie dies oft bei der Baumwolle geschieht, der Boden feiner zerteilt wercien. Zeitlich im Frühjahr, von Mitte Februar angefangen, werden die Stecklinge ausgesetzt. Das sind Stengelteile ron etwa 1 III Länge. Das obere Drittel des Rohres gibt bessere Resultate als die übrigen Teile; doch kann nur dann an eine Auslese gedacht werden, wenn auch die unteren Teile Verwendung finden. Das ist nur zur Zeit der Fall, wo die Faloriken arbeiten, und deshalb wähit die Sociéte française diesen Vorgang: Während dei Kampagne pflant man nur das obere Drittel und verarbeitet das andere in der Fabrik, während der übrigen Zeit rerwendet man das ganze Rohr zum Ausstecken. Wichtig ist, daß das Rohr in möglichst irischem Zustande gepflanzt werde, weshalb täglich nur sn viel geschnitten wird, als noch denselben Tug ausgesetzt werten 
kann. Sind die Stecklinge in den Furchen untergebracht und leicht mit Erde bedeckt, so bewässert man sie womöglich ungehend. Das Rohr benötigt noch mehr Wasser als die Baumwolle, muf 12-15 mal bewässert und dazwischen einige Male behackt werden. Ungünstiges Wetter setzt den Zuckergehalt leicht herab; im Delta läßit sich deshalb gar kein erfolgreicher Rohrbau treiben. Der durchschnittliche Zuckergehalt des ägyptischen Rohres beträgt kaum $14 \%$.

Die Zuckerräbe. Obwoll der Rübenbau in Ägypten nicht über das T'ersuchsstadium hinausgekommen ist, mögen die Erfahrungen, die man damit gemacht hat, wegen des Interesses, das diese Pflanze bei uns beanspruchen darf, mitgeteilt werden. Die Rübe läßt sich im ägyptischen Ackerjahre nur im Sommer unterbingen und leidet dann stark unter den zahlreichen ticrischen Schädlingen, die sich um die Zeit dort vorfinden. Ungeachtet der großen Fruchtbarkeit des ägyptischen Bodens erreichten die Erträge wegen dieser Kalamität und wohl auch wegen dei Unerfahrenheit in der Rübenkuitur nư zirka 70 Mc pro Fesldán. Die Versuche haben auch deshalb enttäuscht, weil die Rübe an die Bodennährstoffe zu viel Ansprüche stellt, un als Sommerkultur brauchbar zu sein. Die nachfolgende Baumwollernte blieb stark hinter dem Mittel zurück.

Bersim, der ägyptische Klee. Der ägyptische Landwirt kamn keine ausdauernden mehrjährigen Kleearten brauchen. Das ganze System verlangt die möglichste Konzentration, hohe Erträge in kürzester Zeit. Im Bassinland bereiten die Trockenheit und die Hitze der Vegetation rasch ein Ende, das Land init Kanalbewässerung kann nur durch steten Wechsel zum häufigen Tragen der wertvollsten Pflanzen, wie Baumwolle und dergleichen, gebracht werden. Die Luzerne ist deshalb keine brauchbare Klee. art für Ägypten, das fast ausschließlich den ägyptischen weißen Klee baut. Nach Fohden unterscheidet man drei ägyptische Kleevarietäten: Muscowi, Fachl und Said. Die erste wird am häufigsten und überall gebaut, wo Kanalbewässerung besteht; die beiden anderen Arten sind im Bassinland Oberägyptens heimisch. Auf Kanalland folgt der Bersim gewöhnilch dem Mais oder der Baumwolle, doch dient er dieser, wie wir gesehen haben, auch als Vor'fucht. Der Bersim gedeiht unter den milden Klima auch ohne Überfrucht ganz gut; aber weil jeder Tag, der früher Grünfutter bringt, einen Gewinn bedeutet, so sät man ihn meist 
8-10 fage vor der Ernte zwischen die Reihen der Baumwollstauden oder des Maises. Frühzeitiger Bersim ist sehr gesucht und wird oft mit $65-70$ Mk. pro Feddán bezahlt. Höhere Erträge erzielt man begreiflicherweise, wenn man das Land nach der Vorfrucht erst ordentlich pflügt, namentlich die Kämme, auf denen die Baumwolle gebaut war, ebnet. Dann wird bewässert und der Bersimsamen breitwürfig ausgestreut, wozu $30-35 \mathrm{~kg}$ Samen pro Feddán notwendig sind. Die Saat geht bei warmem Wetter in 2-3 Tagen auf. 50-75 Tage nach der Aussaat erhält man den ersten Schnitt oder die erste Weide. Das Datum der Aussaat beeinflußt selbstverständlich die Vegetationsdauer. Zwischen dem Samenlegen und dem ersten Sclmitt ist gewöhnlich dreimal bewässert worden; jeder Schnitt oder jede Weide erfordert zwei weitere Üherflutungen. Bei viermaligem Ernten, auf das jedoch nur beim Muscowi gerechnet werden kann, ist acht- oder neunmaliges Bewässern nötig. $\mathrm{Ob}$ der Bersim drei- oder viermal heranwächst, hängt auch wieder rom Zeitpunkte der Aussaat ab. Das viertemal bleibt er gewöhnich zur Sanengewinnung stehen. Der Muscowi ergibt 160-190 l̀g Samen pro Feddán; der erste und zweite Schnitt davon ergeben auf gut mittlerem Boden zirka 36 Mc Grünfutter oder rund 7 Mc Heu. "Fachl", der auf land ohne Kanalhewässerung gebaut wird, gibt nur einen Schnitt, der jedoch sehr ausgiebig ist und oft zu Heu gemacht wird. "Saidi" ist weniger ertragreich als .Fachl", hat aber auch geringeren Wasserbedarf wie dieser. Saidi wird zwei- bis dreimal geschnitten oder abgeweidet.

Bei der doppelten Aufgabe, die der Bersim als Futterpfianze und als Stickstoffquelle zu erfüllen hat, ist es von Wichtigkeit, die Henge Stickstoff kennen zu lernen, die or dem Boden zuführt. Makenzie, der frühere Direktor der Ackerbauschule in Ghizeh, hat nach Analysen berechnct, daß ler Boden nach zwei Schnitten Muscowi pro Hektar um $320 \mathrm{~kg}$ mehr Stickstoff besaß als vor der Aussaat, während er die Amreicherung an Stickstoff durch Kleebau in Europa nur auf $64-70 \mathrm{~kg}$ pro Hektar schätzt. Da ich nur die Resultate, nicht aber die Berechnungsbasis kenne, steht mir ein Urteil über diesen Vergleich nicht zu; doch sind die europäischen Zahlen jedenfalls zu niedrig angenommen. Nach H. Weiske ${ }^{1}$ ) sind in den Stoppel- oder Wurzeliückständen

$\left.{ }^{1}\right)$ Lemmermann, Düngerlehre. Leipzig, Schäfer. 
unseres Rotklees $220 \mathrm{~kg}$ Stickstoff enthalten, wobei natürlich. je nach dem Kultur- und Düngungszustande des Bodens und der Üppigkeit des Ḱleestandes, Schwankungen eintreten.

Weizen und Gerste. Unter den Wintersaaten steht der Ausdehnung nach der W $\mathrm{E}$ izen obenan, das zweitwichtigste Wintergetreide ist die Gerste. Beide gedeihen in ganz Ägypten und werden ebenso im Bassinland Oberägyptens gebaut als auf den Böden mit Kanalbewässerung in Unterägypten und im Delta. Dort wird der Samen in den Schlamm gestreut, wenn das C̈berschwemmungswasser in den Nil zurückgetreten ist, hier, auf dem Kanalland, entweder nach rorangegangener oder mit nachfolgender Bewässerung ausgelegt. Der Vorgang, der dabei eingehalten wird, ist sehr einfach. Nach dem Pflügen wird mit der Z a haffa, dem hölzernen Balken, dem Felde ein glättender Strich gegeben, dann wird der Samen ausgestreut und mit Hilfe des einheimischen Pfluges zugedeckt. Der Gebrauch europäischer Eggen ist selten. Im Januar oder Anfang Februar, wenn das Getreide etwa 20 $\mathrm{cm}$ hoch geworden ist, wird wieder bewässert und im März oder Anfang April. zur Zeit des Ausährens, das dritte- und letztemal. Weizen wird manchmal mit Stallmist oder Coufri gedüngt; in den letzten Jahren hat man auch Düngerversuche mit Chilisalpeter angestellt. Gerste erhält keinen Dünger, obgleich sie meistens in ärmere Büden als der Weizen gebaut wird. Sie ist eine der ersten Nutzpflanzen. die man in den urloar gemachten entsalzten Boden sät.

Die Ernte, in Oberägypten in April, in Unterägypten im Mai oder Juni, erfolgt entweder durch Pflücken mit der Hand oder mit Hilfe schmaler Sicheln, nit denen die Ähren melır ausgerauft als abgeschnitten werden; fünf Mann ernten 1 Feddán im Tag. Mähmaschinen kennt man nicht, sie ließen sich wegen der Bewässerungsfurchen wohl auch schwer anwenden. Sowohl von Weizen wie von der Gerste werden einige Arten gebaut. Unter den Weizensorten ist Triticum durum, der Hartweizen, am verbreitetsten. Der Handel unterscheidet den weißen, feineren Beheri-Weizen ron dem roten Saidi-Weizen, der dunkler, härter und glasiger ist und niedriger im Preise steht. Alle Sorten, einerlei ob rot oder weik, sind arm an Kleber und ohne Beimischung fremden Mehles zum Brotbacken nach europäischer Weise nicht geeignet. Die Eingeborenen ziehen den meist roten Weizen der Bassinländer Oberägyptens dem Kanallandweizen ror. 
Merkwürdig ist die Tatsache, daß die ägyptischen Weizensorten nach Fohden vollkommen frei von Rost bleiben, während importierte ausländische Rassen in Ägypten stark daron befallen werden. Der Durchschnittsweizenertrag des Landes ist 13-15 Mc pro Helitar, die besten Böden tragen auch 27-30 Mc Körner und 13-15 Mc Stroh.

Die Gerstenkörner sind mager, langgestreckt und dünn, das Hektolitergewicht beträgt durchschnittlich $64-0 \mathrm{~kg}$. Mit Ausnahme der besseren Mariout-Gerste, die am Wüstenrand in der Nähe Alexandriens unter Ausnutzung des dort häufigeren Regens gezogen wird und zufolge dessen sehr unsichere und ungleiche Ernten gibt, bringt Ägypten nur Futtergerste hervor. Die Araber bereiten wohl eine Art Bier daraus, mischen das Mehl auch ihrem Brot bei, aber zur Malzerzengung ist die Gerste wegen des sehr hohen Stickstoffgehaltes nicht verwendbar. Anbauversuche mit ausländischen Biaugersten haben wohl qualitativ bessere Resultate ergeben, der quantitative Ertrag blieb aber hinter dem der einheimischen Gersten zurück. Ton diesen erntet man auf den besten Böden bis 55 He pro Hektar, im Durehschnit des Landes nur 17-20 Mc. Auf die besondere Beschaffenheit des ägyptischen Gerstenstrohes wurde bereits anläßlich der Viehfütterung hingewiesen.

Den wichtigsten Kulturpflanzen sind auch Bohnen und II is zuzuzählen. Die Bohnen bercichern ủen Stickstoffgehalt des Bodens, schaffen das Grundfutter der Haustiere für den größeren Teil des Jahres, sind gleich wichtig als Volksnahrungsmittel wie als Exportartikel. Ton der beträchtlichen Bohnenproduktion, die auf rund onjorio Feddán betriehen wird. entfällt der vierte Teil auf Oberägypten. Namentlich im Fayn̂m, in Minje und Siut werden viele Bohnen gebaut. Die leldnäßig gezogene Art ist die Baladi mit kurzen Schoten und weißen oder roten Bohnen. Über die Kultur ist nicht viel zu sagen. Im Bassinland werden die Samen sofort nach dem Abfliefen des Überschwemmungswassers mit der Hand in den Schlamm gesät, dann kümmert man sich his zui Ernte im Frühjahr nicht mehr darum. In Unterägypten erílgt Bocienbearbeitung und Aussaat zur gleichen Zeit und in gleicher Weise wie beim Getreide, und auch die Einte und das Dreschen mit dem Norag wird ebenso gehandhabt. Auf mittelgutem Boden erzielt man Erträge ron 18-20 Mc pro Hektar von etwa 2 Mc Samen. 
Der Mais, arabisch Durra schâmi genannt, wird, wie bereits erwähnt, in den offiziellen Ausweisen mit Sorghum und Hirsc zusammengeworfen, so daß der Anteil jeder dieser Pflanzengattungen an der unter Mais ausgewiesenen Gesamtfläche nicht festzustellen ist. Einen Anhaltspunkt liefert die Erfahrung, dia in Unterägypten fast nur Mais gebaut wird, während man $\mathrm{D}$ ura (Sorghum vulgare) und die verschiedenen Hirsearten in Oberigypten kultiviert. Die Bedeutung der drei Getreidearten ergibt sich schon aus der Ausdehnung der Ackerflächen. Von 1797927 Feddán wurden nur 10\% als Sommerfrucht, alles übrige als Nilikultur gebaut, deren charakteristischste Pflanzen Miis, Sorghum und Hirse sind.

Bodenvorbereitung und Aussaat erfolgt bei allen drei Pflanzen in gleicher Weise wie bein Getreide. Nachdem dem regelmäßigen Legen der Samen dabei nicht die geringste Aufmerksamkeit geschenkt wird, kann man sicil leicht rorstellen, wie groß die Samenverschwendung namentlich beim Mais ist. Ein Bursche streut die Körner in die Saatfurche und verbraucht auf diese Weise $80-90 \mathrm{~kg}$ pro Hektar an Samen, also etwa zehmmal so viel als bei uns oder in Amerika. Folnden berechnet die Anzahl Pflanzen, die damn auf einem Feddán stehen, mit 13-20000. Es ist leicht zu ermessen, daß das Vereinzeln de ${ }^{\circ}$ Pflanzen viel Mühe gibt und zweimal vorgenommen werden muk. Das erstemal bald nach dem Aufgang, das zweitemal, wenn die Pflanzen größer geworden sind. Sonst ist die Kultur nicht besonders mühsam; dreimal wird mit der Hand behackit, sechs- oder siebenmal bewässert. Die einheimischen Maisarten sind von niedrigem Habitus und besitzen kleine Kolben. Die andern Varietäten, die als amerikanische bezeichnet werden und größere Kolben liefern, reifen lingegen erst in 100-120 Tagen, gegen 70-90 Tage bei den einheimischen Rassen. Deshalb sind sie bei den Fellahs nicht sehr beliebt, denn jeder will seinen Boden so bald als möglich wieder fïr den Kleebau frei bekommen. Der Mais ist die am häufigsten gedüngte Pflanze Ägyptens. Neben Stallmist wird häufig Coufri rerwendet. Die Erträge variieren nach der Güte des Bodens von 15-44 Mc pro Hektar. Mitunter, besonders wenn der Klee mißraten ist, wird der Mais auch als Grünfutter gebaut. Durra, die ebenso wie der Mais unter Beimischen von Hornkleesamen zu Brot verarbeitet und außer an Tauben und Hühner nicht verfüttert wird, gibt ähnliche Erträge. 
Stengel und Kolben der Maispflanze werden nicht verfüttert, sondern als Brennmaterial benutzt.

Der Reis gehört nicht zu den viel gebauten Früchten Ägyptens; die Eignung für neu erschlnssene, noch salzhaltige Böden verleiht ihm aber dennoch Wichtigkeit. Vielleicht erklärt sich seine geringe Empfindlichkeit gegen hohen Salzgehalt zum Teil durch die starke Bewässerung, die das Salz in tiefere Schichten, wohin die Wurzeln nicht gelangen, hinabschwemmt. Der Reis wird im Sommer und in der Nilsaison gepflanzt. Der Sommerreis (Sultani) ist wertvoller als der Flutreis (Sabeini), doch wird sein Anhau wegen des sehr großen Wasscrbedarfes in Jahren mit niederem Nilstand durch Regierungsdekret rerboten. Die besondere Aufgalue, die der Reis zu erfüllen hat, führt auch zu namhaften Schwankungen in den Anbauflächen. 1904 und 1907 wurden beispielsweise die gleichen Flächen mit Flutreis bebaut, aber im crsten Jahre 97769 Feddán und im zweiten Jahre 155934 Feddán mit Sonmerreis. Dieser wird im Mai oder Juni gesät und reift langsam heran. Manche Varietäten benötigen bis zu sieben Monaten dazu und werden fast gleichzeitig mit dem Flutreis, der schon in 90 Tagen reif wird, geerntet.

Ein Haupterfordernis des Reisbaues ist die vorhergehende vollkommene Ebnung des Bodens und eine gute Verteilung des Überschwemmungswassers. Wo das nicht zutrifft, ersticken die jungen Pflanzen auf den tiefer gelegenen Stellen und verdorren auf den höheren. Deshalb ist die Vorbereitung eines Feldes zum Reisbau keine kleine Mühe, und die größeren Grundbesitzer ziehen es meistens vor, das Land zum Reisbau zu verpachten. Der Fellah zahlt für guten, nicht zu salzigen Boden gern 17-21 Mk. pro Feddán oder gibt bei schlechterem, stark salzhaltigem Boden die Hälfte der Ernte an Zahlungsstatt. Dahei nimmt er noch die Arbeit auf sich, dic Dämme herzustellen, die das C̈berschwemmungswasser auf dem in Rechtecke geteilten Gelände zurückhalten, und die Haupt- und Seitengräben, die zur Bewässerung und Entwässerung der Beete notwendig sind. Die ganze Anlage erfordert eine Erdbewegung von 1,865 cbm pro Feddán, wofür in Ägypten allerdings nur $8 \frac{1}{2}-9 \mathrm{Mk}$. gezahlt werden.

Wenn der Boden so vorbereitet ist, läibt man das Wasser in die Felderabteilungen hinein und streut den Samen mit der Hand in die 8-9 $\mathrm{cm}$ hoch stehende Flut. Den Samen hat man vorher sechs Tage in Wasser quellen gelassen, dann flach aus- 
geloreitet und erst zur Saat rerwendet, lis er nach weiteren zwei oder drei Tagen zu keimen begonnen hatte. Nun nach dem Ausstreuen bleibt die Wasserschicht drei Tage über dem Samen stehen, der in dem sich absetzenden Schlamme einigen Halt gewinnt. Zwei Tage läßt man den Boden dann trocknen, um denselben Vorgang innerhalb der nächsten zehn Tage noch zweimal zu wiederholen. Damit sind die kritischsten Tage für den Reisbancr vorüber. Die $14-15$ cm hoch gewordenen Pflanzen werden dann noch verdünnt, das Unkraut entfernt, und wenn die Zeit der Ernte herangekommen ist, schneidet man die Rispen unit Messern ab, legt sie in kleine Bündel und drischt sie init dem Norag aus. Gedüngt wird der Reis fast nie. Die ägyptische Reiskultur, deren Beschreibung ich Mr. Fohden verdanke, unterscheidet sich, namentlich was die Art der Aussaat betrifft; wesentlich von der anderer Länder. In den Hauptreisland, in Südkarolina, gilt es z. B. als Grundsatz, das Feld, snbald die Keimspitzen erscheinen, trocken zu legen und nicht früher neuerlich zu überschwemmen, his die Pflanzen Blätter getrieben haben. Nachfolgender Bersim wird zwischen die Reispflanzen gesät, wenn diese sich zu kräuseln beginuen. Im guten Gedeihen des Klees crblickt der Landwirt den Beweis, dalis der Salzgehalt des Bodens schon genügend ausgewaschen ist, um die Wiederholung des Reisbaues unnötig zu machen.

Es würde zu weit führen, wenn alle Kulturpflanzen, die die ägyptische Landwirtschalt kennt, hier ausführlicher hesprochen werden sollten. Zur Charakterisierung des landwirtschaftlichen Betriebes dürften die bisher aufgezählten wohl genügen, während einige andere nur noch kurze Erwähnung finden mögen. So die Zwiebel, die das wichtigste Gemüse für Konsum und Export ist und 1907 im stattlichen Ausmaße von 28491 Feddán gebaut wurde. Exportiert werden auch die Tomaten oder Paradiesäpfel, die man namentlich im Delta feldmäßig zieht. Die Kartoffel wird in geringem Ausmaße gebaut. Ihre Qualität ist nicht gut, der Ertrag läbt gleichfalls zu wünschen übrig. Von Leguminosen wären noch die Linsen zu erwähmen, die in der Nahrung des Fellahs eine gewisse Rolle spielen, während sich von Erbsen meist uur die Felderbse gemischt mit Bohnen vorfindet. Der Hornklee (Trigonella Focnum graecum, arabisch helba), wird mitunter als Grünfutter gepflanzt und mit Bersin gemischt verfüttert, aber auch auf Samen gezogen und 
als Zusatz des Mais-, Sorghum- oder Hirsemehls zum Brotbacken rerwendet. Auf den leichten Sandböden Unterägyptens zieht man auch die $\mathrm{ErdnuB}$ (Arachis hypogaca), die eine achtmonatliche Vegetationszeit beansprucht, aber gute Erträge gibt. Erdnüsse sind ein Exportartikel, besonders nach der Türkei. Flachs wird weniger als früher kultiriert. Die Faser ist sehr minder. dei Samen wird vermahien und verfüttert.

Vom Obst gedeihen Orangen, Mandarinen, Zitronen gut, hingegen kommen Ïpfel. Birnen und derglcichen wegen des zu heifen Klimas nur schwer fort. Die Weintrane gedeiht ausgezeichnet, wird aber nur als Tafelobst und nicht zur Weingewinnung verwendet. Einer der wenigen Bümme Ägyptens. der für die Landeskultur in Betracht kommt, ist die Dattelpalme (Phoenis dactylifera). Jeder Fellah trachtet einige Dattelpaimen zu besitzen; man fincet sie einzeln selbst in dem spärlichen Fruchtlande Nubiens, in reicherem Boden überall, Haine, Wälder bildend. Sorgfältig wird der junge Baum mit. cinem Wall umgeben, der bessere Bewässerung erlaubt und Schutz gewährt, die Neupflanzung wird auch ron oben durch Zudecken geschützt. Aus dem Kern gezogen gibt die Dattelpalme nach zchn Jahren die ersten Früchte, von Áblegern schon nach sechs oder acht Jahren. Dic Dattelpalmen tragen entweder nur weibliche oder nur männliche Blüten, so daß die Befruchtung bei weiterer Entfernung der Bäume künstlich durch Bestäuben der weiblichen Blüten mit den Pollen der männlichen herbeigeführt werden mußs. Bei größeren Anlagen rechnet man 10-20 weibliche Bäume atif einen männlichen und pflanzt sie so in Gruppen zusammen, daß die männliche Palme an der Seite steht, von der ler Wind zu kommen pflegt. Als Erträgnis eines guten Baumes gibt man 15t)-2(n) $\mathrm{kg}$ an. Ägrpten kennt dreißig verschiedene Spielarten, darunter eine samenlose, früh-, mittel- und spät-reifende. Manche sind in frischem Zustande genießbar, andere, ron herbem Geschmack, erst nach eingetretener Fermentation. Die Zeit der Reife ist in den verschiedenen Gebieten ungleich. In Oberägypten erntet man die Datteln schon Ende Juni und im .Tuli, in Unterägypten von August bis Ende Oktober. Den Dattelpalmen Agyptens kommt es zustattsn, daß sie salzigen Boden gut vertragen und in trockener Luft besser als in feuchter gedeihen. 


\section{Fünftes Kapitel. \\ Die Weiterentwicklung.}

\section{Elemente der Weiterentwicklung.}

Während hisher versucht wurde, den Charakter des gegenwärtigen Landschaftsbetriebes aus dessen Voraussetzungen zu erklären, sollen jetzt die Maßnahmen betrachtet werden, durch die Staat und Gesellschaft in Ägypten die Weiterentwicklung der Landwirtschaft anstreben. Aus den früheren Darlegungen geht hervor, daßs diese Weiterentwicklung häuptsächlich von zwei Umständen abhängt: ron dem Fortschritt des Bewässerungswesens und von der Anpassung der Landwirt. schaft an dessen neue Form.

Wie wenig das eine ohne das andere nützen würde, zeigt ein Blick auf die Anbaustatistik vom Jahre 1904. Von den 4 Mill. Feddán, die um diese Zeit mit immerwährender Kanalbewässerung versehen waren, standen nur 1/1/2 Mill. Feddán unter Repetitionskultur. Nur die Bewirtschafter von 1/2 Mill. Feddán hatten es verstanden, sich den ungeheuren Vorteil der Kanalbewässerung voll zunutze zu machen und den Boden das ganze Jahr über zu bebauen. Die Erklärung dafür ergibt sich aus der Zusammenfassung des bereits Ausgeführten von selbst: Die ägyptische Landwirtschaft steht in dem Augenblicke schwereren Problemen gegenüber, wo das Bewässerungswesen den gewaltigen Schritt von der Bassinbewässerung zur immerwährenden Kanalbewässerung zurückgelegt hat. Bis dahin war der Betrieb einfach und die primitive Kunst des Fellahs für seine Bewältigung vollständig ausreichend; die Stagnation der Landwirtschaft hat bis dahin ihren Grund nicht in veralteten und mangelhaften Methoden der Ackerbestellung gehabt, sondern in dem Verluste der Erkenntnis, daß der Kernpunkt der ganzen Frage in einem hohen Stande des Bewässerungswesens liegt. Mit der Änderung des 
Bewässerungswesens wird das gänzlich anders; denn die Ausnutzung des Kanalsystems stellt viel größere Ansprüche an die Umsicht und das Wissen des Ackerbauers. Die Bodenbearbeitung ist nicht mehr so einfach, denn jetzt heißt es, den Boden in möglichst kurzer Zeit und ohne vorherige Überschlammung in einen Zustand bringen, der zur Aufnahme des Saatgutes geeignet ist; die Bcwässerung will den Ansprüchen der einzelnen Kulturpflanzen angepaßst, will richtig bemessen und über die ganze Vegetationsperiode verteilt sein. Die Fruchtfolge verlangt mehr Aufmerksamkeit als früher; man kommt auch nicht mehr ohne Düngung aus, denn abgesehen ron dem Fortfall der natürlichen Schlammdüngung erfordert die erst jetzt lebensfähige, anspruchsvolle Baumwolle, erfordern die zwei Ernten im Jahr mehr leicht aufnehmbare Bodennährstoffe als bisher. Und schließlich: die Gefahr des Bodenversalzens rückt jetzt in drohende Nähe.

Man sieht also, mit der Ausgestaltung des Bewässerungswesens allein ist der Landwirtschaft noch nicht viel geholfer, diese muß sich den geänderten Verhältnissen auch anpassen können. Das immerwährend mit Wasser rersehene Ägypten braucht deshalb seine neue Kultur und seine neuen Menschen, und erst dann, wenn der allgemeine Fortschritt der Landwirtschaft dem Fortschritt des Bewässerungswesens gefolgt sein wird. kann dieser seine Wirkung voll und ganz äußern. An dem allgemeinen Fortschritte werden manche der schon aufgezählten und erst unlängst geschaffenen Vorbedingungen zweifelsohne später stärker mitwirken als heute. Dazu treten nun die weiteren Maßnahmen, die hier neben den Projekten für die Ausgestaltung des Bewässerungswesens besprochen werden sollen.

\section{Die Weiterentwicklung des Bewässerungswesens.}

Der Mehrwert des kanalbewässerten Ägyptens. - 4 Milliarcien Kubikmeter Stauwasser. - Der Nildamm von Assuan und seine Erhöhung. - Ein moderner Mörissee. - Das Programm Sir William Garstins. - Wassernot in Ägrpten. Sicherung gegen zu niedrige Flut. - Die Umwandlung der Jassinländer und die Erhöhung des Grundsteuerertrages.

In seinem Werke "The Nile in 1904" sagt der herrorragende Bewässerungsiachmann Sir William Willcocks: „Ägypten besitzt im ganzen eine bewässerbare Fläche von $6^{1 / 4}$ Mill. acres ${ }^{1}$ ).

1) 1 Feddån $=1,03804$ acres. 
Davon 1/4 Mill. Feddán, die an Wüstensaume liegen, stets wie hisher durch die Flut bewässert werden müssen. Ihr Wert beträgt 5 Mill. $\mathscr{L}$. \& Mill. Feddán sind bis jetzt mit inmerwährender Kanalbewässerung versehen worden und besitzen einen Mindestwert von $55 \mathscr{L}$ pro Feddán, demnach insgesamt einen solchen ron 220 Mill. $\mathscr{L}$. Von den restlichen 2 Mill. Feddán werden $2_{3}$ nur durch die Flut und ${ }^{1 / 3}$ noch gar nicht bewässert. Diese 2 Mill. Feddán repräsentieren heute einen durchschnittlichen Wert ron 25 $\mathscr{L}$ pro Feddán, in Summe 50 Mill. $\mathscr{L}$. Der ägyptische Kulturboden stellt demnach einen Gesamtwert von 275 Mill. $\mathscr{L}$ dar. Wäre es möglich, die 2 Mill. Feddán mit immerwährender Kanalbewässerung zu versehen, so würde ihr Wert um $30 \mathscr{L}$ pro Feddán steigen und der Gesamtwert Ägyptens um 60 Mill. $\mathscr{L}$."

Nicht weniger als 60 Mill. $\mathscr{L}$ oder 1248 Mill. Mk. bedeutet also nach Willcox in Geldwert ausgedrückt die Verbreitung des Kanalnetzes über ganz Ägypten. Die Erreichung des verlockenden Zieles setzt natürlich zunächst die Aufspeicherung genügender Wassermengen voraus. Zur Zeit der Hochflut wird man weniger Wasser als heute benötigen, denn die Ersparnis durch die Kanalbewässerung gegenüber der Bassinbewässerung ist ja, wie an anderer Stelle ausgeführt wurde. bedeutend. Während des Sommers hingegen werden die Gewässer des Nils weiter ganz unzureichend sein. Will cox hat berechnet, daß die immerwährende Bewässerung von 2 Mill. Feddán neuen Landes Reservoire in Ägypten selbst beansprucht, die $t$ Milliarden Kubikmeter Wasser fassen und zur Sommerszeit den Wasservorrat des Nil ergänzen können. Jede Milliarde Kubikmeter Wasser gestattet, 1/2 Mill. Feddán Land mit Kanalbewässerung zu versehen. Von den 4 Millarden soll nach Will cox eine Milliarde durch den Assuan damm in seiner heutigen Gestalt gespeichert werden, die zweite Milliarde durch dessen Erhöhung um 6 m, und für die Speicherung der restlichen zwei Milliarden legt Willcox ein großartiges Projekt, die Schaffung des Reservoirs von Wady Rayan, anstoßend an den ehemaligen Möris-See vor.

Der große Nildamm bei Assuan, nördlich ron der Insel Philä", ist schon im Jahre 1@o2 vollendet worden. Die schwierige Finanzlage Ägyptens hatte das längst ausgearbeitete Projekt lange nicht zur Ausführung kommen lassen. Endlich streckte der Engländer Ernst Cassel die nötigen Mittel vor, und die Regierung 
konnte 1898 der schottischen Bauunternehmung John A ird \& Co. die Herstellung übertragen.

$106 \mathrm{~m}$ hoch und $2000 \mathrm{~m}$ lang sind nun die mächtigen Granitmassen des Dammes senkrecht dem ersten Nilkatarakt bei A ssuan vorgelagert. 140 Unterschleusen ron $14 \mathrm{qm}$ Weite haben dem Durchlak zu dienen, und 4) Oberschleusen von $71 / 2$ qm entleeren das Wasser, das zur Zeit des niederen Nilstandes dem Reservoir zu Bewässerungszwecken entnommen wird. Die Unterschleusen, die man öffnet, wenn das schlammige Wasser der Hochflut heranstürmt, gestatten das Durchschwemmen der mitgeführten festen Teile, da sonst das Reservoir bald mit Schlamm erfüllt und die ägyptische Landwirtschaft um ihren wertvollsten Dünger gebracht würde.

Geht die Hochfiut zu Ende, und strömt verhältnismäßig klareres TVasser heran, dann wird eine Schleuse nach der anderen geschlossen und das Reserroir gefüllt. Das Füllen beginnt gewöhnlich gegen den 1. Dezember und dauert 100 Tage. Anfangs Mai reicht, bei dem gegenwärtigen Umfange der Kanalbewässerung, das Nilwasser allein nicht mehr aus, und nun muß las Wasser im Reservoir so lange zur Aushilfe herangezogen werden, bis die Flut wieder eintritt. In Jahren mit spätem Flutanfange hat das Reservoir dieser Aufgabe bis Mitte Juli zu dienen. Es ist selbstverständlich, daß die Wirksamkeit, des Reservoirs un so nachdrücklicher sein kann, je früher die Flut kommt, und je kürzere Zeit die Landwirtschaft demuach auf die Mithilfe des aufgespeicherten Wassers angewiesen ist. Ungeachtet der geradezu zyklopischen Ausführung des ganzen Werkes, hat dieses anfangs manchen Schaden durch das mit großer Gewalt durch die Schleusen drängende Wasser erlitten und allerlei Terstärkungsarbeiten nötig gemacht. Eine schwere und verantwortungsvolle Aufgabe bleibt Gie Regulierung der Schleusen. Sie beansprucht ununterbrochene Vachsamkeit, stete, unermüdliche Beobachtung aller Vorgänge in den Oberlaufgebieten des Nils. Der Chefingenieur von Assuan, Mr. Cooper, hat die zweckmäßige Handhabung der Schleusen zu einer wahren Wissenschait erhoben. Der Damm leistet die erwartete Arbeit vollkommen und hält tatsächlich die Milliarde Kubikmeter Wasser im Reservoir von Assuan zurück, die zur Vermehrung des Kanallandes um ${ }^{1}$ 's Mill. Feddán erforderlich ist.

Das zweite Projekt, den Damm um $6 \mathrm{~m}$ zu erhöhen, seinen Fassungsraum dadurch zu verdoppeln und so Platz für die Auf- 
speicherung der anderen Milliarde zu schaffen, ist so alt wie die Idee des Staudammes selbst. Dem Entwurfe des verstorbenen Sir Benjamin Baker standen indessen lange Zeit hindurch Bedenken mancherlei Art entgegen. Zunächst das Bedenken, das Anfüllen eines so mächtigen Reservoirs, ohne gleichzeitige Vermehrung des Zuflusses, könnte in Jahren geringer Flutstärke die Winterschiffahrt in Frage stellen. Ein zweites galt der Geführdung der einzig schönen Denkmäler der Insel Philä. Das Stauwerk setzt die Tempel und die anderen dort befindlichen Bauten schon jetzt alljährlich teilweise unter Wasser, und nach der Erhöhung: des Dammes würde dies noch wesentlich mehr der Fall sein.

Beide Gegengründe haben seither ihre Widerlegung gefunden. Was besonders den zweiten betrifft, so sollen genaue Untersuchungen der bereits mehrere Jahre hindurch überschwemmt gewesenen Teile durch den Ägyptologen Eduard Naville und den Generaldirektor des Antiquitätendienstes von Ägypten, C. Maspero, bewiesen haben, daß, dank der vorgenommenen Sichertingsarbeiten eine Schädigung der berühmten Baudenkmäler nicht zu befürchten wäre. So ist man denn an die Arbeit gegangen. Die Erbauer des Dammes, J. Aird \& Co., haben im Mai 1907 mit der Erhöhung begonnen und sich verpflichtet sie binnen fünf Jahren durchzuführen. Statt der ursprünglich beabsichtigten $6 \mathrm{~m}$ sollen es jetzt nur $5 \mathrm{~m}$ werden, aber auch die sollen genügen, um den Wasserstand im Assuanreservoir un $7 \mathrm{~m}$ zu heben und dessen Fassungsraum zu verdoppeln. Die Vor. anschläge von Willeox und der Bericht Garstins hatten den Wasserzuwachs mit 1 Milliarde Kubikmeter Wasser und die dadurch im Kanalland umwandelbare Fläche mit 1/2 Mill. Feddán angenommen. Der dem englischen Parlament im April 1908 vorgelegte offizielle Report ..by his Majesty's Agent and Consul-General on the Finances, Administration and Condition of Egypt and the Soudan in $1907^{\prime \prime}$, spricht dagegen von nahezu 1 Mill. Feddán heute brach liegenden Landes im nördlichen Teile des Deltas, die nach Durchführung der Erhöhung zur Sommerszeit bewässert werden könnten. Der Aufbau sellost wird nur 500000 L. E. kosten, aber die Vorkehrungen zur Sicherung der Denkmäler auf der Insel Philä und die Ablösung der innundierten Gründe in Nubien steigern die Gesamtkosten auf 1500000 L.E..

Nicht so leicht wird sich wohl das dritte und gröbte Projekt von Will cox, das Reservoir von Wa dy Rayan im Gebiete des 
bekanntlich ebenfalls künstlichen, historischen Mörissee verwirklichen lassen. Auch dieses Projekt hat seine Vorgeschichte und seine Schicksale. Die Überlieferung rom alten Mörissee, dessen Anlage nach Brugsch um 2300 r. Chr. erfolgt sein soll, ließs seit den Zeiten Mehemed Alis die Gemüter nicht zur Ruhe kommen. Herodot (II, 148) beschreibt dieses Wunder „von Menschenhänden gegraben und rom Nil aus durch einen Kanal gespeist" noch nach eigener Anschauung und gibt seinen Umfang mit 3600 Stadien an. Nachdem Linant Pascha die Lage des Mörissee im südöstlichen Fayûm ermittelt hatte, dachte man immer wieder daran, das alte Werk, von dem noch Reste mächtiger Schleusen vorhanden sind, neu aufleben zu lassen. Das Miß̈geschick der ersten Barrage, die ungünstige Finanzlage Ägyptens, haben dann lange Zeit jeden solchen Plan im Keime erstickt. Als Will cox endlich 1894 mit der Prüfung der vorhandenen Projekte betraut wurde, verwarf auch er die zuerst ron Cope Whitehouse angeregte Idee, die WadyRay an-Depression als Reservoir auszugestalten. Er wies darauf hin, daß dieses Reservoir wegen seiner tiefen Lage wohl im April und Mai viel Wasser liefern künnte, aber schon weniger im Juni und fast keines mehr im Juli. Der neue Mörissec würde nämlich mit dem Nil kommunizieren und seine Oberfläche deshalb um so mehr fallen, je mehr der Sommer fortschreitet, und schlieflich, an Ende des Sommers, künnte der See nicht mehr ein Viertel so viel Wasser hergeben als zu Beginn.

Im Zusammenhang mit der Erhöhung des Staudammes sieht Willcox nun ganz neue Möglichkeiten für das Wady-RayanProjekt voraus. Man wird die Wassermengen des hochgelegenen Reservoirs von Assuan eben für die späteren Sommermonate aufsparen müssen und zunächst den Vorrat des Wady Rayan verwenden. So nach Bedarf durch jenes ergänzt, wird das Reservoir von Wady Rayan die erforderlichen 2 Milliarden Kubikmeter Wasser leicht liefern können.

Willeox hat das ganze Projekt in allen Teilen neu aus. gearbeitet und begründet. Das Wady Rayan liegt nicht wie der einstige Mörissee im Fay ûm selbst, sondern in der Lybischen TVüste, südlich vom Fayum, das ron der Depression durch eine natürliche Kalksteinvorlagerung geschieden ist. Der neue Stausee ist in einer Ausdehnung von $700 \mathrm{qkm}$, das ist der vierte Teil des historischen Mörissee gedacht. Seine Oberfläche 
soll etwa 2 ? $m$ ïbex dem Meerestpiegel liegen, und da seine tiefste Einsenkung $41 \mathrm{~m}$ unter den Meeresspiegel reicht, so besäße der See an der tiefsten Stelle eine Wasserhöhe von $70 \mathrm{~m}$. Den Fassungsiaum berechnet Willeox mit nicht weniger als 20 Milliarden Kubikmeter Wasser, von denen aber jährlich nur etwa 3 Milliarden Kubikmeter, die etwa den oberen 4 oder 5 m des Sees entsprächen, zur Bewässerung herangezogen würden. Die Durchführungskosten beziffert Willeox mit 2600000 L. E. hei einer Bauzeit von drei Jahren.

Das hochinteressante Projekt findet vorläufig in Ägypten noch viele Gregner. Die cinen halten es nur unter gleichzeitiger Ausführung kostspieliger Ergänzungsarbeiten für ausführbar, welche die oben angeführten Kosten mehr als verdoppeln würden, die anderen fürchten wieder die Bildung von Sümpfen und Springquellen in den tieferen, möglicherweise mit dem Wady Rayan kommunizierenden Teilen des Fayûms. Die von der Regierung eingesetzte technische Kommission gab ihr Gutachten dahin ab, daß sie diese Umbildung des Wadys in ein Reservoir, wegen des zu gewärtigenden WVassereinbruches, direkt als Gefahr für das Fayûm betrachte.

Sir William Garstin, der so makgebende Mann im ägyptischen Wasserwesen, sieht in der Sache doch nicht gar so schwarz. Er weist in seinem Berichte auf die zweifache Reihe ron Felsenketten hin, die das Wady Rayan von der Gharak-Depression des Fayûms und die Gharak-Depression wieder von dem übrigen Teil des Fayums trennt und das Durchdringen von Wasser recht unwahrscheinlich mache. $\mathrm{Er}^{*}$ empfiehlt weiteres, gründliches Studium der Frage, geologische Untersuchungen und detaillierte Berechnungen über die Dimensionen der ein- und ausmündenden Kanäle, durch die man erst zu einem richtigen Urteile über das ganze Projekt gelangen könne. Vorläufig hält er eine Menge von anderen Arbeiten im Interesse der Bewässerungspolitik für dringender, unaufschiebbarer, welche die verfügbaren Geldmittel nicht unbeträchtlich in Anspruch nehmen würden. Das sind, außer der Staudammerhöhung von Assuan im Kostenpreise von 500000 L.E., die Regulierung der Nilarme von R osetta und Damietta (Kosten 900000 L.E.), die Umgestaltung der Bassivländer von O berägy pten in Kanalland (Kosten 5000000 L.E.) nud zwei neue Staudämme zwischen Asy ut und Keneh (Kosten 2000000 L.E.). Alles in allem Arbeiten für rund $8^{1: 2}$ Mill. L.E. 
Das Programm zeigt so recht, wie kompliziert der ganze Wasserapparat Ägyptens ist, und wie vielfacher Natur die Maßnahmen sind, die er erfordert. Da ist gleich die Regulierung des Rosetta- und des Damiettaarmes, deren Projektierung ebenfalls ron Willcox herrührt. Die Regulierung soll Vorland für besonders hohe Nilflut schaffen, die Überschwemmungsgefahr verringern. Die Forderung wird so dringend behandelt, daß man daraus auf ihre Wichtigkeit schließen kann. Die Wassernot droht in der Tat alljährlich während der Hochflut heranzurücken. In Oberägypten steht dann der Wasserspiegel schon in normalen Jahren $1 \mathrm{~m}$ über dem Niltale, in Mittelägypten und an Rosettaarme $2 \mathrm{~m}$, und im Damicttaarme steigt das Wasser gar $31 / 2 \mathrm{~m}$ über die umgebenden Ackerflächen. Ausgedehnte und wohlberechnete Deichbauten schützen die Nilufer deshalb seit alters her und ziehen sich von Assuan in ununterbrochener Folge zum Meere hin. In Oberägypten sind stärkere Krümmungen des Flusses an manchen Stellen, in Unterägypten überall, mit besonderen steinernen Gefahrdeichen versehen. Aber auch die besten Deiche reichen nicht aus, wenn es an den anderen Maßnahmen fehlt, die sie unterstützen müssen. Willcox weiß daron zu erzählen, wie es früher trotz der Deiche in Ägypten zur Zeit einer wirklichen Hochflut zugegangen ist. Es war im Jahre 1887, als er sich nördlich von Mansourah in einem Dorfe aufhielt, das durch seinen unmittelbar vorliegenden Deich hinlänglich gegen die Hochflut geschützt schien. Auf einmal kommt die Nachricht ins Dorf, der Deich wäre durchgebrochen. In unbeschreiblicher Verwirrung stürzt alles mit Kind und Kegel zum Deiche. Die Dorfbewohner nehmen ihre ganze spärliche Habe mit, das Vieh und den Hausrat, denn niemand weiß, ob er seine Lehmhütte noch wiedersehen wird. Bald ist der enge Deich mit Büffeln und Kindern, mit Geflügel und Hauskram über und über bedeckt. Die rerzweifelten Weiber hocken am nahen Grabe des Lokalheiligen herum, bedecken es mit Küssen, schlagen sich in die Brust, raufen die Haare, schreien und jammern. Jeden Augenblick holen die Mäuner ein anderes Stück des Hausiates aus den Gewirr, was ihnen gerade in die Hände fällt und irgendwie zum Stopfen des Deiches geeignet sein könnte. Andere Fellahs sind einstweilen ohne Bedenken in die brandende Flut gesprungen, kämpfen dort Schulter an Schulter eng gedrängt gegen die anstürmenden Wogen an und versuchen die Bresche mit Türen und 
Fenstern, mit Mais, Stroh und allem müglichen Hausrat auszufüllen. Willcox fällt ein alter Mann auf, der trolz seines schneeigen Haares mit wahrem Feuereifer an der Arbeit ist. Man crzählt, der wäre noch gar nicht so alt, ein Ereignis in seinem Leben hätte ihn nur vor der Zeit gealtert. Der Mann war 1878 Aufseher auf dem Nildeich ron Mit B a dr gewesen, als dier grobe Durchbruch dieses Deiches erfolgte. Der Khedive Ismail Pascha, ein Mann energischer Tat, telegraphieite sofort, man möge den Aufseher samt dem diensthabenden Ingenieur durch die Bresche in den Strom werfen. Der Lokalchef erwirkte einen zwölfstündigen Aufschub der Exekution. Später wurde der Mann dann begnadigt; die zwölf Stunden Todesangst aber hatten inzwischen seine Haare gebleicht.

Der heutigen Zeit entsprechen so drastische Mittel, das Verantwortichkeitsgefühl zı heben, nicht, und die Tausende von Fronarbeitern, die früher auf den Nildeichen beschäftigt waren, stehen jetzt auch nicht mehr unentgeltlich zur Verfügung. Da sucht man die Gefahr der Deichbrüche und die Zahl der aufzubietenden Hilfskräfte dadurch zu vermindern, daß man den Überschul des angeschwollenen Nils, statt ihn wie einst in möglichst viele Kanäle zu verteilen, in die beiden Nilarme von $R$ osetta und Damietta leitet, deren Regulierung eben den Wassermassen leichten Abfluf schaffen soll.

Ganz ohne Zwang, ganz ohne Mithilfe der Fellahs wird es freilich auch jetzt, nach Aufhebung des Frondienstes nicht abgehen, wie ja auch das heute in Deutschland geltende Deichrecht die persünlichen Dienste der Deichgenossen in Fällen dringender Gefahr fordert. In Ägypten tritt die Deichwehr bei hoher und niedriger Flut in Tätigkeit. Bei Hochflut sind die Nildeiche mit Wachposten übersät. Alle $50 \mathrm{~m}$ zwei Mann, an besonders geïährlichen Stellen Posten von $50-100$ Mamn. Damplschiffe und Boote mit Säcken, Pfosten, Steinen beladen, werden im Nil postiert, während die Erdbedeckung der Deiche beinahe längs der ganzen Strecke durch Pfosten. Maisstroh, Baumwollstauden vor dem Abschwemmen bewahrt ist. Zur Zeit einer niederen Nilfut tritt die Aufgabe der Bewachung der Nildämme vor Aer Aufgabe in den Hintergrund, das Wasser in die richtigen Fanäle zu leiten. Das Jahr 1907 war beispielsweise durch besonders niedrigen Wasserstand hemerkenswert, und dennoch spricht der offizielle Bericht der Regierung von 1215200 Fronarbeitstagen, die in 
Anspruch genommen werden mubten. Davon entfielen 1138300 Arbeitstage auf Oberägypten und nur 76900 Tage auf Unterägypten. Der Bericht sagt: „Ohne Einberufung der Fronarbeiter hätten viel mehr Böden, Sharaki-Länder" bleiben müssen. Die Arbeit war zu dringend und mußte in zu kurzer Zeit erledigt werden, als daß es möglich gewesen wäre, sich anders zu helfen." Und er fügt hinzu: .Nach der Tollendung der Esneh-Barrage wird das zumindest in der $\mathrm{Keneh-Prorinz}$ nicht mehr vorkommen."

Unter ,Sharaki-Land" versteht man sonst bewässerbares Land, das wegen geringer Flut keine Bewässerung erhalten konnte und deshalb für das Jahr der Kultur verloren geht. Es gehört zu den Errungenschaften des neuen Kurses, daß die Ausdehnung der Sharakiländer auch bei niederster Flut fortgesetzt verringert wird. Das Jahr 1907 brachte so geringe Flut, daß man es diesbezüglich nur mit dem Jahre 1877 vergleichen kann. Dieses Jahr 1877 gilt als das ungünstigste, das der ägyptischen Landwirtschaft beschert war, seitdem verläßliche Aufzeichuungen existieren. Damals gab es viel Elend und Hungersnot in Ägypten, denn 753992 Feddán mußsten Sharakiland und daneben noch so große Flächen "Halb-Sharaki“, d. h. ungenügend bewässertes Land bleiben, dab die Gesamtarea wohl mit 1 Nill. Feddán anzunehmen ist. 1907 hingegen gab es nur 96985 Feddán Sharakiland und 15400 Feddán "Halb-Sharaki", das sind kaum 10\% von 1877. Diese Zahlen zeigen, wie man den verhecrenden Einflub einer geringen Nilflut auf die Landwirtschaft zu rerringern gelernt hat, sie erklären aber auch die Vielseitigkeit des aufgestellten Bewässerungsprogrammes. Neben den Staudämmen, die das Wasser speichern, sind Vorkehrungen für das Unschädlichmachen zu hoher Flut und gegen die Schädigung durch zu niedrige Flut nötig. Gegen diese haben die kleinen Barragen vorzusorgen, von denen die von Esneh am 9. Februar 1909 durch den Khediven Abbas II. Hilmi feierlichst eröffnet wurde. Sie wird die Landwirte der Esneh-Provinz, die früher in Jahren mit niederem Wasserstand stark in Mitleidenschaft gezogen waren, unabhängig ron dem Ausfall der Flut machen. Und jetzt, da der Wasserbedarf für den Sommer sichergestellt, das Land vor den. Übel zu hoher oder zu geringer Flut bewahrt ist, gelangt auch der letzte Programmpunkt Sir Garstins zur Ausführung. Alljährlich schreitet die Umänderung des Bassinlandes in Kanalland nun 
weiter fort. 1906 wurden nach den of fiziellen Berichten 700000$) \mathrm{L}$. E. verwendet, un $\$ 4550$ Feddán in Mittelägypten umzuwandeln, 1907619000 L.E. für den gleichen Zweek bewilligt, aber nur 30000 Feddán in der Provinz Ghizeh umgewandelt. Insgesant, hat man in Mittelägypten in den letzten Jahren schon 322961 Feddán Bassinland mit Kanalbewässerung versehen und 30509373 L.E. dafür ausgegehen. Die Kosten stellen sich danach auf 9,44 L.E. pro Feddán. Nun sollen die Bassinländer Oberägyptens daran kommen, und auch sie werden nach dem früher besprochenen Projekte Millionen von L.E. verschlingen; alle diese Unsummen aber wird der Boden selbst mühelos herbeischaffen, sie stellen nur cinen verschwindenden Bruchteil des Mehrwertes dar, den das Schaffen von Kanalland bewirkt. Sir Garstin schätzt die Mehreingänge an Grundsteucr nach Durchführung seines Programmes auf 1205000 L.E. pro Jahr. Er berechnet sie so:

Oberägy pten: Nunmehr Bassinland in Kanalland umgewandelt

750000 Feddán, Mehrerlös pro Feddan 0,50 L.E. . . .

375006 L.E.

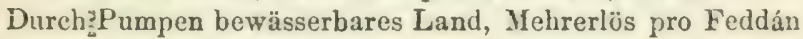

0,30 L.E. 100000 Feddán . . . . . . . . .

30000

Unterägy pten: Wertvoller gewordenes Land, Mehrerlös pro

Feddán 1 L.E. 800000 Feddán

1205000
ung der

Der Schulmeister leitet die Wiedererweckung der ägyptischen Landwirtschaft ein. - Kuttabs. - Die Regierung und die alte Form moslemitischen Erzichungswesens. - Inspektion der Dorfschulen. - Regierungskuttabs. - Handwerkerschulen. - Frauenstudium. - Die Ackerbauschule von Gîseh. - Die KhedivialAgrikultur-Gesellschaft. - Das künftige Regierungsdepartement für Landwirtschaft. - Hortikultur. - Andere administrative Maßnahmen. - Kom-Ombo und die Bodenausfschließungsgesellschaften.

Ein Vergleich des jetzigen Schulwesens mit dem zu Beginn der Britischen Okkupation legt den Gedanken nahe, daf es nirgends eine raschere Entwicklung des Unterrichtswesens, nirgends eine lernbegierigere Bevölkerung gegeben hat als im modernen Ägypten. Damals, im Jahre 1881, hatte die Regierung in ihrem Budget für Unterrichtszwecke alles in allem $2300 \mathrm{~L}$. E. ausgesetzt, und diese Summe war, wie es scheint, noch zu hoch gegenüber der Abneigung der breiten Volksschichten gegen das 
Lernen. 1908 wendet die Regieiung den Schulen 150450 L. E. zu, und die wohlhabende Bevölkerung wetteifert, durch Spenden die Weiterverbreitung der Bildung rascher zu ermöglichen. In der

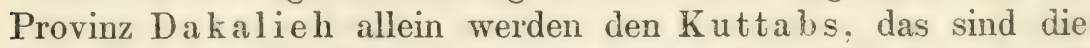
Dorfschulen, 430 Feddán Land geschenkt und in der Stadt Mansourah Liegenschaften im Werte ron 65000 L.E. Damals standen die wenigen Schulen leer, weil sich niemand für die Erziehung seiner Kinder interessierte, heute fassen 4324 Dorfschulen und 505 andere höhere und Fach-Schulen die drängende Schülermenge nicht. Noch im Jahre 1901 zählt man in allen Dorfschulen zusammen nur 31361 Schüler, und 1907 sind es schon 165000 , wozu noch 92000 Schüler der übrigen Lehranstalten, ohue die El-Azhar-Universität, kommen. Und wie vielerlei Art sind die Lerngelegenheiten jetzt geworden! Da gibt es aufer den Kuttabs höhere ägyptische Primär- und Sekundärschulen nach europäischem Muster und ähnliche Anstalten aller möglichen fremdländischen Nationen. Neben der altehrwürdigen mohammedanischen Universität von $\mathrm{El-Azhar}$, die, in wahrem Korankultus erstart, für die Wissenschaft nicht mehr in Frage kommt, tauchen die Umrisse einer modernen nationalägyptischen Unirersität auf. Der Khedive $\mathrm{Abbas}$ II $\mathrm{Hilmi}$ setzt sich für ihre Gründung warm ein, und ein Komitee unter dem Vorsitze des Prinzen Ahmed Fouad Pascha, dem auch der frühere Unterstaatssekretär in Unterrichtsministerium, Jacoub Artin Pascha, eine Autorität auf dem Gebiete des ägyptischen Schulwesens, angehört, hat bereits die Organisation in großen Zügen festgestellt. Einstweilen wird Gesetzeskunde nach europäischem Muster und für Kadis der einheimischen Gerichte vorgetragen, Mediziu und Veterinärwesen gelehrt. Sonst gibt es noch technische Schulen für Ingenieure, die landwirtschaftliche Schule in Giseh und Schulen für Mädchen, Lehrerbildungsanstalten und Handwerkerschulen. Diesen dienen Musterwerkstätten zur Unterstützung; der höheren Bildung steht die große Khedivial-Bibliothek offen.

Es ist selbstrerständlich, daß eine solche Entwicklung des Schulwesens vom Standpunkite der Landwirtschait nicht gleichgültig sein kann. Wie man einst dem preußi-cheis Schulmeister den Sieg der deutschen Waffen zugeschrieben hat; so wird man dem ägyptischen Schulneister die Wiedererwechung der ägyptischen Landwirtschaft zu dankeu haben. Die Dorfschule, in der der Fellah zum Alphabeten wird, die Ackerbauschule, die ihm erst 
das volle Terständnis seines Bodens erschliebt, werden die geforderte neue Kultur am raschesten herbeischaffen. A ber anch die anderen höheren Schulen und die Fachschulen müsson zu ihrem Fortschritt beitragen. Technisch geschulte Ägypter werden bei den Arbeiten des Bewässerungswesens besser mitwirken können, gelernte Handwerker die landwirtschaftlichen Geräte und Maschinen instand halten. Vom Veterinärwesen wird die Viehhaltung profitieren, rom allgemeinen höheren Bildungsiniveau der ganze Zuschnitt des Landes, der wieder auf die landwirtschaftlichen Verhältnisse zurückwirkt. Direkt und indirekt wird das Wissen so von allen Seiten in die Triebräder des Wirtschaftsorganismus eingreifen und die Landwirtschaft fürdern.

Ägypten hat sehon durch den fortschrittlichen Khedive Nohamed Ali Schulen erhalten. Die Schüler wurden damals auf Staatskosten unterrichtet, auf Staatskosten heherbergt, genährt und gekleidet. Aber damals konnten die Schulen nur mit physischer Gewalt gefüllt werden. Sie überlebten ihren Schöpfer nicht lange, denn schon der nachfolgende Thedive Abbas I. hat diese Anstalten, für die das Tolk noch nicht reif war, geschlossen. Cromer erzählt ron Müttern. die ihre Kinder blendeten, um ihnen den rerhaßiten Schulhesuch zu ersparen. Der Khedive Ismail $\mathrm{P}$ a scha hat es dann wieder ron neuem mit der Eröffnung von Schulen versucht und zu allen früheren Vorteilen noch den hinzugefügt, daß̉ die Schulzeit in die Pensionsansprüche des Beamten eingerechnet wurde. Jetzt ging es doch schon besser, und Ismail Pascha gewam auf diese Weise den gewünschten Stab ron intelligenteren Terwaltungsbeamten. Die Bildung der breiten Schichten aber, ohne die ein allgemeiner kultureller Aufschwung nicht denkbar ist, blieb der Gegenwart vorbehalten, denn sie läßt sich nicht einfach anschaffen wie der Bau ron Kanälen oder irgendwelche Terwaltungsmaßregel. Die Gründung der besten Schulen bingt einem Volke nur dann Wissen, wenn es das Bedürfnis nach solehem in sich empfindet.

Warum der Wissensdrang erst jetzt erwacht ist, läßt sich nicht leicht ergründen. Uns hann hier die Tatsache genügen. das er erwacht ist. Die Schulen sind roll besetzt, obwohl es in Ägypten keinen Schulzwang gibt, und obwohl für den Schul. unterricht sogar gezahlt werden nuß. Ton den Kuttabschülem waren nur $31 \%$ rom Schulgeld befreit, die höheren Schulen, mit Ausnahme der Lohrerbillunganstalten. der technischen Schule zu 
Bûlâe und der Kadischule, wo der Unterricht unentgeltlich ist, fordern noch höheres Schulgeld als die Kuttabs und gewähren nur ausnahmsweise und nach strenger Prüfung der Mittellosigkeit Befreiung vom Schulgeld.

Die Regierung hat nicht so viel Mittel zur Verfügung, um alle Schulen aus eigenem erhalten zu kömmen, und wählt deshalh den Vorgang, die Beiträge der Schüler, die zahlen können, zur Mehrung der Lerngelegenheiten für die ganz armen Berölkerungsklassen heranzuziehen. Dabei besteht die Tendenz, das Schulgeld in den höheren Schulen, die ohnedies überfüllt sind, nach und nach so weit zu erhöhen, daß sie sich selbst erhalten könmen. Das erübrigte Geld wird den Kuttabs zugute kommen, in denen der Unterricht womöglich ganz unentgeltlich erteilt werden soll. Daßs die Dorfschulen heute, wo dies noch nicht der Fall ist, besucht sind, daß sogar die Ärmsten der Armen, die Fellahs, ihr sauer erworbenes Geld aufwenden, um ihre Kinder etwas lernen zu lassen, ist der beste Beweis für das intellektuelle Erwachen des Landes. Crom er bereiste 1889 einige entlegene Dörfer in Oberägypten, in denen selten ein europäisches Gesicht gesehen wird, und erzählt, wie dort keine Bitte häufiger an ihn herantrat als die, die Regierung zu veranlassen, eine Schule im Dorf zu gründen.

Es wäre freilich verfehlt zu glauben, daß mit der Gründung der vielen Dorfschulen auch schon Volksschulbildung in europäischem Sinne ihren Einzug in Ägypten hielt. Der Fellah hat von der Aufgabe der Schule seine ganz eigene Meinung, die hauptsächlich darin besteht, studieren heiße, den Koran gründlich kennen. Der offizielle Regierungsbericht vom Jahre 1906 zeigt in anschaulicher Weise, wie sehr der Unterricht diesen Verhältnissen Rechnung trägt. Bei der letzten Inspektion durch die Regierungsorgane brillierten nicht weniger als 4531 Schüler mit dem fehlerlosen Aufsagen des ganzen Korans, 3538 Schüler konnten ${ }^{3 / 4}$ des Korans aus dem Gedächtnis aufsagen, 4180 Schüler die Hälfte und 6212 Schüler mehr als ein Viertel davon. Der Rest der durchwegs jüngsten Schüler hatte zumindest die ersten Kapitel des Korans gelernt. Viel weniger erfreulich waren dagegen die übrigen Resultate des Unterrichtes. Von 145000 Schülern, die bei der Inspektion anwesend waren, hatten 94000 Schüler nicht schreiben gelernt, 87000 nicht rechnen und 68000 nicht lesen.

Die Regierung hat den Kampf gegen diese Form des mos- 
lemitischen Erziehungswesens nicht ohme Erfolg aufgenommen. Es war schon der erste Schritt dazu, daß sie sich die Inspektion der Privatdorfschulen zu sichern wuliste. Der Unterrichtsminister hatte 19084181 private Kuttalss, die ron der Regierung subventioniert wurden, mit einer Schülerzahl von 164546 Kindern unter seiner Aufsicht, wozu damn noch 143 Kuttabs mit 11014 Kindern kamen, die, von der Regierung selbst gegründet, unter deren direkter Leitung stehen. Allzu rasch darf die Regierung dabei sellsstverständlich nicht vorgehen, denn die religiösen und nationalen Eigentümlichkeiten müssen geschont und ror allem die nütige Anzahl geschulter Organe herbeigeschafft werden. Die Kontrolle der Dorfschulen ruht in den Händen ron drei Inspektoren und 36 Unterinspektoren, durchwegs ägyptische Schechs, welche die Unterrichtskurse zu Al-Azhar und der Nasrieh-Lehranstalt durchgemacht haben. Der Lehrernot sollen die Lehrer. seminare abhelfen, wo unentgeltlich gelehrt wird, um so rascher die erforderlichen gebildeten Lehrkräfte zu gewinnen. Man bestätigt allgemein, daß die beiden Maßnahmen, die strengere Oberaufsicht und die Termehrung geeigneter Lehrkräfte, die Qualität des Unterrichtes jetzt sehr verbessern. Die Einrichtungen der Inspelition äubern aber auch nach anderer Richtung ihre günstige Wirkung. Es wurde gleich im ersten Kapitel erzählt, wie schlecht es bein Fellah um die Gesundheitspflege der Kinder bestellt ist. Das schlimmste C̈hel, das dort grassiert, ist eine granulöse Augenentzündung (vermutlich handelt es sich da um die sogenannte ïgyptische Augenentzündung, das Trachom, das auch in Europa epidemisch aufzutreten pflegt). als deren Folge zahlreiche Erblindungen eintreten. Im Jahre 19198 gab es in den

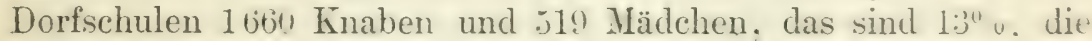
gänzlich erblindet waren. Die Regierung hat nun verfügt. dais vorläufig wenigstens die von ihr selbst errichteten Kuttabs zweimal in der Woche irztlich risitiert werden und dadurch den Prozentsatz der augenleidenden Schüler von $190^{\circ}$ o im Jahre $1 \leq ! 18$ auf $64 \%$ im Jahre 1907 herabgemindert.

Viel Aufmerkamkeit wird den Gewerbeschulen, besser gesart Handwerkerschulen, zugewendet, die in den letzten Jahren an vielen Orten errichtet wurden. Die leitenden Kreise der Landwirtschaft sehen in der Heranbildung tüchtiger Professionisten eine notwendige Voraussetzung der Treiterbildung des ägyptischen landwirtschaftlichen Maschinenwesens und treten für die Ter- 
mehrung solcher Anstalten warm ein. Die Handwerkerschule in der Behêrap jovinz z. B. verdankt ihre Entstehung der Initiative des Prinzen Hussein Pascha Kamil, des Präsidenten der Khedivial-Agrikultur-Gesellschaft.

Bedeutungsvoll in allgemeiner kultureller Hinsicht und für die Gestaltung des landwirtschaftlichen Betriebes scheint mir die starke Zumahme des Frauenstudiums zu werden. Die Notwendigkeit hat ror den strengen Gesetzen des moslemitischen Haremslebens nicht haltgemacht und der Frauen manchen Anteil an der Berufsarbeit des Fellahs zugewiesen. Nun werden die Fellahfrauen, die etwas lernen, auch dem landwirtschaftlichen Berufe mit mehr Verstündnis gegenüberstehen. Wie rasch sich diese Richtung des Schulwesens entwickelt, zeigen einige Zahlen: 1900 waren die Dorfschulen insgesamt ron 1640 Mädchen besucht, 1907 von $1 \pm 58 t$ Mädchen. Der Einführung des Mädchenstudiums, namentlich eines Mädchenstudiums, das über die allerersten Anfangsgründe hinausgeht, standen noch größere Schwierigkeiten entgegen als der des Knabenstudiums. Die herrschende Sitte rerbictet nicht nur den gemeinsamen Schulunterricht von Knaben mit Mädchen, die über die allererste Kindheit hinaus sind, sie verbietet auch den Unterricht solcher Hädchen durch männliche Lehrer und die Inspektion durch männliche Schêchs. Zudem macht das Heiraten der Mädchen gewöhnlich noch im Kindesalter dem Schulunterricht ein Ende. Der Wunsch nach Mädchen. unterricht scheint jetzt indessen, stärker als alle Bedenken und Hindernisse geworden zu sein. Man hat ein Seminar zur Heranbildung einheimischer Lehrerinnen ins Lehen gerufen, gründet nach Maßgabe der verfügbar werdenden weiblichen Lehrkräfte besondere Dorfschulen für Mädchen und selbst höhere Schulen, und alle diese Anstalten sind überfüllt. In die Stelle des inspizierenden Schêchs ist dort natürlich der weibliche Schulinspektor getreten. An dem höheren Unterricht nehmen jetzt, Europäerinnen imbegriffen, über 20000 Mädchen teil. Da hier auf das ägyptische Schulwesen nicht weiter eingegangen werden kann, möge nur noch eine Gründung von besonderer Wichtigkeit für die Landwirtschaft Erwähnung finden: die Ackerbauschule von Gîseh.

Über die große Nilbrücke, zwischen den herrlichen Syknmoren und Akazienalleen des Gesîreh-Parks hindurch, führt der Weg zur Ackerbauschule von Gîseh. Ein zweckmäßiger, moderner Bau, bei dessen Betreten nur der fremdländische Typus 
des Fellahportiers. mit dem man sich in keiner emroüischen Sprache verständigen kann, daran gemahnt, dafs die Schule nicht in irgendeiner Hauptstadt Europas steht. Mr. Fletscher, der Direktor, der unseren freundlichen Führer abgibt, ist Engländer und ein begabter Botaniker, speziell Physiologe. Er wurde erst vor kurzem aus Indien berufen, um Dr. Makenzie zu crsetzen, den Gesundheitsı̈ücksichten nach 15jähriger Wirksamkeit an der Spitze der Schule in die Heimat zurücktrieben. Auch Makenzio war Engländer, und alle Professoren der Ackerbauschule sind es noch heute, bis auf den Schêch Ali Abdul MIgd, den Lehrer der arabischen Sprache, und den Assistenten des chemischen Laboratoriums, den Ägypter Abd El Hamid Eff Fathi. Der Name des verdienstrollen ersten Direktors ist mit der Organisation des landwirtschaftlichen Schulwesens in Ägypten eng verknüpft. Es war in Jahre 1888, als die geringe Nilschwelle und der schwere Notstand der bäuerlichen Berölkerung, den jene mit sich brachte, im Ministerium für öffentliche Arbeiten den Gedanken einer landwirtschaftlichen Schulgründung zeitigte. Zwei Jahre später trat das neue Institut ins Leben. Es sollte dem Programm nach junge Landwirte in allen technischen Zweigen des Ackerbaues, in der Anwendung landwirtschaftlicher Maschinen sowie in der Behandlung neuer Kulturarten, z. B. der Kartoffel, unterweisen, auch der Tierzucht und deren Produkten Aufmerksamkeit zuwenden. Der Zuschnitt der neuen Schule wurde anfangs ein wenig zu weit für die dortigen Verhältnisse genommen. Die Aufnahmebedingungen sahen das Zeugnis einer Sekundärschule vor, wodurch der Schule selbst Hochschulcharakter aufgeprägt werden sollte. Das lief sich nicht aufrechterhalten. Es gab in Ägypten nicht genug Studenten mit einer Vorbildung, die etwa unserer Mittelschulbildung entspricht, um die bereits vorhandenen höheren Fachanstalten zu füllen. Diese boten dabei ihren Absolventen sofortige Staatsanstellungen, während den diplomierten Agronomen, mangels eines Ackerbaudepartements, bei der Regierung keine Stellung in sichere Aussicht gestellt werden konnte. So meldeten sich kaum zwei oder drei Kandidaten, die Zeugnisse über absolvierte Sekundärschulen besaßen, und man mukte sich entschließen, es bei milderen Aufnahmebedingungen bewenden zu lassen. Zuerst stillschweigend, dann, seit 1896, auch offiziell. Jetzt sollte schon das Zeugnis einer absolvierten Primärschule, etwa unserer Untermittelschule entsprechend, zum Ein- 
tritt berechtigen. Bei vorhandenem Platze durfte in die erste Klasse sogar eine Anzahl von Schülern aufgenommen werden, die auch ein solches staatsgültiges Zeugnis nicht besaßen; sie muften jedoch höheres Schulgeld entrichten. Dabei kommen meistens Europäer in Betracht, die ihre Vorbildung nicht in den staatlichen Primärschulen, sondern im Ausland oder in irgendwelchen Privatschulen erworben haben.

Bei ganzer Pension zahlt ein Schüler mit staatsgültigem Zeugnis einer absolvierten Primärschule pro Schuljahr 40 L. E., ohne Primärzeugnis 50 E.L.; Tagesschäler, ohne Verpflegung, zahlen 15 L.E. mit Primärzeugnis, 35 L.E. ohne Primärzeugnis pro Schuljahr.

Und nun füllt sich die Schule. $1902 / 03$ zählt sie 48 Schüler, 1905/06 71 Schüler und 1901/08 schon 147 Schüler. Ton diesen sind nur 22 keine Ägypter, und nur 34 oder $23 \%$ besitzen kein Abgangszeugnis einer Primärschule. Das Schuljahr beginnt am ersten Samstag des Monates Olitober und endet Mitte Juni. Vier Schuljahre hindurch währt der Unterricht, rier Jahre sieht der Lehrplan ror. Das ist eine lange Zeit; man hegreift aber, daß daran um so zäher festgehalten werden mußte, je nachsichtiger die Ansprüche an die Vorbildung der Aufzunehmenden gestellt wurden. Ein Schülermaterial, das im günstigsten Falle über die Kenntnisse einer Primärschule rerfügt, mub erst entsprechend rorgebildet werden. So stellt der erste Jahrgang eigentlich nur einen Vorbereitungskursus dar, in dem man Sprachen. Mathematik, allgemeine Bildung lehrt und nur nebenbei cine Einführung in die Landwirtschaft versucht. In den nächsten Jahrgängen erst trift die Landwirtschaftswissenschaft in ihre vollen Rechte. Nun unterscheidet sich der Lehrplan wcnig ron dem einer höheren landwirtschaftlichen Fachschule in Deutschland. Die arabische Sprache wird freilich weiter eine Stunde wöchentlich gelehrt, und der Kenntnis der englischen Sprache sind noch in zweiten Jahre vier Stunden wöchentlich gewidmet; ausführlicher wird auch das Bewässerungs- und Entwässerungswesen rorgetragen. Eine erwähnenswerte und rorteilhafte Einrichtung ist die Zureisung von Ackerland an die Studenten. Die Schule besitzt eine Schulfarm von ca. 100 Feddán. Ein Teil daron wird als Musterfarm betrieben, der andere Teil so unter die Schülpr aufgeteilt, dak jeder ein Viertel Feddán für drei Jahre zu eigen erhält. Der Schüler bekommt das Zugrieh, die Geräte. das Wasser beigestellt, 
cr hat aber jeden Handgriff, jede nötige Arbeit allein mul ohne Mithilfe auszuführen. Die Fruchtfolge wird für drei Jahre vorgeschrieben, und nun muß er selbst pflügen und eggen. säen und jüten, bewässern und ernten. Der Ertrag des Bodens gehört dem Schüler. Zwei Stunden am Morgen, viermal in der IVoche, sind im Lehrpian der Feldarbeit gewidmet, und die Art der Arbeit. die erzielten Resultate werden geradeso klassifiziert wie die ührigen Lehrgegenstände.

Die Schüler des vierten Jahrganges erhalten kein Land zugewiesen und übernehmen die Arbeiten und die Aufsicht auf der Versuchsfarm. Die Klasse wird in vier Sektionen geteilâ, unci jecle versieht einen Monat hindurch den Dienst an anderer Stelle: zuerst im Stall, dann in der Milchwirtschaft, dann im Genüsegarten, und einmal hat die Sektion die Aufsicht über die gesamten Farmarbeiten beizustellen. Ist die Reihe um, so beginnt der Turnus von neuem.

Die praktische Betätigung in der Schule ist für die ägyptische Landwirtsehaft besonders wichtig, weil der Schüler auferhalb der Schule dort kaum die einfachsten landwirtschaftlichen Arbeiten richtig ausführen sieht. Man denke heispielsweise daran, daß die ersten Meiereien nach europäischer Art erst den Schülern der Ackerbauschule ihre Entstehung verdanken. Odel wic wichtig mußs es gegenüber dem dortigen Usus erscheinen, daßs die Schüler die Tiere gut behandeln lernen, dabs sie praktische Übungen in der ärztlichen Behandlung kranker Tiere abhalten. Gerale in der jüngsten Zeit wurde sogar eine eigene Abteilung des Vereines für Tierschutz an der landwirtschaftlichen Schule gegründet. Die Hörer hatten im Vorjahr die recht unerwünschte Gelegenheit, ihre Kenntnisse der Tierseuchen durch eigene Anschaumg zu bereichern, der ganze Rindriehstand wurde von der Maul- und Klanenseuche befallen. Zur Zeit meiner Anwesenheit war alles wieder glücklich vorüber und der Viehstand recht vielartig und in besserer Kondition, als man ihn sonst in Ägypten findet: 10 Zugochsen, 1 Stier, 8 gewöhnliche Milchkühe und $t$ Büffelkühe, 1 Büffel, ein paar Stück Jungvieh, eine prächtige Schaf́herde von 52 Stück, und etwas Geflügel. In bezug auf Geräte und Maschinen beschränkt man sich nicht auf die landesüblichen, es finden sich neben solchen eine Anzahl europäischer Eggen, Walzen, Sämaschinen u. dgl. vor. Die Milchwirtschaft besitzt ihre Kühlvorrichtung, ihren Alpha separator und alle müglichen Butter- 
und Käsebereitungsmaschinen. Was nicht im Original vorhanden ist, wird den Schülern zumindest im Modell vorgeführt. Die Schule hat ein kleines Museum von landwirtschaftlichen Maschinen, das äußerst instruktiv ist, und trefflich eingerichtete Laboratorien. So wohl versorgt und ausgerüstet ist die Lehranstalt in der Lage. ihre Aufgabe voll zu erfüllen und der Landwirtschaft die Kräfte zur Verfügung zu stellen, deren sie dringend bedarf. Die Schüler der Anstalt sind denn auch im ganzen Lande gesucht und geschätzt und vielfach in leitenden Stellungen tätig. In allen großen Domänenverwaltungen sind sie zu finden, im Ministerium für öffentliche Arbeiten und selbst die sudanesische Regierung hat sie vielfach in ihre Dienste berufen. Die großen Erfolge der KhedivialAgrikultur-Gesellschaft, von der jetzt gesprochen werden soll, wären nicht denkbar, stünden ihr nicht in den Absolventen der Ackerbauschule die erforderlichen, geschulten Hilfskräfte zur Verfügung.

Die Khedivial-Agrikultur-Gesellschaft ron Ägypten läßt sich, was ihre Stellung und ihre Bedeutung für die Landwirtschaft betrifft, wohl kaum irgendeiner andern landwirtschaftlichen Vereinigung außerhalb Ägyptens vergleichen. Das Land hatte bisher weder ein Ackerbauministerium noch ein besonderes Ackerbaudepartement in einem seiner Ministerien besessen und die Gründung der Gesellschaft, die im Jahre 1898 unter der Patronanz der Regierung erfolgte; schuf zum ersten Male einen Mittelpunkt für den wichtigsten Zweig des ägyptischen Erwerbslebens. Eine freie Vereinigung zahlender Mitglieder, meistens Landwirte, sollte die Gesellschaft Ausstellungen veranstalten, Kulturversuche anregen, landwirtschaftlich-wissenschaftliche For'schungen unternehmen, Samen und Kunstdünger beschaffen und in anderer Weise das allgemeine Interesse ihrer Mitglieder und der gesamten Landwirtschaft des Reiches fördern. Der Erfolg entsprach gleich anfangs den Erwartungen, die man in die Gründung gesetzt hatte; er übertraf sie vollends nach der Reorganisation im Jahre 1904. Der Wirkungskreis der Gesellschaft war schon vorher fortgesetzt gewachsen. Sie hatte in ihre Tätigkeit immer neue Zweige der Landwirtschaft einbezogen, ihren Ausstellungen und ihren Bemühungen immer mehr Ausdehnung gegeben. Die Zahl der Mitglieder blieb freilich vorerst beschränkt und noch im Jahre 1904 waren es nur 243, die insgesamt 920 L. E. an Jahresbeiträgen zahlten. Da hieß es, ungeachtet der Regierungs. 
subvention sparen, die Ziele nicht gar zu weit ausdehnen. Aben schon hat der Erfolg den Wert einer landwirtschaftlichen \%entralstelle schätzen gelehrt. Ton allen seiten. in allen Tageshlättrm werden Wünsche nach vermehrter Fördermng der Landwirtschaft. nach Schaflung eines Ackerhandepartements bei der Pegierung laut. Diese verschliebt sich nicht der Notwendigkeit, Hilfsaktionen für die Landwirtschaft ins Lelen zu rufen, möchte sie aber lieher dureh die Selbsthilfe der Landwirte entstehen sehen. Der passive Charakter des Orientalen überläßt es, ohne dringenden Zwang. leicht ganz und gar der Regierung für ihn zu denken und zu handeln, de halb soll erst der Geist der Selbsthilfe geweckt werden. Die Schaffung eines Ackerbaudepartements wird also vorläufig herausgeschoben, aber die Regierung schlägt eine Neunrganisation der Gesellschaft vor. Der leitende Gedanke dabci ist. die Wirksamkeit der Gesellschaft nach und nach über ganz Ägypten auszudehnen, inmer enger mit dem gesamten landwirtschaftlichen Leben des Landes zu verbinden. Um die Zentralisierung in der Landwirtschaftsgesellschaft herbeizuführen, soll zunächst eine Dezentralisierung Platz greifen. In allen $14 \mathrm{Mou} \mathrm{d}$ riehs (Provinzen) will die Regierung Vertretungsstellen der Gesellschaft errichten, deren jede einen besoldeten Sekretär erhält. Die Sekretäre müssen diplomierte Schüler der Ackerbanschule ron Gîseh sein und auf den Tersuchsfeldern der Ge. sellschaft praktiziert haben. Den Moudiriehdelegationen der Agrikulturgesellschaft gehören an: Der Moudir als Präsident, die Bewässerungs und Sanitätsinspektoren der Provinz oder ihre Stcllvertreter, der offizielle Tertreter der Moudirieh im großen Zentralkomitee der Gesellschaft, dessen Wahl dem Exekutir. komitee in Kairo zusteht, dann ein Vertreter der Agrikulturbank. Die Regierung ist sichtlich bemüht, alle gebildeteren Elemente zur Mitarbeiterschaft heranzuziehen. In den Moudiriehs werden die Spitzen der Intelligenz mobilisiert und in den Dienst der landwirtschaftlichen Entwicklungspläne gestellt. Mindestens einnal im Monat sollen die Delegationen tagen und wichtige Fragen von allgemeiner landwirtschaftlicher Bedeutung besprechen. Die Delegation hat die Ackerbauer ihrer Provinz über Zweck und Ziel der Gesellschaft aufzuklären und über die Bedingungen der Samen- und Düngerrerteilung. Sie soll die Grundbesitzer zu Ackerbaurersuchen anregeu, ihnen in jeder Beziehung rorbildlich und beratend zur Seite stehen. Mit der Muttergesellschaft. ron 
der sie alle Direktiven zu empfangen hat, steht die Delegation durch jährlich abzuliefernde Berichte über die geleisteten Arbeiten in Beziehung, wirbt Mitglieder für die Zentralstelle und sammelt die jährlichen Mitgliedsbeiträge ein.

Der gewiß äußerst glückliche Gedanke der Moudiriehdelegationen konnte bisher erst teilweise verwirklicht werden. Die Moudiriehs leiden keinen Mangel an den zur Bildung der Delegationen bestimmten Würdenträgern, aber der ganzen Einrichtung fehlt eine Kleinigkeit: die landwirtschaftlich gebildeten Sekretäre, ohne die die Sache einmal nicht durchzuführen ist, sind nicht aufzutreiben. Bi 1907 hatte man mit Müh und Not fünf Sekretäre zustande gebracht und schleunigst fünf Moudiriehsdelegationen ins Leben gerufen. Die Propaganda für die KhedivialAgrikultur-Gesellschaft war aber schon dadurch erleichtert und die Mitgliedschaft 1906 auf 4450 Personen gestiegen. Nach dem neuen Statut beträgt der Jahresbeitrag nicht mehr 5 L.E. wie früher, sondern nur 1 L.E. Die Gesamtsumme der Mitgliedsbeiträge würde auch jetzt nur den kleinsten Teil des unfassenden Programms zu erfüllen gestatten und die Regierung mußte die Subvention daher wesentlich erhöhen und für jede neu zu errichtende Moudiriehdelegation überdies weitere 500 L.E. in Aussicht stellen. Daneben hat sie wiederholt Staatsgelder zu $2 \%$ pro anno für besondere Zwecke hergeliehen. So zwang überraschende Entwicklung der Kunstdüngerbeschaffung die Gesellschaft, einige Jahre hindurch je 100000 L.E. auszuborgen. Trotzdem hätte sie unmöglich im Jahre 1907 Dünger für 135000 L.E. umsetzen können, wenn die Agrikulturbank ihr durch Zahlungserleichterungen, die dem kleinen Fellah gewährt wurden, nicht tatkräftig zur Seite gestanden wäre. Und jetzt kann die Gesellschaft erst nicht so viel Kunstdünger herbeischaffen, als bei ihr bestellt wird und muf wieder $31000 \mathrm{~L}$. E. von der Regierung ausleihen, um ein großes Hauptdepot am Kai von Alexandrien und Verteilungsmagazine für Kunstdünger in den verschiedenen Teilen des Landes zu errichten. Die Resultate, die mit Kunstdünger erzielt werden, sollen auferordentliche sein. Im offiziellen Berichte heißt es darüber: Kunstdünger bei Getreide angewendet hat mit einem Aufwande von $1-1^{1 / 2}$ L.E. den Ertrag pro acre um 3-4 L.E. vermehrt.

Eine ebenso segensreiche Tätigkeit entwickelt die Gesellschaft auf den zahlreichen andern Gebieten, die ihr die neuen Statuten zuweisen. Artikel 1 davon lautet: 
.Aufgabe der Gesellschaft ist es, die Entwicklung und Verbesserung der ägyptischen Landwirtschaft durch folgende Mittel anzustreben:

a) durch Selektion und Verteilung von gutem Samen;

b) durch Einführung geeigneter neuer Arten von Samen, Setzlingen und Bäumen;

c) durch Ausführung von Düngungs- und anderen Versuchen, die anscheinend von praktischem Werte für die Landwirte sind;

d) dureh Kauf und Verteilung von Kunstdüngern, die sich als vorteilhaft für die verschiedenen Kulturpflanzen erwiesen haben;

e) durch Bestrebungen, die einheimischen Viehrassen zu verbessern:

f) durch Versuche, die einheimischen Ackergeräte und Maschinen zu verbessern und durch Einführung solcher fremder, die für die Landwirtschaft vorteilhaft wären:

g) durch praktische und wissenschaftliche Beobachtungen der verschiedenen Insekten- und Pilzkrankheiten, von denen die Kulturgewächse in Ägypten befallen werden und durch Bestrebungen Abhilfe dagegen zu schaffen;

h) durch Veröfientlichung von Flugblättern, die landwirtschaftliche Tagesfragen behandeln, dann von Jahresberichten, die die Tätigkeit der Gesellschaft eingehend schildern und von wichtigen Arbeitsergebnissen ausländischer Landwirtschaftsgesellschalten;

i) durch Veranstaltung einer alljährlichen Landwirtschaftsausstellung zu Kairo und von möglichst häufigen Lokalausstellungen in den rerschiedenen Provinzen;

j) durch Anknüpfen von Verbindungen mit ähnlichen Gesellschaften und Ackerbaudepartements anderer Länder, die Informationen auf den verschiedenen Gebieten der Landwirtschaft liefern könnten;

k) durch Ergreifen jedes weiteren Mittels, das im allgemeinen Interesse der Gesellschaftsbestrebungen zu sein scheint.

In der Tat ein weit ausgreifendes Programm, das in der Hand energischer. zielbewußter Männer großes leisten könnte. Die Regierung hat sich in Erwägung der Bedentung, die dabei der Personalfrage zukommt, die Bestätigung des Präsidenten und der beiden Vizepräsidenten und die Ernennung des Generalseliretärs vorbehalten. Die Jahresberichte und die Arbeiten der Gesellschaft, 
in die ich Einsicht nehmen konnte, zeigen, daß die KhedivialAgrikultur-Society in ihrem Präsidenten, dem Prinzen Hussein Pascha Kamil und in dem trefflichen englischen Generalsekretär Fohden die Männer besitzt, die sie braucht. Die Tätigkeit der Gesellschaft läßt keinen Zweig der ägyptischen Landwirtschaft unbeachtet. Unermüdlich müssen die drei Inspektoren der Gesellschaft von Ort zu Ort reisen, überall Anbau- und Düngerversuche überwachen, die Verhältnisse studieren, unter denen gebaut wird, die Landwirte belehren, aufklären. In der Zentrale und in ihren Laboratorien werden dann die beobachteten Übelstände weiter erwogen, Ackerböden, Pflanzenkrankheiten und tierische Schädlinge untersucht. Man studiert, wie die Bewässerung bei den verschiedenen Kulturpflanzen am vorteilhaftesten angewendet wird, wie und was man bauen soll, welche Fruchtfolgen angemessen wären, man studiert die Fragen, die das Vieh und seine Ernährung betreffen und trachtet alle gewonnene Einsicht den Landwirten zu vermitteln. Dann werden wieder Ausstellungen veranstaltet, die alljährliche Hauptschau in Kairo und Provinzausstellungen, einmal in F a y $\mathrm{um}$ oder in Man s o u rah, das nächste Jahr anderswo. Und nun kommen noch Zusammenstellungen, die Produktionsstatistik betreffend, dazu und alles, was die Ziele der Gesellschaft irgendwie fördern und zur Durchführung des großen Programmes beitragen könnte. Es ist keine Kleinigkeit, Neuerungen in einem Lande einzuführen, das so sehr am Althergebrachten hängt, keine Kleinigkeit, dem Fellah Vertrauen in die neue Richtung beizubringen. Der Generalsekretär Fohden, in dessen Hände alle Fäden zusammenlaufen, spricht mir in der ruhigen, zielbewußten Art des Engländers davon und von den weiteren Arbeiten und Zielen der Gesellschaft. Und mit dem lebhaften, hinreißenden Wesen des Südländers erzählt mir dann Prinz Hussein von seinem Arbeitseifer und von seinen Plänen. Unter Hinweis auf den Präsidenten Roosevelt hebt er die Bedeutung hervor, welche die Arbeitskraft eines einzigen Mannes für ein Volk gewinnen könne. Seine eigene Arbeitssphäre ist wohl nur die Landwirtschaft, aber auch sie bietet in Ägypten keine kleine und keine undankbare Aufgabe. Prinz Hussein hat einen Teil seiner Jugendzeit, in Ungarn zugebracht, wo man ihn mit seinem Vater, dem Khedive Ismail, während dessen Exil gastfreundlich aufnahm. Vielleicht hat er dort etwas von den aufgeklärten Ideen angenommen, die 
ihm nachgerühnt werden, wie ja auch der entschieden fortschrittiche Geist des Khedive $\mathrm{A}$ b bas $\mathrm{Hilm}$ i II. nicht mbeeinflubt von dessen Erziehung im Wiener Theresianum sein wird.

Neuerdings hat sich der Plan wieder verdichtet, der Landwirtschaft doch noch ein eigenes Departement in Lnterrichtsministerium einzuräumen. Es soll den Titel „Abteilung für landwirtschaftlichen und technischen Unterricht" führen und sich mit der Administration des landwirtschaftlichen und des damit eng verbundenen technischen Unterrichtswesens befassen. Der Regierungsvorschlag stellt als Vorbild für das zukünftige Departement die Organisation jenes hin, das Sir Horace Plunkett in Irland ins Leben gerufen hat. Die Regierung verlautbart ihren Plan nicht, ohne die wohlerworbene und anerkannte Stellung der Khedivialgesellschaft mit einer Verbeugung zu grüßen. .. Die genaue Relation des neuen Departements zur Khedivialgesellschaft ". heibt es im Bericht, „kann noch nicht bestimmt werden. Es ist indessen das Verständnis dafür zu wünschen, daß das neue Departement, fern davon eine Organisation wie die Khedivialgesellschaft und ihre Provinzkomitees unnötig zu machen, im Gegenteil an die Existenz eines solchen Vertretungskörpers der landwirtschaîtlichen Interessen gebunden ist. Das neue Departement soll die Gesellschaft nicht ersetzen, sondern unterstützen und mit ihr zusammen arbeiten."

Sie werden wohl beide nebeneinander genügend Platz für ihre Wirksamkeit haben, die Selbsthilfe, welche die Khedivialgesellschaft repräsentiert und die Regierung mit ihrem neuen Departement. Beide finden sich einstweilen bei mancher andern Bestrebung in Dienste der Bodenproduktion. Da ist gleich das Gebiet der Hortikultur, das bisher in Ägypten recht wenig gepflegt wurde. Gesellschaften dafür hat es freilich zwei gegeben, eine in Alexandrien und eine in $\mathrm{Kairo}$, aber so verdienstvoll deren Bemühungen auch waren, so konnten sie doch nur innerhalb enger Grenzen Nutzen stiften.

Klima und Boden eröffnen der Kultur von Früchten. Gemüsen, Blumen sehr günstige Aussichten, aber bei dem niederen Stande der ägyptischen Gärtnerei und bei der geringen Beschaffenheit des rorhandenen Pflanzenmaterials hängt dabei viel von dem Import geeigneter Samen. Stecklinge und Pfropfreiser ab. Auch die besten Sorten sind nicht immer gerade für die ägyptischen Bodenverhältnisse und für die lokalen klimatischen und anderen 
Bedingungen geeignet. Deshalb sollten Importe stets an Ort und Stelle durch Anbauversuche auf ihre Tauglichkeit untersucht werden. Solange die Hortikulturgesellschalten solche in den verschiedenen Teilen des Landes durchzuführen nicht imstande sind. kann man es dem Fellah wahrlich nicht verargen, wenn er, statt der unsicheren fremden, lieber seine alten, elenden, aber immerhin sicheren Arten baut.

Auch hier ist also der Fortschritt an Versuchsstationen gebunden und an eine weite, das ganze Land umfassende Organi sation. Die Regierung muß wieder der Privatinitiative zu Hilfe kommen. Die Zauberformel "Subvention" beseitigt alle entgegenstehenden Bedenken. Alexandrien behält seine alte Agrikulturgesellschaft, die die Subvention ausschließlich für Hortikulturzwecke bekommt und ihr Wirken auf den Umkreis ihres Standortes zu beschränken hat. während alle Bestrebungen zur Hebung der Hortikultur sonst in einer neuen Gesellschaft „Der Commercial Hortikulturgesellschaft von Ägypten" konzentriert werden. Den Vorsitz übernimmt Prinz Hussein Pascha Kiamil, dessen Name schon einmal von jedem Unternehmen im Interesse des landwirtschaftlichen Fortschrittes unzertrennlich ist. Nun sollen gleich zwei Versuchsgärten, einer von füní Feddán, der andere kleiner, angelegt werden, und ein wissenschaftlich gebildeter, englischer Gärtnereifachmann, ein Mr. T. Brown, wird dort Akklimatisationsversuche mit Gemüsen und Früchten anstellen und eine Anzahl junger Ägypter in der Gärtnerei unterrichten. Nach deren Ausbildung will man ähnliche Experimentiergärten in allen Provinzen einrichten und dort nicht nur Anbauversuche anstellen, sondern auch den Landwirten praktisch vorführen, was in Ägypten nach dieser Richtung möglich ist. Der Förderung von Baumkulturen, die in Ägypten bekanntlich sehr wenig verbreitet sind, hat die neue Gesellschaft gleichfalls zu dienen.

Um was für Dinge die ägyptische Administrative sich sonst noch zu kümmern hat, durch wie vielerlei Maßnahmen sie die kulturelle Weiterentwicklung des Landes und damit die ungestörte Arbeit des Landwirtes sichern muß, lehrt ein Blick in die jährlichen Berichte des englischen Generalagenten. Da werden Maßnahmen geschildert zur Erhöhung der Sicherheit, zur Bekämpfung der mannigfachen Seuchen und Laster von Mensch und Tier; Vorkehrungen zur Trockenlegung der ungesunden Tümpel und 
versumpften Stellen. die sich in der Nähe oder gar imnitten mancher Dörfer und Stärte vorfinden, zur Verhinderung der Tierquälerei, die der Landwirtschaft so viel Schaden zufügt, und all die andern Dinge, die den Übergang zur Hochliultur in europäischem Sinne hegleiten müssen. Dazu gehört auch das Abstellen oder zumindest die Herabsetzung des $\mathrm{Hasch}$ ischSchmuggels. Der Fellah enthält sich, den Geboten seiner Religion entsprechend, meist des Genusses ron geistigen Getränken, aber er bezeigt nicht immer dieselbe Standhaftigkeit gegenüber den Verlockungen des $\mathrm{Haschiseh}$. Das ist ein in seiner Wirkung dem Opium ähnliches Berauschungsmittel, das in Griechenland aus einer Hanfsorte erzeugt und in grolien Miengen nach Ägypten geschnuggelt wird. Von dem Anwert. den das süße Gift dort findet, gilht es pine Idee, wenn man hört, daßs im Jahre 1907 allein $15345 \mathrm{~kg}$ Haschisch Schmugglern abgenommen wurden. Die ägyptische Regierung hält die Gefahr. die das Haschisch für die Gesundheit und Arbeitskraft der Bevölkerung mit sich bringt, für so groß, daß sie anläßlich der Erneuerung der Handelsverträge mit Griechenland das Verbot der Haschischkulturen in diesem Staate forderte. Griechenland ist darauf wohl nicht eingegangen, hat aber den Haschischbau mit einer hohen Steuer belegt und den Export nach Ägypten ganz verboten. Bei der langen Küstenlinie Griechenlands und bei der Menge von kleinen Inseln, die es umgeben, finden Schmuggler leicht Nittel und Wege, um das Verbot zu übertreten.

Ein anderes Bild entrollt eine kurze Fotiz in dem offiziellen Berichte von 1907, "Sklaverei* überschrieben. Da heißt es: .. Der Sklavenhandel hat wohl in Lnterägypten aufgehört, aber in Oberägypten noch nicht. Im Dezember 190.5 erhielt das AntiSklaverei-Departement Nachricht von einem Raubzug der As h a b a bAraher, die in dem ägyptischen Teile der Atbai.Wüste, zwischen dem Nil und dem Roten Meere leben. Die Patrouille, die sofort ron Derawi ausgesandt wurde, kam unglücklicherweise zu spät, um die Einschiftung eines Trupps von Sklaven noch hindern zu können, sie konnte indessen die Sklavenjäger zu Stande bringen. Diese wehrten sich energisch und die Patrouille mußte sich mit einem Sehwerverwundeten und einigen erbeuteten Kamelen und Gewehren zurückziehen. Daraufhin sandte man eine gröfere Soldatenpatrouille: verstärkt durch eine Abteilung ron Küstenwächtern, aus. dic die Hauptschuldigen hinnen 14 Tagen 
gefangennahm. Zehn davon wurden zu 15 Jahren und einer zu 6 Jahren schweren Kerkers verurteilt."

Der Bericht schliebt mit den Worten: "Am Suezkanal konnte im letzten Jahre kein Fall von Sklavenhandel beobachtet werden, es wäre aber verfrüht, daraus auf dessen Aufhören schließen zu wollen; es ist im Gegenteil zu fürchten, daß Sklavenhandel dort im Verborgenen immer noch getrieben wird.

Die Regierung hat. wie man sieht, wirklich alle Hände voll $\mathrm{zu}$ tun, muk dem einen wehren, das andere anregen und das Dritte fördern. So vielseitig in Anspruch genommen, hat sie alle Ursache die Mithilfe derer freudig zu begrüßen. die den Fortschritt auf eigene Faust herbeizwingen. Solche Kulturträger sind die Bodenaufschließungsgesellschaften, ron denen schon im dritten Kapitel die Rede war. Wurde dort ihrer Tätigkeit in der letzten Vergangenheit gedacht, so soll hier auf ihre Bedeutung für die Zukunft hingewiesen werden. Das markanteste Beispiel dafür liefert die 1904 gegründete Société anonyme de Wadi $\mathrm{K}$ om- $\mathrm{Ombo.}$

Jeder Ägyptenreisende, der die Nilfahrt bis Assuan unternommen hat, kennt den Tempel des Ptolemäus Epiphanes zu Kom-Ombo. Die Landschaft hat dort schon ganz den nubischen Charakter angenommen, der sich so sehr rom ägyptischen unterscheidet. Die Wüste tritt vielfach bis an den Strom heran, die menschlichen Niederlassungen werden spärlicher und noch armseliger als bis dahin. der Ackerbau ist nur stellenweise auf einem schmalen Uferstreifen möglich. Inmitten eines Wüstenplateaus erhebt sich der Hügel, der die Tempelreste von Kom-Ombo trägt. $\mathrm{Bis}$ vor kurzem schienen diese rettungslos verloren $\mathrm{zu}$ sein, da der nachdrängende Wüstensand sie auf der emen Seite verschüttete, während auf der anderen Seite die austretenden Wässer des Nils das Zerstörungswerk fortsetzten.

Gegenwärtig ist der Tempel durch Dammbauten vor der Überschwemmung gesichert, am Ufer erheben sich stattliche Pumpenstationen mit hohen Schloten und mächtige, stählerne Bewässerungsrohre ragen wie die Läufe gewaltiger Festungsgeschütze in den Nil hinein. Die Wüste aber, im Hintergrunde, ist verschwunden und hat wogenden Feldern, grünen Fluren Platz gemacht. Das ist das Werk der Société anonyme de Kom-Ombo, über die ich, dank der Güte ihres liebenswürdigen Administrators, Monsieur J. A. Cattaui Bey. und ihres Direktors, Herrn 
Walter Horschitz, einiges mitteilen kann. Die Gesellschaft besak bei ihrer Gründung cin Kapital von 3000000 L.E. . das im Jahre 19197 anf 1000000 L.E. erhöht wurde. Sie hat von der Regierung :30000 Feddán au Wüstenplateau von Kon-Ombn zu 21) Piaster den Feddán (41 Pfennige) gekanft und sich üherdies das Optionsrecht auf weitere 90000 Feddán gesichert. Der P'reis ist nicht gerade hoch, aber das Unternehmen war dennoch ein Wagnis, denn das Plateau liegt $18-20 \mathrm{~m}$ über dem mittleren Niveau des Nils und noch 13 m über der maximalen Fluthöhe. So ist im vorhinein damit zu rechnen gewesen, dali das Wasser, das die Wüste in Fruchtland verwandeln soll, jahraus jahrein in kostspieliger Weise durch Pumpen herbeigeschafft werden muk. Günstiger liegt dagegen ein anderes Moment: Das ganze Plateau ist so eben, dab die jeder Bewässerungsanlage vorausgehende Nivellierung der Bodenfläche sich mit relatir geringen Mitteln erzielen läßst. Und noch eines: Der Boden ist überall von vorzüglicher Qualität, meist sandiger Lehmboden, der nur hier und da von Sandstellen unterbrochen wird und nicht allzu reich an Kochsalz ist, dem weit verbreiteten Übel der ägyptischen Böden.

Die Landseite Kom-Ombos liegt dicht an der Keneh-AssuanEisenbahn. Es war daher möglich zu Wasser und zu Land die riesigen Mengen von Materialien und Vorräten herbeizuschaffen, deren die Niederlassung bedarf. Die Dimensionen der Bewegung wird man nach diesen Zahlen ermessen können: Bei den Erdarbeiten zur Nivellierung des Bodens, bei dem Bau der Kanäle, der Hilfsgebäude usw. waren nicht weniger als 50 menschen beschäftigt. Auf den Anschlubgeleisen besorgten 8 Lokomotiven und 155 Waggons die Zu- und Abfuhr der Materialien, wozu noch 337 Zugochsen und 44 Maultiere kamen. Zum Umackern dienen vier Fowlersche Dampfpflüge zu je 30 und fünf solche zu 12 Pferdekräften. Zur Zeit meiner Anwesenheit waren zwei Pumpenstationen fertiggestellt. Die eine enthält zwei Pumpen zu je 1400 Pferdekräften und 10 Dampfkessel zu je 200 qm Heizfläche. Die andere Station besitzt nur eine Pumpe zu 1400 Pferdekräften und 4 Dampfkessel. Die Pumpenrohre heben das Wasser $18 \mathrm{~m}$ hoch, weisen einen Durchmesser von $2 \mathrm{~m}$ auf und münden in lange zementierte Rohre, die zu einem groben, beiden Pumpwerken gemeinsamen Sammelbassin führen. Die Kanäle und Rohre hatten 1907 eine Länge von $91 \mathrm{~km}$ erreicht, die Anschlub- 
geleise eine solche ron $48 \mathrm{~km}$ und die Schienenstränge der Agrikuiturbahn eine Länge von $50 \mathrm{~km}$. Die Gesellschaft läft eine ganze Stadt in Kom-Ombo erstehen. Da gibt es Wohnhäuser, die insgesamt 1472 Wohnungen enthalten, einen gedeckten Bazar mit 63 Terkaufsständen, eine Moschee, eine Polizeiwache, Magazine und Mühlen, Stallungen und dergleichen mehr. Aus den unliegenden Provinzen, aus Keneh, Girgeh, Minieh ziehen die Ansiedler herbei und die Wohnhäuser füllen sich, ehe sie noch fertig geworden sind. Mit dem Anbau war man vorerst noch vorsichtig gewesen, hatte Nutzpflanzen aller Art, Getreide, Baumwolle, Gemüse, Obst- und Zierbäume zunächst auf kleinen Flächen ausgepflanzt: las erste Jahr nur 60-70 Feddán, dann, durch den Erfolg kühner gemacht, mehr. 1908 waren schon 21000 Feddán so weit instand gesetzt, daß man an ihre Bebauung denken konnte und num soll in der weiteren Urbarmachung ein Stillstand cintreten. Die rorsichtigen Leiter des Unternehmens wollen erst die Rentabilität abwarten, die der regelmäßige Betrieb der erschlossenen Länder ergeben wird.

Der gröbere oder geringere kaufmämnische Erfolg Kom-Ombos ist hente noch nicht endgültig erwiesen, aber Kom-Ombo stellt in jedem Falle eine neue Etappe auf den Wege zur kulturellen Erschliełung Ägyptens dar, hesonders wichtig dadurch, daß es sich hier um eine neue Art del Urbarmachung handelt, die für ganz Oberägypten und für den Sudan vorbildlich werden und un. erwartete Aussichten eröffnen könnte. 


\section{Sechstes Kapitel.}

\section{Land, Leute und Bodenproduktion im Sudan.}

\section{Einige Voraussetzungen der Bodenproduktion.}

Slatin Pascha glaubt an die Zukunft der sudanesischen Bodenproduktion. Möglichkeiten und Hindernisse ihrer Entwicklung. - Läßt sich der ganze Sudan in eine grüne Flur verwandeln? - Das Klima: Regen, Temperatur Winde, Luftfeuchtigkeit, Regenstürme. - Zeitweise Unerträglichkeit des Aufenthaltes. - Die tropischen Feinde des Menschen. - Transport- und Absatzschwierigkeiten. - Wechselwirkung zwischen Mensch und Land und Betrieb

Der ehemalige üsterreichische Reserveoffizier, Rudolf Slatin, jetzt General Sir Rudolf Baron von Slatin Pascha, ist zweifelsohne der beste europäische Kenner des Sudans. Sein Schicksal, wohl eines der merkwürdigsten Menschenschicksale der neueren Zeit, ist seit mehr als 30 Jahren mit diesem Lande verknüpft. Schon 1874 hat er Kord ofan bis zu den Nubabergen bereist, ist 4 Jahre darnach in die Dienste der ägyptisch-sudanesischen Regierung getreten und war Gouverneur von Darfur, bis dieses in die Hände des Mahdis Mohammed Achmed fiel. Slatin wurde dam fast 13 Jahre als Gefangener im Sudan festgehalten, wurde zuerst in Eisen gelegt und mußte später als Leibwächter des Khalifa, des Nachfolgers des Mahdi, neben dem Pferde seines Herrn herlaufen. Jetzt ist Slatin eine der leitenden Persönlichkeiten des Landes, in dem er solange als Sklave gelebt hat, ist Generalinspektor des ganzen Sudans geworden und wegen des besonderen Vertrauens, das er bei den eingeborenen Stämmen geniefit, auch in mancher wichtigen Angelegenheit, die nicht in sein Ressort fällt, der erwünschte Mittler zwischen Regierung und Bevölkerung.

Während meines ersten Besuches im Amtsgebäude des nun. mehrigen Generalinspektor's zu Kh a rtu m war beispielsweise gerade 
der Schêch el Islam, der oberste geistliche Würdenträger des Sudans, mit einigen vornehmen Schêchs zu einer Besprechung dort erschienen. Neben solchen Berührungspunkten setzen ausgedehnte militärische Inspektionsreisen Slatin Pascha in die Lage, das Land wie kein Zweiter zu kennen und dessen Entwicklung $\mathrm{zu}$ verfolgen.

Und Slatin glaubt an die Zukunft des Sudans, glaubt an die Aussichten seiner wirtschaftlichen Grundlage, an eine mächtige Entwicklung der sudanesischen Bodenproduktion.

Der englisch-ägyptische Sudan unfaßt die Landschaften Nubien, Sennar, Kordofan, Darfur, das obere Nilgebiet und das Bahr el Ghazal. In administrativer Beziehung ist er gegenwärtig in 1:3 Provinzen unter eben so vielen Gouverneuren geteilt:

$$
\text { Provinz: }
$$

1. Halfa

2. Dongola

3. Berber

4. Rote Meer-Provinz

5. Kassala

6. Khartum

7. Blaue Nil-Provinz

8. Weiße Nil-Provinz

9. Sennar

10. Kordofan

11. Obere Nil-Provinz (früher Faschoda)

12. Mongalla

13. Bahr El Ghazal
Hauptstad:

Halfa

Merowe

El Damer

Port Sudan

Kassala

Khartum

Wad Medani

El Duesin

Singa

El Obeid

Kodok (früher Faschoda) Mongalla

Wau.

Eine einzige dieser Provinzen und nicht eimmal die größste, die Bahr-El-Ghazal-Provinz, ist nach Sir Reginald Wingate, dem gegenwärtigen Generalgouverneur des Sudans, etwa fünfmal so groß als England und der Unfang des ganzen Reiches gibt dem eines Dritteils von Europa nicht viel nach. So gewaltig sind die Ländermassen, die jetzt durch die Kolonialkunst der Engländer aus der Barbarei zu neuem Leben erweckt werden sollen.

Man wagt kaum den Gedanken an die Rückwirkung solchen Geschehens auf die Weltwirtschait zu Ende zu denken. Endlose 
Strecken neuen Kulturbodens, weite Gebiete der Bodenproduktion erschlossen, die ähnlich wie in Ägypten mehrfache Ernten im Jahre tragen würden! Fast empfindet man's als Erleichterung, daf das Urbarmachen dieses Teiles von Alrika sich doch nicht gar so einfach bewerkstelligen läßt, als es zunächst den Anschein hat. Von dem Standpunkte betrachtet, den wir als den Standpunkt der Nationallandwirtschaft bezeichnet haben, werden wir der sudanesischen Bodenproduktion Hindernisse und Schwierigkeiten erstehen sehen, die sich nur schwer und schrittweise bekümpfen lassen. Die bedeutenden Aussichten der sudanesischen Landwirtschaft bestehen zweifelsohne, aber man darf sie nicht dahin deuten, dak sich der Sudan einfach in eine einzige grüne Flur, in eine blühende Ebene, wie etwa unser Marchfeld, verwandeln ließe. Die folgende Betrachtung der landwirtschaftlichen Voraussetzungen wird das unschwer erkennen lassen.

Es ist schon gesagt worden: Im Sudan hängt nicht jedes Leben vom Nil ab. Es gibt eine Anzahl anderer Flüsse, es gibt überall, wo Hügel oder Berge das sudanesische Flachland unterbrechen, Bäche, die den Weg nach tieferen Stellen suchen, es gibt schließlich viele Gebiete mit starkem Regenfall. Gerade die Regenmengen könnten, ohne Beachtung der übrigen klimatischen Verhältnisse, zu den optimistischesten Auffassungen berechtigen. In B erber ( $18^{0} 1^{\prime}$ nördlicher Breite, $34^{0} 4^{\prime}$ Länge östlich von Greenwich) ist Regen noch geradeso unbekannt wie in Oberägypten. Aber schon Suakin, das wohl nördlicher (190 $7^{\prime}$ nördlicher Breite), aber näher gegen das Rote Meer zu liegt (Länge $37^{\circ} 20^{\prime}$ östlich von Greenwich) hat beispielsweise im Jahre $190(1$ von Oktober bis Dezember $178 \mathrm{~mm}$ Regen erhalten. Die ron der Regierung in Khartum (150 $36^{\prime} 33^{\prime \prime}$ nördlicher Breite, $32^{0} 33^{\prime}$ östlicher Länge) errichtete meteorologische Station konnte im selben Jahre 130,9 mm Regen beobachten:

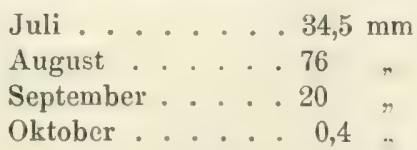

Gegen Süden und gegen die Mceresküste nehmen die Regen weiter an Stärke, die Regenzeit an Dauer zu. Es bekamen beispielsweise einige Orte nach den Aufzeichnungen ihrer meteorologischen Stationen im Jahre 1904 diese Regenmengen: 
Kassala: $15^{0} 28^{\prime}$ nördlicher Breite, $36^{\circ} 24^{\prime}$ östlicher Länge

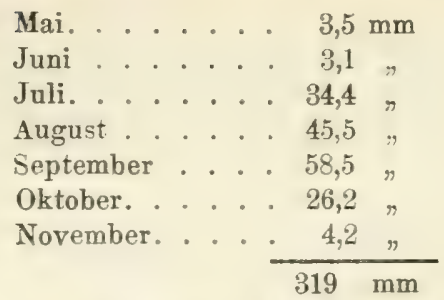

El Obeid: $13^{\circ} 11^{\prime}$ nördlicher Breite, $30^{0} 14^{\prime}$ östlicher Länge

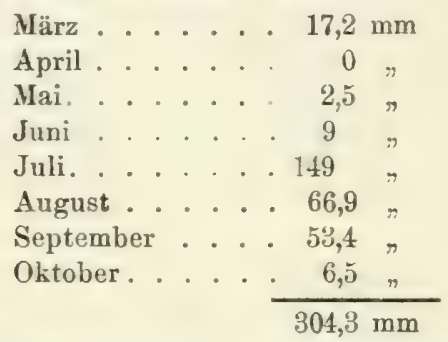

Kodok: $9^{0} 53^{\prime}$ nördlicher Breite, $32^{0} 8^{\prime}$ östlicher Länge

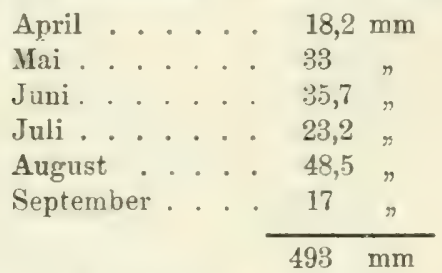

W a u: $7^{0} 42^{\prime \prime}$ nördlicher Breite, $27^{0} 43^{\prime}$ östlicher Länge erhielt nur im Dezember keinen Regen und in den übrigen Monaten insgesamt $718 \mathrm{~mm}$. Mo ngalla, der südlichste Ort, $5^{0} 11^{\prime}$ nördlicher Breite, $31^{\circ} 47^{\prime}$ östlicher Länge gar $912 \mathrm{~mm}$ Regen, der nur im Januar ganz ausblieb. Vergleichsweise sei daran erinnert, daß z. B. Wien im 50 jührigen Mittel eine Niederschlagsmenge von $618 \mathrm{~mm}$ aufweist, von der etwa die Hälite in die eigentliche Vegetationszeit der Kulturpflanzen fällt. Ohne die bekannte Bedeutung der Winterfeuchte für das Gedeihen der Kulturen im mindesten zu unterschätzen, wäre man darnach versucht den Zerealienbau ohne künstliche Bewässerung in den meisten Teilen des Sudans für möglich zu halten. Diese Meinung erfährt indessen sofort eine starke Einschränkung, wenn man Temperatur. Winde und den Grad der Luftfeuchtigkeit, dann die Verteilung 
und die Art des Regens berücksichtigt, lauter 1)inge, die die Verdunstung beeinflussen oder über den Bedarf der Kulturpflanzen an Wasser mit entscheiden.

Die durchschnittlichen Jahrestemperaturen haben, un wiecier einige Beispiele anzuführen, 1904 in suakin $27,38^{\circ} \mathrm{C}$, in Khartum $28,43^{\circ} \mathrm{C}$, in Kassala 27,33 , in El Obeid $25,22^{\circ} \mathrm{C}$ und in Mongalla ( $5^{0} 11^{\prime}$ nördlicher Breite, $31^{0} 47^{\prime}$ östlicher Länge) $25,54^{\circ} \mathrm{C}$ betragen. Das gibt allerdings noch lieine rechte Idee, weil die Tempcraturschwankungen in Verlaufe eines Jahres sehr bedeutend sind und selbst in Verlaufe eines Monats, eines Tages stark zum Ausdruck lrommen. Im April 1904 beobachtete man in Khartum eine Minimaltemperatur von $15^{\circ} \mathrm{C}$ und eine Maximaltemperatur von $45^{\circ} \mathrm{C}$ im Schatten; die monatlichen Durchschnittstempcraturen betrugen im Januar $22,85^{\circ} \mathrm{C}$, im April $29,38^{\circ} \mathrm{C}$, im Juni $33,34^{\circ} \mathrm{C}$. Über $45^{\circ} \mathrm{C}$ im Schatten geht die Temperatur nicht häufig hinaus. Im Suak in registrierte man im August 1904 $48^{\circ} \mathrm{C}$, in Dueim im September $190447,5^{\circ}$. Aber auch ohne solche Extreme gehört der Sudan zu den heißesten Gegenden der Erde. Es läßt sich denken, um wieviel rascher die Verdunstung bei so hohen Temperaturen vor sich geht. Zudem wehen die Monsunwinde im Sudan fast das ganze Jahr über. Der Südwestmonsun bläst vom 18 . Breitengrad an ununterbrochen von Mai oder Juni bis Oktober und wird nur in den südlichsten Teilen des Landes in der Nähe des Äquators ron leichten Brisen abgelöst, deren Richtung kaum festzustellen ist.

Hitze und Winde verringern naturgemäßs den Grad der Luftfeuchtigkeit und äußern so neben der direkten Wirkung eine indirekte, beschleunigende Wirkung auf die Verdunstung, vergrößern weiter den Wasserbedarf der Pflanzen. Während die relative Feuchtigkeit von Wien im Jahresdurchschnitt $72 \%$ beträgt, bringt es Suakin trotz der Lage an der Meeresküste nur auf $620_{0}$, Kassa la auf $40,9 \%$ und K h a tu sogar nur auf $30,4 \%$ relative Luftfeuchtigkeit. Und selbst Mongalla, im südlichsten Winkel des Sudans gelegen, schon dort, wo die Monsunwinde schwächer werden, hat ungeachtet seiner enormen Regenmengen eine durchschnittliche jährliche Luftfeuchtigkeit auizzuweisen, die jene von Wien unwesentlich übersteigt. Freilich, nur im Jahresdurchschnitt, denn während die Luftfeuchtigkeit in unserem gemäßigten kontinentalen Klima das Jahr über ziemlich gleich verteilt ist, wechselt sie in den Tropen auferordentlich stark. Zur 
Regenzeit ist die Luft mit Wasserdampf über und über geschwängert, nachher außerordentlich trocken. In Mongalla zeigten die Durchschnittsmessungen vom Januar $1904 \quad 53,2 \%$ relative Luftfeuchtigkeit, die Augustmessungen dagegen nicht weniger als $86,7 \%$.

Die Regen, oft von Sturmwinden und Gewittern begleitet. treten meist in so heftigen Güssen auf, daf das Wasser gar nicht in den Boden dringen kann und an der Oberfläche abfließt. Die Dauer und der Zeitpunkt der tropischen Regen ist nicht allerorten gleich, und der Verlauf zeigt ebenfalls gewisse Abweichungen. Im Südostsudan, wo die Regenzeit von Ende Februar bis November verteilt ist, regnet es zuerst in Intervallen von 8-14 Tagen nur mäßig, dann beginnen die Regenstürme, die immer heftiger werden und von der zweiten Hälfte des Juni angefangen alle 24 Stunden die stärksten Güsse mitbringen. Im östlichen Teile der D o n g o la -Provinz gehen die Regen in langen Zwischenpausen, aber oft in solchen Strömen nieder, daß sich die Wassermengen auf dem felsigen Untergrunde zu wahren Wildbächen vereinen, die auf ihrem Wege zum Nil alles hinwegschwemmen, mit sich reißen, was sie vorfinden. Im Bahr el Ghazal gibt es von April bis November fast jeden dritten Tag Regengüsse, die indessen nur zwei oder drei Stunden dauern. In den ersten Monaten pflegen sie die Begleiter fürchterlicher Gewitter zu sein.

Aus alledem ergibt sich, daß ein guter Teil des zur Erde fallenden Regens den Kulturpflanzen nicht zugute kommt, während diese wegen der erhöhten Verdunstung bedeutendere Wasseransprüche als in unseren Ländern stellen. Davon abgesehen haben die Regen im Zusammenhange mit den übrigen klimatischen Verhältnissen vielfach andere unangenehme Erscheinungen im Gefolge, die regelmäßigem Ackerbau nicht günstig sind. Sie nehmen im selben Maße gegen Süden zu wie die Regenmengen und die Üppigkeit der Vegetation. Kordofan liegt schon in einer Zone ausreichenden Regens. Der "Kharif" oder die Regensaison dauert dort von Mitte Juni bis Ende September und wird dann von der "Shita" oder dem kalten Wetter abgelöst, das bis Ende Februar anhält. Von März bis Juni ist die heiße Zeit. Kord of an hat ein weniger extremes Klima als andere Teile des Sudans; während der "Shita", wenn die Winde von Norden kommen, ist es sogar ganz angenehm und gesund, und auch die 
heibe Weit kemnt nu selten Maxima, die $11,0^{\circ}$ Fahrenheit ühersteigen. während auch dam noch die Nächte kühl und erfrischend bleiben. Aber mit der Regenteit wird das Leben geradezu merträglich. Die mit Feuchtigkeit geschwängerte Iuft lälst die Hitze doppelt drückend empfinden; in der Nacht hält man es in den Wohnräumen kaum aus. Bis Ende Juli hat sich der Boden unter dem Einfluß der fortwährenden warmen Feuchtig. kcit rings um die Hütten, überall, wo nur cine Handbreit Erde rorhanden war, mit der dichtesten Vegetation üherzogen, und das schielit so beispiellos üppig in die Höhe, rankt und schlingt sich so durcheinander, daß man dessen gar nicht Herr verden; hamn. Der betäubende Geruch des Pfianzengestrüppes, die vielen Kröten, Frösche und Reptilien, die Moskitos und die Sandfliegen tragen dazu bei, den Aufenthalt bei Tag und Nacht noch qualvoller zu gestalten. Dabei nimmt jetzt die Malaria zu, und Seuchen, Dysenterie, Lungenleiden treten in jeder Form auch unter den Einheimischen auf und unter dem Vieh, das sie stark verringern. In D a r f u r soll alljährlich ein Sechstel der Haustiere während der Regenzeit zugrunde gehen. Was so eine Regensaison den Menschen für Entbehrungen und Mühen auferlegt, läßt sich erst vollends ermessen, wenn man bedenkt, daßs die ganze Ackerbestellung während dieser vorgenommen werden mul. Die Shilluks, die längs der westlichen Ufer des Nils zwischen Kaka und dem No-See wohnen, sind ein ganz kräftiger, gut gebauter Menschenschlag. Die Erde, die sie bestellen, ist reich, und die Ackerkrume geht nach Untersuchungen 12 Fuß tief herab. Was die Shilluks bauen, Durra, Mais, Bohnen, Melonen, Erdnüsse, Baumwolle, Sesam, könnte prächtig gedeihen. Aber der überreiche Boden und die Regenzeit lassen auch das Unkraut üppig wuchern, und die jungen Kulturen können nur durch nnunterbrochenes Jäten vor dem Ersticken bewahrt werden, durch unendliche Mühe vor den Schäden des Hochwasser's. So kommt es durch die ermüdende, schwächende Arbeit dahin, daß der offizielle Regierungsbericht sagen konnte, es gebe gar keine Europäer, die so heruntergekommen und mager wären wie die Shilluks nach der Ackerbestellung zur Regenzeit. Dennoch muß diese ausgenützt werden, denn das Land der Shilluks, das von Oktober bis Dezember überschwemmt ist, trocknet nachher so rasch aus, daß bis zum April selbst alle Bäche ihr Wasser gänzlich verloren 
haben. Noch weiter südlich, im Gebiete des Bahr el Ghazal, finden sich ausgedehnte Sümpfe vor. Die Eingeborenen kennen ihre gefährliche Nachbarschaft und die der Inundations. gebiete. Sie bauen ihre Dörfer niemals nahe der Ufer, sondern wenigstens eine Meile landeinwärts daron. Vermutlich wollen sie dadurch auch den Moskitos einigermaßen entgehen. Aber der Malaria und den anderen Krankheiten, die die Regenzeit dort in furchtbarer Weise mit sich bringt, können sie doch nicht entfliehen. Die Eingeborenen leiden weniger als die Ägypter und Europäer unter der Malaria; aber rund $80^{\circ}$ o aller Erkrankungen im Gebiete des Bahr el Ghazal sind darauf zurückzuführen.

Recht wenig vorteilhaft für die Ausbreitung der Bodenproduktion sind auch die Transportverhältnisse. Überall drängt sich die Wüste oder die Steppe zwischen Kulturfläche und Absatzgebiet. Ihre Passierung auf Karawanenwegen ist entsetzlich mühsam und beschwerlich, und auch der Verkehr mittels Kamelen die erstaunlich lange ohne Wasser aushalten, findet in der totalen Wasserlosigkeit mancher Gegend seine Einschränkung. Selbst in der reichsten und blühendsten Provinz des Sudans, in Dongola, sind die guten Verbindungen nur am Nil und seinen Ufern zu finden. Die Abkürzung von Dongola nach Merove am rechten Nilufer führt schon 100 Meilen durch vollkommen wasserlose Wüste. Gegen so absoluten Wassermangel kämpfen auch die Eisenbalınen einen schweren Kampf. Die bisherige Hauptlinie der Sudanbahn, von $W$ âdi $\mathrm{Halfa}$ nach $\mathrm{Khartum}$, führt $925 \mathrm{~km}$ weit fast ausschließlich durch die Nubische Wüste und die in der trockenen Zeit kaum wasserreichere Bajûdasteppe. Jeder Güterzug muß daher 7000 Gallonen Wasser mitführen, was den Wert der Bahn stark herabsetzt.

Neben der Wasserlosigkeit erschweren im Sudan noch andere Gründe den Verkehr. Da sind glühende Luftwellen, die mitunter im Sommer bei heißem Wetter plötzlich auftreten und schon manche Karawane zwischen Korosko und $\mathrm{Abu} \mathrm{Hamed}$ vernichtet haben. Oder man hört ron fürchterlichen Staubstürmen, die namentlich im Distrikt von Suakin in den Monaten, die der Regenzeit vorausgehen, auftreten. Sie machen es unmöglich, auch nur meterweit vorauszublicken, der Wanderer verfehlt seinen Weg und geht elend zugrunde. Im Sommer 1891 ist eine Truppe Regierungskavallerie zwischen 
Tokar und Suakin von so einem Sturme überrascht worden und hat einen grofen Teil ihrer Leute und Tiere verloren.

Zur Regenzeit wird der Verkehr wieder auf andere Weise unterbunden: Der lehmige, schwere Borlen versumpft ganz und gar. Solche schwarze Erde unterbricht schon in Kordofan längs der Nilufer vielfach den leichteren Sandboden. Sobald der Regen auigehört hat und der Fluf fällt, trocknet der Boden aus tind wird rissig. Pfade, die einige Zeit hindurch benutzt werden, sind dann erst recht schlecht gangbax. In $\mathrm{B}$ ah $\mathrm{r}$ el Ghazal ist ein großer Teil des Landes während der Regensaison vom Mai oder Juni bis November überflutet und unpassierbar. Im Kimpfe gegen die Trockenheit ist das Kamel, das hauptsächlichste Transportmittel des Sudans, eine wichtige Hilfe; es versagt gänzlich gegenüber der Unwegsamkeit, die durch Nässe hervorgerufen wird. Nässe verträgt das Schiff der Wüste gar keine. Die Sudanesische Regierungspost hat eine Zeit hindurch auch während der Regenzeit Kamele verwendet, diese sind aber fast alle eingegangen. Nicht viel mehr Glück hatte man in Bahr el Ghazal mit Eseln und Maultieren. Die Ursache davon wurde in den schlechten Wegen und in giitigen Gräsern gesehen; man erzählt aher auch von einer Fliege, die der gewöhnlichen Pferdefliege ähnelt und Esel, Maultiere und Rinder angreift. Sie tritt am häufigsten in W a auf, und die gestochenen Tiere sollen in derselben Nacht erkranken und zugrunde gehen. Am Bongoflu \& hat Major G. R. Griffith eine Art Tsetsefliege (Glossina morsitans) entdeckt, die indessen nur den Tieren, nicht den Menschen gefährlich wird. Der Karawanenverkehr in Sudan wird ausschließlich durch Tragtiere bewerkstelligt; erst in der allerletzten Zeit hat die Regierung versucht, eine Art starker mit Ochsen bespannter Wagen ( rough carts"), nach den Vorbilde der in Ostafrika und speziell bei den Buren gebräuchlichen, einzuführen.

Die Morastbildung macht den Verkehr zeitweise gerade so unmöglich wie der allzu üppige Graswuchs während der Regenzeit. In Distrikt ron Gedaref im Zentralostsudan gibt es Stellen, wo das Gras 3-5 Fuß, mitunter bis zu 15 Fuß hoch den Boden bedeckt. Wird dieses Gras nachher von der' Tropensomne getrocknet, so ist es für WVanderer wie für Reiter gleich undurchdringlich. Mühsam gelangt man dann auf den Spuren vorwärts, die etwa ein Nilpferd oder eine Herde von Elefanten in dem 
Dickicht hinterlassen hat. Oder man legt Feuer an das trockene Gras, um den Weg frei zu bekommen und die wilden Tiere fernzuhalten. Diese Feuer sind schon mancher Kultur gefährlich geworden. Die Wälder des Bahr el Ghazal mit ihren Tamarinden, Rubiaceen, Euphorbiaceen 11 . a. m. wissen davon ebenso zu erzählen wie die Gummiakazien Kordofans. Der, mit Ausnahme der östlichen Grenzen sowie einiger Teile Südkordofans, des Bahr el Ghazal und Darfurs fast ganz fiache Sudan bietet deshalb wohl theoretisch, nicht aber in Wirklichkeit leichte Verkehrswege. Von seinen Flüssen ist der Nil nördlich von Khartum das ganze Jahr über schiffbar. die fünf Katarakte sind es nur zuzeiten. Der Blaue $\mathrm{N}$ il kann von Januar bis Juni nicht befahren werden, der Weike Nil, wohl bis Gondokoro in $\mathrm{Uganda}$ schiffbar, besitzt in den berüchtigten Pflanzenbarren des Oberlaufes ein gefährliches Schiffahrtshindernis. Diese Barren ziehen sich kilometerweit hin und reichen 10-15 Fuß unter die Oberfläche des Wassers hinab. Der Sobat und der Baro sind von Januar bis Mai für Dampfer nicht fahrbar.

Neben der Feuer-und Wassernot, neben so mancher Erschwerung des Verkehrs, welche die wirtschaftliche Entwicklung des Landes niederhält, gibt es dann noch andere Plagen für die sudanesische Bodenprodulition. Man kann sich als europäischer Landwirt gar nicht hineinfinden, wenn man von Viehverlusten hört, die im Oberlauf des Nils durch Krokodile verursacht werden, oder von den wilden Elefanten, die dort die Durrafelder zusammentreten. Das Vieh leidet auch durch eine Art Guinea wurm, der zwischen die Klauen eindringt. In Kordofan vernichten große Raupen, „Surffa“ genannt, mitunter das Getreide vollkommen, und was sie stehen lassen, wird oft von Heuschrecken heimgesucht. Hat man die Frucht, allen Gefahren und Erschwerungen zum Trotz, glücklich heimgebracht, dann ist sie wohl ein Wertobjekt für den eigenen Gebrauch und die Bedürfnisse der nächsten Umgebung. Aber was darüber hinaus erzeugt wird. hat nicht ständigen Handelswert wie in zivilisierten Ländern. Es fehlt an geregeltem Handelsverkehr, es fehlt an der Sicherheit, das Produkt jederzeit absetzen zu können. Die Entfernung des nächsten Marktortes wird durch die Beschwerlichkeit des Verkehrs vervielfacht, der Wert des Produktes unendlich rermindert. Im selben Maße verringert sich der Amreiz, über den eigenen Bedarf $\mathrm{zu}$ produzieren. 
Man sicht, dab es doch nicht gar so einfach ist, die Landwirtschaft in diesem Teile Afrikas zu erwecken. Sie findet ihre Feinde im Steppenklima des Nordens und im Tropenklima des siudens, und die natürlichen Voraussetzungen des Landes bieten der Pflanzenkultur wohl manche Aussicht, aber noch lange keine Sicherung. Dabei äußjert sich die gegenseitige Einwirkung von Bevölkerung und äußeren Bedingungen auf der primitiven Stufe des sudanesischen Ackerbaues ungleich stärker als bei höherer Kultur. Die Bodenproduktion unterliegt Einflüssen im weitesten Maßje, mit denen zivilisierte Länder gar nicht rechnen müssen. Wenn jetzt der Versuch gemacht werden soli, das ungeheuere Gebiet rom Standpunkte seiner landwirtschaft. lichen Eignung wenigstens oberflächlich zu charakterisieren, so wird uns diese besondere Wechselwirkung von Mensch und Land und Betrieb überall entgegentreten.

\section{Der nubische Teil des Sudans.}

Ackerban in Dongola. - Nomadenleben und „Wadi"-Bau in der Bajudasteppe. Die sogenannte "Nubische Wüste" und ihre Kulturstätten. - Anpflanzungen in Berber. - Im Distrikt von Suakin. - Die Provinz Kassala und die Landwirtschaft am Gashflusse.

Der nördliche, nubische Teil des anglo-ägyptischen Sudans, der von Wâdi Halfa bis zum Parallelkreise oberhalb Khartums reicht, steht durch Lage, Geschichte, Bevölkerung und Klima Oberägypten fast näher als den übrigen Gebieten des Sudans. Seine reichste, blühendste Provinz ist Dongola. Dieses hat wie alle Gebiete des Sudans seine Wüsten und seine fast wasser- und regetationslosen Steppen. Aber an den Ufern des Nils ist der Boden reich an fruchtbaren Sedimenten und bei genügender Bewässerung für alle Kulturpflanzen geeignet. Die Bewässerung wird durch den alljährlichen natürlichen Austritt des Nils herbeigeführt, nebenbei aber auch durch ein paar Tausend Sâkíjes ägyptischer Art und, wie der offizielle Bericht hervorhebt, durch eine zunehmende Anzahl von Shadûfs, denen sich 1904 sogar zwei Pumpen zligesellten. Da die Regenmengen dort ganz unzureichend sind, findet die Kultur gewöhnlich 200-300 m rom Flusse ihr Ende und erstreckt sich nur an wenigen Stellen bis zu drei englischen Meilen ins Land hinein. Gebaut wird Durra, Mais. Gerste, Weizen, Sesam. auch Baumwolle; daneben gibt es im Frühjahr 
und Herbst reichlich Melonen und Zitronen. Längs des Nils erblickt man Dattelpalmen in ziemlicher Anzahl, die im Oktober oder November, also früher als in Ägypten, Tunis oder Tripolis, reif werden und von glänzender Qualität sein sollen. Die Dumpalme, rereinzelte Tamarindenbäume finden sich gleichfalls ror. daneben Mimosen und die Suntakazie, deren Holz man zum Bau der Sâkîjes verwendet. Senna wächst viel und wird von den Arabern gesammelt und in Assuan auf den Markt gebracht. Dongola besitzt alle Vorbedingungen zu einer Bodenkultur im Stile Ägyptens : ein relativ gesundes Klima, das fast fieberfrei und nur ron Juni bis September etwas heiß und entnervend ist, breite Wrege auf beiden Seiten des Nils, die im Verein mit der Nilschiffahrt und einigen Karawanenwegen durch die Wüste, guten Verkehr ermöglichen; Dongola wird seit 1900 durch die Militärbahn von Halfa nach Khartum durchquert und besitzt schließlich eine seßhafte Bevölkerung von mehr als hunderttausend Berbern, neben etwa 2000 nomadisierenden Arabern und Bischarin (Nachkommen äthiopischer Urvölker). Die Berber oder Nubier haben wir als fleißige Ackerbauer bereits in Oberägypten kennen gelernt. Sie sind friedlich und gutmütig veranlagt, bewohnen in Dongola weit netter und sorgfältiger gebaute Häuser aus Schlamm und Steinen als die Fellahs Ägyptens, stehen ihren ägyptischen Berulsgenossen aber sonst in der Kunst des Ackerbaues stark nach. In bezug auf Bodenbearbeitung und Bodenbestellung hätten sie von diesen viel zu lernen. Die Erträge sind deshalb trotz aller guten Vorbedingungen recht geringe, wogegen allerdings der größte Teil des Bodens drei Ernten im Jahre trägt, meistens zwei Ernten Durra und eine Ernte Weizen oder Gerste. Der Verlauf ist folgender:

$\begin{array}{ccc}\text { Anbauzeit } & \text { Anzahl der } & \text { Ertrag auf gutem } \\ \text { Ernten in Jahr Lasd pro Hektar }\end{array}$

Durra

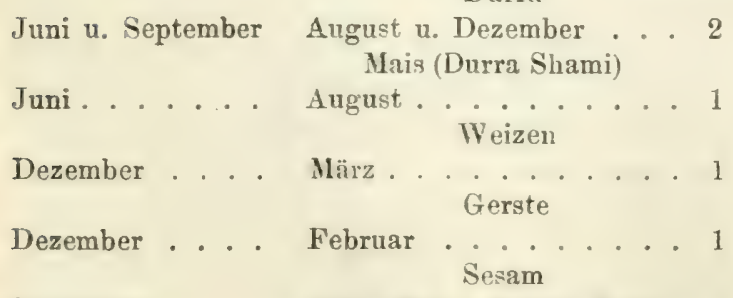

September.... Ende Oktbr., Anfang Novbr. 1

$9-12 \mathrm{Me}$

8-9 Mic 
In den weiten Gehieten abseits des Nils gibt es anch in den reichen Dongola fist keine Vegetation. Westlich vom Flusse zwischen $\mathrm{Halfa}$ und $\mathrm{Kerma}$ zicht sich die Wüste bis an die Ufer heran. Nur hier und da in irgendemem Winkel, wo sich gerade ein wenig Wasser nach einen der seltenen Regen angesammelt hat, findet sich vielleicht einmal spärliches Cirün vor. Meistens aber zieht der Frühling übers Land, ohne auch nur cine Spur tierischen oder pflanzlichen Lehens zu bringen. Selbst die wenigen Oasen sind unbewohnt und werden nur hier und da vou umherschweifenden $\mathrm{Haw}$ awir- oder $\mathrm{Ka}$ babish-Arabern auf der Suche nach Natron oder wilden Datteln berührt, oder von Bedaiat-Arabern, die nürulich ron Darfur leben und ihre Kamelherden bis hierher treiben. Die Kamele finden ja überall genügend Nahrung, wo üherhaupt noch ctwas wächst, und die trockenen Gebiete gelten sogar als besonder's geeignet für die Zucht leistungsfähiger und genügsamer Tiere. Die Bajûdrsteppe, berühmt durch ihre leichten und schmellen Kamele, bietet diesen kaum mehr als hier und da junge Zweige rom "Samr", die sukkulenten Blätter des Marakhdorubusches und das Kamelgras „el ga u“. Wenn die alljährlich nicht gleichen Regenmengen einmal stärker ausfallen, hauen die nomadisierenden Araber der Bajûdasteppe, besonders in den südlicheren, regenreicheren Distrikten, wohl einmal Durra in die .Wadis". "Wadis" nennt man die mehr oder minder sichtharen Vertiefungen, die der Regen in den Boden gewascheis hat. ausgetrocknete Wasserläufe, in denen immerhin noch mehr Feuchtigkeit zurückgeblieben ist als in dem umliegenden Erdreich. Diese "Wadis" spielen in der Bodenproduktion des Sudans eine gewichtige Rolle. Sie sind nicht blok die Kulturstätten aller Gegenden, die nicht an einem Flusse liegen und lieinen genügenden Regenfall haben, sondern auch die Standorte der besten natürlichen Weiden. Das tritt uns gleich in der sogenannten ..Atbai" recht anschaulich entgegen. Diese ron nomadisierenden Bisharin und Amarar-u. a. Arabern bewohnte Gegend wird auf den meisten Karten als .Nubische Wüste" bezeichnet. Obwohl sie namentlich im südlichen Teile noch wenig erforscht ist, läßt sich heute doch schon sagen, daß man die Bezeichnung Wüste nicht auf das ganze Gebiet anwenden kann. Es gibt zwischen dem Nil und dem Roten Meer eine Ḿenge von Hügeln, denen eine Anzahl von Flüssen und Bächen 
ihren Ursprung rerdanken. Die sonst so spärliche Tegetation erreicht in den. "Wadis" aller dieser Gewässer nach gutem Regen außerordentliche Fülle. Die sind freilich unsicher; man kann niemals darauf rechnen, an einer Stelle wieder Weide anzutreffen. wo solche im Vorjahr prächtig gediehen ist. Immerhin läßt sich doch roraussetzen, daß Schafen, Kamelen, Schafen, Ziegen in irgendwelchen tiefen Stellen des Gebietes alljährlich gute Nahrung gehoten sein wird. Der größte Fluß der Ost. Atbai, der Di-ib, bildet ein weites Bassin, ein Meile breit und 8-10 Meilen lang; das nach dem Verschwinden des Wassers der Bodenkultur reiche, alluviale Böden zur Verfügung hält. Die Araber bauen dort alljählich an rerschiedenen Stellen ihre Durra und gewinnen gute Erträge.

In der Provinz Berber ist die Kultur auf die Ufer des Nils beschränkt. Sie spielt sich ähnlich wie in Dongola $a b$, mit dem Berber die meisten Yoraussetzungen, Klima, Art der Bevölkerung, sogar die Lage an der Halfa-Khartum-Bahn gemeinsam hat. Die Nilufer in der Berberprovinz zwischen A bu Hamed und der Einmündung des Atbara in den Nil zeigen bis nun weniger häufig Anpflanzungen als Dongola; die Datteln sollen auch in Berber qualitativ minder sein. Dafür erzählt man von höheren Durchschnittserträgen als in der anderen Provinz. Als Durchschnittserträge Berbers werden angegeben:

$\begin{array}{lrr}\text { Gerste pro Hektar } & 12-13 & \mathrm{Mc}, \\ \text { Weizen " } & 10-11 & \\ \text { Durra } & . & 16\end{array}$

Die sebhaften Berber rerstehen es, mit der Bodenproduktion noch ein weiteres Gewerbe zu rerknüpfen. Sie verarbeiten das Stroh der Dumpalme zu Matten. Sandalen. Mützen u. dgl. und treiben ganz schwunghaften Handel damit. Die Wüste im Norden von Berber gilt als gute Kamelzuchtgegend.

Von der Stadt gleichen Namens, von Berber aus führt ein $2+2$ englische Meilen langer. Wüstenweg nach Suakin. Der Weg passiert unmittelbar nach dem Verlassen von Berber eine riesige Ebene mit anscheinend sehr fruchtbarem Boden. Man wäre versucht, zu glauben, daf sich hier zwischen Nil und Atbara durch Bewässerung enorme Kulturstrecken gewinien ließen. Der Distrikt von Suakin hat den Hauptsitz seiner landwirtsehaftlichen $\mathrm{Zu}$ kunft zweifelsohne in der Ebene ron Tokar. Am Barakaflub gelegen ist ihr reicher Boden für Bammolle ebenso geeignet wie 
für alle anderen Kulturpflanzen. Vorläufig läßt die Regelmäbigkeit des Ackerbaues noch zu wünschen übrig; denn die natürliche C̈bertlutung durch den $\mathrm{B}$ a ra ka tritt alljührlich in sehr ungleichem und oft ganz unzureichendem Maße auf. 1904 wurden 742:) Feddán mit Baumwolle bepflanzt und davon 29039 Kantars geerntet. Im Distrikt ron Suakin ist wohl die seßhafte Bevölkerung wegen der Unsicherheit der Jahresernten nicht zahlreich, dafür blüht das Nomadentum mit allen seinen Auswüchsen dort noch sehr. 1904 hat man die sekhaften Einwohner mitsamt denen der Hafenstadt nur auf 14000 geschätzt, die nomadisierenden Araber dagegen auf mehr als 50000 Köpfe. Die sind ununterbrochen das ganze Jahr über unterwegs, nur dort rorübergehend haltmachend, wo es gerade geregnet hat oder gute Weide sich vorfindet. Die nonadisierenden Araber von Suakin, deren Hauptstämme die Am a rar und die $\mathrm{H}$ a de ndoa sind, wohnen in zeltartigen Hütten aus Strohmatten, die über gekrümmte Baumzweige gebreitei werden. Soll der Marsch weiter gehen, dann werden Zelte, Weiber, Kinder und die wenigen Habseligkeiten rasch auf die vorhandenen Kamele und Esel geladen, Rinder, Schafe, Ziegen vorausgetrieben, während die übrige Karawane nachfolgt. Diese Nomaden unternehmen übrigens, durch die Nähe der Meeresküste begünstigt, noch immer von Zeit zu Zeit Sklavenjagden und sind deshalb eine rechte Plage für Bevölkerung und Regierung.

Die Provinz $\mathrm{Kas}$ sala besitzt im $G$ a shil $u$ G einen wichtigen Kulturfaktor. Er bringt alljährlich zur Zeit der Hochflut aus seinem Ursprungsland Abyssinien befruchtenden Schlamm mit, und wenn die Flut so um den Anfang des Juli herum die Hauptstadt Kassala erreicht hat, wimmelt es in seinem Bette von Fischen, die von den Bewohnern leicht gefangen werden. Die Bewohner der Stadt Kassala, unter denen die HalengaAraber vorherrschen, gelten als treffliche Ackerbauer. In der Stadtnähe wird mit Hilfe des Gashflusses ein treffliche weibe Durraqualität gebaut. Nan nennt sie .Taulib" und schätzt sie der besten Nildurra gleich. In guten Regenjahren kann man manchmal daran denken, noch eine zweite Einte (N aggad genannt) mit Hilfe der natürlichen Niederschläge zu gewinnen, die dann Ende Oktober reif wird. Das Getreide wird ron Schwärmen kleiner Vügel und ron Heuschrecken devastiert; es leidet auch stark unter einer besonderen Art von Brand, dem ..El Asal *. im Gordon College zu Khartum als "Aphis Sorghi" bezeichnet. 
Die Art, wie der Fluß zur Bewässtrung herangezogen wird, ist noch sehr primitiv und wenig ökonomisch. Sâkîjes und bessere Bewässerung durch Brunnen weisen zahlreiche Gärten der Stadt auf. Oberhalb der Stadt Kassala deuten üppiger Graswuchs an den Ufern des Gash und eime ununterbrochene Reihe von Dumpalmen auf reiche Fruchtbarkeit hin. Aber dort gibt es gerade so wenig ständige Bevölkerung als südlich der Stadt, in der flachen wasserlosen Ebene. Und auch die Ufer des A tha ra und seiner Nebenflüsse, des Bahr el Salam, des Angareb und des Setit, sind fast gänzlich unbewohnt.

Die Flubufer besitzen vielfach ausgezeichneten Baumwollbocien; dieser wird aber während der Regen morastig und gänzlich unpassierbar. Nachher macht auch hier dichter, hoher Graswuchs die Gegend unzugänglich. Dem Persuche, den natürlichen Austritt der Flüsse zu regeln, irgendein Bewässerungssysten einzuführen, begegnet man nirgends und iolglich kaum hier und da den Anfängen einer Bodenbestellung.

Nur während der trockenen Zeit erwacht das Leben an den Ufern. Am Gashflub suchen dann Tausende Stück Rinder und Schafe der Beni-Amer- und der Baria-Araber ihre Nahrung, an den übrigen Flüssen die der Hadendoa-Araber, der Bisharin und anderer. Am Setit gibt es eine kleine Niederlassung der Ha mranAraber: die aber keinen Ackerbau treiben und von der Jagd leben. Sie gelten als aukerordentlich kühne Jäger und henützen weder Flinte noch Bogen, sondern eine Art Wursspeer. Die Ufer des Bahr el Salam und des Angareb werden sich wohl nicht leicht kultivieren lassen. Dort wechseln ielsige Klippen mit tiefen Sümpfen ab, in denen zahlreiche Krokodile und Nilpferde hausen. Der Atbara und der Setit haben ihr Bett stellenweise bis zu $150 \mathrm{Gu} 3$ tier sie durchfließen, und die Uferränder weggeschwemmt und in tiefe Klüfte gespalten. Auch da gibt es demnach Kulturhindernisse aller Art.

\section{Der zentrale Ostsudan.}

Die Landschaft Sennar und ihre Kulturadern, der W eiße und der Blave Nil. - Bei len Dinkas. - Jaumwollbau am Dinder. - Flüchtiges Leben in der Ebene von „Ei Butana". - Die Gärten von Gedaref. - Merkwürdiger Ackerbau bei den Takruri-Negern.

Es ist kein Zufall, daß der zentrale Ostsudan von alters her die Hauptstädte mächtiger Reiche beherbergt hat. Dort liegt 
Shendi, die einstige Residenz der Königin von Saba, die Ilaupt. stadt des alten Königreiches von Meroe, dort Khartum, dir Kapitale des früheren ägyptischen und des jetzigen englischägyptischen Sudans; kaum drei Meilen davon entfernt Ondurman, die Hauptstadt des Mahdistenreiches. Dieser Teil des zentralen Sudaus hat eben schon stärkeren Regenfall und üherdies am meisten Wasserläufe rom ganzen Sudan aufzuweisen: den Weiben Nil, die Hauptlebensader des Landes, und dessen Nebenfluf den Blauen Nil, in den wieder Dinder und Rahad ihren Weg finden. Der Weiße und der Blaue Nil umschließen die Provinz Sennar, im engeren Sinne auch Dschesiret oder Gezira, d. h. Insel genannt. Sie reicht von dem Vereinigungspunkte der beiden Flüsse, von $\mathrm{Khartum}$ bis Fazogli, und bildet das fruchtbarste und engbevölkertste Gebiet des Reiches. In der Nähe von Khartum ist der Boden dieser riesigen Alluvialebene noch sandig; er wird aber reicher und reicher, je weiter südwärts man fortschreitet. Die Kulturentwicklung ist freilich nicht in gleicher Richtung gefolgt. Seßhafte Stämme gibt es zwar äberall an den Ufern des Weißen und des Blauen Nil. aber gerade der nördliche, von Natur aus ärmere Teil besitzt dichtere Bevölkerung, eine höhere Kulturstufe. Namentlich am Blauen Nil sieht man bis zum Orte Sennar vielfach Uferkulturen, die mittels Sâkîjes bewässert werden. Von dort ziehen sich die Dörfer und Ansiedelungen bis an den Weißen Nil hinüber, und die Durrafelder erstrecken sich in ununterbrochener Folge meilenweit längs der Flußufer. Nach und nach gegen Süden zu wird die Kultur dann geringer, und die Einwohner nehmen trotz des reichen Bodens selbst an den Ufern an Zahl ab. Das Innere des Distriktes wird im Norden noch von Halbnomaden bewohnt. die während der Regenzeit im Innern weiden oder ihre Durra bauen. In der trockenen Zeit ziehen sie zu den Flüssen, wo sie dann geeignete Tränke und Weide für ihre Herden finden, und der zurücktretende Nil läßt den Boden in einem Zustand zurück. der zur Ackerbestellung geeignet ist.

Der südliche Teil ist nahezu unbewohnt. Der Wassermangel der trockenen Zeit, der schwammige, ungangbare Boden der Regenperiode begründen das zur Genüge. Dabei wird das Dorngebüsch an den Ufern immer dichter und undurchdringlicher. Noch weiter südlich verdrängen Wälder mit hohen Tamarinden, Dumpalmen, Sykomoren, baumartigen Euphorbien und allen 
möglichen Akazienarten das niedere Dschungel. Die Wäldel werden streckenweise durch ausgedehnte Marschen unterbrochen. die in der trockenen Zeit ausgezeichnete Weiden abgeben. Das Gras erreicht dort eine Höhe von 8-10 Fuß. Die Eingeborenen haben eine Art Weidekultur eingeführt. Sie besteht darin. daß das trockene Gras verbrannt wird, um dem kommenden Platz zu schaffen.

Im Senna r wird viel Baumwolle gepflanzt. Am Weißen Nil bei Khartum legt man den Samen im Juli, wenn der Nil schon stärker gestiegen ist, und kann dreimal pflücken, bevor dieser im Februar seinen niederen Wasserstand erreicht hat. Sesam wird zum eigenen Bedarf gebaut, im Norden mit Hilfe von Shadûf- oder Sâkîjebewässerung. Auch Weizen kultiviert man so und sät ihn im November, um ihn nach drei Monaten zu ernten. Die Durchschnittserträge werden mit 5 ardeb pro Feddán (16 Mc pro Hektar) angegeben. Die Hauptfrucht des Semnar bleibt indessen die Durra, von der die Sorte "Feterita" gebaut wird. Die Eingeborenen rechnen mit $96-360$ fältigem Ertrage des Saatquantums, das indessen sehr gering bemessen sein míb, da die Erträge nur 3 ardeb pro Feddán (I1) Mc pro Hektar) betragen sollen.

Der Norden von Senmar beherbergt ein rechtes Tïlkergemisch: Araber, Neger, Nubier. Der Süden dagegen bleibt die Domäne der eingeborenen Negerstämme, deren niedrige Kulturstufe und mitunter merkwürdige Gebräuche auch dem Ackerbau und der Vichzucht das Gepräge verleihen. Am Weißen Nil von Jebelein südlich wohnen die Dinkas. Sie sind wenig intelligent und ganz besonders unzugänglich für jede Neuerung. So konnten sie lange Zeit nicht dazu gebracht werden, sich zum Transporte der Lasttiere zu bedienen, und das nur deshalb, weil ihre Vorfahren keine benutzt hatten. Sie fanden, daß ihre bisherigen einzigen Transporttiere, ihre Weiber. die Lasten ganz gut weiter wie bisher auf den Köpfen fortschaffen könnten. Die männlichen Dinkas gehen, mit Ausnahme einiger älterer Leute, die in Kairo als Sklaven gedient haben und unter der jetzigen Regierung repatriiert wurden, splitternackt. Dafür sind sie stets speerbewaffinet und tragen das Haar, mit rotem Schlamme pomadisiert, in höchst kunstvollen phantastischen Frisuren. Als Lager dient dem Dinka die Asche des Kuhdüngers, dessen reichliche Spuren der Körper auch am Tage zeigt. Die 
verheirateten Weiber binden vorn und hinten einen Lederschur\% um, die Mädchen begnügen sich mit einem Gürtel aus Glasperlen. Die eigentümlichen Sitten bei den Dinkas sind der Viehzucht günstig. Sie behandeln die Tiere gut, weil sie manchem wertvollen Stücke ihrer Herde denselhen Einfluf auf ihr Schicksal zutrauen als dem Geiste irgendeines rerstorbenen großen Schêchs. Sie schützen das Vieh aber auch, das ihnen die einzige Form des Reichtums darstellt, den einzigen Kaufpreis ihrer Weiber. Und Moral und Unmoral und alle die heiligen Güter der Hausehre finden bei den Dinkas ihre Umwertung in Form von Rindern. Ist die junge Frau vor der Hochzeit verführt worden. dann kann der Mann sie heimschicken oder behalten. Entscheidet er sich für das erste, dam erhält er vom Vater das als Kaufpreis gezahlte Vieh zurück, das der Verführer dem schwergekränkten Vaterherzen ersetzen muk. Behält der Mann aber die Frau trotz ihres Makels, dann mub der Verführer ihm den Kaufpreis, natürlich wieder in Vieh, zurückerstatten. Für Geschlechtskrankheiten macht man ausschiließlich den Verkehr unter Blutsverwandten verantwortlich. Läßt sich ein schuldtragender Verwandter nicht ermitteln. dann müssen alle männlichen Familienmitglieder, die überhaupt in Verdacht kommen können, dem Vater Strafen in Form ron Vieh erlegen. Der Begriff ier Blutsrerwandtschaft wird weit genommen. Selbst unter entfernt Verwandten ist daher die Ehe rerboten. Dafür darf der Dinka alle Witwen seines Vaters, die eigene Mutter ausgenommen, heiraten. In welchem Ausmaße er ron dieser Erlaubnis Gebrauch macht, ist mir nicht bekannt; aber jedenfalls hat der Dinka volle Ursache, das Vieh zu schätzen und $\mathrm{zu}$ vermehren, das ihm über so viele Schwierigkeiten des Daseins hinweghilft.

Die 8000 Dinkas, die am Weißen Nil leben sollen. wurden 1904 auf einen Herdenbesitz von 8000 Rindern, 16000 schafen und 13000 Ziegen geschätzt. Wenn von Rindern im Sudan die Rede ist, so handelt es sich dabei stets un das Zebu, das Buckelrind ( $B$ os Indicus). Daron sieht man ganz stattliche Exemplare, Tiere. die kräftiger, besser gebaut als die ägyptischen Rinder erscheinen. Einen eigentümlichen Typus besitzen die sudanesischen Schafe. Sie haben lang hinabhängende Ohren, keine Wolle, sondern Haare und ähneln Ziegen mehr, demn den uns bekannten Schafarten. Andere, ägyptische Rassen, sind mir nur vereinzelt in der Nähe von $\mathrm{Kh}$ a $\mathrm{r} u \mathrm{~m}$ und $\mathrm{Omdurm}$ a begegnet. 
Während der trockenen Zeit treiben die Dinkas ihre Herden auf die ausgedehnten Weiden. die jetzt die Marschen bieten. Beginnt die Regenzeit, dann rerläßt der größte Teil wieder die Ufer und baut 20 oder 30 Meilen weiter landeinwärts seine Durra. Selten wird mehr als zum eigenen Bedarf nötig gewonnen. Nur dann und wann bringen dic Weiber kleine Quantitäten zu Markt.

Von den beiden kleineren Flüssen kommt dem Dinder die größere Bedeutung in landwirtschaftlicher Beziehung zu. Künstliche Bewässerung wird an keinem der beiden versucht; man legnügt sich damit, die überschwemmten Flußufer zur Regenzeit zu bebauen. Am Dinder wird auf diese Weise sogar Baumwolle gepfianzt. Im Juli, wenn die ersten Regen eingetreten sind, legt man die Kerne aus, vier Monate danach wird zum ersten Male gepflückt. Gewöhnlich nimmt man drei Pflückungen vor, wovon die letzte das schlechteste Resultat ergibt, da die Pflanzen einstreilen unter der eingetretenen Dürre gelitten haben. In guten Jahren ergibt ein Acker Land 400-1000 Pfund rohe, von den Samen nicht getrennte Baumwolle. Ihre Faser ist nie so fein als solche von Baumwolle, die mit künstlicher, wohl verteilter Bewässerung gewonnen wurde. Am Dinder wird eine Sorte „Mumtanz" gebaut. Sie ist von Mumtanz Pascha zur Zeit des alten, vormahdistischen Reiches aus Ägypten eingeführt worden. Die Pflanze ist einjährig. während die am Blauen Nil sonst am meisten gebauten einheimischen Sorten, "Abu Hareira" und „Belwa". angeblich drei Jahre ausdauern sollen.

Reicher Boden und stärkerer Regenfall eröffnen im Osten des Blauen Nil auch abseits der Flüsse manche Nahrungsquelle. Zwischen dem Blauen $\mathrm{Nil}$ und dem Atbara sieht man in der erstaunlich flachen Ebene von „El Butana" zwar meilenweit weder Baum noch Strauch außerhalb der W adis, aber zur Zeit der Regen sprieft in der El Butana vorzügliches Hantutgras, das mit den Sihapflanzen die Kamelzüchter aus allen möglichen Teilen des Sudans heranlockt. Ein oder zwei Wochen nach dem Aufhören der Regen wird das üppige Gras freilich hart und zäh, und hald liegt das Land wieder kahl und rerödet da. Der Distrikt ron Gedar ef zeigt gleiche Zeichen von Kulturmöglichkeit, wird aber bisher nur in der Nähe des gleichnamigen Ortes bebaut. Dort gibt es eine Menge sorgfältig gepflegter Gärten mit Gemüsen, Feigen, Limonen, Flaschenbäumen (custard apples genannt) und Datteln. Diese geben dort zwei Ernten im Jahr. Auf den um- 
liegenden Gründen wird einmal im Jahre, zur Regenzeit. Durra gebaut, dam Hirse, Sesam, auch Baumwolle für den örtlichen Konsum. Gedaref besitzt eine besondere Art ron Durra, ..Kurgi" genannt, die sehr weißes Mehl liefert.

In der Nähe der Stadt finden sich, eine Seitenheit im Sudan. einige Bäche ror, die das ganze Jahr über Wasser führen. Der übrige Teil des Distriktes ist freilich mit seinem Wasserbedarf an Brunnen gewiesen. Den Bewohnern kommt die gute Verbindung mit dei benachbarten abyssinischen Grenze und der dadurch erleichterte Absatz der Produkte zugute. Es sind Takruris, aus Darfur stammende Neger. Diese armen, aber fleißigen Menschen haben eine äuberst originelle Art der Ackerbestellung ersonnen. Die eigenartige Kultur wird hauptsächlich etwa 15 Meilen nordwestlich von der Stadt Gallabat betrieben, wo eine Menge Dörfer liegen. Während das trockene hohe Gras sonst überall im November oder Dezember verbrannt wird, lassen die Takr u r is es gerade an den Stellen bis zum Eintritt der nächstfolgenden Regenperiode stehen, die für den Ackerbau bestimmt sind. Dann wird der Boden nicht etwa umgestochen, sondern das junge, aursprießende Gras mit dem dürren zusammen rerbrannt. Auf dem so gereinigten und mit der Asche des verbrannten Grases gut gedüngten Boden erfolgt die Aussat. Neben Durra und Hirse wird selbst Baumwolle in der gleichen Treise gepflanzt.

\section{Kordofan und Darfur.}

Das Erbe des Mahdi. - Kordofan und seine Landwirtschaft. - Sesamölund Gummigewinnung. - Eigentümlicher Wasserhaushalt. - Ackerbau mit Hindernissen bei den Nubas. - Die Shilluks. - Das Sultanat ron Darfur.

Kordofan ist bis zu seiner Wiederbesetzung durch die englisch-ägyptischen Truppen im Dezember 1899 der Mittelpunkt der Herrschaft des Mahdis und seines Nachfolgers gewesen. Bei diesen war Herrschen und Vernichten gleichbedeutend, und so wurde das arme $\mathrm{K}$ ord of $\mathrm{n}$ in seiner naturgemäßen Entwicklung recht weit zurückgeschraubt. Kein einziger größerer Ort hat die böse Zeit überstanden. An der alten Straße ron Tur a nach del' Hauptstadt El Obeid blieb kein Brunnen unzerstört, und die zahlreichen Shad̂ffs und Sâkîjes in dem ehemals blühenden Distrikt von $\mathrm{Dar} \mathrm{Ham}$ id sind zerfallen. Jetzt erst wagt sich die Kultur schüchtern wieder ans Tageslicht, und die seßhafte wie die nomadisierende Bevölkerung besinnt sich so mancher Erwerbs- 
gelegenheit, die ihr das Land bietet. Dieses ist eine ausgedehnte, rund $250000 \mathrm{qkm}$ weite und von Hügelgruppen unterbrochene Ebene. Die Hügel erheben sich selten mehr als 6--800 Fuß über die Meeresfläche.

Im Norden wird die Ebene durch zahlreiche Wasseradern belebt. Im Mittelkordofan werden sie seltener und verflachen. bis der Regen schließlich keine sichtbaren Sammelkanäle mehr findet und versickert, wo er gerade fällt.

Die Wadis heben sich scharf durch ihre üppige Vegetation von der Umgebung ab. Sonst trägt der Norden auf seinem rötlichen Sandhoden zur Zeit der Regen reichlichen Graswuchs, bei genügenden Niederschlägen selbst gute Ernten von Hirse. Es gibt aber auch Jahre mit geringen Regenmenger, in denen nicht einmal die Vegetation der Wadis zur Weide für das anspruchslose Dromedal genügt und die Brunnen im Lande versiegen.

An den Ufern des Weiben Nils ersetzt an mancher Stelle schwarze, reiche Erde den Sandboden. Dort schiebt das Grün üppig in die Höhe, und dichtes Buschwerk findet sich ror. Hat weiter nördlich zwischen El Obeid und dem Flusse die graue Gummiakazie unter den Bäumen vorgeherrscht, so ist hier die große rote Suntmimose zu Hause.

Südlich vom 13. Breitengrad gibt es mehr Regen und tiefe Wasserläufe mit steilen Uferm. In der waldigen Gegend der Nubaberge ist das Dschungel der Schlupfwinkel von allerlei Wild, Giraffen, Antilopen Affen, Elefanten und auch zahlreichen Schlangen.

Dongola beherbergt Araber in der Ebene, die Nubas in den Bergen. Die Araber treiben als seßhafte Dorfbewohner Ackerbau oder ziehen als Nomaden mit ihren Herden umher. Im Norden von El Obeid sind diese alle Kamelbesitzer, Siat el Ilbil, im Süden Baggara, d. h. Vieh- und Pferdeeigner. Die sekhaften Araber bauen in der Nähe der Flüsse, auf den Flußinseln oder in feuchteren Niederungen Durra, Bohnen, Zwiebeln. Hirse, auch etwas Baumwolle. Sie besitzen kleine Herden ron Schafen, Ziegen, einige Esel und Buckelrinder, hier und da ein Kamel.

Vor dem Beginne der Regenzeit, im Mai, wird der Boden von der Grasnarbe befreit. Dann macht man mit einem Stabe Löcher in die Erde und streut die Körner hinein. Sobald der Regen begonnen hat, geht das Getreide auf. Ende Oktober oder Anfang 
November ist die Ernte. Die Hirse ron Kortofan, des geringen Wasserhedarfes halber die Hauptfrucht der trockenen (xegemien. wird wegen ihrer guten Qualität gerühnt. Die Araher verspeisen sie zu flachen Kuchen (.Kisra") rerbacken oder gekocht als "Asida", verstehen auch ein luerauschendes Getränk, Merisial oder .. C'n Bilbil" genannt, daraus zu bereiten.

In den wasserreichen Gegenden südlich won El Obeid nimmı Durra die Stelle der Hirse ein. Sie gilt ebensor zu. bereitet als das schmackhaftere Nahungsmittel. dem aber geringerer Nähwert zugeschriehen wird. An das Vich rerfüttert man Durra lieber als Ifirse. da diese als zu hitziges Futier angesehen wird.

Sesam. in kleineren (Quantitäten überal gel)ant, wird meist gleich an Ort und Stelle zu Öl gepreßst. Man rerarbeitet den Sameu in prinitiven, aus dem ausgehöhlten stamme einer Suntakazie hergestellten Mühlen. An Stöliel ist ein langer Seitenarm angebracht, den ein Kamel oder pin Rind im Treise herumbewegt. Das Öl dient zum Kochen und zum Salben der Haare, der Rückstand als Viehfutter.

Im Usten Kordofans wird aus der gramen frmmiakazie. Hashab genannt, viel Gummi gewonnen und gegen Durra oder Baumwolle ausgetauscht. Es gilut dort wohlgepflegte Gummigärten. wo das Gras und die abgestorbenen Äste sorgfältig entfernt werden. Im Januar macht man Schnitte in die Rinde. aus denen dann das Gummi, bekauntlich die Wundreaktion des Gummibaumes, bei Beginn der heißen Witterung und des Saftsteigens rinnt. Das Gartengummi. .Geneina *, wird alle paar Tage gesammelt und auf dem Markte weit höher hezahit als das minderwertigere Gummi der wild wachsenden Bäume. Die ausgedehnten IVälder von roten Gummiakazien in Süden exploitiert man bisher nicht, da ihr Produkt geringen Wert besitzt.

Seßhaftigkeit und regelmäßiger Ackerbau sind ohne andauernde Wasservorräte nicht möglich. In Gegenden, wn die Brunnen oft nach den Regen versiegen, hat die Bevölkerung Mittel gefunden, um sich und das Vieh über die trockene Zeit besser hinweg. zubringen. Bei vielen Dörfern sieht man künstliche Teiche. die durch Absperren eines kleinen Baches gebildet wurden. Ihr Wasser hält freilich selten länger als bis Ende Oktober an. Interessant ist der Wasserhaushalt, den die Eingeborenen mit Hilfe der Tebeldibäume (Adansonia digitata) treiben. Diese. 
von Natur aus hohl, werden überdies noch künstlich ausgehöhlt, wenn sie zur Aufspeicherung von Regenwasser dienen sollen. Oben schneidet man eine Öfinung in den Stamm, die gewöhnlich so über einem starken Ast angebracht wird, daß ein Mann darauf bequem stehen kann, wenn er Wasser schöpft. Um den Stamm herum wird der Boden zu einem kleinen Becken vertieft, in dem sich während der Regen das Wasser ansammelt. Manche oben offene, alte Bäume mit Ästen, die als Rinnen dienen können, fïllen sich zu der Zeit ron selher, die anderen werden mittels Eimern aus dem Sammelbecken gefüllt.

Die Tebeldibäume besitzen oft einen Umfang von $7-8 \mathrm{~m}$. Das Wasser in ihrem Innern wird bis $\mathrm{zu} 7 \mathrm{~m}$ hoch aufgespeichert und soll die heiße Zeit gut und frisch überdauern. Man kann sich denken, welchen wertrollen Besitz ein guter Tebeldibaum darstellt.

Sehr wichtig für den Wasserhaushalt sind auch die fast geschmacklosen, kleinen Melonen. Ganze Dörfer, Menschen und Tiere hängen von ihnen $\mathrm{ab}$, die in der trockenen Zeit oft die einzige Wasserquelle bilden. Die Eingeborenen bauen sie an und bewahren die Ernte in Haufen für die trockene Zeit auf. Die Schalen werden nicht weggeworfen, sondern an die Ziegen verfüttert, wenn das Gras verdorrt ist.

Im Gegensatz zu den nördlichen trockeneren Gegenden, wo der Ackerbau außerhalb des Nils von der wechselnden Stärke der jährlichen Regen abhängig und oft nur in geringem Ausmaße möglich ist, erzielen die $\mathrm{Nubas}$ im Süden alljährlich reichliche Ernten. Die Nubas sind Schwarze mit wolligem Haar und leben in den Nubabergen, in einer Zone ausreichenden Regens. Sie sind die einzigen Bewohner Kordofans, die der Okkupation durch die Derwische erfolgreich widerstehen konnten, indem sie ihre schwer zugänglichen Wohnsitze mit festen Wällen umgaben. Die $\mathrm{Nubas}$ sind in früheren Zeiten von arabischen Sklaren. jägern viel verfolgt worden und haben deshalb beizeiten sich $\mathrm{zu}$ verteidigen gelernt. Der Regierungsbericht schildert sie im übrigen als große, faule Kinder, die unausgesetzte Aufsicht brauchen würden, um dagegen geschützt zu sein, daß die Araber ihre Dummheit und Leichtgläubigkeit nicht ausnutzen. Sie bewohnen an manchen Plätzen Schlammhäuser mit flachen Dächern, meist aber Strohhütten oder rechteckige Hütten aus Holzstecken, mit Gras oder Schilf überdeckt, die "Rakubas" genannt werden. 
Iie Nubas hesitzen viel Vieh, namentlich Schafe und Ziesen. Die Mämor gehen unbekleidet, aher immer mit. Specen bewaffnet. iVer ein Gewehr hesitzt, trägt es ununterbrochen zur Schau, auch wenn die Munition dazu fehlt. Die vorheirateten Weiber kleiclen sich in Fellschürzen oder Baumwolle, die ledigen begnügen sich mit einem sorgfältig geflochtenen Haarschopl, cinem Perlengürtel oder einer Schürze aus den Blättern der Dumpalme.

Diese sudanesischen Agrarier hauen in der ungemein fruchtbaren Ehene rings um ihre Berge hauptsächlich Durra. Dem Überfluf3. den ihmen die gütige Natur schenkt. wissen sie dadurch zu begegnen. dabs sie aus der Durra grobe Mengen von "Merissa“, dem einheimischen Biure. herstellen und dieses in übermäßiger Weise genieken. Ihre Furcht ror der Sklaverei mag heute, unter dem neuen Regime, vielfach übertrieben sein, findet aber bei der Ackerbestellung cinen merkwürdigen Ausdruck. Sie lassen nämlich bei der Klärung der Felder die Baumstumpfen hier und da $1 / 2-1$ m hoch stehen und machen danehen Fallgruben in den Boden, an deren Basis spitze Plähle angebracht werden. $W^{\top}$ em zur Erntczeit berittene Araber auf Sklavenraub ausgehen, damn stolpern vie Pferde über die in der hohen Durra verborgenen Hindernisse und bringen den Reiter mit zu Fall. Der $\mathrm{Nuba}$ gewinnt unterdessen Zeit, in seine Berge zu entkommen.

Im Süden von Kordofan wohnen, längs des westlichen Nilufers, zwischen Kaka und dem No-See, die Shilluks, das einzige Volk des Sudans, das noch gegenwärtig unter seinem unabhängigen Könige steht. Dessen Macht ist heute freilich in vielen Dingen beschränkt. Ihre Gegend ist fast zur Gänze Grasland und deshalb auch Viehzucht ihre Hauptbeschäftigung. Die Viehzählung ergab im Jahre 190312173 Rinder und 63473 Schafe und Ziegen. Die Rinder sind kräftig und gut gebaut, Schafe und Ziegen dagegen klein und verkümmert, die Schafe wieder von der bereits geschilderten Art, mit langen, herabhängenden Ohren und straffem, nicht wolligem Haar. Unter den Kühen ist ein merkwürdig großer Prozentsatz unfruchtbar, weshalb Milch oft rar und gute Milchkühe ein wertvoller Besitz sind. Sie werden niemals geschlachtet, auch nicht bei festlichen Anlässen, wie die männlichen Rinder und die Hammel und Ziegen. Eine Frau kostet eine Kuh oder 3-t Ochsen. Es läßst sich nicht leugnen, daß die Shilluks ärmer oder ungalanter als die Dinkas sind, an deren 
Sitten die ihren erinnern; kostet doch bei den Dinkas ein Weib oft 20 oder mehr Rinder.

Der Ackerbau hat keine große Ausdehnung erreicht, obwohl die Ackerkrume längs des Flusses aus reichem, $4 \mathrm{~m}$ tiefem schwarzen Boden besteht. Im Alter von 13 oder 14 Jahren beginnt der junge Shilluk ein Stück Feld zu bestellen, um bis zur vollendeten Mannbarkeit die Mittel zum Kaufe einer Frau zu erwerben. Mehr als zwei oder drei Weiber gewinnt selten einer, aber mancher soll sein Lebenlang den Kaufpreis für eine einzige nicht zusammenbringen. Die gebauten Pflanzen sind Mais, Bohnen, Baumwolle, Erdnüsse, Sesam, Melonen. Die Produktion deckt nicht immer den eigenen Bedarf, so daß Hungersnot im Lande kein allzu seltener Gast ist. Von den vielen anderen Plagen der Shillukgegend, den Seuchen und wilden Tieren, den Löwen und Elefanten, den Nilpferden und Krokodilen, ist schon an anderer Stelle erzählt worden.

Auch Darfur unterliegt dem englisch-ägyptischen Einflusse in viel geringerem Maße als die anderen Landschaften. Der Sultan ron Darfur zahlt der sudanesischen Regierung einen jährlichen Tribut und ist als deren offizieller Vertreter beglaubigt. Die Verwaltung der internen Angelegenheiten liegt indessen ganz in seinen Händen. und die Sonderstellung des Sultans kommt schon darin zum Ausdruck, daß er seine eigene Armee von Derwischen nit heiläufig 6000 Gewehren hält. Das ungefähr 500000 qkm große Darfur soll vor dem Auftreten des Mahdi $1^{1 / 2}$ Million Einwohner besessen haben und ein wichtiger Stapelplatz für den Sudanhandel gewesen sein. Jetzt ist die Berölkerung auf die Hülfte zusammengeschmolzen, und das Land hat den Weg zu seinem früheren Wohlstande noch nicht gefunden. Norden und Nordosten bis zum zentral gelegenen Mar ragebirge erinnern in ihrem Charakter an den wasseramen Teil Kordofans, während das übrige $\mathrm{D}$ arfur besser mit Wasser versorgt und fruchtharer ist. Dementsprechend sind Norden und Nordosten die Domäne der nomadisierenden, Kamelzucht treibenden Araber: daneben wird im Osten in beschränkten Distrikten Hirse und etwas Durra gebaut. In einigen Depressionen findet man dort auch Sesam, Gurken, Kürbis, Wassermelonen, sogar kleine Mengen Baumwolle für den Lokalkonsum. Im Testen nimmt der Ackerbau wegen des größeren Wasserreichtums an Umfang zu. Der reichste, bestkultivierteste Teil des Landes ist die 
hügelige Mitte. Die reichen Weiden an den Bergahhängrn bieten dem Vich der sebhaften Bevölkerung reiche Nahrung: anf den Hügeln wird Genüse in terrassenförmigen Gürten gezogen, weite Flächen tragen Gerste, Weizen, Hirse, Durra, Sesam, Baumwolle. Selbst in der regenlosen Zeit zieht man im Bett der trocken gewordenen, kleinen Wasserläufe Zwiebeln und Wassermelonen.

Der Viehreichtum der Ackerbaner erstreckt sich auch auf das südliche Darfur. Dort gibt es auker dem wohlgebanten, meist gut angefleischten Buckelrind noch eine zweite langhörnige Rinderart, die an das ägyptische Rind erinnert und geradeso wenig wert zu sein scheint als dieses. Unter den Schafen findet man neben dem schon beschrichenen Langohrschafe cine Art mit langem, wolligen Haar. Überall daneben Ziegen in großer Zahl. Den Hauptteil der seßhaften Bevölkerung bilden die Fors, nach denen das Land richtiger Darfor heißt, Neger, mit auffallend platten Nasen und zurücktretender Stirn. Sie sind fanatische Mohammedaner und stehen auf einer relativ höheren Kulturstufe. Die Fors treiben neben Ackerbau auch so manches Gewerbe, verweben Baumwolle, fertigen Matten und dergleichen. Man sagt ihnen allerlei üble Dinge nach, nennt sie furchtbar eitel, unzuverlässig und heimtückisch; sie gelten aber für sehr fleißig.

In Gruppen überall eingestreut sind Takruris, die wir als gute Ackerbauer bereits in Gedaref kennen gelernt haben. Die im südlichen Darfur lebenden Araberstämme, die Baggara, züchten neben Rindern auch vielfach Pferde; kleine unansehnliche Tiere, die aber äußerst ausdauernd sind und auf dem Marsche angeblich bis zu 60 Stunden ohne Wasser auskommen. Der gegenwärtige Herrscher, Sultan Ali Dinar, der, wie seine ganze Dynastie, ein Mischling von Neger- und Araberklut ist. hat in der Gegend von Zeiadia ein Gestüt ins Leben gerufen, durch das er die heimische Pferdezucht verbessern und wiederbeleben will.

\section{Der Südsudan.}

Die bewegten Schicksale des Südsudans. - Die Provinzen des B a h r el Gh a zal und des oberen Nils. - Das Gebiet der Wälder und des Elfenbeins. - Die Fleischfrage bei den Nyam-Nyam. - Die Anuaks als Ackerbaner. - Das Schwergewicht der Bodenproduktion liegt in der Bevölkerung. - Einige Beispiele dafür.

Der Süden ist der am wenigsten bekannte Teil des Sudans geblieben, obwohl wir viel ron seinen bewegten Schicksalen wissen, 
die manchmal bis nach Europa ausgestrahlt haben. Zum Süden des englisch-ägyptischen Sudans gehört ein Bruchstück der ehemaligen Äquatorialprovinz, die der Deutsche Edu ar S Sch nitzer als Gouverneur Emin Pascha wissenschaftlich erforscht und so trefflich geleitet hat, dab sie in vormahdistischen Zeiten zu den bestverwalteten Bezirken des ganzen Reiches gezählt wurde. Zum Süden gehört auch die $\mathrm{Obere-Nil-Provinz,} \mathrm{die} \mathrm{unter} \mathrm{dem}$ früheren Namen Faschoda einst viel von sich reden machte. Ihre Besetzung durch Marschand hat damals zu erregten Unterhandlungen und fast zum Kriege zwischen Frankieich und England geführt. Dem Süden des englisch-ägyptischen Sudans ist schließlich die Provinz des Bahr el Ghazal, des Amaznnenstromes zuzuzählen, die Junker und Schweinfurth bereist und beschrieben haben.

Als die Regierungstruppen die $\mathrm{Bahr}$ el Ghazal-Provinz im Winter 1900-1901 wieder besetzten. glich sie nicht mehr dem Lande, das früher geschildert worden war. Die mahdistische Hochflut hatte inzwischen alle rorhandenen Kulturkeime weggeschwemmt. Mit den Wegen und Ortschaften waren die einstigen Bewohner vielfach verschwunden, waren vernichtet worden oder sind ausgewandert. Andere Gegenden des Südens hat man erst kürzlich zum ersten Male betreten. Diese sind wohl politisch, kaum aber intellektuell der Einflußsphäre der englisch-ägyptischen Regierung zuzuzählen. Kapitän N. T. Borton berichtet so von einem im Jahre 1904 erfolgten Besuche des Beristammes, der auf dem 2000 Fuf hohen Jebel Lafol-Berge wohnt, und bemerkt dazu, daß noch kein weißer Mann vor ihm dort gewesen sei.

Aus den vorhandenen Berichten scheint sich indessen das eine zu ergeben: Die südlichen Provinzen des Ga z ellenstromes und des oberen $\mathrm{Nils}$ gehören in bezug auf Bodenproduktion zu den vielversprechendsten des ganzen Sudans. Die zahlreichen Sümpfe und die großen Strecken Landes, die alljährlich überschwemmt werden, schließen den Ackerban ebensowenig aus als das ungesunde und erschlaffende Tropenklima, das nur die Mitwirkung des weißen Mannes einschränkt. In einem Regierungsbericht vom Sobat heibt es übrigens: "Die Eingeborenen erscheinen gesuna, und es ist kein Grund vorhanden, warum bei entsprechenden Vorsichtsmaßregeln nicht auch die weißen Rassen dort gesund bleiben sollten." Die südlichsten Teile liegen freilich inmitten der 
gefährlichen "Schwarzwasser"Fieherzone. Dägegen sinci reichlicher Regen, viel Wasserlüufe, üpnigster Boden und rine ankerordentlich reiche Tropenvegetation die verheißungsvollen Nierkmale der beiden südlichen Provinzen.

Die Provinz des Bahr el Ghazal wird in sürlen und Westen vom Kongo und $\mathrm{Nil}$ und im Osten rom $\mathrm{Bahr} c$ l Dschebel begrenzt. Bevor ihr Hauptstrom. der Bahr e] Ghazal, sich in der "No-Se $\mathrm{N}^{u}$ genannten Lagune mit dem $\mathrm{Bahr}$ el Dschebel verbindet und zum Weißen Nil wird. nimmt er eine ganze Reihe von Nebenfiüssen auf. Rohl, Poah, Tondy (Issu), Dschur (Djur, Sueh), Bahr el Homer. Bahr el Arab ergiefsen sich in diesen und bilden ehensoviel fruchthares Gebiet in dem Lande, das sie durchflieben. Es sind zumeist 70-117 in breite Ströme, die einander in der Gestaltung der Ufer ähneln und wäh!end der Hochflut für kleine Damıfer schiffihar sein sollen. Sie ähneln einander auch darin, dafs sie alle stark mit Sedd, den schwimmenden Pflanzenbarren, criüllt sind. Die Durchfahrt der Dampfer bis W a w wurde erst möglich, nachdem es 1903 gelungen war, das Sedd im Dschur zu durchschmeiden und den dadurch geschaffenen Kanal zu verbreitern und offen zu halten.

Im nördlichen Teile dehnen sich die Steppen mit hohem Graswuchs, und dazwischen liegen die ausgedehnten Sümpfe, ron denen Sch we in furth erzählt. Gegen Süden und Westen steigen die Steppen zu einem mäßig hohen Plateau an. Kristallinisches Gestein durchbricht hier überall den schwarzen, tonigen Boden, der in den tiefer gelegeneren Stellen und in den Wasserläufen seine hohe Fruchtbarkeit bewahrt, selbst dort bewahrt, wo herahgeschwemmter Sand sich dazu gesellt. An den Flukufern gibt es reichsten Alluvialboden.

Der Ackerbau hat bis jetzt nur wenig Gebrauch daron gemacht. Am Hochplateau werden Nais, Durra, Sesam, Hirse, verschiedene Gemüse gebaut, aber in so geringem Unfange, daß jeder Militärposten der Provinz sich sein Getreide selhst pioluzieren muß. Der Boden wird im April vorbereitet und der Samen im Mai ausgelegt. Im November oder Dezember erfolgt die Ernte, die einzige im Jahr, die man dem Boden dort abgewinnt.

Sonst ist die Provinz das Gebiet der IVälder und des Elfenbeins geblieben. Was sollte die Menschen auch zu regerem Acker- 
bau führen, da die Natur ihnen die Sorge um die Nahrung so leicht gemacht hat und den Anlaß zu Bedürfnissen so gering. Die elenden Gras- oder Schlammhütten schützen genügend gegen die Unbill des dortigen Klimas; Kleidung ist bei der hohen Temperatur nur überflüssiger Ballast. Man begreift es gar nicht, warum unter diesen. anscheinend dem ganzen Süden eigentümlichen Verhältnissen manche der durchweg negroiden Stämme sich geistig besser entwickelt und eine höhere Stufe des Ackerbaues erreicht haben als andere. Im $\mathrm{Bahr}$ el Ghazal ragen so die Nyam-Nyam durch ihre Intelligenz hervor. Sie sind heller gefärbt als die anderen Sudanneger und bezeichnen sich selbst als ,weiße Männer". Ober'st Sparkes nennt die Ny a mNyam das fortschrittlichste Volk des ganzen Sudans. Ihre Landwirtschaft bestätigt das Urteil wenigstens in Hinsicht auf die Mannigfaltigkeit der Kulturpflanzen. Sie ziehen große Quantitäten von Durra, Bananen, Zitronen, Tomaten, süßen Kartoffeln, Zuckerrohr, Maniok, Zwiebeln. Der Viehzucht wird dagegen bei den Nyam-Nyam gar kein Wert heigemessen. Nur einige Häuptlinge besitzen Rinder und Schafe. Dennoch haben auch die Nyam-Nram ihre Fleichfrage, - sie sind nämlich noch immer Menschenfresser. Man darf sich das aber nicht etwa so vorstellen, daf jeder Ny am-Ny am am Sonntag sein Stück Menschenfleisch im Topfe haben müsse. So arg ist es nicht. Nur ihre Feinde, die im Kampfe Gefallenen oder die Verstorbenen verspeisen sie gern.

Unter den Völkem der Oberen Nilprovinz gelten die Anuaks oder $\mathrm{Yambos}$ für fleißige und tüchtige Ackerbauer. Sie bewolmen: die fruchtbare Ebene, die der Baro, einer der Quellflüsse des Sobat, durchzieht. An seinen Ufern wird der Boden meilenweit zweimal im Jahre sorgfältig bestellt. Die Anuaks halten auch viele Ziegen und Schafe. Sonst gibt es nicht viel Ackerbau in der Oberen Nilprovinz, deren Merkmale jenen des $B$ a hr el Ghazal ähneln: viel Wälder und fruchtbarer Boden. Wasserreichtum und Sümpfe. Fon den landwirtschaftlich in Frage konmenden Wasserläuten sind außer den schon erwähnten, dem Sobat und dem Baro, der andere Quellflufs des Sobat, der Akobo, dann der Bahr el Zeraf zu nennen. Aber das Schwergewicht der Bodenproduktion liegt auch hier weniger in den übrigen Voraussetzungen als in der Berölkerung. Unter dieser sind die Nuer am Sobat der zahl- 
reich-te Stamm. Ein sehr niodriger Menschentypus, hanen sie gerade nü so viel Getreide, als nötig ist, um sechs Honate davn leben zu kömnen. Die ährige Zeit des Jahres nähren sie sich hauptsächlich ron Fischen, die der Flufis zur Zeit der Hochflnt massenhaft herbeischwemmt. Die Nuer hesitzen zahlreiche Herden ron Schalen und Ziegen, aber keine Rinder, obwohl sie diese sehr schätzen. Für eine Kuh kamn man :3.) Ziegen nder Schafe von ihnen eintauschen. Rinderzucht neben schaf- und Ziegenhaltung treiben dagegen im Sürlen die Dinkas. Das hängt wieder mit dem Kaufpreis ilner Weiber zusammen. Ein Weih kostet : Kühe oder 4" Ziegen oder Schafe. Die Dinkas sind starke Raucher und bauen deshall, viel Tabak, dessen Qualität sehr gerühnt wird. Die Dinka-Schêchs ron Bor und Kur ziehen eine besondere Durra-Art, die Mehl ron guter, weiler Beschaffenheit gilut. Ton Bor bis Mongalla. dem südlichsten Posten der sudanesischen Regierung, wohnt ein anderer Negerstamm, die Beris. Auch hier hat die Bedürfnislosigkeit zu einer halbwegs nennenswerten Entwicklung des Ackerbaues ehensowenig führen können wie bei den Beris des. Jehel Lafol östlich ron Miongalla. Nur in der Ebene rings um den ron ihnen bewohnten Berg bauen sie etwas Durra, Tahak und Erdnüsse. Die Beris sind auffallend gesunde, wohlgeformte Leute. Das soll damit zusammenhängen, daß sie, wie einst die Spartaner, schwache, mißgestaltete Kinder gleich nach der Geburt töten. Bei dem vielköpfigen Stanme der Karuno an den Ufern des Karunoflusses konstatiert Major A ustin regeren Ackerbau. Er passiert auch den Hügeldistrikt ron $\mathrm{Boma}$ mit vielen Strömen, Tälern und Bergabhängen und findet den Boden dort sehr fruchtbar und fähig, alle Arten von Getreide zu tragen, daneben wilde Feigen in Unmengen. ..Ein Üherfluß ron Nahrung könnte hier zweifellos gewonnen werden," ruft Major Austin in seinem Berichte aus, ,wenn die Eingeborenen zur Erkenntnis unseres mächtigen Schutzes kämen." Vorläufig hatten die Eingeborenen wohl begründete Ursache mit dieser Erkenntnis zuzuwarten. Austin berichtet selbst, dak sie gerade vor seiner Hinkunft ron den Mago is überfallen und ihres ganzen Viehstandes beraubt worden waren. 
Siebentes Kapitel.

\section{Kultureinflüsse im Sudan.}

\section{Die kulturelle Vorarbeit.}

Ihr Wesen, - Straßen, Brunnen, Binnenschifiahrt und Schienenstrang. Suakin und Port Sudan. - Post und Telegraph. - Öffentliche Sicherheit und Sklavenhandel. - Die englische Militärverwaltung und ihre Organe. Opfer der Sudanforschung. - Die wissenschaftliche Hilfsarbeit. - Vermessungs- und Forschungsarbeiten.

Aus den Zuständen und Verhältnissen, die im letzten Kapitel geschildert wurden, ergibt sich, daß jedem Versuche, die Landwirtschaft des Sudans zu hehen, eine ganze Reihe allgemeiner kultureller Maßnahmen vorangehen mußite. Ruhe im Lande und Sicherheit von Eigentum und Person sind die unerläßliche Grundlage jeden weiteren Schrittes. Bevor man die Bodenbestellung zu verbessern gedenkt. mußs erst deren ungestörter VerlauI gewährleistet sein. Sicherheit setzt auch der Absatz der Produkte voraus, Sicherheit die notwendige Erforschung des Landes und seiner natürlichen Bedingungen. Und was muf nicht alles erforscht werden, bevor die Berechtigung eines einzigen Spatenstiches erwiesen ist: Klima, Bodengestaltung und Zusammensetzung. die Wasserverhältnisse. die geeigneten Kulturgewächse, die Dichte und das Wesen der Bevölkerung, Krankheiten der Menschen, Tiere und Pflanzen, die Verkehrsverhältnisse und alle möglichen anderen Dinge. Das Land soll nicht nur regiert und reformiert werden, es soll auch möglichst bald zu dem Aufwand beitragen, den es erfordert. Das richtige Bemessen, Verteilen und Einheben von Steuern setzt in dem unzivilisierten Lande wieder eine Unmenge von Vorarbeiten voraus. Da heißt es auf der ganzen Linie beobachten und registrieren, untersuchen und rormessen. Dann all die anderen Arbeiten des Kulturpioniers: Verkehrsmittcl schaffen, Flüsse regulieren. Bewässerungskanäle herstellen, die 
Bevölkerung durch die Gesetzgebung zur Zivilisation führen, durch Beispiel und Unterricht belehren u. dgl. m. Nichts predigt eindringlicher den Zusammenhang zwischen der Bodenproduktion und dem allgemeinen kulturellen Zustande, als die Erwägung dessen, was die Bodenproduktion in einem unzivilisierten Lande hindert und zurückhält.

Sicherheit von Eigentum und Personen in einem $1858000 \mathrm{qkm}$ großen Gebiete dauernd zu crhalten, dessen fortgeschrittenste Teile noch tief in der Barbarei stecken, ist wahrlich keine kleine Aufgabe. Sie erscheint noch schwerer, wenn man die relativ geringe Truppenmenge, die der Regierung zur Verfügung steht (18591 Mann, 126 englische, 711 ägyptische Offiziere), und die Mangelhaftigkeit der Verkehrsmittel in Betracht zieht. Ohne den Bahnbau von Halfa nach $\mathrm{Khartum}$ wäre die Wiedereroberung des Sudans kaum gelungen, und ohne schleunige Verbesserung der Verkehrsmittel hätte sich weder die Herrschaft festhalten noch die Sicherheit verbürgen lassen. Erst dadurch wurde es möglich, im Bedarfsfalie Truppen rasch fortzubewegen und die Verständigung mit den entferntesten Teilen des Landes jederzeit herzustellen. Nicht weniger Bedeutung gewinnen die neugeschaffenen Verbindungen für die zivilisatorischen und ökonomischen Aufgaben, denen sie in ruhigeren Zeiten zu dienen haben.

So mußte die kulturelle Eroberung des Sudans mit dem gleichen Hilfsmittel unternommen werden, mit dem die kriegerische cingeleitet worden war: mit der Ausgestaltung des Verkehrsnetzes.

Straßen sind den nichtzivilisierten Völkern ein unbekannter Luxus: Ersparnis an Zeit und Wegelänge bedeutet für sie nicht viel. Die Fufpfade machen einen Umweg um jeden Baum, schlängeln sich ohne Rücksicht auf die Dauer des Weges stets dort durch, wo es gerade am wenigsten Hindernisse gibt. Die Regierungsstraßen im Sudan darf man sich auch nicht als Straßenbauten in unserem Sinne vorstellen. Der Weg wird einfach in einer Breite von etwa $10 \mathrm{~m}$ von Stämmen und Gestrüpp gereinigt, in unbedeckter Gegend mit Steinen abgesteckt und, wo er durch ausgetrocknete Wasserläufe führt, durch Erdanschütting mit der Flußsohle und von dort mit dem gegenüberliegenden Ufer verbunden. Zur Regenzeit lassen solche Straßen natürlich viel zu wünschen übrig, namentlich in den südlicheren Provinzen, wo die Entfernung des überwuchernden Pflanzengewirres Schwierig- 
keit und Ausgaben verursacht. Die Regierung hat bis zum Jahre 19094650 Meilen dieser Straken hergestellt, die immerhin schon wegen der Abkürzung les WVeges einen Fortschritt bedeuten.

Die Straßenfrage und die Brunnenfrage sind eng verbunden. Es mußten demnach gleichzeitig mit den Straßen Brunnen längs des Weges geschaffen werden. Im Jahre 1906 wurden allein 88 Brunnen, 1907100 und 190890 Brumnen neu hergestellt.

Das Bemühen der sudanesischen Verkehrspolitik, sich die Bimenschiffahrt nutzbar zu machen, hat trotz der entgegenstehenden Schwierigkeiten Erfolge aufzuweisen. Der Weisse Nil besitzt seiner ganzen Länge nach geregelten ständigen Dampferverkehr. Die Regierungsschiffe gehen von Khartum bis Mongalla, der letzten Sudanstation, und noch weiter bis Lado im Kongo. staate und bis Gondokoro (Lganda-Protektorat). Der $\mathrm{Blaue} \mathrm{Nil}$ ist vorläufig; wegen seiner zahlreichen Untiefen und Schlammassen, nur während der Hochflut und während der ersten Wintermonate bis Roseires unweit der abrssinischen Grenze für größere Dampfer schiffbar. Während dieser Zeit herrscht hier reger Verkehr, der zumeist von Regierungsdampfern und den subventionierten Dampfern des Soudan Development and Exploration Syndicats bestritten wird. Danelen besorgen noch etliche kleinere Privatampfer, zugleich mit den Segellonoten. Barken, Flößen, den Warentransport auch während des niedrigen Wasserstandes.

Die Regierung hat den Schiffsterkehr auch noch auf anderen Flüssen cingerichtet. Der Sobat, der Bahr el Ghazal und dessen Nebenfluf, der Jur, werden von Dampfern und anderen Schiffen und Booten in großer Zahl befahren. Wie energisch dabei ins Zeug gegangen wird, zeigt ein Bericht des Mr. Bond, des Vorstandes des Binnenschiffahrtsdepartements, der erzählt, daß ron Juli bis September 1908 auf dem of ur, der zuletzt in den Schiffsverkehr eimbezogen worden ist, $1200 \mathrm{t}$ an Baumaterialien, Vorräten und Proviant nach TW a u geschafft wurden. Die letzten $200 \mathrm{t}$ blieben freilich im Schlamme stecken und mußten mühsam ans Land geschleppt werden: aher so ganz ohne Zwischenfälle geht es ja beim Transport im Sudan selten ab. Blieben doch auch am Bahr el Ghazal in Herbste des gleichen Jahres 6 Dampfer und 18 Boote mehrere Wochen lang in der Nähe ron Meshra el Rek im Schlamme eingesperrt. Solche Unfälle mahnen zur Vorsicht; sie können aber den Wert von Wasser- 
straben in llas Innere der Provinzen: in die der landwegy jetzt so mühsaun und gefahrvoll führt, nicht aufhehen. Administrative und kommerzielle Gründe lassen an die Schifflharmachung des Tony, des $\mathrm{K}$ hir, des $\mathrm{Chell}$, des $\mathrm{N}$ a am, die alle dem Flußgehiet des Bahr el Ghazal angehören, und noch anderer Flüsse denken. Die Ausführung wird freilich noch verschoben werden müssen, bis die nötigen Vorarbeiten und Mittel beschafft sind und die Erfahrung den Kampf gegen Verschlammung und schwimmendes Pflanzengestrüpp aussichtsioller erscheinen läßst.

Dic Länge des Schienenstranges botrug Ende 190- 1list km. Davon entfallen $925 \mathrm{~km}$ auf die bisherige Hauptlinie von Wa d Halfa nach Khartum, die zum Teil schon während des Feldzuges gegen den Mahdi als schmalspurige Bahn gebaut worden war. 1907 wurde dam die Abzweigung von $\mathrm{A}$ bu $\mathrm{H}$ amed nach Kerma fertiggestellt, wolurch die Verbindung mit der D o n g o la. provinz vermittelt wird. Gegenwärtig schlägt man bei K ha rtum eine Brücke über den Blauen Nil, über die eine Bahn den Fluts aufwärts projektiert ist.

Das Ereignis des sudmesischen Verkehrswesens bilkete die Eröffnung der Bahnlinie rom Nil zum Roten Meer. Sie gewinnt ihre volle Bedeutung erst durch den Zusammenhang mit dem neugeschaffenen Port. Sudan. Port Sudan liegt unweit Suakins, das bisher der einzige Hafenplatz des Landes war. In Vertrage mit England vom 19. Januar 1899 hatte Ägypten zu seiner Genugtuung den alleinigen Besitz dieses wertvollen Schlüsselpunktes des Sudans erreicht. England fiel es nicht ein, Ïgypten das errungene Vorrecht streitig zu machen. Leider hatte S u a k in bald darauf das Malheur, von England als ungeeignet für die Ausgestaltung zu einem modernen Hafen erkannt zu werden. So wehte die ägyptische Flagge wohl noch einige Zeit weiter in stolzer Einsamkeit, nicht flankiert von der englischen Flagge, wie sonst überall im Sudan, auf den Zinnen von Suakin; aber zum Haupthafen des Landes war Port Sudan geworden. Die unfruchtbare Wüste wurde dort in unglaublich kurzer Zeit zu einer Hafenanlage umgestaltet, die mit dem ganzen Rüstzeug fortgeschrittenster Technik versehen ist. Die Bahn führt rom Nil nach Port.Sudan; der Tarif begünstigt dieses Ziel, alle möglichen anderen Maßnahmen und Einrichtungen lenken den Handelsverkehr des Landes dahin. In einem späteren Abkommen 
vom 10. Juli 1899 hat Ägypten dann auf seine Vorrechte in $\mathrm{Su}$ a k in verzichtet.

Was PortSudan und die Rote Meer-Bahn in ökonomischer Beziehung bedeuten, mögen einige Zahler zeigen: Kurz vor Eröffinung der Bahn betrug der Preis der Durra in Khartum 25-30 P.T., an der Küste $90-110$ P.T. per ardeb. Jetzt beträgt die Bahnfracht von Khartum bis Port Sudan nicht mehr als 15 P.T. per ardeb, und der Preis der Durra konnte deshalb in Khartum auf 70 P.T. steigen. In diesem Falle hat die neue Verbindinng den Landwirten im Innern gedient; sie kann ein anderes Mal in gleicher Weise wichtigen Exportinteressen nützlich sein. Nicht weniger bedeutungsvoll kann sie für den Import werden. Die Fracht von einem englischen Hafen nach Port Sudan beträgt nur $3-\frac{1}{4}$ Schilling per Tonne mehr als nach A lexandrien. Bisher hat die Fracht von eisernen Trägern bis Khartum 10 L. E. per Tonne gekostet, nun kostet sie über Port Sudan nur 7 L.E. Die Fracht von Portlandzement hat sich von 6-7 L.E. auf 3-4 L. E. ermäfigr. Wichtig ist auch die Abkürzung der Transportdauer. Pakete vom Ausland, wie von Ägypten, ersparen bis Khartum über Port Sudan 8-9 Tage; von England werden sie nun in 18-20 Tagen hinbefördert.

Das Post- und Telegraphennetz zählte 190756 Stationen. Der Draht erreicht jetzt selbst die südlichsten Orte, wie Bor, Mon galla, Gondokoro u. a. m. 1908 kamen neue Stationen in Süd-Kordofan, am Weißen Nil, am Bahr-el-Jebel hinzu, und nun umfaßit der Telegraphendienst 4930 Meilen. Khartum und Omdurman sind zudem mit Port Sudan durch eine Telephonlinie verbunden. Soweit der Sektor des englisch-ägyptischen Sudan in Betracht kommt, ist demnach das von Cecil Rhodes aufgestellte Ziel - eine direkte telegraphische Verbindung zwischen dem Norden und dem Süden Afrikas zu schaffen mehr als erreicht worden.

Vielleicht ist es nicht ohne Interesse zu hören, daß fast alle Telegraphenbeamten eingeborene Sudanesen sind. Unter 79 Telegraphisten befanden sich 1906 nur 6 Ägypter und 73 Sudanesen, was gewiß für den guten Willen und die Bildungsfähigkeit der Rasse spricht. Weniger günstig scheinen dagegen, besonders im Süden, die übrigen Bedingungen beschaffen $\mathrm{zu}$ sein. Major Turner' der Abteilungsvorstand, berichtet einmal, daß die Leitung von Bor nach Taufika in neun Monaten nicht weniger als achtmal unterbrochen war. 
Dreimal hahen schwinmende J'flanzenmassen im sobat das Kabel während der Flut vom Ufer fortgerissen, ein anderes Mil sind weilie Ameisen in der Kabelumhüllung zur Ursache der Linterbrechung geworden. Ein einziger wilder Elofint hat siehen Telegraphenstangen zerbrochen und vier von den eisernen Ständerm ausgerissen, auf denen die Stangen in den Tropen angebracht werden. Andere Gründe der Stürungen waren eimmal ein Grasfeuer, einmal ein Fischadler und einmal sogar - ein Frosch.

So geht es mit der Telegraphenleitung wie mit den Wegen, und mit der Schiffahrt: Überall sorgen die Naturgewalten dafür, dabi der Verkehr nicht allzu leicht auriechterhalten werden kann. Und mit der Eisenbahn geht's nicht ander's. Bald ist es der Wüstenstaub, hald der Sturmwind, bald der Wassermangel, der den Betrieb erschwert. Oder das Wasser der Hochflut rückt dem Schienenstrang zu Leibe. Während der Regenzeit 1908 gah es an der Roten-Neer-Linie allein jov Dammbrüche, und die Strecke wurde in der Ausdehnung ron : $::^{1}$ a Meilen unterwaschen. Das Schaffen und Erhalten vou Verkehrsmitteln wird im Sudan immer eine kostspielige Sache bleiben und der Bahnbetrieb wohl noch lange Zeit den ökonomischen Zwecken des Landes besser dienen als den eigenen.

Der Sicherheit hat die Verbesserung des Verkehr's zweifellos gute Dienste geleistet. In den zivilisierten Teilen. oder besser gesagt, in den Teilen, die mehr unter den Augen der Regierungsgewalt gelegen sind, etwa im Bezirk von $\mathrm{Khartum}$, kann sich der Europäer heute geradeso unbeliümmert und unberraftinet herumbewegen als in irgendeiner Gegend Deutschlands. In den entfernteren Distrikten gärt es freilich noch immer hier und dort, am meisten in solchen, in denen britische oder ägyptische Truppen wegen des ungesunden Klimas nicht dauernd gehalten werden können. 19gs hatten die Regierungstruppen Unruhen am Blauen Nil, in Kord of a n und in Mongalla nierlerzuschlagen, was nicht ohne Blutrergießen auf beiden Seiten ror sich ging. Religiöser Fanatismus, die Raubgier wilder Stämme und der Sklavenhandel lassen das Land nicht so leicht zur Ruhe kommen. Mit den beiden ersten wird die Regierung schneller fertig als mit dem Sklavenhandel. Einen neuen Mahdi kann man aufhängen, wie das dem armen $\mathrm{Abdul}$ Kader Mohammed Jmam Wad Habuba rom Stamme der $\mathrm{Hal}$ owin erst kürzlich passiert ist. als er gerade die Nachfolge des alten Mahdi. seines Ferwandten. 
antreten wollte. Der Raub- und Mordlust der freien Söhne Afrikas weiß die Regierung durch energisches Vorgehen und strenge Bestrafung der Schuldigen Einhalt zu tun. Anschauungen dagegen, die im ganzen Volke wurzeln, wie die von der .Ehrenhaftigkeit" des Sklavenhandels und der Sklavenhaltung. Gebräuche, die in die ökonomischen Verhältnisse so tief eingreiien. lassen sich weder rasch noch ohne schwere Kämpfe beseitigen. Wie soll man barbarischen Arabern und Sudanesen das Terständnis für das menschliche Recht auf Freiheit beibringen? Unseren Kulturvölkern hat es noch ror 104) Jahren so sehr gefehlt, daf der Herr bei Aufhebung der Leibeigenschaft in den meisten europäischen staaten dafür erst entschädigt werden mußte.

Die Aufhebung der Sklaverei, des Sklavenhandels. bringt eine ganze Reihe anderer Fragen ins Rollen. Der Gallabas. der reisende Kaufmann, so eine Art afrikanischer Gottscheer. der das Land nach allen Richtungen durchzieht und die Bevölkerung mit Salz und anderen wichtigen Gebrauchsartikeln rersieht, treibt nebenbei Sklavenhandel. Der Handelsverkehr wird die abgelegensten Orte rielleicht gar nicht mehr erreichen, wenn der Gallabas auf seinen wertrollsten Handelsartikel verzichten mub. Oder die Waisenversorgung! Die Nubas rerkaufen, nach dem Berichte des Major Ravenscroft, einfach ihre unbeschützten Stammesgenossen, wie Waisen usw. Wird diese jetzt ein besseres Los erwarten? Major R avenscroft berichtet weiter, wie die Araber und Nubas sich gegenseitig verhandeln, wie diese in ihren Bergen unerreichbare Schlupfwinkel für ihre Sklaren besitzen und jene es verstehen, sie unbehelligt an die Küste, nach Darfur. über die südlichen Grenzen zu schaffen. Der Kaufpreis. den der sudanesische Araber für sein Weib an die Eltern entrichtet. begreift oftmals einen oder zwei Sklaven mit ein. Und wie es, ethisch genommen, rom Kaufe der Frau zum Kaufe des Sklaven nicht weit ist, so ergibt sich aus allem anderen die Ummöglichkeit, das Sklavenwesen so kurzerhand aus dem Dasein des Sudans zu streichen. Slatin Pascha schreibt einnal: "Meiner sicheren Kenntnis nach ist heute kein Sklave durch Gewalt gezwungen, bei seinem sogenannten Herrn zu bleiben." Und er meint weiter, , daf jetzt jeder Schwarze die Gesetze genügend kenne. und nicht zögern würde den Schutz der Behörde anzurufen, falls er Grund zur Klage gegen seinen Herrn hätte." Die Worte des erfahrensten Sudankenners sind wohl dahin zu verstehen, dalis die Regie- 
rung bisher die Sklaverei nicht ganz ausrotten komnte. dab sie indessen das Los der Sklaven weit gemildert hat. 1)re letzte Sklave wird noch lange nicht aus dem Sudan verschwunden sein, aber bessere Behandlung, die Gewibheit, nicht ganz chuntzund rechthos zu sein, wird ihm nach und nach den C̈loergang zum freien Dienstrerhältnis finden lassen, für das heute weder der Sklive noch der Herr reif sein dürften. Bei der Menschenleere des Sudans besitat die Weitergestaltung dieser Frage für die Landwirtschaft wie für die Entwicklung des ganzen Kulturorganismus außerordentliche 'Tragweite.

Die Verwaltung des Sudans ist eine militärische. Wenn Lord Cromer in seinem Werke .. Das heutige Ägypten" behauptet, es wäre ein rollständiger Irrtum anzunehmen, daß das Land unter Militärverwaltung stünde, so wird das wohl mehr für den europäischen Leser bestimmt als ernst gemeint sein. Der Generalgouverneur, die Departementschefs mit Ausnahme der Departements der Justiz, des Unterricht-, Forst- und Jagdwesens und der Landwirtschaft sind Offiziere. Desgleichen alle Provinzgouverneure und die Vorstände der Verwaltungsbezirke, der Mamurias. in die jede Provinz geteilt ist. In einem Sinne kann man indessen die Cromersche Angabe gelten lassen: Eine englische Militärverwaltung unterscheidet sich wesentlich ron dem, was man bei uns unter Militärverwaltung versteht. Der Unterschied liegt ehenso im Geiste der Führung, als im Wesen und in der Heranbildung der zur Mitwirkung Berufenen.

Die englische Militärverwaltung ist bei aller Entschlossenheit elastischer, schmiegsaner. Sie rasselt, bildlich gesprochen. weniger mit dem Säbel, verschmäht keinen ehrlichen Weg, der zum Ziele führt. Der kriegerische Erfolg wertet ihr nicht höher als der friedliche. Demzufolge wird auch die Ausbildung des Offiziers in anderer Richtung gepflegt als bei uns, vielleicht auch der militärische Ehrbegriff weniger einseitig entwickelt. Man legt nicht gar zu riel Wert auf uniformierten Drill, auf buchstähliches Einhalten des Reglements, fördert dagegen das Gefühl der eigenen Verantwortlichkeit, selbständiges Handeln in hohem Maße. So besitzt der englische Offizier wohl viel Selbstzucht, bleibt aber dabei stets ein freier Mann, der sich, wenn nötig. für ein Ziel aufopfert, niemals aber aus disziplinierter Selbstverleugnung.

Solche Eigenschaften sind gegenüber den kulturellen Aufgaben, die das englische Militür im Sudan zu erfüllen hat, ynn 
großem Wert. Sie setzen die Militärverwaltung instand, mit einer Handvoll Offizieren, denen nur wenige Berufsgelehrte beigesellt sind, die Erforschung des Landes, ungeachtet aller Hindernisse und Gefahren, durchzuführen. Der Bericht Lord Cromers vom Jahre 1906 gibt in ergreifender Weise Kunde von den Opfern, die das Werk erfordert hat: "Afrika fährt fort, seinen schweren Zoll von denen einzufordern, die durch die Pflicht in das bisher fast unbetretene Innere geführt werden. Von 1901 bis 1904 verloren wir 13 britische und 32 ägyptische und sudanesische Offiziere. Von jenen wurde einer ermordet, einer durch einen Elefanten getötet, die anderen fielen Krankheiten, meistens dem Fieber zum Opfer. 1905 starben wieder sechs englische Offiziere und Beamte und sechs ägyptische Offiziere. Damit ist das Maß an nationalen und persönlichen Opfern indessen noch lange nicht gekennzeichnet; denn im gleichen Zeitraume wurden zehn britische Offiziere, ein Zivilbeamter und 23 ägyptische Offiziere infolge Erkrankung gänzlich dienstuntauglich." Und wie groß mögen die Entbehrungen und Wühen all der anderen militärischen und zivilen Kulturpioniere gewesen sein, die sich, ohne dienstuntauglich zu werden, an der Erforschung des Landes beteiligt haben?

Im früheren Kapitel wurden einige klimatologische Daten angeführt. Sie entstammen den Aufzeichnungen der klimatologischen Stationen des Sudans. Solche Beobachtungsposten hat man in Berber, Suakin, Khartum, Wad-Medani, Dueim, Kassala, Addis Abbaba, Doleib Hilla, Wau, Mongalla, Kodok, Roseires, El Obeid errichtet. Die Stationen sollen alle klimatologischen Lagen des Landes umfassen. Ihr Standort läßt sich nicht nach der Zuträglichkeit für den Beobachter auswählen, und die wahren Fiebertemperaturen, von denen berichtet wird, die verzeichneten Ungeheuerlichkeiten der Witterung sind alle von Beanten der Regierung niterlebt worden. Die Forschung kann auch nicht dort haltmachen, wo bewohnte Gegenden den Aufenthalt weniger gefährlich erscheinen lassen. Das Vermessungsdepartement unter der Leitung des Kapitäns $\mathrm{P}$ e arso $\mathrm{n}$ hat bereits alle bewohnten Teile des Sudans kartographisch aufgenommen. Bis 1908 wurden zudem 750000 Feddán landwirtschaftlich benutzter Fläche in Hinblick auf deren Steuerfähigkeit ausgemessen, katastriert. Irrigationsvermessungen sind ringsum im Lande begonnen worden und alle Flüsse werden auf ihre topographischen und Wasservcrhältnisse untersucht. Da geht es in die entsetzlichen 
Sumpfgegenden hinein, die kein menschliches Wesen dauernd ertragen kann. Ohne Bedenken schreitet die Forschung weiter und weiter. Barron, der Geologe, büßt seinen Eifer mit dem Leben, Mac Tier Pirrie, der Anthropologe des Wellcome-Laboratoriums in Khartum, überlebt seine ergebnisreiche Forschungsreise in die Barungegend nur wenige Monate. Andere treten mutig in die Bresche. Der zweite Rapport der Wellcome-Research-Laboratorien und des Gordon-Memorial-College $\mathrm{zu}$ Khartum vom Jahre $1900^{\circ}$ weiß davon zu berichten. Diese Institution bildet gewissermaßen das Arsenal der Sudanforschung, repräsentiert die wissenschaftliche Hilfstruppe der Sudanregierung. Der prächtige Bau des Gordon-College enthält die Laboratorien, cin Museum für Landeskunde und die Gordon-Schule für die Eingeborenen. Dem Direktor steht ein Verwaltungsausschuß zur Seite, dessen Zusammensetzung die Rolle erkennen läßt, die der Einrichtung zugedacht ist. Kein Geringerer als der König von England selber ist ihr oberster Schutzherr, der Generalgouverneur des Sudans Präsident, der Chef des Unterrichtsdepartements Vorsteher. Daneben gehört noch eine ganze Reihe hervorragender Männer dem Verwaltungsausschusse an. Lord Cromer befand sich, solange er in Ägypten war, darunter, und auch der Gouverneur der Bank von England ist statutengemäß Mitglied der Verwaltung. Ein kurzer Auszug aus dem Berichte wird den Umfang des Arbeitsgebietes und die Mithilfe der Anstalt bei dem Forschungswerk am besten zeigen.

Das chemische Laboratorium hat die Zusammensetzung der Getreidearten, Bodenproben aus verschiedenen Teilen des Landes, die Milch der einheimischen Tiergattungen und Rassen, Futterpflanzen, Pfeilgifte der Eingeborenen, einheimische Pulversorten, Eisenerze aus der Bahr el Ghazal-Provinz und anderes mehr untersucht. Die Bedeutung der künstlichen Bewässerung führte zu Analysen des Wassers rom Blauen und Weißen Nil, denen dann nach und nach analytische Untersuchungen der meisten anderen Flüsse folgten. Über die Zusammensetzung der Gummiarten, die zu den wichtigsten Handelsartikeln des Sudans gehören, ist noch wenig bekannt - man war daher eifrig bemüht, die verschiedenen Varietïten nach ihrem Werte zu charakterisieren und einzuteilen.

Die Zunahme der Schlafkrankheit im nördlichen $\mathrm{U}$ ganda schafft ein neues. schwieriges Forschungsproblem. Der General- 
gouverneur betraut eine Kommission mit der Erhebung, welche Ausdehnung die entsetzliche Krankheit im Sudan gewinnen könnte. Der Direktor der Wellcome-Research-Laboratorien gehört der Kommission an, und die Laboratorien sollen die erforderlichen wissenschaftlichen Untersuchungen übernehmen. Man engagiert einen eigenen "reisenden Pathologisten und Naturforscher" in der Person eines Dr. N eave, dem die besondere Aufgabe zugewiesen wird, das Vorkommen der Glossma palputis im Lande zu bestinunen. Die G. palpatis ist die Art von Tsetsefiiege, welche die menschliche Trypanosomiasis, die zur Schlafkrankheit führt, durch Übertragung hervorruft. Gleichzeitig bricht Kapitän Greig von der Royal Societys Commission in Uganda zum Studium derselben Frage nach den Niluferm des südlichen Sudans auf. Man kommt zu dem übereinstimmenden Gutachten, daß die Palpalis bisher in den durchzogenen Gebieten nicht vorkomme, daß3 damit die Gefahr für die Hoffnung des Sudans, die Baris, die Dinkas und die anderen ackerbautreibenden Stämme des Südens als geringer anzusehen sei. Beide Forscher beobachten dagegen im Bahr el Ghazal eine andere Art der Tsetsefliege, die Glossinu morsitans, die angebliche Ursache der Trypanosomiasis der Tiere. Rinder, Esel, Maultiere, Kamele werden von dieser Parasitenkrankheit in gleich verheerender Weise ergriffen. Dr. Neave entdeckt dort zudem Trypanosomen im Blute der Fische und Vögel, und aus Südkordofan kommt die Nachricht, daß Major Morant daselbst die G. morsitans ebenfalls vorgefunden hätte.

Das alles erhöht die Sorge. Die Infektionsgrenzen zwischen Tier und Mensch, die Erreger selbst sind noch nicht eingehend genug studiert und unwiderleglich festgestellt worden. Der Schaden durch die Tierverluste bedeutet gleichfalls ein großes Hindernis der Kulturentwicklung. So werden neue Kämpfer nobilisiert. Major D a n s e $\mathrm{Br}$ ow $\mathrm{n}$ in $\mathrm{g}$ vom ägyptisch-militärärztlichen Korps geht zum Studium der Schlafkrankheit nach dem Süden der Bahr el Ghaza l-Provinz und die K hartume r Laboratorien studieren die Physiologie und Biologie der Trypanosomen, impfen und beobachten erkrankte Nutzticre. Daneben kommen noch andere Krankheitscrreger der Tiopen zur Erforschung: Die Maggotfliege (Bengalia depressa Walker), deren Larve unter der Haut der Menschen und Tiere nistet und schwere Hautentzündungen hervorruft; die vielen Moskitos-Arten, deren Magen nach $\mathrm{RoB}$ die Begattungsstätte der Malariaparasiten ab- 
giht. Die Entwicklung der Parasiten in der Mücke hängt von gewissen Temperaturen ab. Parasiten des Tropenfieber's vollenden ihren Entwicklungsgang bei $30{ }^{\circ} \mathrm{C}$ in acht Tagen, bei Temperaturen unter $15^{\circ} \mathrm{C}$ unterbleilst er völig. Anch diese Plage des Menschen und seiner Haustiere wächst daher in den Tropen ins Ungemessene und vermehrt die vielen Aulgaben der liulturellen Erschlieber des Sudans. Jetzt soll diesen ein neues wertvolles Hilfsmittel geschaffen werden: ein schwimmendes Lahoiatorium. Gerade der südliche, ungesündeste Teil des Sudans besitzt cine Menge ron Wassersiraben. Untersuchungen an Ort und Stelle sind weit wertvoller als solche nach langem Transport. Sofortige Blutuntersuchungen, manche andere mikroskopische und chemische Arheiten werden erst dadurch ausführbar werden und der Forschungsarbeit zugute kommen.

\section{Weitere Maßnahmen und Pläne.}

Rechtsprobleme und Rechtspflege im Sudan. - Ein neuartiges Stenersystem. Bodenbesiedlung und andere Bodenfragen. - Schulwesen und Missionswerk. Landwirtschaftliche Wanderinspektoren und die Arbeit der Versuchsfarmen. Zuckerrohr im Sudan. - Die Lösung der Bewässerungsfrage.

Selbst die heidnischen Neger haben ihre bestimmten Reehtsanschauungen. Man rühmt ihnen sogar ausgesprochen juridischen Sinn nach. Sie ziehen Rechtsfragen in gewissenhafte Erwägung, urteilen nach Präzedenzfällen, holen wohl auch in schwierigen Fragen den Rat eines benachbarten Häuptlings ein. Die mohammedanischen Neger und Araher besitzen schon im Koran Gesetzes. normen von unantastbarer Autorität. Nun konmt als dritte Rechtsquelle des neuen sudanesischen Staatengebildes die europäische Rechtsüberzeugung hinzu. Zugleich bringt die Neuordnung der Dinge eine Reihe schwieriger Rechtsprobleme mit sich und kompliziert die bereits rorhandenen. Tehmen wir nur die Regelung des Bodenbesitzes als Beispiel her. Das alljährliche Okkupieren von Weideplätzen durch einen Stamm, das vorübergehende Be. nutzen des Ackprbodens, wie es im Sudan so vielfach vorkommt, ist, genau betrachtet, noch nicht als Eigentumstitel anzusehen. Die Gewohnheit hat vielleicht in manchen Fällen gewisse Anspiüche verliehen, doch bedeuten diese noch lange nicht das Privateigentum am Boden. Das Labile dieser Ansprüche, ihr Verhältnis zum wirklichen Bodenbesitz, der Übergang in das Privateigentum — das alles hildet die unerschöpfliche Quelle komplizierter Rechtsfragen. 
Ein anderes Beispiel, um den Unterschied in den Anschauungen von Negern und Europäern zu zeigen: Der Schilluk Kwat Wad Awaibung hat den Schilluk Ajak Wad Deng ermordet. Vor Gericht verantwortet er sich mit dem unerschütterlichen Bewubtsein des gerechten Mannes: Ajak Wad Deng hätte seinen Sohn verhext und durch ein Krokodil auffressen lassen. Und er findet eine Anzahl Zeugen, die das Hexenwerk und die Anstiftung des Krokodils bestätigen, und alle Leute im Dorfe sind von der Möglichkeit des Geschehens fest überzeugt. Lord Cromer wirft gegenüber diesem Beispiele die Frage auf, ob eine Bevölkerung mit solchen Ansichten wohl nach einem Verfahren behandelt werden könne, das in Paris oder in Berlin in Geltung steht ${ }^{1}$ ).

Das Recht hat sich stets und überall aus den tatsächlichen Verhältnissen entwickelt. Es wird nur dann als gerecht empfunden, wenn es den wirtschaftlichen Bedürfnissen und den sittlichen, religiösen und sozialen Anforderungen des momentanen Kulturzustandes entspricht. Den gegenwärtigen Verhältnissen des Sudans entsprechen weder die bisherigen negroiden oder mohammedanischen Rechtsnormen, noch lassen sich die des Europäers einfach dahin verpflanzen. Die Engländer haben deshalb einen Beweis ihrer Kolonisationserfahrung und ihres praktischen Blickes gegeben, wenn sie, diesem Umstande Rechnung tragend, ihre Zivil- und Strafgerichtsbarkeit nach orientalischen Gesetzesbüchern, unter Berücksichtigung der wichtigsten Forderungen europäischer Rechtsanschauung eingerichtet haben. Der sudanesische „Criminal Procedure Code ${ }^{4}$ ist weniger abstrakt als die europäischen Gesetze gehalten. Instruktionen erleichtern seine Anwendung, die Einführung erfolgt nach und nach. In der Bahr el Ghazal-Provinz wird der Codex erst seit 1908 angewendet. Eine besondere Rücksichtnahme auf die mohammedanische Bevölkerung bekundet die Einführung von mohammedanischen Gerichtshöfen, an denen moham-

1) Nicht weniger charakteristisch ist ein Bericht des Gouverneurs von Mongalla, des Kapitäns R. C R. Owen. Zu dem kommt der Berri Kid-Di mit den Bitte, seinen Vater, den alten Schêch Alikori, töten zu lassen. Das sei bei dem Beristamme von altersher Sitte, wenn der Sohn ein gewisses Alter erreicht hätte; Alikori wäre zudem bein Stamme verhaßt, weil er den Regen verhindere. Der Vater fand das Begehren anscheinend ganz natürich und begann erst dann su schimpfen, als der Sohn, nach Abschlagen des Verlangens, den Alten nach Khartum verschicken lassen wollte. 
medanische Kadis kleinere Personalangelegenheiten nach den unabäderlichen Gesetzen des Islans entscheiden. Dalei hat man auch diese Gerichte gerade genug reformiert, dab das Bagatellverfahren nicht so endlos lange Zeit in Anspruch nimmt als in $\ddot{\Lambda} g y p t e n$. Sonst liegt die Kriminaljustiz in den Händen der Offiziere; für Zivilangelegenheiten werden nach und nach Zivilrichter herangezogen. In Khartum und Suakin bestehen schon Zivilgerichtshöfe unter nicht militärischen Vorsitzenden, die nördlichen Provinzen Halfa, Dongola, B erber müssen sich vorläufig damit zufrieden geben, daß dort dreimal jährlich Gerichtstag durch einen sie bereisenden Richter gehalten wird.

Es ist anzunehmen, daß die meisten Rechtshandlungen auf der Kulturstufe des Sudans irgendwie mit der Bodenproduktion zusammenhängen. Es wird sich wohl zumeist um Vieh und Viehprodukte, um Bodenerzeugnisse, Anerkennung von Landbesitz und Landbenützungsansprüchen, um Landkäuie und -verkäufe, um Steuern aus Bodenbesitz handeln. Vom Standpunkte der Regierung gehören von den zivilen Fragen die des Landbesitzes und der Steuern mit dem ganzen Komplexe, den sie einschließen, zu den wichtigsten. Sie braucht die Bildung von Bodeneigentum, um Organe der Zivilisation und Steuerzahler zu gewinnen, und die Steuergesetzgebung ist ihr wieder eine Handhabe, um Ansprüche auf Boden, der nicht zu kultivieren beabsichtigt wird, zu beschränken. Ein neuartiges Steuersystem soll dies bewirken und die Eingeborenen zur Bestellung ihres gesamten Ackerbesitzes veranlassen. Das System wurde zuerst in Dongola versucht. Zwei Jahre nach der ersten Verständigung wartet die Behörde zu, dann wird die Steuer von einem Viertel des Bodenbesitzes eingehoben. Nach vier Jahren belegt man schon die Hälfte des Besitzes mit der Abgabe, nach sechs Jahren drei Viertel davon und nach acht Jahren den ganzen Besitz. Die Höhe der Steuer beträgt 10-60 Piaster pro Feddán, die Einreihung in eine von sechs Klassen erfolgt durch die Lokalbehörden. Vorläufig wurde nur Boden, der durch Sâkîjes, Schadûfs, Brunnen oder durch Flut bewässerbar ist, der Steuer unterworfen; Land mit Regenkultur soll erst dann darankommen, wenn das Besiedlungswerk, das Vermessen, das Katastrieren weiter gediehen sind.

In Dongola hat sich das System gut bewährt, die bebaute Fläche vergrößert sich stetig, und das Eintreilsen der Steuern 
macht keine Schwierigkeiten. Das Gesetz sieht Expropriierung im Falle der Zahlungsverweigerung ror, doch sind Zugvieh. Ackergerät und Kleidung davon ausgeschlossen. Eine Reihe von Bestimmungen mildert überdies die Härte des Gesetzes. Im Falle die Ackerbestellung ohne V'erschulden des Besitzers oder Pächters nicht möglich war oder die Ernte mißraten ist, hat die Ortsbehörde den Zahlungsauftrag zurückzuhalten und dem Generalgourerneur darüber Bericht zu erstatten. Dieser kann die Steuer ganz erlassen. In manchen Teilen des Landes darf die Steuer auch in den Landesprodukten abgestattet werden, was eine weitere Erleichterung bedeutet. Das Gesetz soll auch nicht überall gleiche Geltung haben. In der Sennarprovinz, die kulturell rückständiger ist, hat man so die Steuer statt mit dem anfängỉchen Viertel nur nit einem Fünftel bemessen, und die rolle Stener wird dort erst nach zehn Jahren eingehoben.

Eine andere Seite der Bordenfrage ist die Verleiluung ron Regierungsland an Ansiedler und die Entschädigung der Eingeborenen. denen tatsächliche Ansprüche an den anderweitig zu vergebenden Boden zustehen. Dem Konzessionsbewerber wird nach Erlag einer Kaution zunächst die Erlaubnis zur Einleitung der Vorarbeiten erteilt. Nach Ablauf der eingeräumten Frist hat er der Regierung den Plan der Ánlage und der Bewässerung rorzulegen. auf Grund dessen die Bewilligung erteilt und der Kontrakt ausgefertigt wird. Dabei sind Spekulationserwerbungen ron Land mit der Absicht, es weiter zu rerkaufen, ausgeschlossen. Für das erworbene Land wird nur ein geringer Pachtschilling, 40-50 P.T. pro Feddán, eingehoben, denn die Regierung berücksichtigt eben den Wert, den die Bodenbesiedlung für die künftige Staatsentwicklung hat, dann die Kosten und Mühen der Urbarmachung und der Bewässerungsanlagen. Grundsätzlich sollen nicht mehr als 4-5000 Feddán in eine Hand gegeben werden, auch weniger: wenn die Größe des zu konzessionierenden Landes den Mitteln des Bewerbers nicht entspricht. Einem Gebot der Klugheit folgend. will man rorläufig. in Anbetracht des geringen Zivilisationsgrades, nicht in einem Teile des Landes allzu grobe Privatinteressen schaffen.

Bei Ablösung der alten Bodenansprüche spielt bares Geld eine geringe Rolle. Die Eingeborenen haben dafür entweder keine Verwendung oder verschwenden es auf einmal, un dann wieder Not zn leiden. In Fällen von zweifelhaften Besitztiteln wird ein 
Teil des Bodens nunmehr in das unumschränkte Eigentum des Eingeborenen gegeben, der andere Teil dagegen für die Regirrung beschlagnahmt. Es wurde auch versucht, die Ablösung eines Besitzteiles so durchzuführen, dab der andere, dem IBesitzer verbleibende Teil dagegen an Zahlungsstatt mit Bewässcrung versehen wurde. Ohne genügende Wasserzuleitung ist ja lamblhesitz ein zweifelhaftes Gut.

Es kamn hier nicht auf alle Verwaltungsnubiegeh eingegangen werden, die mit dem Bodenbesitze und mit der Bodesausnutzung zusammenhängen, wie auf die Gesetze und Torschriften über die Walderhaltung, den Wildsciutz u. a. m. Dagegen will ieh einiges üher die der Aufklärung und dem Unterrichte de’. Bevölkerung gewidmete Fürsorge berichten.

Den nördlichen Provinzen fehlte es niemals an Berühnurgspunkten mit höherstchenden Kulturfaktoren. Die Verbreitung des Islams hat dort zudem gewisse intellektuclle und ethische I'oraussetzungen geschaften, auf Grund derer sich die Erfahrungen, die in Oberägypten mit dem Schulwesen gemacht wurden, mit geringen Abweichungen verwerten lassen. Man hat eine Anzahl von Kuttabs, Elementarschulen für die Eingeborenen, darunter auch eine Mädchenschule, emichtet. 1908 sind diese insgesamt von 1781 Schülern besucht worden. Im Sudan fehlt es erklärlicherweise noch mehr an den nötigen eingeborenen Lehrern als in Ägypten. Bevor an die Vermehrung der Kuttabs zu denken war, mußte daher die Lehrerfrage gelöst werden. Die Errichtung ron Lehrerkursen in Khartum am Gordon-College, in Ondurnan, Suakin und Rufar soli dem Mangel abhelfen. Gegenwärtig nehmen 174 den einflußreichsten Familien angehörende Eingeborene im Alter von 17-24 Jahren an dem Unterichte teil. Ihre Ausbildung zu Lehrern oder Kadis wird fünf Jahre heanspruchen.

Höhere Primärschulen gibt es in Khartum, Omdumman. Wad Medani, Suakin, Halfa und Berber. Handwerkerschulen bestehen am Gordon-College, in Ondurman und in Kassala. Es ist schmeichelhaft für die hosnische Landesregierung, daß ihre einschlägigen Einrichtungen für die des Sudans vorbildlich geworden sind. Die Sudanregierung sandte 1905 einen Beamten ihres Unterrichtsdepartements zu Studienzwecken nach Bosnien. Del Bericht darüber hebt die außerordentlichen Erfolge hervor, die in Bosnien nach dieser Richtung erzielt wurden, indem man euro- 
päisches technisches Können eingefüht habe, ohne die überlieferte heimische Volkskunst zu vernichten. Lord Cromer meint, daß die primitive Stufe des sudanesischen Kunsthandwerks sich wohl nicht mit dem viel höheren Können der ursprünglichen bosnischen Heimatskunst vergleichen lasse, daß aber das System an und für sich ein nachahmenswertes wäre und Resultate gezeitigt hätte, wie sie auch in Ägypten nicht annähernd erreicht wurden.

Im Sudan handelt es sich freilich nicht so sehr um Volkskunst als um die Hebung des praktischen Handwerks. Daneben braucht man vor allem Hilfskräfte für die Beobachtungs- und Vermessungsarbeiten, für die Regierungsbauten, für den Betrieb der öffentlichen Einrichtungen usw. Am Gordon-College besteht eine Abteilung zur Ausbildung ron technischen Hilfskräften, die vier Klassen enthält, und eine Abteilung für Vermessungsgehiifen mit zwei Klassen. Da die Nachfrage nach so ausgebildeten Leuten sehr groß und die Bezahlung relativ hoch ist, sind diese beiden Kurse stets voll besetzt.

Im heidnischen Afrika, das kaum noch ein Strahl der Gesittung erreicht hat, läß sich mit der Schulweisheit vorläufig noch nicht viel anfangen. Dort kann man nicht einfach Schulen durch Gesetze ins Leben rufen, sondern num erst schrittweise das Vertrauen der Bevölkerung erwerben und sie die Vorteile der Zivilisation kennen und rerstehen lehren. Bei dieser mühsamen, gefahrvollen und unendliche Geduld erheischenden Kleinarbeit leisten die christlichen Missionsgesellschaften unschätzbare Dienste. Die Regierung verbietet das Missionswerk unter den Mohammedanerı. nimmt es dagegen für die Heiden dankbar in Anspruch. Wo die Berölkerung am barbarischsten, das Land besonders unzugänglich, das Klima recht mörderisch ist, sind diese wahren Vertreter christlicher Nächstenliebe unermüdlich an der Arbeit. Als Ärzte, Bodenbebauer und treue Ratgeber gewinnen sie das Vertrauen der Eingeborenen und bringen den armen Wilden viel Gutes. Die Church Missionary Society entsendet drei Missionare nach Mongalla; sie nehmen gleich einen tüchtigen Agrikulturisten und einen technisch ausgebildeten Handwerker mit. Die verschiedenen Stationen der österreichischen Nission am oberen Nil und in der Bahr el Ghazal-Provinz unter Bischof Gayer setzen ihre kulturelle Tätigkeit, ungeachtet der Krankheiten, die das Klima unter ihren Brüdern hervorruft, bei den Shilluks und unter den verschiedenen Stämmen bei Wau fort. Sir Reginald Wingate 
bestätigt, dak die Mission zur landwirtschaltlichen un? technischen Erziehung dort viel beiträgt. Die englisehen Missionäre zu Bor wurden bis aul drei invalid, aher die drei haben einstweilen die Dinka-Sprache erlernt und ziehen weiter in das Innere, in die Allabgegend am westlichen Ufer des oheren Nils, wo sic unter den Dinkas und Baris wirken. Über die Missionsarbeit unter den Paganstänmen äufert sich unser Landsmamn Baron Slatin Pascha: Sie ist eine wahrhaft zivilisatorische. Die Missionare lehren die Wilden zuerst die Elemente rernünftigen Denkens und guter Sitten und Gehorsamkeit gegen die Regierung, damn crst Religion. Soviel ich hoobachten konnte, haben sie woder cinen einzigen Wilden getauft noch zum Christentum bekehrt, aber es ist unzweifelhaft, daßs sie einen äuß̉erst günstigen Einfluß auf den Charakter der Eingeborenen, unter denen sie sich angesiedelt haben, ausüben, und daks sie das Vertrauen der Bevölkerung gewonnen haben."

Dort, wo die Voraussetzungen hereits günstiger sind, errichten die Missionare auch Schulen. So hat die amerikanische Mission Mädchenschulen in Athara, Khartum und Omdurman eröffnet, die "English Church Missionary Society" läßt zu Khartum und Omdurman Mädchen ron englischen Damen unter Assistenz ron syrischen Lehrerinnen unterrichten. Die Osterreicher halten zu Khartum, Omdurman und Port Sudan vier Missionsschulen, die von mehr als zweihundert Knaben und Mädchen besucht werden. Die beiden ersten Gesellschaften haben in Khartum und Omdurman auch Missionsspitäler errichtet.

Die Arbeit der geistlichen Missionare erleichtert die Wirlisamkeit der weltlichen Aussendlinge im Dienste landwirtschaftlicher Kultur. Das Ackerbaudepartement zu Khartum entsendet vier Inspektoren, die die Verhältnisse rings im Lande studieren, Versuche anstellen, den eingeborenen Landwirten mit Rat und Tat an die Hand gehen und der Regierung nach deu gemachten Beobachtungen Vorschläge erstatten. Der Inspektor Mr. Darie kehrte gerade während meines Aufenthaltes in Khartum ron seinem Arbeitsgebiete an der Abyssinischen Grenze zurück. Er hatte in Kassala und in Debelawaid Farmversuche angestellt und die Verteilung von Land unter die Eingeborenen vorgenommen, das durch Anlage einer Stauanlage im Gashflusse mit Bewässerung versehen worden war. Die Nachfrage nach Boden reichte an die verfügbare Fläche lange nicht heran. Im ganzen wurden 
3267 Feddán in Losen von 5-10 Feddán und zum Pachtzinse von 20-40 P.T. pro Feddán den Reflektanten zugewiesen. Mr. Da vie hätte auch die Regenkulturen in der Nähe ron Gedaref inspizieren sollen, Schadenerhebungen über die Verheerung durch Heuschrecken verlängerten indes seine Anwesenheit am Gashflusse.

Die Versuche bei Kassala umfabten eine Fläche von 80 Feddain. Durra, Kotton, Sesam, Mais. Weizen, Erdnuf wurden in verschiedenen Varietäten zu verschiedenen Zeitpunkten und unter verschiedenen Bewässerungsverhältnissen gebaut. Die richtige Anwendung der Bewässerung ist im Hinblick auf die Bedürfnisse. der Pflanzen und auf die jeweilig zur Verfügung stehenden Wassermengen ron besonderer Wichtigkeit. Die Versuche ergaben, daß der Boden einen aukerordentlich reichen Torrat an Bodennährstoffen besitzt und nur genügend Wasser braucht, um glänzende Erträge $7 u$ geben. Bei einer Bewaisserungsdauer von 67 Tagen, wie sie die normale Flut des Gash nit sich bringt, läßt sich allerdings mit vollem Eriolge nur Durra pflanzen. Die anderen Früchte haben eine zu lange Vegetationsdauer und würden die Ausdehnung der Bewässerung um 20-25 Tage beanspruchen. Auf Böden, die nicht durch Überflutung, sondern, ähnlich wie wir das in Oberägypten gesehen haben. mittelst Bassins bewässert werden, ist das Datum der Aussaat in anderer Hinsicht ron großer Bedeutung. Pflanzen, die man zu bald nach Beginn der Juliflut baut, sind im heiken Monate Oktoher im Wachstum zu sehr vorgeschritten. Wegen der großen Oberflaiche ihrer ausgebildeten Blätter sind sie nicht imstande, ihren Wasserhaushalt zu regeln. Die Transpiration ist bei der Sonnenglut und den heißen Winden zu stark, und die Wurzeln sind unfähig, den Wasserverlust aus dem ebenfalls rasch ausgedörrten Boden zu decken.

Die zeitweilige Trockenheit des Sudans hat zu dem interessanten Versuche geführt, eine strauchförmige, perennierende Bammollart, Carabonica, dahin zu verpfianzen. Die Baumwollstaude war in ihrer Urform ausdauernd, und die Carabonica, angeblich aus Australien stammend. stellt wohl eine ältere Form dar, die wegen ihrer Strauchform tiefer im Boden wurzelt und deshalb Trockenperioden besser übersteht. Der zwölf Fuß hoch werdende Strauch gilst nur eine Ernte im Jahr. Die Samen werden $3 \mathrm{~m}$ im Quadrat gelegt und keimen sehr langsam. Das erste Pflücken beginnt sechs Monate nach der Aussaat. Die Faser ist seidenweich und langstapelig. 
Von Versuchen in anderen Distrikten sind hervorzuhoben: eine Indigoanpflanzung in Berber. die jedoch kein günstiges Resultat ergah. Reishauversuche in Wan und in Bahr el Ghazal sind noch nicht abgeschlossen, doch erwartet man ebensoviel davon wie von den Versuchen Sesan in Süden zu ziehen. In der Semnarprovinz reift Sesam als Regenfrucht ohne künstliche Bewässerung. In Dongola werden Versuche, die Weinrebe dort heinisch zu nuachen, unternommen. 200n Stecklinge, die aus Italien hezogen wurlen. sollen im Mudiriagarten zu Merove ausgepflanzt werden. Es sei hierzu bemerkt. dalis verschiedene Obstarten im Sudan ganz gut gedeihen. Zu Dueim und Erkowit gibt es schon rereinzelte Weingärten, in Khartım Feigenbäume; custard-apples (Flaschenbäume) mit genießharen Früchten kommen überall fort, und im Süden findet sich die Banane vor.

In einem Lande mit so rerschiedenen Bedingungen, wite sie der Sudan aufweist, ist eine Konzentration des Versuchswesens noch weniger denkhar als anderswo. Ergelmisse, die in Berber oder Dongola erreicht wurden. sind für den Westen oder Süden nicht mafgebend, nicht eimmal für die näher gelegene Blaue-Nil-Provinz oder Khartum. Die Eimrichtung der Wanderinspektoren hilft in dieser Hinsicht über manche Schwierigkeit hinweg. doch erfordern die kulturell weiter fortgeschrittenen Teile des Sudans eine eingehendere Behandlung des landwirtschaftlichen Versuchswesens, als sie dem einzelnen Aussendling möglich ist. Von allen Provinzen ist Khartum schon als Sitz der Zentralregierung die wichtigste. Die Provinz Khartum besitzt aber auch eine Berölkerung, die im Terhältnis zu ihrer Ausdehnung genug zahlieich ist und sich für den Ackerbau gut eignet, ein besseres Kilmal als die meisten anderen Provinzen, geordnetere Eigentums- und Rechtsverhältnisse als diese. Zudem an den Ufern des Blauen und des Weißen Nils gelegen (sie umfaßst die Städte Khartum und Omdurman mit einem kleinen Hinterland), stehen der raschen Entwicklung ihrer Landwirtschaft am wenigsten Hindernisse entgegen. In Würdigung all dieser Umstände hat man in Khartum eine Zentralexperimentalfarm geschaffen und eine zweite Versuchsfarm nur bo Meilen davon entfernt. in Kamlin. dem früheren Hauptorte der Ghezira- oder Blauen Nil-Provinz errichtet. Khartum ist auch als Sitz einer demmächst zu eröffhenden Mustermilchwirtschaft ausersehen, und dort soll mit der Hochzucht der einheimischen Rassen begonnen werden. 
Die Stationen von Khartum und Kamlin stellen die Beobachtung des Pflanzenbaues unter verschiedenen Bewässerungsverhältnissen gleichfalls in den Vordergrund. Die Versuche werden mit wechselndem Erfolge auf ägyptische und heimische Baumwollsorten, auf sudanesischen, ägyptischen und indischen Weizen, auf Gerste, Sesam, Erdnüsse, Mais, Bohnen, Boxhorn und Futterpflanzen ausgedehnt. Die Bersimernte gab 1907 zum ersten Male ein günstiges Ergebnis. Von verschiedenen Gemüsen wurde bisher noch nicht viel geerntet; Versuche mit englischen Kartoffelsorten sind noch nicht abgeschlossen.

Höchst bemerkenswert ist der gute Ausfall eines Zuckerrohrversuches. Es scheint, daß das Zuckerrohr im Sudan ausgezeichnete Vorbedingungen findet. Solange indes im Lande keine Faktoreien errichtet werden, ist an Rohrbau in weiterem Umfange wegen Mangel an Absatz nicht zu denken.

Die Musterfarm in Kamlin hat sich an den Experimenten nur in beschränktem Umfange beteiligen können, weil sie sich selbst erhalten soll und deshalb den größten Teil der Fläche mit gut rentierenden, erprobten Früchten bebauen muß, die gerade vom Standpunkt des Versuchswesens weniger Interesse erwecken. Im Berichtsjahr waren zwei Drittel des Bodens mit Erdnuß bestellt.

Die Anordnung der Versuche wurde im Einverständnis mit Mr. Dupuis, dem Generalinspektor des sudanesischen Bewässerungswesens, getroffen. Könnte die Wichtigkeit, die man der Wasserfrage bei der Entwicklung der sudanesischen Landwirtschaft zuerkennt, wohl augenfälliger gekennzeichnet werden? "Wenn man im Sudan bewässern kann, ist das Agrikulturproblem leicht", berichtet der Regierungsagrikulturist Ibrahim Effendi Fahmy von Khartum. Er unterschätzt vermutlich die Schwierigkeit der Situation, hat aber sicherlich darin recht, das der landwirtschaftliche Erfolg der wichtigsten Provinzen von der Beschaffung ausreichender Bewässermug abhängt. Das ist die übereinstimmende Meinung aller Funktionäre des Sudans, die Will cox in scharf bestinimter und abgegrenzter Form zusammenfaßt: "Ohne die Erlaubnis, zwischen dem 15. Juni und 15. Februar im Sudan Wasser pumpen zu dürfen, kann die Kultur von Baumwolle und Weizen in halbwegs nennenswertem Umfange in den nördlichen Teilen der Ghezireh, längs des Nils zwischen Khartum und Dongola und an Athara nicht in Frage kommen. Mais, Hirse, dann einige 
anspruchslosere Leguminosen lieben sich mit l'umpenbewässerung. die zwischen dem 15. Juni und 15. Olitober in Tätigkeit stünde, hauen. doch rentieren sie die Kosten der Pumparbeit nicht." Was die ohen geschiläerten Experimente an Gashflusse gelehrt haben, wird hier wicder bestätigt: Alle wertvolleren Pflanzen brauchen cine Bewässerungsdauer, die über die Flutzeit hinüber währt. Ohne künstliche Bewässerung, mit dem natürlichen Regenfall lält sich kaum etwas anderes als Durra hervorbringen und die in ausgedehntem Maße nur in guten Regenjahren.

Diese Erkenntnis ist schwerwiegend genug. Bis jetzt war das Bewässern mit Flußwasser in Sudan rom 1. Februar bis 15. Juli untersagt. Die Wasseradern des Landes gehören alle dem Systeme desselben Nils an, der Ägypten befruchtet. Jede Entnahme aus dem Nil und seinen Nebenflüssen verringert daher die Wassermenge, die nach Ägypten hineinkommt. Ägypten hat ältere Anrechte auf Bewässerung, in Ïgypten stchen mehr wirtschaftliche Interessen auf dem Spiele, der ägyptische Boden soll schlieblich die Mittel zur kulturellen Erschließung des Sudans herbei schaffen. So müssen der Wasserentnahme im Sudan so lange Beschränkungen auferlegt werden, bis der Bedarf Agyptens sichergestellt ist. Die Wasserfrage des einen Landes aber läßt sich von der des anderen nicht trennen, und die Lösung des Problems setzt die Vermehrung des Wasserzuflusses in Ägypten zur Sommerszeit auf eine Weise roraus, die den bisherigen Wasserrorrat des Sudans zumindest nicht verringert.

Das Studium der Frage, das den Nil bis in seine Quellgebiete verfolgt, hat indessen das scheinbar Unvereinbare in dieser Forderung in das Bereich des Möglichen gerückt. Wir wissen, daß das Wasser, das zux Zeit der Hochflut nach Ïgypten gelangt, zumi größten Teile dem Blauen Nil entstammt, während der trägere Weife Nil erst nachher, wenn der Wasservorrat des Blauen Nil und des Atbara sich vermindert haben, an der Versorgung Ägyptens stäkeren Anteil nimmt. Der Blaue Nil ließe sich nach dem Berichte Sir William Garstins durch eine Stauanlage am Tsana-See, den er in seinem Oberlaufe noch unter dem Namen Abai durchfließt, verstärken. Dieser einfachste Weg der Nilregulierung kann indessen nicht eingeschlagen werden, weil der Tsana-See in Abyssinien liegt und es wohl ungeachtet aller Verträge nicht empfehlenswert wäre, den Schlüssel zu den WVasser- 
verhältnissen Ägyptens und des Sudans in fremde Hände zu legen. Die Aufmerksamkeit wendet sich daher dem Weißen Nil zu, der dem unerschöpflich reichem Quellgebiete der Äquatorialseen entstammt. Ton deren Wasserüberfiuß gelangt freilich nicht viel bis in den Weißen Nil. Der Bahr el Dschebel verliert mehr als dic Hälfte der Wassermassen, die ihn bei Austritt aus dem Albert Ny ansa bilden, bevor er, zum Weiken Nil geworden, den Sobat in sich aufnimmt. In den Sumpfgebieten des Weiken Nils und des Bahr el Dschebel hat sich das Wasser verlaufen, hat die Morast. bildung vermehrt. wie fü̈her zwischen dem ersten Quellsee des Nil. dem Tiktoria Nyansa und dem Albert.See. Dort schon hat die grofartige Wasserverschwendung begonnen. Sir William Willeox berichtet. dab der Viktoria Nyansa allein genug Wasser besitzt. um Ägypten mitsamt dem ganzen Sudan ansreichend bewässern zu können.

Diese Tatsachen liegen dem weit ausgreifenden Plane zugrunde. den Sir William Garstin in seinem schon erwälnten Berichte ron 1904 ausführt: Den Blauen Nil für die Versorgung seiner Uferstrecken zu verwenden und die Wasserreservoirs in Ägypten und im Niltal nördlich ron Khartum aus dem Weißen Nil zu speisen. Ton den beiden Vorarbeiten, die nötig sind. um die Leistungsfähigkeit des Weißen Nils den erhöhten Ansprüchen anzupassen, bietet die eine, die Regulierung der großen Quellseen. geringere technische Schwierigkeiten. Es hätte indessen keinen Wert, den Ausfluk der Seen zu verstärken, solange sich das Wasser des Flusses in den weiten Marschen rerliert. Die Regulierung des oberen Flublaufes muls daher rorangehen.

Weit ist man bisher damit nicht gelommen; kaum so weit. um der Regierung bestimmte Vorschläge erstatten zu können. Eine Reihe hegabter junger Forscher, wie Walsh. Totten ham und Colvin, leistet Auferordentliches bei den Arbeiten im Sumpfland des Sobat. des Bahr el Zeraf und des Bahr el Dschebel. aber in diesen fürchterlichen Gebieten wird die Zeit, in der Europäer überhaupt schaffen können, nicht durch den Willen. sondern durch die Natur bestimmt und bleibt immer beschränkt. Das Problem des Weißen Nils ist noch weit von seiner Erfüllung entfernt und wird es rermutlich noch jahrelang bleiben. Ernste Kostenroranschläge für die Durchführung aufzustellen, ist kaum möglich. Unter diesem Vorbehalt schätzt Sir Garstin die Kosten der Regulierungsarbeiten an den Quellseen auf etwa 2 Millionen I. E. 
und die der Regulierung des Niloberlaufes, des Bahr el Ischebel und des Weiken Nil, auf $51 / 2$ Millionen L.E.

Am Blanen Nil geht die Arbeit rascher vonstatten. Das Ackerland, das in der Ghezireh der Bewässerung harrt, ist immens. Mr. Dupuis, der Vorstand des sudanesischen Bewässerungsdepartements, schätzt es blof nördlich von $W$ ad Medani auf 3-4 Millionen Feddán, das sind zwei Drittel der ganzen Fläche, die in Ägypten überhaupt kultivierhar ist. Für das Bebanen solcher Riesenflächen fehlt es heute im Sudan noch an Menschen, und dafür wird wohl auch der Blaue Nil nicht früher genug Wasser liefern können, his Ägypten seinen Haupthedarí aus dem regulierten Weißen Nil deckt und am Blauen Nil Staudämme und Wasserreservoirs angelegt sind. So weit versteigen sich die gegenwärtigen Pläne nicht. Nur ${ }^{1}{ }_{2}$ Million Feddán sollen vorläufig am Blauen Nil mit Bewässcrung versehen werden. Eine Barrage im südlichen Sennar, ein Kanal, der das Land bis nach Khartum hinab bewässert, dafür reicht schon heute das Wasser im Blanen Nil aus. Die Kosten beziffert man maximal mit $1 / 2$ Million für the Barrage und etwa ebensoviel für den Kanal, und das Land, das dadurch dem Weizen- und Kottonbau zugeführt wird, kann leicht 50 P.T. Steuern vertragen. 500000 Feddán zu 50 P. das gibt jährlich ${ }^{1}{ }_{4}$ Million L.E., also 8\% vom Anlagekapital. Die Vorstudien sind so gut wie beendet. Bald wird die vollendete Ghezirehbahn die Materialien herbeischaffen, und das große WVerk kann beginnen.

Noch bessere Rentabilität wird von den Regulierungsarbeiten am Gashflusse erwartet. Sir Garstin macht wohl auch hier den Einwand ganz unzureichender Niveaukenntnisse, glaubt aber doch mit 500000 L. E., 100000 Feddán Kulturland die Bewässerung schaffen zu können. Abermals mit 50 P.T. zur Steuerleistung herangezogen, würden sie jährlich $10 \%$ des Kapitalaufwandes zurückbringen. Auch hier hat man sich einstweilen mit Versuchen in kleinerem Ausmaße begnügt und hat 1906 eine niedere Stauwehr und einen Verteilungskanal gebaut. Die Vorsicht war am Platze, denn die erste Flut zerstörte Dämme und Kanäle, und es fehlte an Arbeitskräften, ım den Schaden wieder gutzumachen. Resigniert gibt Garstin zu, daß am Gashflusse nach ungenügenden Vorstudien gearbeitet wurde. Der Gashfluf mit seinen vielen Windungen und dem verhältnismäßig kurzen Lauf bietet plötzlich hereinbrechender, reifender Flut viel Angriffspunkte. Nach der 
Landverteilung und den Versuchen bei Kassala zu schliefen, vor denen früher berichtet wurde, scheint man jetzt doch schon Herr der Situation geworden zu sein.

Es fehlt auch sonst nicht an kleineren Projekten, die Bewässerung hier und da zu verbessern, irgendeinen Nebenfluß zu stellenweiser Bewässerung heranzuziehen. So war einmal die Rede davon, durch die Eindeichung des Khor Barraka unter Zuziehung des Gashflusses in der Tokarebene weitere ungemessene Flächen der Baumwolle zu gewinnen.

Wir wollen heute auf all diese noch unbestimmten Plän nicht eingehen, da die Zukunft der Ausführung der wohl begründeten Projekte noch so viel vorbehalten hat.

\section{Das bisherige Ergebnis.}

Lin Durra-Offert aus Omdurman. - Die bebaute und bewässerte Fläche. Die Dichte cier Bevölkerung. - Grundsteuerertray und andere Aktivposten.

Das Arbeitermaterial. - Landkonzessionäre. - Eine Farm an Blauen Nil.

Während ich eben bemüht bin, aus vorliegenden Zusammenstellungen des sudanesischen Ackerbaudepartements ein Bild von dem bisher Erreichten zu gewinnen, bringt mir die Post einen Brief aus $\mathrm{Omdurman}$. Er ist vor zehn Tagen abgesanat worden, and der Verfasser, der mich von meinem dortigen Aufenthalt kennt, schreibt: "Ich habe in diesem Jahre erstmals und mit gutem Erfolge kommissionsweise den Gummiarabikumeinkauf für ein erstes deutsches Haus besorgt und würde mich freuen. wenn ich auch von Threr Firma wegen Durra Auíträge erhalten würde."

Nur zehn Tage hat der Brief aus $\mathrm{Omdurman}$ gebraucht, um nach Wien zu gelangen, und der Marn offeriert mir Durra aus dem Innern Afrikas wie irgendwer Hafer aus Florisdorf. Fürwahr, der Brief aus Omdurman ist ein Symbol des schon Erreichten, ein schlagender Beweis, daß die unsäglichen Opiel für die Zivilisation des Sudans nicht vergebens gebracht worden sind.

Einen ziffermäßigen Maßsstab für den bisherigen Erfolg der Kulturarbeit geben diese Daten des Ackerbaudepartements.

\begin{tabular}{lrrrr} 
& $\begin{array}{c}1904 \\
\text { Feddản }\end{array}$ & $\begin{array}{r}1906 \\
\text { Feddán }\end{array}$ & \multicolumn{1}{c}{$\begin{array}{c}1907 \\
\text { Feddán }\end{array}$} \\
Künstlich bewässertes Land. . . . . . & 100339 & 116773 & 120760 \\
Durch Fiut bewåssertes Land . . . . & 42463 & 95241 & 116697 \\
Unter Regenkultur gestandenes Land & 386437 & 796628 & 1186514 \\
\cline { 2 - 5 } & & 529239 & 1008642 & 1423971
\end{tabular}


Die gesamte bebaute Fläche hat darnach 1907 112:3971 Foddain 600000 ha umfafit. Im Verhältnis zur Ausdehmung des Landeist das freilich sehr wenig, im Verhältnis zur Bevilkerungszahl und zu dem Zustand, in dem sich die Landwirtschaft noch vor wenigen Jahren hefand, viel mehr. In Jahre 190), hat die sudanesische Regierung den Versuch einer Volkszählung unternommen und dabei eine Berölkerung von 1870500 Menschen festgestellt. Daron entfielen auf die einzelnen Pro. vinzen :

\begin{tabular}{|c|c|c|c|c|}
\hline Berber. . & & & & \\
\hline Dongola. & & & & \\
\hline fezireh . . & & . & & \\
\hline Wadi Halfa & & & & \\
\hline ala.. & & & & \\
\hline $1 \mathrm{~m}$. & & & & \\
\hline an. & & & & \\
\hline . & & & & \\
\hline & & & & \\
\hline Nil-P & & & & \\
\hline Gha & & & & \\
\hline
\end{tabular}

Die Bevölkerung der südlicheren Provinzen läb̉t sich indessen wegen ihrer Rückständigkeit nicht recht zählen, man ist hier mehr oder weniger auf Schätzungen angewiesen, die sich bei fortschreitender Erschliefung des Landes ändern. Sir Reginald Wingate konnte deshalb die Bevölkerung 1905 nur mit 1853000 Menschen beziffern, trotzdem sie sich einstweilen stark vermehrt hatte, vermehrt wie der Sand am Meer. Der Kinderreichtum der Sudanesen ist erstaunlich. In der Dongola-Provinz sollen sich unter den 90000 Einwohner, die die Richtigstellung Sir Wingates ausweist, allein 43000 Kinder unter nem Jahren befunden haben; aus den anderen Provinzen werden ähnliche Verhältniszahlen gemeldet. Die Zukunft des Sudans erscheint in dieser Richtung gesichert. die bebaute Fläche aber im Verhältnis zu der erwachsenen Bevölkerung schon jetzt ganz ansehnlich.

Der Fortschritt im landwirtschaftlichen Zustande wird durch den Vergleich der Jahre 1904 und 1907 genügend gekenuzeichnet. Die bebaute Fläche ist von 5229239 Feddán auf 1423971 Feddán gestiegen, hat sich demnach in drei Jahren fast verdreifacht. Das Jahr 1908 lehrt, daf der Kontinuität in Fortschritt gewisse Grenzen gesetzt sind, denm die Ackerfïche kann sich nicht auf der vollen Höhe erhalten und fällt in diesem Jahre um rund 
300000 Feddán. Noch ist die Wasserversorgung nicht genug gesichert; Regenmangel in den nördlichen Provinzen hat die Entwicklung aufgehalten, zurückgeschraubt. Aber dennoch sieht man deutlich: Selbst die ungünstigen Witterungseinflüsse sind nicht imstande gewesen, den Fortschritt ganz ungeschehen zu machen; die Menschen sind unabhängiger von der Natur geworden. Das: Jahr 1908 hat immer noch die doppelte Ackerfläche bestellen können wie das Jahr 1904. Die künstlich bewässerte Fläche wurde vermehrt, die Flut ist dem Bodenbebauer in erhötem Maße dienstbar gemacht worden, und selbst den natürlichen Fegenfall hat er besser ausnutzen gelernt.

Die nachstehende Zusammenstellung zeigt den Anteil der verschiedenen Fruchtgattungen an der bebauten Fläche sowie die Art der Wasserversorgung:

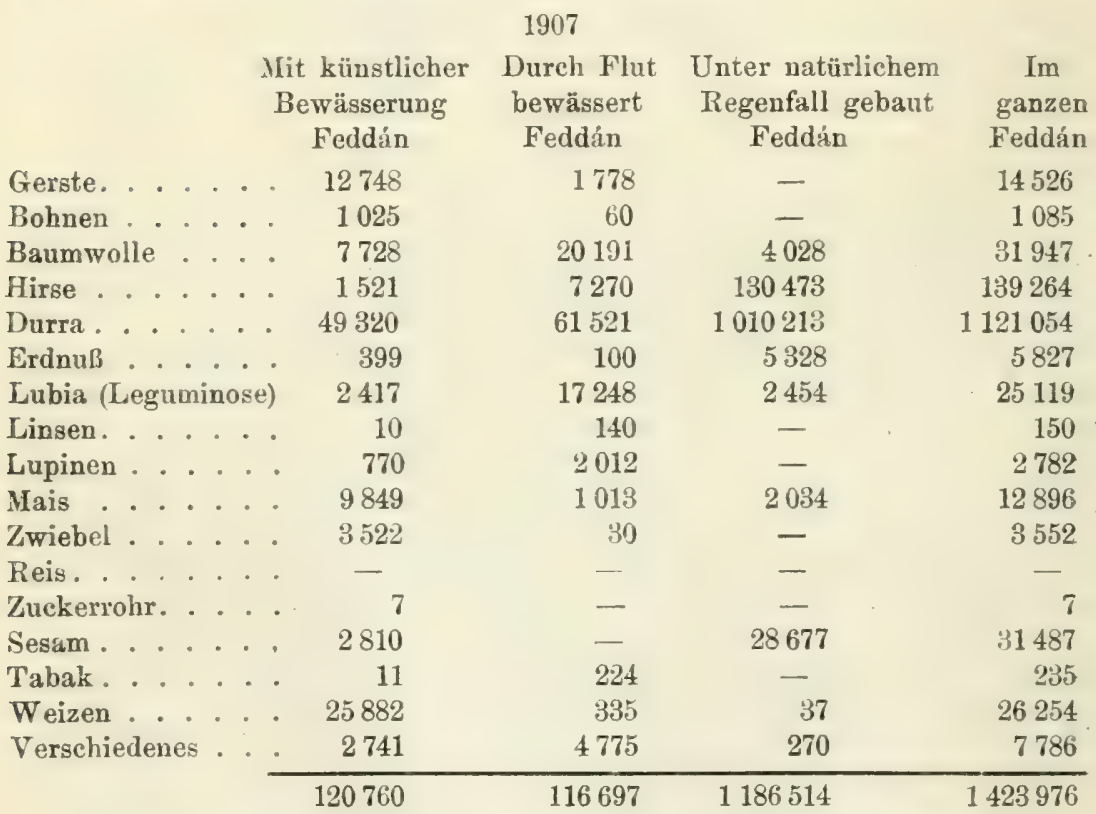

Als besonderer Fortschritt wird hierbei der erfolgreiche Bar von Sesam und Erdnüssen unter natürlichem Regenfall in den südlichen Teilen bezeichnet. Da sich die künstliche Bewässerung noch Jahre hindurch nicht stark ausbreiten lassen wird, ist es sehr wichtig, der Regenzone wertvollere Früchte abzugewinnen und dadurch die Exportartikel zu vermehren. Eine Vermehrung wert- 
voller Bodenprodukte hat auch das Anpflanzen zahliejelere Dattrelbäume, namentlich in Berber und Dongola. gebracht. In der BerberProvinz wurden in den letzten fünf Jahren üher son Stück gep)flanzt, in Dongola im ahgelaufenen Jahre allein gegen 1000).

Üher den gegenwärtigen Viehstand lassen sich verlïbliche Daten kaum bringen, da jede Aufnahme den Argwohn der Eingeborenen hervorrufen würde. Auĺ der Kulturstufe des Sudans ist die Statistik überhaupt eine schwierige Sache und ihre sicherste Grundlage noch die eingehobene Steuer, die wenigstens das Ausmab des bebauten Landes einigermaben erfaßt. Auch dabei ist es natürlich ganz unmöglich, jede Fläche, die unter Kultur liommt, gleich zu erfahren und der Steuerptlicht zuzuführen, besonders in den Landesteilen, die noch der Zehent oder Ouchouri nach altem orientalischen Gehrauch unterworfen sind. Die neue Steuerart, die auf genauer Vermessung und Schätzung beruht und wohl abgestuit ist, schafït hierin vorerst bezüglich der künstlich oder durch Überflutung bewässerbaren Fläche Abhilfe. Es dürfte immerhin einen gewissen Überblick über den Kulturzustand und die Prnduktionsverhältnisse der rerschiedenen Provinzen geben, wenir nachstehend die nach einem der beiden Systeme hesteuerten Flächen angeführt werden:

\section{7}

Neue Grundsteuer Ouchouri Insgesamt besteverte Fläche

Feddán Feddín Feddán

\begin{tabular}{|c|c|c|c|c|c|c|}
\hline Berber..... & . & . & . & . $\quad 47113$ & 2000 & 49113 \\
\hline Dongola .... & & . & . & . 68595 & - & 68595 \\
\hline Kassala.... & . . & . & . & 70173 & 69994 & 140167 \\
\hline Blaue Nilprovinz & . & - & . & 5631 & 546980 & 552611 \\
\hline Sennar . . . & - . & . & . & 2448 & 179494 & 181942 \\
\hline Suakin .... & . . & . & . & 36815 & - & 36815 \\
\hline Khartum ... & . . & . & . & . 15896 & - & 15896 \\
\hline Bahr el Ghazal. & . & . & . & - & - . & - \\
\hline Halfa. . . . . & . . & . & . & 16477 & - & 16477 \\
\hline Weiße Nil-Provin & $n z$ & . & . & 41762 & 118219 & 159975 \\
\hline Kordofan ... & . & . & . & $13: 3$ & - & 138 \\
\hline Mongalla . . . & . & . & . & - & - & - \\
\hline Obere Nil-Provin & $a z$. & - & . & - & - & 一 \\
\hline
\end{tabular}

305043

916681

1221724

Berber, Dongola. Suakin, Khartum und Halfa zeigen schon dadurch, daf das neue Grundsteuergesetz dort angewendet werden kann. ilren kulturell höhern Rang unter den übrigen 
Provinzen an. Nahezu die ganze jetzt bebaute Fläche ist schon vermessen, katastriert und mit künstlicher Bewässerung oder Flutwasser versorgt, die gesamte Produktion wickelt sich in gesichertem und übersehbarem Umfange ab. Sennar, Kassala und die Weike Nil Provinz beginnen sich langsam dem Kreise geordneter landwirtschaftlicher Verhältnisse anzugliedern. Kordofan dagegen hat kaum den ersten Schritt dazu gemacht, und Mongalla, sowie die Provinzen des oberen Nil und des $\mathrm{Bahr}$ el Ghazal lassen vollends ihre tiefe Gesittungsstufe schon dadurch erkennen, daßs sie auch nicht mit dem Ertrage eines einzigen Feddán zu den Bedürfnissen des Landes beitragen können.

Die augenblickliche finanzielle Situation eines erst zu erschließenden Landes ist mehr für das eingeschlagene 'Tempo als für seine wirtschaftliche Gestaltung bezeichnend. Der Aufwand gilt zum kleineren 'Teile dem gegenwärtigen Staatshaushalte, zum größeren Teile Erwartungen, Hoffnungen, die man in die Zukunft setzt. In dem aussichtsvollen Lande mit reichen natürlichen Produktionsmöglichkeiten werden am ehesten Investitionen am Platze sein, die sich erst in der Zukunft bezahlt machen können und das Verhältnis zwischen Aufwand und Leistung verschlechtern. Die Eingänge dagegen hängen vorerst nicht mit der Gröbe der vorhandenen Bodenreichtümer, sondern blobs nit jenem Teile davon zusammen, der dank der erreichten Kulturstufe bereits in der Gegenwart gehoben wird. Ans diesen Gründen spricht es weder für noch gegen den Kulturzustand des heutigen Sudans, wenn wir wissen, dak das Defizit im Jahre 1906 238000 L. E. betragen hat. Dieses Defizit konnte übrigens durch den jährlichen fixen Zuschuß von 253000 L.E., den Ä̈gypten leistet, vollständig gedeckt werden, und es blieben danach noch 15000 L.E. für den Reservefonds übrig. Die Eingänge, die uns als Maßstab wertvoller sind, stiegen von 665400 L. L. im Jahr 1905eauf 969250 L.E. im Jahre 1908. Sie setzen sich aus diesen Titeln zusammen:

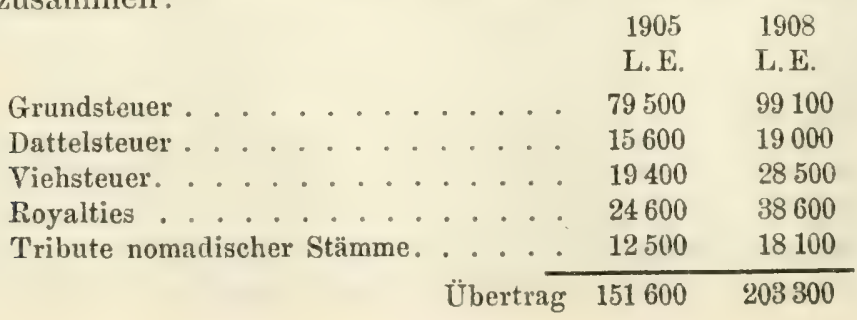




\begin{tabular}{|c|c|c|c|}
\hline & & $\begin{array}{l}1905 \\
\text { L. E. }\end{array}$ & $\begin{array}{l}1908 \\
\text { L.E. }\end{array}$ \\
\hline & Übertrag & 151600 & 203300 \\
\hline Holzverkn̈ufe ... & .... & 16700 & 29400 \\
\hline Diverses. . . . . & $\ldots$ & 48300 & 56700 \\
\hline Zolleingänge . & $\ldots$ & 98000 & 70900 \\
\hline Schiffahrt . . . . & ... & 109800 & 124500 \\
\hline Post und Telegraph . & & 30500 & 47000 \\
\hline Bahnen ...... & & 175000 & 322500 \\
\hline Andere Departments . . . . & . . . & 25700 & 62200 \\
\hline \multirow{2}{*}{\multicolumn{2}{|c|}{ Eingänge bei den Provinzverwaltungen. }} & 9800 & 53600 \\
\hline & & 665400 & \\
\hline
\end{tabular}

Man ersieht deutlich aus den Ziffern, wie die Produktion und der Besitz an Boden und Vieh sich vermehrt haben, wie Handel und Verkehr sich neu beleben, wie die Sicherheit zunimmt. Selbst die Tribute der Nomaden hahen sich gehohen und zeigen, dat; auch die freien Bewohner der Steppe in ein festeres Verhältnis zur Regierung gelangt sind. $\mathrm{Zu}$ den Grundsteuereingüngen hat der große Landbesitz der Konzessionäre bis jetzt noch wenig beigetragen. Die schönsten Gesetze und̉ Regehn zur Förlerung der Landbesiedlung rersagen eben gegenüber den unsicheren Wasserverhältnissen, den hohen Transportspesen, der geringen Erfahrung usw. Keines der vielen Hindernisse wiegt indessen schwerer als der Mangel an Arbeitern. Der Amerikaner Leigh Hunt hat sich für seine Baumwollplantagen Sehwarze aus Caro. lina und Luisiana kommen lassen; Pläne aber, in gröberem Maßstabe Neger oder Kulis einzuführen, sind wohl ganz aussichtslos. Die Regierung wird sich hüten, ein neues Element der Beunruhigung unter die vielen sich feindlich gegenüberstehenden Rassen und Stämme zu bringen. Der ägrptische Fellah. dessen verwandtere Art weniger Befürchtungen nach dieser Richtung erweckt, will seinen heimatlichen Boden um keinen Preis rerlassen, und der Nubier sucht sein Brot lieber in Unterägypten. in Kairo. in Alexandrien und im Delta als im Sudan. So bleibt nur die einheimische Berolkerung übrig. Der Sudanneger mit seinem Kinderreichtum, der mit der Zeit reichliche Arbeitskräfte beistellen wird, und der Beduine, der nach und nach seine Eignting zum Kulturarbeiter erwerben soll. Die ersten Versuche, den Wüstensohn zur Arbeit an der "Nil-Rotes-Meer"-Eisenhahn heranzuziehen, sind kläglich gescheitert. Nun hat sich der Moudir von Kordnfan. der Major O'Connell. als hesserer Beduinen- 
dompteur crwiesen. $\mathrm{Er}$ schreibt in seinem Berichte: "Die Bagarastämme haben heuer weit größere Flächen bebaut, und ein namhafter Teil der Bodenarbeit wurde von Arabern geleistet. Ich bemerke das, um zu zeigen, wie lächerlich die so oft aufgestellte Behauptung ist. dafs Araber mfähig wären, Ackerban zu treiben."

Einer der ersten Konzessionäre, die trotz der Arbeiterkalamität mit der Bodenerschließung zu beginnen wagten, ist der schon erwähnte Leigh Hunt. Er hat südlich von Berber am Nil, in recht großzügiger Weise, die ebenso seiner amerikanischen Herkunft als dem riesenhaften Ansiedlungsgehiete des Sudans entspricht, gleich 200000 Feddán Land erworben. Baumwollfarmen nach amerikanischem Muster sind dort im Entstehen begriffen. "Die "Sudan Exploration Limited" hat sich $190 \%$ in London konstituiert. Sie besitzt zwar nur ein Kapital von $100000 \mathscr{E}$, von dem noch dazu erst $59417 \mathscr{E}$ eingezalilt sind, aber ihre Pläne sind um so weiter ausgreifend. 5000 englischen Quadratmeilen sollen im Sudan erstanden und bebaut werden. Die Gesellschait hat bis jetzt weder einen Bericht ausgegeben noch eine Dividende gezahlt. Die Sudan Development und Exploration Company Limited ist schon 1900 in London mit einem Kapital von $150000 \mathscr{L}$ gegründet worden. Sie beschränkt ihre Tätigkeit nicht auf das landwirtschaftliche Gebiet allein, hat aber auch hier schon schöne Resultate erzielt. Von iner Plantage "Koball oder Mar Joab" wird noch gesprochen werden. Das "Sudan Experimental Plantation Syndicate Limited" hat seinen Sitz in El Damer und ein Kapital ron 80000 L.E. Diese Gesellschaft kann, obwohl erst 1904 ins Leben gerufen, bereits auf bemerkenswerte Erfolge in Baunwollbau hinweisen.

Neben den Unternehmungen der .. Haute finance“, die sich so den Auteil an der künftigen Wertsteigerung im Sudan sicherte, ist so mancher unter die Konzessionäre gegangen, den der '̌ufall oder ein anderer Beruf in das Land geführt hat. In der Dongolaprovinz finden sich ägyptische Offiziere darunter, die in Sudan gedient haben und nun als Landwirte ihr Glück ver. suchen wollen. Ein Mr. Grieve hat bei Fadlab eine Farm errichtet und baut dort prächtige ägyptische Baumwolle. Armenier und Griechen, die gesehäftigen Händler und Geldgeber Ägyptens, haben auch den Sudan zu ihrer Domäne gemacht. Einer der 
untermehnendsten Griechen, Mr. Kallatos, lere in Khartum als Kanfmam ein Vermögen erwarb, hat sich jetzt auf die Bodenkultur geworfen und besitzt, teils allein, teils in (iemeinschaft mit der Sudan Development. Company, teils zusammen mit Zobheir Pascha, den wir schon an anderer Stelle? kennen gelernt haben, vicr Plantagen im Gesantausmalie ron (1000 Feddán. Mr. Ka patos hatte die Freundlichkeit, mich auf seiner eigenen Jacht nach der Baumwollplantage .Koball" am Blauen Nil zu führen. Bei einer Schattentemperatur von einign $40^{\circ} \mathrm{C}$ sind wir da stundenlang in der Sonnenglut zwischen din Feldern herumgewandert. Ififi-, Ashmouni- und Abloasiba um wolle wechselte nit ägrptischem Weizen und Gerste ah. und das alles stand so trefflich, dali man sich inmitten des fortgeschrittensten ägyptischen Betricbes glauben konnte. Nur dab das Grün der Blätter noch tiefer sehien als dort und das Getreide noch üppiger und die Baumwolle noch weiber. Der Anfang war hier freilich schwer genug gewesen. Die spärliche natürliche Flora der trockenen Gebiete treibt ihre Wurzeln tief in die Erde hinein, wo sie im Untergrund länger Feuchtigkeit finden. Da hat der Dampfpthog bei der Urbarmachung harte Arbeit gehabt. Nun ist der 2) pferdige längst wieder nach dem nächsten Gute des Kapatos albgegangen, das jetzt in Kultur genommen wird, und .j2 Paar Buckelrinder besorgen die Ackerung und die andere Feldarbeit anf den 2156 Feddán ganz gut allein. Zwei topferdige Pumpen hebən das Wasser aus dem Nil in den breiten Haupthanal, aus dem es nach Bedarf durch die kleinen Verteilungsgräben auf die Felder gelangt. Dic Bestellungsart, der Kammbau, die Düngung. unterscheiden sich in nichts von dem ägrptischen Ackerbetriebe. Nur die Anbauzeiten sind andere, und der noch unausgenützte Boden gibt öfters Baumwollernten her. Die Aussaat der Baumwolle erfolgt im Juni, die Ernte im Närz. Der Ertrag von fünf Cantar pro Feddán wäre auch in Ägypten ein guter zu nennen. Der Baumwolle folgt erst Sommerdura, dann Bersimklee. Oft bleibt die Durra fort und man pflanzt gleich Bersim oder Helba, den Hornklee, ersetzt wohl auch beide durch andere Leguminosen, Erbsen oder Linsen. Nachler beginnt die Folge ron neuem. Weizen liefert 22 fültigen Ertiag, if-s Ardeb pro Feddán, was 20-24 Me pro Hektar entspricht. Stallungen und Wirtschaftsgebäude sind einfach, aber sauber gebaut; ihnen schließt sich eine Sesamölpresse mit Dampfbetrieb an. Sie wird natürlick: 
wie der Kessel des Dampfpfluges und das Punpwerk mit Holz geheizt, denn Kohlen gibt es ja im Sudan, außer der sagenhaften Braunkohle, die irgendwo in Dongola gefunden worden sein soll, vorläufig nicht. In einem Winkel des Hofes liegt ein Haufen seltsam gestalteter Gebilde. Bei näherer Betrachtung entpuppen sie sich als einigermaßen mumisicrte Futterrüben. Herr Kapatos hat den originellen Versuch gemacht, der Beta rulgaris im Herzen Afrikas einen Platz zu schaffen. Thre ersten Nachkommen sind recht traurig ausgefallen. Wer kann indessen sagen, welcher Anpassung diese höchstgezüchtete aller pflanzlichen Kulturformen noch fähig ist. welche Überraschungen uns der Boden Afrikas noch bringen wird. 


\section{Achtes Kapitel.}

\section{Das kulturelle Räderwerk.}

Nationallandwirtschaft und Kultur. - Was die Untersuchung bezüglich Ägyptens lehrt. - Das Sudan-Problem. - Noch einmal das englisch-ägyptische Kompagniegeschäft und die leitenden Gesichtspunkte der englischen Kolonialpolitik. - Die Zukunft des Sudans und das europäische Wirtschaftsleben. - Der ökonomische Kreislauf.

Der Versuch, die Nationallandwirtschaft von Ägypten und rom englisch-ägyptischen Sudan zu erfassen, hat zur Betrachtung einiger Umstände geführt, die sie beeinflussen könnten. Dabei mußte sich die Untersuchung, ungeachtet ihrer fragmentarischen Form, auf Dinge erstrecken, die man sonst überall eher zu finden gewohnt ist als in einer landwirtsehaftlichen Darstellung. Das Ergebnis ist ein buntes Mosaik der verschieciensten biologischen und sozialen Erscheinungen, die alle untereinander verbunden sind, sich gegenseitig beeinflussen, fördern oder hemmen. Wir wollten die Landwirtschaft von diesen Teile Afrikas kennen lernen und sind unversehens dazu gelangt, einen Blick in das Räderwerk seiner gesamten Kulturentwicklung zu werfen. Überall hat sich die Überzeugung von der Wechselwirkung zwischen dem Menschen, der umgebenden Natur und dem Landwirtschaftshetrieb aufgedrängt und überall hat sich die Wechselwirkung als die Quelle der gesamten Kultur erwiesen. Indem diese weiter fortschreitet, wirkt sie wieder zurück auf den Menschen und auf den Landwirtschaftshetrieb, ja auf die Natur selber, die sich der Mensch mehr und mehr unterwirft. So wird das Kulturbild. das wir erhalten, zum Ausgangspunkt für unser Urteil über die Aussichten der Bodenproduktion und lehrt mit unwiderleglicher Beweiskrait, daß sich die Nationallandwirtschaft überall auf den vorhandenen Bedingungen und Voraussetzungen aufbaut und nur aus diesen heraus zu beurteilen ist. 
Soweit Ägpten in Betracht kommt, hat die Untersuchung gezeigt, daß hier nicht wie in andern, sich regelmäßig weiterentwickelnden Staaten starke Vermehrung der Bevölkerung oder namhaft gesteigerter Konsun dafür verantwortlich zu machen sind, wenn der einstige Überfluß an Agrarprodukten sich in das Gegenteil rerwandelt hat. Auch die natürliche Fruchtbarkeit des Bodens ist nicht geringer geworden. Von der Stagnation der ägyptischen Landwirtschaft kann trotzdem nicht länger die Rede sein, denn ist diese von einer Betriebsintensität in mitteleuropäischem Sinne auch weit entfernt, so haben wir anderseits gesehen, daß es geradezu ein rerhängnisroller Irrtum wäre, unsere intensiven Methoden den von unsern so verschiedenen Voraussetzungen $\ddot{\text { gyll) }}$ tens aufpfiopfen zu wollen. Die ägyptische Landwirtschaft mul einen ganz andern Weg einschlagen, un vorwärts zu kommen und sie hat den richtigen jetzt zweifellos betreten; lag doch der Hauptgrund ihres Rückganges darin, dab dic Bewïsserungswerke der Vorzeit nach und nach eingegangen waren, während niemand laran dachte. sie durch nene zn ersetzen. Der rasche Aufstieg, in dem die ägyptische Bodenproduktion begriffen ist, wird dadurch indessen noch nicht genügend gekennzeichnet. Wir konnten an der Hand der Tatsachen nachweisen, 'welch emsiges, zielbewußtes Bemühen ihr ganzes Getriebe durchdringt. Wie aus einem zu eng gewordenen Kleidungsstïcke wächst die ägyptische Landwirtschaft ans den Verhältnissen hinaus, die sie bisher niedesgehalten haben. Die Gesetzgebung verteilt dic Stenern gerechter, befreit, entschuldet den Fellah. Der ist nicht mehr der willenlose Sklave von früher, hat sein Rückgrat entdeckt und seinen Bodenbesitz rermehrt. Nun nimmt er Teil an dem geistigen und technischen Fortschritt seines Landes und lernt seinem Boden mittels einer neuen Fruchtfolge und richtigerer Ackerhestellung mehr Ernten im Jahr und höhere Erträge abgewinnen. Neben der Förderung des kleinen Fellahs, dem in der ägyptischen Landwirtschaft noch immer die Hauptrolle zufällt, tragen dann die neuerstandenen großen Landerschließungsgesellschaften zur Entwicklung der Bodenproduktion manches bei. Ihnen allen aber: den grofen wie den kleinen Bodenwirten, kommt es zustatten, daß Gesetz und Recht, Handel und Verkehr in gesicherte, geordnete Bahnen gelenkt haben.

Die Gegenwart ist wieder zu dem Prinzip zurückgekehrt, dem die ägyptische Bodenproduktion einst so unvergleichliche 
Entfaltung rordankte: freilich, unter uenen Gesieht-punkten, aul zanz anderer Grundlage und mit den grobartigen Hilfsmitteln. dir. die molerne Technik an Stelle tausendkönfiger Sklavenarben setzt. Und nun scheinen der ägyptischen Landwirtschaft in ah). sehbarer Zeit so weitausgreifende und glückliche. Unwäilzungen hevorzustehen wie keiner andern. Die Wiedergehurt des buwässerungswesens hat sehon 190-t die Anbaufläche auf ti., Mill. Feddán gebracht, woyon 11/2 Mill. Feddan stets Massol zur Verfügung haben und daher zwei his drei Ernten im Jahre tragen können. Kü̈nftighin werden 4 Mill. Feddin mit immerwährender Bewässerung rersehen sein und dazu werden 2- Mill. Feddán nene. Kulturland liommen, das man durch die Dränicrtung der Salzseen in Delta und durch die Ausdehnung der Kanalhewässerung üher gan\% Ägypten schaffen will. Eine zweite jührliche Ernte ron 21/2 Mill. Feddsin und zwei neue Ernten im Jahre ron 2 Mill. Feddin, d. 1. nichts anderes. als daßs sich die Anbaufläche Ägrptens in absehbarer Zeit nahezu verdoppelt haben wird.

Fom Sudan läßst sich eine gleiche Entwicklung rorläufig nicht erwarten. Es ist etwas ganz anderes, cin Land mit reichen Kulturerimnerungen, ein Volk init allen Ansätzen zu seiner Wreiteribildung zu fördern: als den ersten Spatenstich in einem Gebiete zu tun. das es aus eigener Kraft niemals zu einer Zivilisation gebacht hat und ron deren Prämissen nur wenige besitzt. Das gilt aber von dem ganzen mittleren und südlichen Sudan wie von Zentralafrika überhaupt. Bis in die Gegenwart hat auch kein höherstehendes Tolk es rersucht. seine Kultur bis dahin zu verpflanzen.

Jetzt wird dic Welt ihren alten Völkern nachgerade $z$ eng und der holoniale Wettbewerl) dehnt sich auf Lünder aus, deren Besiedlungsschwierigkeiten früher gemieden wurden. Nun ist man schon beim dunkelsten Afrika angelangt und einer seiner unzugängigsten und am schwersten zu kultivierenden Teile ist England noch in letzter Stunde gemeinsam mit Ägypten zugefallen. Wir haben alle Schrecken kennen gelernt, die der Sudan in sich birgt: Den Nangel und das Übermaß;, durch die die Natur gleich verderblich wirkt: die Wüsten, die Stürme und Seuchen; die Verkehrsschwierigkeiten, die enorme Ausdehnung. die spärliche Berölkerung. und anderes mehr. Alles ebenso viele Hindernisse für die kulturelle Arbeit. Wir waren aber auch Zeugen des todesmutigen, ergreifenden Kampfes. der im Sudan gegen diese Hindernisse geführt 
wird. Ein Amerikaner, der das Land vor einiger Zeit bereist und die Aussichten des Baumwollbaues und der übrigen Bodenproduktion eingehend studiert hat, meinte: "Der Sudan ist ein ebenso unfertiges Land als unser Mississippital vor 100 Jahren, nur eröffnet es noch größere Aussichten für die Zukunft als dieses damals." Der Miann ist sicherlich ein großer Optimist und der Sudan wird die heutige Entwicklung des Mississippitales vermutlich niemals erreichen. Da der offizielle Regierungsbericht an das englische Parlament es indessen nicht verschmäht, sein Urteil wiederzugeben, so mag es auch hier als Beweis gelten, welchen Ausgang des Kampfes man erwartet.

Der Gegensatz zwischen den natürlichen Voraus setzungen und dem Endziele, zwischen dem, was war, und dem, was schon heute ist, dünkt so unwahrscheinlich, dafs man gern dem überlegenen Willen nachspürt, der das alles lenkt. Die Frage nach den leitenden Gesichtspunkten drängt sich auf, nach den Mitarbeitern, nach den riesigen materiellen Mitteln, die wohl aufgewendet werden müssen. Eine Antwort darauf, und noch dazu eine vielsagende, gibt die anglo-ägyptische Konvention vom 19. Januar 1899. Diese verleiht dem neuen Staatengebilde eine konstitutionelle Grundlage von ganz eigener, nie dagewesener Art. Das mächtige England übernimmet gemeinsam mit dem ägyptischen Vasallen des Sultans den Besitz des Sudans. Man glaubt nicht recht gehört zu haben: England hat die Hand auf den Sudan gelegt und beansprucht seinen Besitz nicht für sich allein. Es übernimmt nicht etwa das Protektorat über die ägyptische Besitzergreifung, nein, klipp und klar herausgesagt: Die Weltmacht England teilt die Herrschaft über den Sudan mit dem kleinen Ägypten.

In früheren Zeiten hat manches Volk blutige Kriege um eines Titels wegen geführt und mancher Monarch der Gegenwart führt stolze Herr'schertitel aus alten Zeiten, denen längst keine Herrschaft mehr entspricht. Und hier erleben wir zum ersten Male wie ein moderner Staat die Zweckmäßigkeit höher als alle Machtsymbole wertet. Im Sudan wird ein großes Reich als Gesellschaft mit beschränkter Haftung gegründet, die Oberhoheit von England und Kompagnie protokolliert.

Der ägyptische Teilhaber erhält natürlich die Rolle des stilien Kompagnons zugewiesen. England teilt nur den Herrschertitel, nicht die Herrschaft selbst; Lord Salisbury trifft mit der 
neuen Form gleich zwei Mücken auf einen thohlag. Er zeigt Ägypten seine Uneigennützigkeit und schafit das Gespenst des Internationalismus mitsant der Frage der türtischen Oherhoheit aus der Welt.

Wie wünschenswert das Zweite ist. wird man nach den Erfahrungen, dic in Ägrpten mit der internationalen Kontroll." gemacht warden, gerne glauben. Uns den Wert des ersten zu erkennen, mufs an die Lnmöglichkeit gedacht werden, ein weit entferntes Iand in dauernder Abhängigkeit zu erhalten. ohne dab es seinen imneren geistigen oder materiellen Bedürfnissen entspräche. England hat das an eigenen Leibe edfahren. Nur solange die nordamerikanisehe Cnion aus der Verbindung mit dem Mutterlande Nutzen zog. blieb sic die gehnisame Tochter. Kein Staat in neveren Europa hat seither seine Kolonien rücksichtsvoller behandelt als England, dessen Weltreich jetzt aul dem Grundsatze gegenseitigen Vorteiles ausgebant ist. Ein einziges Mal noch, in Indien, ist es von dem Prinzip abgewichen. Dieses komnte ehen beherrscht werden, indem man die eingeborenen Fürsten. dic unheschränkte Macht über ihre Lntertanen besaken, beherrschte.

In Ägypten tritt England als der väterliche Freund und Berater auf, der nach der Versicherung Lord Cromers nicht einmal daran denkt, die Okkupation dauernd aufrechtzuerhalten. Nach unserer Überzeugung ron der notwendigen Voraussetzung. eines inneren Bedürfnisses auf beiden Seiten wird England wohl auch nicht viel länger in Ägypten bleiben kümuen. als es den wirklichen oder vermeintlichen Interessen des Landes entspricht; es kann aber dafür sorgen; daßs solche mehr und melu* zur Geltung gelangen. Objektir betrachtet. sollte der auberordentliche wirtschaftliche Fortschritt der Okkupationszeit allein schon ein genügendes Interesse Ägyptens an der englischen Führung gewährleisten. Die Geschichte lehrt indessen. daß die Gemeinschaft zwischen Herrschenden und Beherrschten um so schwieriger zu erhalten ist. je verschiedener diese in Rasse. Gebräuchen und Religion roneinander sind. Cromer weist selbst auf die Notwendigkeit hin, in Ermanglung natürlicher Bande "künstliche Bande zwischen den Engländern und den Ägyptern zu schmicden, wie es die Umstände zulassen" IC'romer. Das heutige Ägypten II, 537).

Solche Bande schafft England durch den gemeinsanen BeStrakosch, Frwachende Agrarlander. 
sitz des Sudans und fügt damit allen anderen Vorteilen, die ihm das Zusammengehen mit Ägypten bringt, einen neuen hinzu; man könnte sich schwer ein festeres Bindemittel denken. Tausend Fäden spielen rom Sudan nach Ägypten hinüber, wirtschaftliche und politische. Allein wüßte Ägypten nichts mit ihm anzufangen, er würde eine Quelle steter Beumruhigung bilden. Unter dem festen Zügel des englischen Mitbesitzers gewinnt der Sudan erst für Ägypten den unendlichen Wert. Der Sudanhandel hat kaum angefangen, sich zu rühren. 11/2 Mill. L. E. Import, ${ }^{1}{ }^{\prime} 2$ Mill. Export, das ist das ganze Ergebnis des auswärtigen Handels vom Jahre 1908. Doch der hat İgypten, der Schätzung nach, bereits L. E. 80000 an Zoll für Durchzugsgüter eingetragen. Der Verkehr mit dem Sudan ist noch gering, aber schon ziehen die ägyptischen Eisenbahnen, der Telegraph, die Post Gewinn daraus. Die ägyptischen Kaufleute versorgen den Sudan mit ihren Waren, nehmen den Handel mit seinen Produkten in die Hand. Überall im Sudan ist Ägypten zu Hause, findet dort Ämter für seine Söhne, Beschäftigung für Kapital und Arbeitskraft. Und erst das sudanesische Flußgebiet! Wir haben ja von den grofartigen Anlagen gehört, die dort zugunsten der ägyptischen Wasserversorgung ausgeführt werden sollen. Wird zu alledem noch das geschmeichelte ägyptische Nationalgefühl mit in Betracht gezogen, so begreift man, daß England sich das Nilland durch sein kluges Vorgehen dauernd verpflichtete und num ruhig daran gehen kann, sein sudanesisches Pisiko einigermaken auf den Partner abzuwälzen.

Deutschland hat, wie berechnet wurde, in 22 Jahren 700 Mill. Mark für seine Kolonien ausgegehen. England kostet der Sudan, dank der eingeschlagenen Taktik, nicht einen Pfennig. Die Kosten der Wiedereroberung sind wohl durch eine englische Anleihe aufgebracht worden, aber gleich der erste Vertrag mit Ägypten stellt deren Verzinsung und Amortisation sicher. Was der Sudan weiter braucht, hat Ägypten herbeizuschaffen. Der ägyptische Zuschuß, mit dem das Auslangen gefunden wird, beträgt nur 253000 L.E. jährlich und davon sammelt man bis 1908 sogar noch einen Reservefond von 131500 L.E. England geht eben langsam und vorsichtig vor, hat es gelernt, Wechsel auf lange Sicht zu eskomptieren. Ägypten darf beileibe nicht zu viel zugemutet werden, es muß weiter imstande bleiben, die Mittel für die Erschließung des Sudans herzugeben. Deshalb sollen von den projektierten Regulierungsarbeiten im Sudan zuerst die zur 
Ausführung kommen, die den Wasserworrat Ägrptens zul ver. gröbern bestimmt sind.

Das Schrittweise, das Nichtüberstüryen der Reformen bleiht auch sonst die Devise. Noch in seinem letaten Sudanhericht, so einer Art Testament ror den Verlassen Ägyptens; schärft Iard Cromer den Beamten ein: "Die Arbeit von Generationen kanm nicht in wenige Jahre zusammengedrängt worden." Dic Frage nach der Opportunität einer Reform darf nienals wichtiger. erscheinen als die Frage, ob die Zeit für ihre Einführung bereits geliommen ist. Selbst über die unzivilisiertesten Völker des Sudans soll die Formundschaft der Regierung nicht $z^{11}$ weit getriehen werden, "weil man über ein gewisses Mab hinaus doch niemanden gegen seine ejgene Dummheit schützen kann", und "weil es ökonomische Gesetze gibt die stärker als jede Regierung sind. Nichts wäre aber gefährlicher, als Gesetze zu erlassen, deren Erfüllung nicht erzwungen werden kann". Und noch eine andere Äuferung wirft ein scharfes Licht auf die Ideen, die in der englischen Kolonialpolitili zu Hause sind. Es ist von der Reihenfolge die Rede, in der die Aufwendungen im Sudan gemacht werden sollen, und da meint der Bericht. man müßte vor allem genug Geld beschaffen, un die ordentlich zahlen zu können, die im Dienste der Regierung stehen; denn die Beamten, einerlei ob Einheimische oder Europäer, wïren der wertrollste Altivposten des neuen Landes. In Khartum entsteht im Beamtenviertel ein imponierender Kai mit bequemen Villen. prächtigen Gärten. Die Beamten werden ungleich besser bezahlt als bei jeder anderen Kation, sind die rerwöhnten Schoßkinder der Regierung. Sie bleiben es aber nicht eine Stunde länger, als ihre Tüchtigkeit und Brauchbarkeit anhält. Lebenslängliche Sinekuren kennt die englische Kolonialbeantenschaft nicht. Deshalb bemüht sich jeder, das Beste zu tun. und verlangt von dem Untergebenen das gleiche, da er im anderen Falle dic eigene Haut für diesen zu Markte tragen mülite. Ein solches Vorgehen ist sicherlich gecignet, den englischen Kolonien tüchtige, selbständige Beamte zu schaffen und das Kolonialwerk zu fördern.

Für Englands Anstrengungen, im Sudan Fuf zu fassen, waren wohl anfänglich politische Gründe maßgebender als ökonomische. Die nachfolgende Kulturarbeit hat dann erst alle wirtschaftlichen Möglichkeiten aufgedeckt und den ökonomischen Aufbau organisch entwickelt. Das Land hatte, ron etwas Elfenbein, Gummi, 
Straußenfedern ahgesehen, keine Produkte abzugeben und kaum ein Importbedürfnis an fremden Produkten. Sollte es wirtschaftlichen Wert für England und Ägypten bekommen, so mußten vor allem Konsum und Produlition steigen. Hente kam man sich gar nicht denken, dak die Hebung des einen ohne das andere möglich wäre, und doch ist es gar nicht lange her, daß das Kunststück zum täglichen Handwerk des Kolonisators gehörte. Für Branntwein, Feuerwaffen und andere ebenso gefährliche und verführerische Dinge gab der Eingeborene gern auch das her: was el nicht entlehren konnte: sein Vieh und seine Nahrungs: mittel. Dann kam freilich die Unmöglichkeit, sich beide wieder zu schaffen, die Schwächung durch Hunger und das ungewohnte Feucrwasscr und schließlich die Einengung der bisherigen Lebensverhältnisse durch die fremde Ansiedlung, die das Schicksal des Eingeborenen rollends besiegelte.

Die Neuzeit erkennt den Zusammenhang des WirtschaftsOrganismus zu genau, um nicht zu wissen, daß die Blüte eines Landes durch den Ruin und die Vernichtung der ursprünglichen Bevölkerung niemals elreicht wird. Das ist um so weniger der Fall, wenn die klimatischen Verhältnisse der Besiedlung durch zivilisierte Völker nicht günstig sind. Deshalb sucht man jetzt. das Konsumtionsbedürfnis nach und nach auf gesunder Grundlage zu entwickeln. Beror der Eingeborene zu erhöhter Konsumtion von Kulturgütern veranlakt wird, soll er zunächst mehr erzeugen, als er zur Fristung des nackten Lebens bedarf. Das lernt auch der primitirste Neger bald, wenn ihm dic Gelegenheit geboten ist, seine Produkte leicht abzusetzen. Der Erlös findet dann für Baumwollzeug, Schmuck und dergleichen Verwendung und für Geräte, die die weitere Tätigkeit erleichtern. So kommt die wirtschaftliche Maschine langsam in Gang, wozu freilich nötig ist, daf die Tätigkeit den Eingeborenen zu einer gewissen Selshaftigkeit zwingt. In $\mathrm{K}$ or d o fan gibt es nomadisierende Araber, die mehr als 200 Stück Vieh besitzen und doch nur ein einziges Hemd. Erst mit der Seßhaftigkeit werden die Lebensgewohnheiten anspruchsvoller und der Anreiz ausgelöst, durch Arbeit zu ihrer Befriedigung zu gelangen.

Eine zweite Aufgabe besteht in dem Heranziehen ron Siedlern mit höheren Lebensbedürfnissen. Was könnte die in groken Schar'n in den Sudan locken? Die gewöhnliche Tropenproduktion ron Straußenfedern, Gummi u. dgl. ist steigerungsfähig, aber kaum 
geeignet, die Einwanderung nemnenswert zu beeinflussen. I as Vorkommen von Kohle ist nicht erwiesen; von anderen Bodenschätzen sollen sich Gold und Kupfer vorfinden, zu deren Explojtierung hat aber die Regierung bisher, im wohlverstandenen Interesse des Landes, noch nicht viel getan. Die Erfahrung zeigte genügend, daß neuerschlossene Länder, in denen das Hauptgewicht von Anfang an auf der Metallproduktion lag, am langsamsten vorwärts kamen, die ungesündeste Preisbildung aufwiesen und am häufigsten von Hungersnot heimgesuclit wurden.

So weist alles im Sudan zunächst auf den Ackerban hin. Gelingt es, die unermeßlichen Flächen tragend zu machen, so können Millionen von Menschen Arbeit und Brot finden: der Eingeborene wie der anspruchsvollere Ansiedler, dem reicher, unausgenützter Boden, lohnender Baumwoll- und Zuckerrohrbau genug Aussichten eröffnen. Die Landwirtschaft wirl also zum Brennpunkt der ganzen Kolonisationsarbeit und Wissensehaft und Technik, Gesetz und Verwaltungskunst stellen sich zunächst in ihren Dienst. Jetzt entstehen die gewaltigen Ersehliefungsprojekte, und der Sudan zeigt sich England von einer neuen, bedeutungsvollen Seite: als das künftige ungehenere Reservoir seines Nahrungsmittel- und Bammollbedarfes.

Nach gewissenhafter Gegenüberstellung aller für und wider sprechenden Momente darf man an einer solchen Möglichkeit kaum zweifeln. Dagegen lält sich hente schwer feststellen, welches Ausmaß die Bodenproduktion dort erreichen, und wann sie einen nennenswerten Umfang annehmen wird. Beides hängt, selbst wenn kein unvorhergesehener Zwischenfall das Kulturwerk anhaltend stören sollte, von einer Anzahl Umstände ab, auf die die Regierung nur innerhalb beschränkter Grenzen einwirken kann. Von diesen Umständen wird wohl keiner die Entwicklungsdauer so sehr mitbestimnen, als das Bevölkerungsproblem. Die eingeborene Bevölkerung vermehrt sich, nach dem festgestellten Prozentsatz an Kindern zu schließen, in geradezu verblüffender IVeise; aber mit den Zuzügen von auswärts geht es langsam vorwärts und noch langsamer, wom die Einwanderung von Europäern besonders ins Auge gefaßt wird. 1905 zählte man im Sudan 2787 Europäer und 8209 Abyssinier, Ägypter und andere Fremde. Bis 1908 stieg die Zahl der Europäer auf 3104 und die der übrigen auf 17030 . Das Verhältnis gibt zu denken. In Deutsch-Südwest- 
afrika, das beiläufig halb so groß wie der Sudan ist, nimmt Dernburg europäische Ansiedlungskolonien in der anderthalbfachen Größe des Deutschen Reiches in Aussicht, und England selbst hat in seiner Kapkolonie, die nicht ein Drittel des sudanesischen Umfangs besitzt, 350000 Weike angesiedelt. So viel europäischen Einschlag wird der Sudan schwerlich erreichen. Der Aufenthalt in vielen seiner Teile soll zwar nicht ungesünder als der in Oberägypten sein, die große Hitze macht ihn jedoch zur Sommerund Regenzeit überall sehr unangenehm. Quälende äußere Lebensbedingungen erduldet der Europäer manchmal in der Erwartung. rasch Reichtum errierben und dann das Weite suchen zu können. wie in Diamanten- und Golddistrikten. Der langsame Weg des Ackerbaues, des Kleinhandels, des Gewerbes hat nicht so viel Verlockendes. Im Sudan wird der Europäer deshalb vielleicht große Unternehmungen organisieren, Plantagen anlegen u. dgl. Die tägliche Kleinarbeit aber, die Mitwirkung an dem Wabenban des Wirtschaftsorganismus wird zunächst den Ägyptern, den Abyssiniern und den anderen zivilisierten Siedlern zufallen und damn nach und nach den Eingeborenen. Das kann nicht ohne Einfluß auf die Art der Entwicklung und den Charakter der Bodenproduktion bieiben." Erimnern wir uns anderseits, dak, was ron Ägypten gesagt wurde, noch mehr vom Sudan gilt: Wo genügend Wasser hingelangt, ist die Tegetation so üppig, dab es nicht erst unserer europäischen intensiven Methoden bedarf, un den Boden zu höchster Leistung zu veranlasseu.

Wenn jetzt neben das wiedererweckte $\ddot{A} g y p t e n$, das seine Bodenproduktion zu rerdoppeln im Begriffe steht, der Sudan mit dem Vielfachen der ägyptischen Erzeugung tritt, so wird das unsere europäischen Wirtschaftsverhältnisse nicht unberührt lassen. Vor wenigen Jahren hätte man daran vermutlich die schwäızesten Befürehtungen geknüpft und unsere Landwirtschaft durch dic afrikanische Üherschwemmung stark gefährdet geglaubt. Die jüngste Zeit hat indessen gelehrt, dab solche Überschwemmungen zeitlich begrenzt sind, und dab die Gefahren, dic unserem Wirt. schaftsleben durch die Knappheit der Agrarprodukte drohen, viel größer sind als die durch eine Produktionssteigerung am Weltmarkt heraufbeschworenen. Ton all den überseeischen agrarischen Produktionsstätten, vor denen einst gewarnt wurde, von Amerika, von Mesopotamien, ron Canada u. a. spüren wir wenig; dagegen ist Deutschland in hundert Jahren aus einem agrarischen 
Exportstaate ein Land geworden, dafis alljährlich für 2 Milliarden Mark Agrarprodukte importiert. Dabei soll esseine Bodenproduktion im gleichen Zeitraume um $212 \%$ vermehrt haben. Und eine einzige Mittelerute in den Hauptgetreideländern, nicht etwa eine Mifernte, hat den Weizenpreis am Weltmarkte im Jahre 1907 um mehr als 5 Mark in die Höhe getrieben. Seither ist er all. jährlich weiter gestiegen. Börsentechnische und andere Momente mögen dafür mit verantwortlich sein; man darf aber immerhin auch darin einen Beweis sehen, daß noch eher der Mangel als der Überfluß an Bodenerzeugnissen vor der Tür steht.

So wird das Erwachen von Ägypten und vom Sudan vermutlich nicht die verheerenden Folgen für unsere Landwirtschaft haben, die man früher davon erwartet hätte. Wie jede Neuerschliebung ausgedehnter Ackerbauländer kann auch diese eine vorübergehende Springflut von Bodenerzeugnissen hervorrufen: für die Dauer. ist die anhaltende Steigerung der Produktion ohne gleichzeitige Hebung der Kultur und folglich der Konsumtion nirgends, nicht einmal in den Tropen denkbar, obwohl dort die Natur so leicht hergibt und die Menschen so anspruchslos sind. Bis in die achtziger Jahre haben die Vereinigten Staaten von Amerika den Weltmarkt mit ihren Brotfrüchten geradezu überschwemmt. Das machte sich besonders fühlbar, als Bahnbauten den Ackerbau nach dem Westen verpflanzt und dessen Erzcugnissen billigen Transport nach dem Meere verschafft hatten. Dann hegann der Osten seinen Boden intensiver auszunützen, und im menschenleeren Westen lernte man Maschinen in großem Stile benützen. Von da ab nimmt die amerikanische Landwirtschaft erst recht einen gigantischen Aufschwung und liefert jetzt fast doppelt so viel Nahrungsmittel wie vor einem Vierteljahrhundert. Der Export, weit entfernt, die Steigerung mitzumachen, geht stark zurück, weil der Bedarf im Lande einstweilen noch viel rascher gestiegen ist. Deutschland hat eine höhere Stufe landwirtschaftlicher Intensität erreicht als Österreich und übertrifft dieses in den Ackererträgen bedeutend. Das gleiche gilt von Österreich gegenüber Rußland. Da tritt uns die merkwürdige Tatsache entgegen, daß gerade das Land am wenigsten mit seiner eigenen Produktion auskommt, das sie am besten entwickelt hat. Das Verhältnis zwischen Produktion und Konsumtion verschiebt sich in Deutschland schneller zuungunsten jener als in Österreich und hier schneller als in Rußland. Man 
ist versucht, hinter allen diesen Erscheinungen. unter Bedachtnahme auf die Ursachen, die ihnen zugrunde liegen, eine Gesetzmäßigkeit zu erblicken, welche durch die Malthussche Bevölkerungsformel allein nicht erschöpft wird, und die ich so fassen möchte:

Je weiter die Kultur sich ausbreitet und fortschreitct, desto mehr überragt das Anwachsen des Konsums das Anwachsen der Produktion.

Das Knapperwerden der Rohstoffe und Nahrungsmittel kamn danach vorübergehend zum Stillstand gelangen. sich selbst für cinige Zeit ins Gegenteil rerkehren; ganz aufhalten wird man es nicht können. Schließlich niüssen die Industrieländer mit ungenügender' agrarischer Eigenproduktion gegen solche Länder empfindlich in Nachteil kommen, die noch Überschub an Agrarproduliten herrorbringen und dann die Preise auf dem Weltmarkte diktieren werden. Die hohen Preise der eing eführten Rohstoffe und Nahrungs. mittel treffen die Tolkswirtschaft viel empfindlicher als die hohen Preise der daheim erzeugten Agrarprodukte; diese heben die Kaufkratt des Landwirtes und mildern dadurch ihre Wirkung auf die ïbrige Tolkswirtschaft. Die Mehrzahlung für teuere fremde Agrarprodukte geht der eigenen Volkswirtschatt rettungslos verloren.

In einem Staate mit hohen Industriezöllen kamn man keine billigen Preise der Agrarprodukte erwarten. Wenn die Geräte. die Bedarfsartikel, die Maschinen und alle anderen Dinge teuer sind, steigen auch die Gestehungskosten des Landwirtes. Der Industrielle macht dam für seine ungünstige Situation die Preise der Agrarprodukte verantwortlich, und der Landwirt ruft nach Zollschutz, weil er bei dem bisherigen nicht bestehen kann. Sie haben beide recht, der Industrielle wie der Landwirt. Und weil sie beide etwas gelten im Staate, so schützt bald ein höherer Zoll die Industrie und die Landwirtschaft. Wie sich bei einer Division, deren Divisor und Dividend mit dem gleichen Faktor multipliziert werden, das Verhältnis nicht ändert, so geht es hier mit der Zollpolitik. Nur dann, wenn es dem einen Teil gelingt. seine Multiplikanten einseitig wirken zu lassen, gewinnt er vorübergehend einen Vorsprung. Das Ende voin Liede ist aber doch, daß jeder für sein Geld weniger erhält. Der Landwirt trägt dann noch extra die Kosten des Kamples, wenn el einstweilen einen teueren Pachtrertrag auf Jahre abgeschlossen, 
oder gar zu den Preisen der längst vorübergegangenen günstigen Konjunktur den Boden küuflich an sich gebracht hat.

Diese 'Zustände werden sich nie ganz beseitigen lassen, abel' die fortschreitende Erkenntnis von der Wechselwirkung aller kulturellen Faktoren, auf die der Begriff der Nationallandwirtschaft hinweist, könnte doch manche Mabnahme verhindern, die, scheinbar im Interesse der Landwirtschaft gelegen. diese erst recht auf dem Unwege der Industrie schädigt, oder eine solche, die der Industrie zu nützen scheint und sie wieder auf dem Umwege der geschädigten Landwirtschaft hart trifft.

Es ist eine alte Wahrheit, dab jeder Teil der Volkswirt. schaft am Gedeihen des anderen kaum weniger interessiert ist als am eigenen. Deshalb kann es nichts Kurzsichtigeres, Verderblicheres geben, als zwischen Industrie und Landwirtschaft eine künstliche Scheidewand zu errichten. Für beide ist es von gleicher Wichtigkeit, dab die heimatliche Agrarproduktion gestärkt und leistungsfähiger gemacht werde.

Das englische Imperium denkt jetzt daran, das riesigste Kolonialreich, das dic Welt je gesehen, wirtschaftlich zusammenzuschließen. Den Gefahren, welche die Unzulänglichkeit der cigenen Landwirtschaft für die Zukunft bringen könnte, soll durch die agrarischen Überschüsse von nahezu dem vierten Teil der bewohnten Erde vorgebeugt werden. Die anderen Staaten haben alle Ursache, dem heimischen Ackerbau noch ganz andere Aufmerksamkeit zuzuwenden als bisher, um dadurch ihren Völkern die Brotfrüchte und ihrer Industrie einen großen Teil der Rohstoffe zu sichern. Neben allen sonstigen Förderungsmitteln wird man besonders Eines im Auge behalten müssen, das die Erhöhung der Bodenproduktion ohne jeden Mehraufwand gestattet: Die weitgehendste Nutzanwendung aus der Erkenntnis von der ungleichen Arbeitsleistung der Kulturpflanzen. Die Pflanzen, die bei gleichen Ansprüchen an das Bodenkapital mehr nutzbare Substanz hervorbringen als andere, müssen innerhalb der Grenzen. die die jeweilige Rentabilität zieht. die Stütze unserer Boden. produktion werden. 


\section{Der auswärtige}

$\operatorname{Import}$ (L.E.).

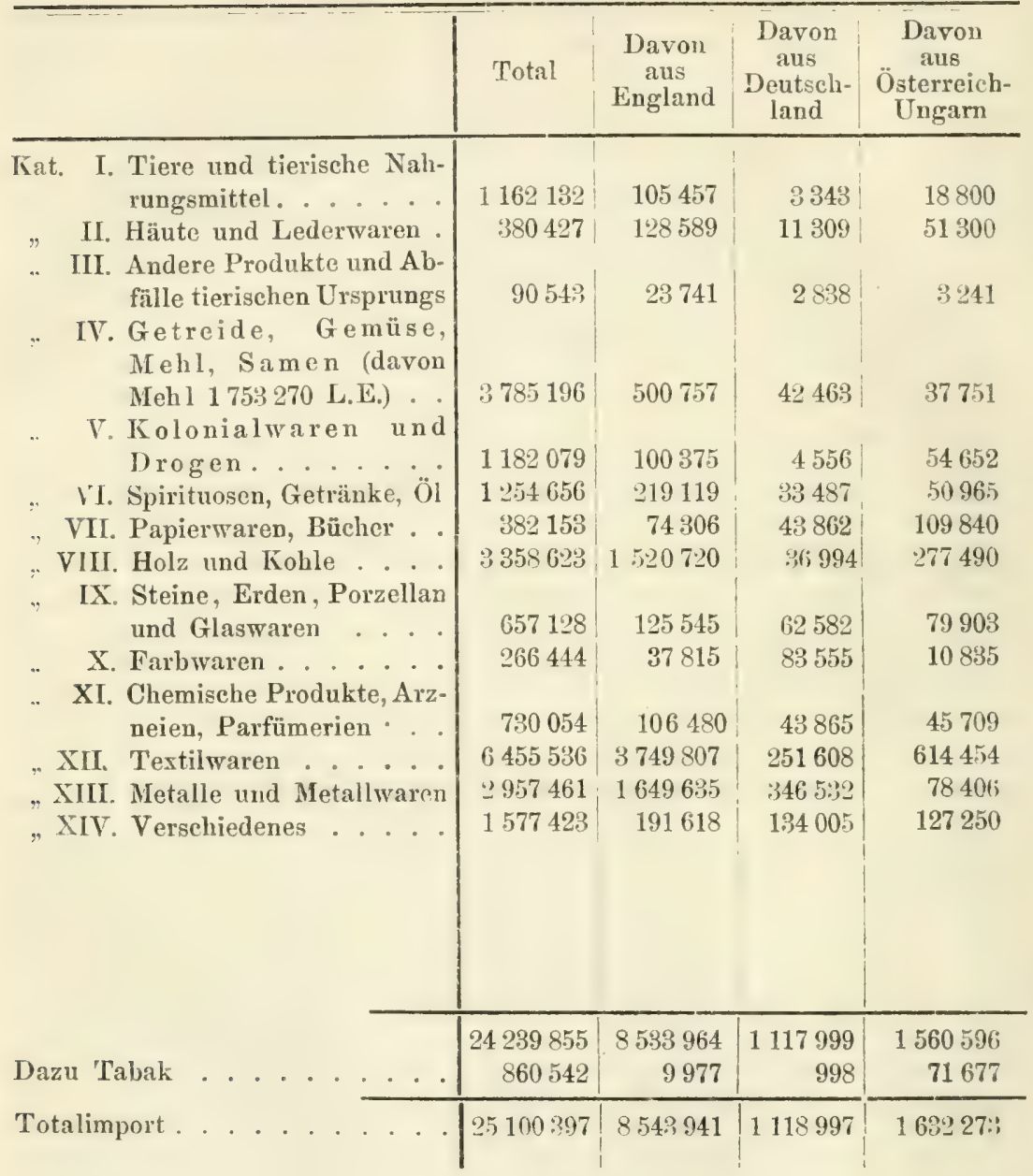




\section{Handel Ägyptens 1908.}

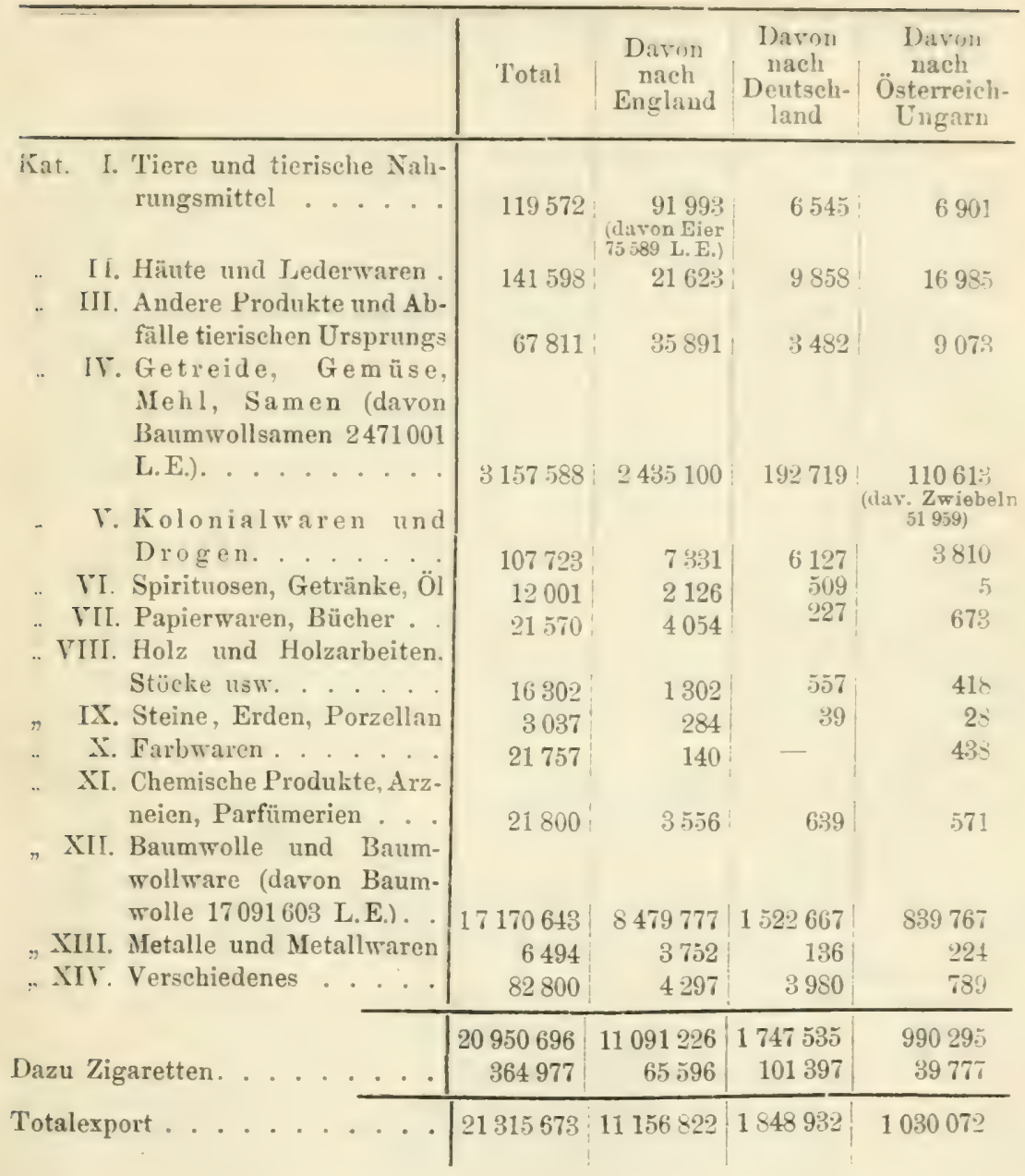




\section{Literaturangabe.}

AuBer einer Anzahl ungedruckter Berichte und Daten, die mir cias Statistische Departement des Ministerium des Innernzu Kairo, das Agrikultur- und Ländereiendepartement der sudanesischen Regierung zu Khartum, die Internationale Handelskammer und die Khédivial-Agrikultur-Gesellschaft zu Kairo, die Landwirtschaftschule in Giseh, die Société Anonyme de Wadi Kom-Ombo u. a. zur Verfügung gestellt haben, wurden folgende Druckiverke benützt oder verglichen:

Reports by His Majesty's Agent and Consul-General on the finances, administration and condition. Egypt and the Soudan 1906, 1907, 1908, 1909.

Commerce Extérieur de l'Égypte 1884-1906, 1907 und 1908. Direction générale des Douanes. Alexandrie.

Bulletin mensuel de la Chambre de commerce internationale de Caire.

List of Companies Established in Egypt, British Chamber of Commerce of Egypt. Alexandria 1907.

Henry de Saint-Omer, Les Entreprises Belges en Égypie. Bruxelles 1907. Crédit foncier Égyptien: Rapport Assemblée générale ordinaire 31./1. 1908. Georg Socolis, Notes sur l'Égpypte et son Histoire Économique. Pris 1903. J. André.

Dr. Alfred Eid, La Fortune Immobiliẻre de l'Égypte et sa Dette Hypothécaire. Paris 1907. Felix Alcan.

Statistical Return of Pupils 1906-07. Statistical Department Ministry of Finance Egypt.

IIeteorological Report 1904, Part. 1 et II. Survey Department Egypt. Cairo 1906. Foaden, Notes on Egyptian Agriculture. U. S. Department of Agriculture. Washington 1904.

Journal of the Khedivial Agric. Society and the School of Agriculture. Cairo 1904 Year Book of the Khedivial Agricultural Society. Cairo 1905, 1906.

Sir William Willeocks, The Nile in 1904. Cairo.

Sir William Garstin, Report upon the Basin of the Upper Nile. Cairs 1904. The Gordon Memorial College at Khartum, Report and Accounts. Khartum 1906. Secoud Report of the Welleome Research Laboratories at the Gordon Memorial College. Khartoum 1906.

The Anglo-Egyptian Sudan. Edited by Lieut.-Colonel Count Gleichen. London, Harrison and sons.

Lord Cromer, Das heutige Ägypten. Berlin 1908. Karl Siegismund. v. Fricks, Ägypten 1894. Berlin. Reimer.

Fraas, Aus dem Orient. Geologische Beobachtungen. Stuttgart 1867.

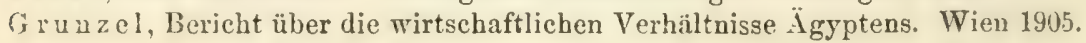




\section{Der englisch - ägyptische Sudan.}

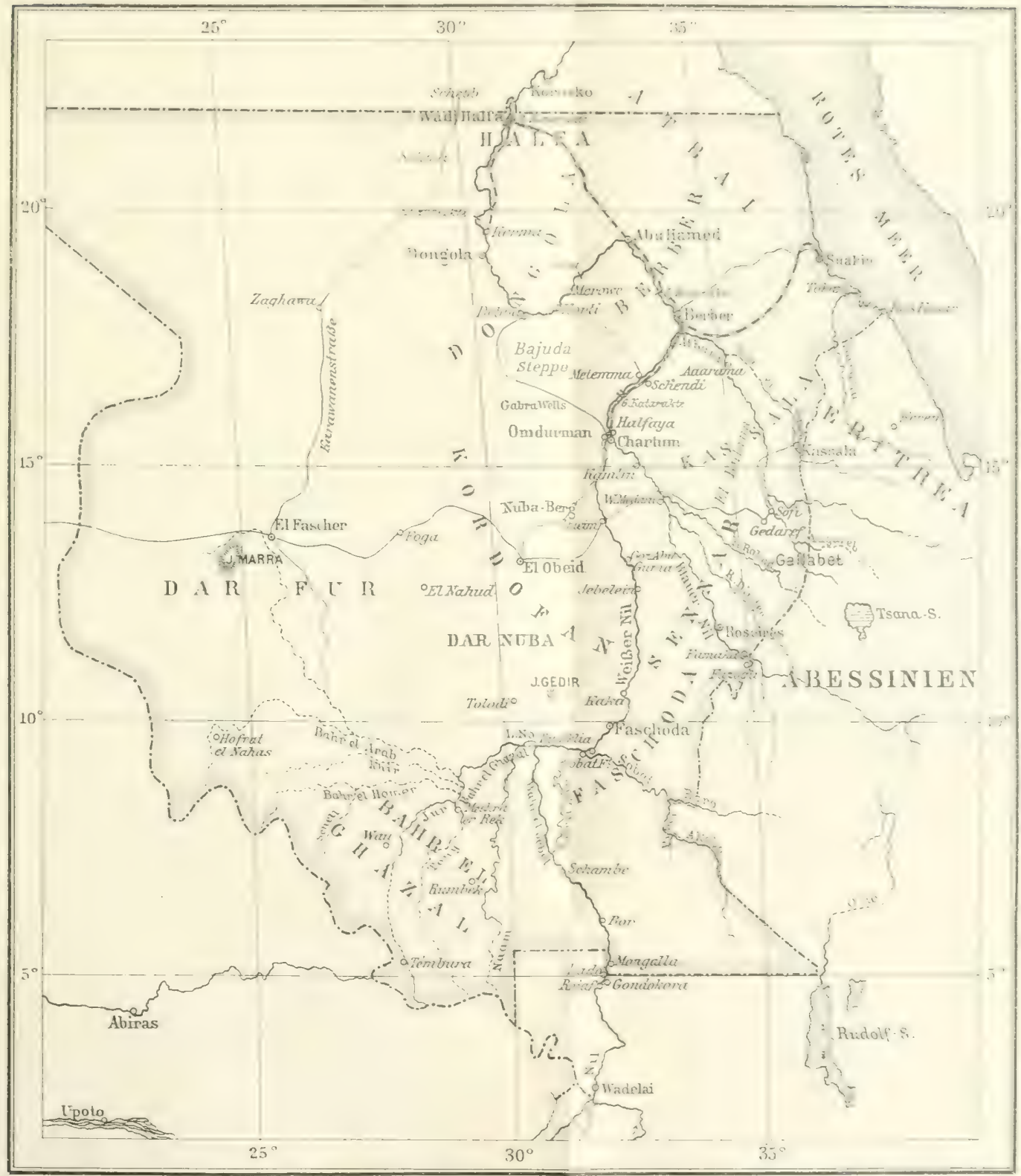

Ferlaĝ́ ron PanlPareyiu Berlin SW.

Maßstab 1: 12000 100. 




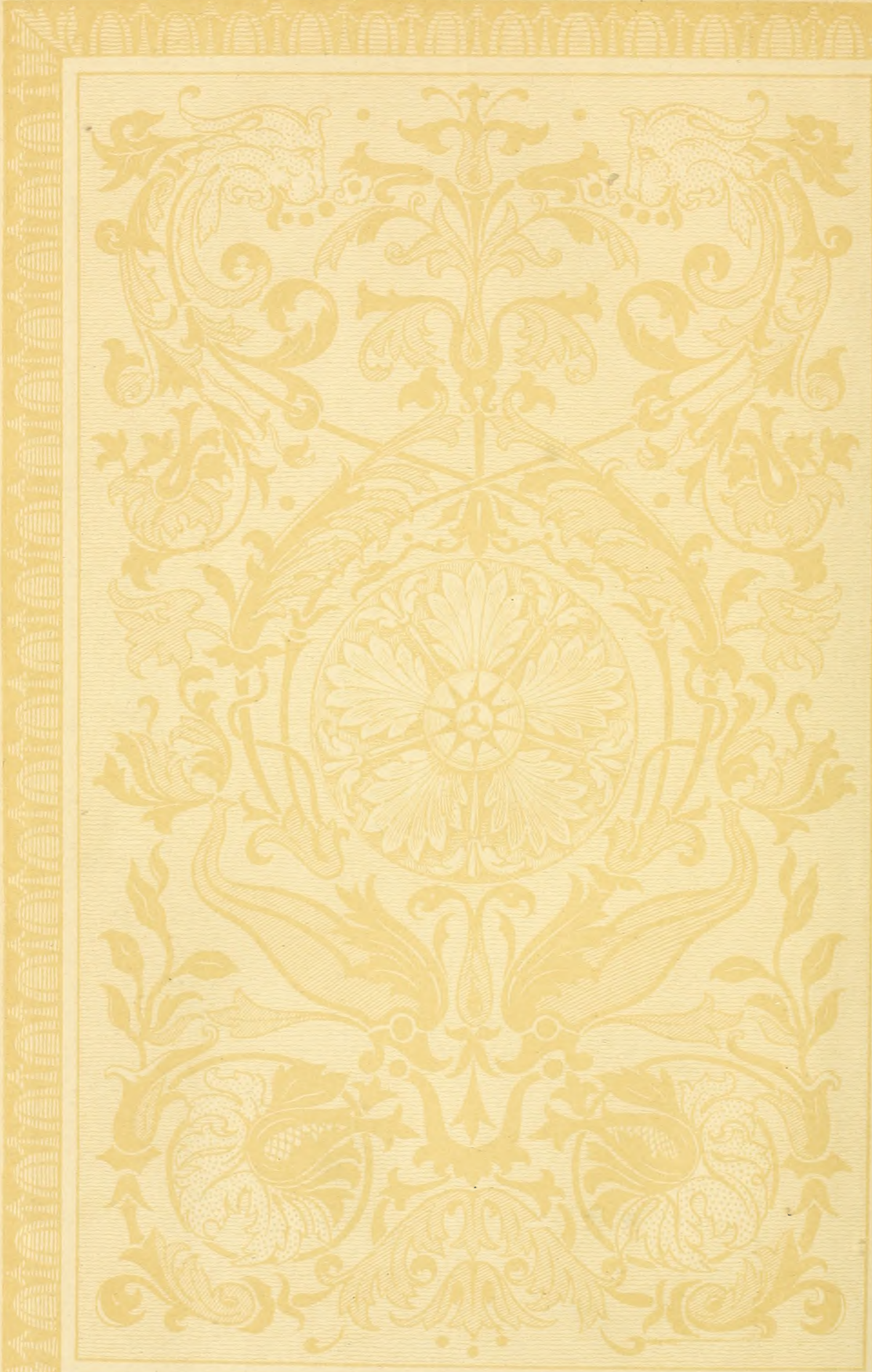


PLEASE DO NOT REMOVE CARDS OR SLIPS FROM THIS POCKET UNIVERSITY OF TORONTO LIBRARY 
